\title{
The discriminative value of patient characteristics and dyspeptic symptoms for upper gastrointestinal endoscopic diagnoses
}

Citation for published version (APA):

Adang, R. P. R. (1995). The discriminative value of patient characteristics and dyspeptic symptoms for upper gastrointestinal endoscopic diagnoses. [Doctoral Thesis, Maastricht University]. Datawyse / Universitaire Pers Maastricht. https://doi.org/10.26481/dis.19950615ra

Document status and date:

Published: 01/01/1995

DOI:

10.26481/dis.19950615ra

Document Version:

Publisher's PDF, also known as Version of record

Please check the document version of this publication:

- A submitted manuscript is the version of the article upon submission and before peer-review. There can be important differences between the submitted version and the official published version of record.

People interested in the research are advised to contact the author for the final version of the publication, or visit the DOI to the publisher's website.

- The final author version and the galley proof are versions of the publication after peer review.

- The final published version features the final layout of the paper including the volume, issue and page numbers.

Link to publication

\footnotetext{
General rights rights.

- You may freely distribute the URL identifying the publication in the public portal. please follow below link for the End User Agreement:

www.umlib.nl/taverne-license

Take down policy

If you believe that this document breaches copyright please contact us at:

repository@maastrichtuniversity.nl

providing details and we will investigate your claim.
}

Copyright and moral rights for the publications made accessible in the public portal are retained by the authors and/or other copyright owners and it is a condition of accessing publications that users recognise and abide by the legal requirements associated with these

- Users may download and print one copy of any publication from the public portal for the purpose of private study or research.

- You may not further distribute the material or use it for any profit-making activity or commercial gain

If the publication is distributed under the terms of Article $25 \mathrm{fa}$ of the Dutch Copyright Act, indicated by the "Taverne" license above, 
The discriminative value of patient characteristics and dyspeptic symptoms for upper gastrointestinal endoscopic diagnoses 
CIP-DATA KONINKLIJKE BIBLIOTHEEK, DEN HAAG

Adang. Robert Peter René

The discriminative value of patient characteristics and dyspeptic symptoms for upper gastrointestinal endoscopic diagnoses / Robert Peter René Adang. Maastricht: Universitaire Pers Mastricht. - Ill.

Thesis University of Limburg Maastricht. - With ref. - With summary in Dutch. ISBN 90-5278-193-1

Subject headings: discriminative value / dyspeptic symptoms / endoscopic diagnoses.

Layout: Rob Adang

Cover illustration: Stephan Adang

Cover design: $\mathbb{R}$. Claus, Buro Vlakvorm

Production: Datawyse | Universitaire Pers Maastricht

The studies in this thesis were made possible by financial support of Merck Sharp \& Dohme BV. Printing of this thesis was financially supported by Merck Sharp \& Dohme BV, Astra Pharmaceutica BV, Janssen Pharmaceutica BV, and Glaxo BV. 


\title{
The discriminative value of patient characteristics and dyspeptic symptoms for upper gastrointestinal endoscopic diagnoses
}

\author{
PROEFSCHRIFT
}

\author{
ter verkrijging van de graad van doctor \\ aan de Rijksuniversiteit Limburg te Maastricht, \\ op gezag van de Rector Magnificus, Prof. Mr. M.J. Cohen, \\ volgens het besluit van het College van Dekanen, \\ in het openbaar te verdedigen \\ op donderdag 15 juni 1995 om 16.00 uur
}

door

Robert Peter René Adang

geboren op 22 augustus 1962 te Vaals

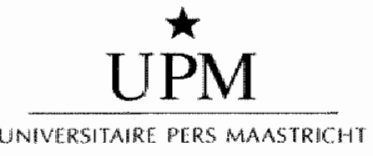




\section{Promotores}

Prof.dr.ir. A. Hasman

Prof.dr. R.W. Stockbrügger

\section{Co-promotores}

Dr. J.L. Talmon

Dr. F.-J.F.E. Vismans (ZH Kennemer Gasthuis Haarlem)

\section{Beoordelingscommissie}

Prof.dr. P.B. Soeters, voorzitter

Prof.dr.ir. J.H. van Bemmel (Erasmus Universiteit Rotterdam)

Prof.dr. P.G. Knipschild

Prof.dr. P. Pop

Prof.dr. G.N.J. Tytgat (Academisch Medisch Centrum Amsterdam) 
Aan mijn ouders

Voor Astrid, Stephan en Roderick 


\section{Contents}

\section{Chapter I}

General introduction and aims of the study

Definition and classiffication of dyspepsia

Prevalence of dyspepsia

Socio-economic aspects of dyspepsia

Endoscopic investigation in dyspepsia

Predictive value of dyspeptic symptoms: overview of the literature Aims of the study and thesis outline

\section{Chapter II}

Methods of data acquisition and description of the study population . . . . . 29

Introduction

Methods of data acquisition

Study population

Discussion

\section{Chapter III}

Evaluation of the computerised history taking system:

a comparison between paper and computerised questionnaires . . . . . . . . 49

Abstract

Introduction

Methods of data acquisition

Results

Discussion

Epilogue

\section{Chapter IV}

The diagnostic outcome of upper gastrointestinal endoscopy:

are referral source and patient age determining factors? . . . . . . . . . 67

Abstract

Introduction

Patients and methods

Results

Discussion 
Chapter V

Appropriateness of indications for diagnostic upper gastrointestinal endoscopy:

association with relevant endoscopic disease $\ldots \ldots \ldots \ldots 3$

Abstract

Introduction

Methods of data acquisition

Results

Discussion

\section{Chapter VI}

Intermezzo

Introduction

Reasons for not answering the questionnaires

Comparison between responders and non-responders

Comparison between pain report in questionnaires and interview

Concluding remarks

\section{Chapter VII}

Are upper gastrointestinal endoscopic findings predictable?

The use of logistic regression analysis $\ldots \ldots \ldots \ldots \ldots \ldots$
Abstract
Introduction
Methods
Results
Discussion

\section{Chapter VIII}

Are upper gastrointestinal endoscopic findings predictable?

The use of a non-parametric partitioning algorithm . . . . . . . . . . 141
Abstract
Introduction
Methods
Results
Discussion
Addendum

Appendices

Summary and conclusions

Samenvatting

Dankwoord 

General introduction and aims of the study 



\section{Definition and classification of dyspepsia}

The term 'dyspepsia' is derived from the Greek words ' $\delta v \sigma^{\prime}$ (dus = bad) and ' $\pi \epsilon \sigma \sigma \omega$ ' (pessoo = to digest). Although patients themselves do not use this term - in English-speaking countries they prefer 'indigestion', a term derived from Latin with the same construction and a meaning closely related to dyspepsia - dyspepsiat is widely used as a medical term. Until recently, the discussion of dyspepsia was encumbered by the lack of agreed definitions. Several working parties have therefore addressed the issues of definition and classification of dyspepsia in the past few years ${ }^{1-5}$. From the reports of these consensus working parties, broadly similar definitions for the entity dyspepsia have emerged: episodic or persistent symptoms that include upper abdominal pain or discomfort, thought to be referable to the proximal gastrointestinal tract. As Heading ${ }^{6}$ pointed out, the term dyspepsia describes a combination of facts (the symptoms) with an interpretation put upon them, namely that the symptoms have an upper gastrointestinal origin.

Dyspepsia can be classified with respect to the underlying disease. In case of organic dyspepsia a specific organic lesion, thought to be responsible for the symptoms, has been identified. When no organic lesion has emerged on limited gastroenterological investigation, dyspepsia is called 'non-ulcer dyspepsia' 1,3, 'functional dyspepsia' 2.4 .5 , or 'idiopathic dyspepsia' ${ }^{6}$. The accuracy of the categorisation of dyspeptic patients into organic and functional disorders will depend on the extent of the diagnostic efforts ${ }^{7}$. According to the recently achieved definitions, upper gastrointestinal endoscopy is obligatory and ultrasound of the gallbladder and pancreas is generally recommended as diagnostic investigations.

It has also been proposed to subdivide patients with dyspepsia into different groups based largely on symptoms which suggest, although imperfectly, causative factors. This classification of dyspepsia based on symptom patterns can be applied, both to the patients in whom no specific organic lesion could be identified 1.8 and to the patients who have not yet been investigated ${ }^{3.6}$.

In 'reflux-like dyspepsia' retrosternal pain or discomfort, heartburn and acid regurgitation are prominent among the dyspeptic symptoms. If patients have only these symptoms and no other dyspeptic complaints, it has been proposed to not consider them as having reflux-like dyspepsia but as having gastro-oesophageal reflux disease ${ }^{4.5}$. Dyspeptic symptoms including localised epigastric pain, pain at night, pain relieved by food or antacids, and a pattern of remission and relapse, are classified as 'ulcer-like dyspepsia'. Symptoms like post-prandial fullness, early satiety, bloating, abdominal distension, nausea and poorly localised abdominal discomfort are named 'dysmotility-like dyspepsia'. 'Idiopathic or essential or nonspecific dyspepsia" denotes dyspepsia that does not fall into one of the above three categories.

The classification of dyspepsia on the basis of symptom patterns is believed to represent different pathophysiological mechanisms, and should provide general practitioners and gastroenterologists with guidelines for the management of the 
patients in whorn investigation did not reveal an organic lesion or in whom initial endoscopy seems not indicated. However, there is such an overlap among the dyspepsia subgroups themselves and between dyspepsia and the irritable bowel syndrome that it remains to be established that a classification of patients with dyspepsia based on symptoms alone is climically useful ${ }^{9-11}$.

\section{Prevalence of dyspepsia}

There are a number of important studies on the epidemiology of dyspepsia. In 1951 Doll et al. ${ }^{12}$ reported on occupational factors in the aetiology of gastric and duodenal ulcers. Approximately 6000 men working for a number of companies in London, England, were interviewed as to whether they had suffered from indigestion. The investigators concluded that $31 \%$ of the sample had symptoms of dyspepsia in the preceding five years. In 1968 Weir and Backett ${ }^{13}$ published their study of dyspeptic symptoms in a semi-rural population of almost 1500 men in north-east Scotland. They demonstrated that nearly $25 \%$ of the subjects suffered from dyspepsia over a period of three years. In 1985 Tibblin ${ }^{14}$ published the results of a crosssectional study on the prevalence of dyspepsia in more than 3000 men living in Göteborg, Sweden; the prevalence of dyspepsia showed a peak at the age of 50 (26\%) and declined to $12 \%$ at the age of 67 . In 1988 Johnsen et al. ${ }^{15}$ established the prevalence of dyspepsia in more than 14,000 middle-aged men and women living in the municipality of Tromsø, Norway, by means of a questionnaire; the prevalence of reported dyspeptic symptoms was $23 \%$ in men and $18 \%$ in women. In 1989 Jones and Lydeard ${ }^{16}$ established the prevalence of dyspeptic symptoms in over 2000 men and women from urban (Southampton) and semi-rural (Andover) practices in the southern part of England by means of postal questionnaires. The six-month prevalence of dyspepsia in these community samples was $38 \%$. In 1990 Jones et al. ${ }^{17}$ estimated the prevalence of dyspepsia in a number of cities in England and Scotland using the same methodology. The six-month prevalence in these representative samples all together constituting almost 7500 subjects averaged $41 \%$; no significant geographical differences with respect to the frequency of dyspeptic symptoms could be observed. In 1990 Bernersen et al. ${ }^{18}$ published the results of a population-based study on the prevalence of peptic ulcers carried out in northern Norway. The prevalence of dyspeptic symptoms in a sample of about 1800 subjects who responded to a postal questionnaire was $27 \%$. In 1994 Agréus et al. ${ }^{19}$ studied the prevalence of abdominal symptoms by means of a postal questionnaire sent to a representative sample of almost 1300 adults from a Swedish municipality. The three month-prevalence of dyspepsia was $32 \%$ in this population. Also in 1994 Kay and Jørgensen ${ }^{20}$ published a study on the epidemiology of dyspepsia in a random sample of over 3600 Danes. Depending on the symptoms included in the definition and frequency of the symptoms, the one-year prevalence was 13-54\% among men and 15-47\% among women, and the incidence was $5-22 \%$ and $6-25 \%$ respectively. 
These studies on the epidemiology of dyspepsia cannot easily be compared. The definitions used are too variable, different methods of assessment have been used, and different target populations have been selected. Therefore, the wide range of prevalences reported probably reflects differences in the survey methods and definitions used as much as true differences in the prevalence of dyspepsia ${ }^{21}$. The results of the more recent studies suggest that the prevalence of dyspepsia in the community has changed little since the early surveys carried out by Doll et al. ${ }^{12}$ and Weir and Backett ${ }^{13}$ more than 25 years ago.

Epidemiological investigations indicate that there is no consistent difference in prevalence of dyspepsia between males and females ${ }^{14,16,17}$. Age seems to be a relevant factor, as the prevalence of dyspepsia has been shown to decrease with age 14,16,17,20,22. On the other hand, Crean et al. ${ }^{23}$ have demonstrated that the ratio of organic to functional disorders in hospital outpatients referred because of dyspepsia increases with age: from $0.6: 1$ in those younger than 25 years to $2: 1$ in those older than 40 years. The prevalence of dyspepsia has been shown to be unrelated to social class ${ }^{16,17}$. Kay and Jørgensen ${ }^{20}$ have demonstrated that dyspepsia is a fluctuating phenomenon, and that psychic vulnerability is most strongly related to prevalence and incidence of dyspepsia. In contrast, they did not find that life-style factors are associated with dyspepsia.

Self care seems to be important in managing dyspeptic symptoms, since only a quarter of the patients with dyspepsia actually seeks medical advice for their symptoms ${ }^{16,17,22}$. A number of factors interact to predict consulting behaviour for dyspepsia. One important factor seems to be the relationship between doctor and patient and the expectations which it engenders ${ }^{16,17,22}$. Although the prevalence of dyspepsia is almost constant across socio-economic groups, social class is an important predictor of consulting behaviour, with the consultation rate rising steeply as the social class falls ${ }^{16,17}$. Despite the decrease in symptom frequency with age, the proportion of dyspeptic patients seeking medical advice gradually increases with age 16,17,22. Simple parameters such as symptom frequency, symptom severity and the effect of symptoms on daily living are poor predictors of consultation; much more important seems to be the concern about the possible serious nature of the symptoms ${ }^{24}$.

Dyspepsia accounts for about 2-5\% of all consultations in general practice ${ }^{25-27}$. This means that a typical general practitioner will see one or two patients with dyspepsia each day. Most dyspeptic patients are managed in primary care, and in general only a small proportion of consultation results in specialist referral. The rates of referral and investigation vary wiclely among general practitioners. Dyspepsia accounts for between $30 \%$ and $50 \%$ of all consultations with hospital gastroenterology specialists.

Dyspepsia in The Netherlands: in The Netherlands, no figures are known regarding the prevalence of dyspepsia in the community. However, an indication of the magnitude of the problem may be derived from population surveys carried out by The Netherlands Institute for Public Opinion and Market Research (NIPO) and by a number of Public Health Services. 
In 1990 the NIPO conducted a survey on health of the Dutch population by means of postal questionnaires ${ }^{28} ; 7 \%$ of the respondents indicated that they had 'recently experienced stomach or gut complaints'. In 1989 and 1990 health surveys were conducted by several Public Health Services throughout The Netherlands ${ }^{29,30}$. These two inquiries were undertaken in representative population samples by means of postal questionnaires, and the average response rate was about $70 \%$. Depending on the degree of overlap between affirmative answers to the questions concerning gastrointestinal complaints, the proportion of respondents suffering from these complainits ranged from $12 \%$ to $28 \%{ }^{29}$ and from $14 \%$ to $24 \%{ }^{30}$. It should be noted that these data may not reflect the prevalence of dyspepsia in terms of the recently proposed definitions. ${ }^{1-5}$.

\section{Socio-economic aspects of dyspepsia}

Both direct costs and indirect costs need to be taken into account in an economic analysis of dyspepsia. The direct costs include costs of consultations, diagnostic procedures, drug therapy, and hospital admissions. Indirect costs include production loss due to sick-leave, disability and death.

Warndorff et al. ${ }^{31}$ have estimated the costs of disorders associated with dyspepsia for The Netherlands during 1988. In the following paragraphs the results of their study will be reviewed. The methods of assessment will not be discussed in detail, since they are beyond the scope of this introduction.

It was calculated that $2.3 \%$ of the consultations in primary care were accounted for by dyspepsia, a figure which correlates reasonably well with that registered by the Royal College of General Practitioners in England ${ }^{25}$. The number of general practitioner consultations because of dyspepsia in 1988 was more than 1.2 million, yielding a cost of approximately $f 41.1$ million. More than 260,000 outpatient specialist consultations for dyspepsia yielded a cost of approximately $f 25.1$ million.

Approximately 83,000 upper gastrointestinal endoscopies and more than 37,000 barium meal studies were performed in outpatients because of dyspepsia. The structure of the Dutch Health Administration does not permit allocating actual costs to these investigations separately, because these costs are included in the patient-day costs.

Almost 20,000 patients were admitted because of disorders associated with dyspepsia, accounting for approximately 300,000 patient-days. Gastric carcinoma was responsible for $26 \%$ of the total number of patient-days, gastric ulcer for $19 \%$, oesophageal disease for $16 \%$, duodenal ulcer for $15 \%$, and gastritis and/or duodenitis for $8 \%$. The direct cost of hospital care was about $f 197.5$ million.

The total cost of drug therapy outside the hospital in dyspeptic patients, including prescribed and over-the-counter drugs, was approximately $f 242.4$ million.

The indirect costs were determined on the basis of the associated loss of production and income, either currently (absence from work during a period of less than 
one year and disability) or in the future (mortality). In 1988 the loss of production to Dutch society on account of absence from work because of dyspeptic disorders equalled roughly 2.5 million days, costing approximately $f 319.2$ million, with peptic ulcer disease responsible for approximately $80 \%$ of this sum. The total cost of disability due to dyspepsia was approximately $f 245.5$ million. Almost 3000 persons died because of a disorder associated with dyspepsia, of whom about onesixth generated costs in terms of foregone income, namely those who died younger than 65 years. Gastric carcinoma and peptic ulcer disease, particularly gastric ulcer, were the major causes of death, accounting for $78 \%$ and $17 \%$ respectively. Costs associated with mortality equalled approximately $f 106.6$ million.

Thus, the direct costs attributable to disorders associated with dyspepsia were approximately $f 506.2$ million and the indirect costs were approximately $f 671.2$ million. The direct costs of managing dyspepsia derive almost entirely from drug therapy $(48 \%)$ and hospital admissions (including the diagnostic procedures in outpatients; $39 \%)$.

Warndorff et al. ${ }^{31}$ also calculated the relative shares of organic and functional disorders in the costs of dyspepsia, thereby not strictly adhering to the definitions as proposed by an international working party ${ }^{2}$. Overall, organic disorders accounted for $63 \%$ and functional disorders accounted for $37 \%$ of the total costs attributable to dyspepsia.

A Swedish study by Nyrén et al. ${ }^{32}$ has demonstrated that production loss due to short-term sick-leave is by far the most important cost item in functional dyspepsia. The risk of absence from work due to sickness is significantly higher for patients with functional dyspepsia than for those having peptic ulcer disease ${ }^{33}$.

\section{Endoscopic investigation in dyspepsia}

Two major diagnostic procedures are available once further investigation of dyspepsia seems to be indicated: upper gastrointestinal endoscopy and (biphasic) radiography. Several studies have compared these two procedures with respect to their diagnostic accuracy ${ }^{34-38}$. These studies conclude that both procedures are equivalent in detecting gastric ulcers, but active duodenal ulcers can be diagnosed more accuratelly by endoscopy, especially in case of bulbar deformation. Mild degrees of oesophagitis can also be diagnosed more accurately by endoscopy than by radiography. Gastric cancers can be detected in an advanced stage by both procedures. Flat mucosal lesions like erosions can rarely be diagnosed by radiology. Although the relationship of diffuse mucosal inflammatory changes in stomach and/or duodenum to dyspeptic symptoms yet has to be established ${ }^{39-49}$, the ability to diagnose mucosal lesions has to be considered as an advantage of endoscopy over radiography. Another advantage of the endoscopic procedure is the possibility to perform additional diagnostic interventions, such as taking biopsy specimens for histological examination (for example to demonstrate Helicobacter pylori infestation) or assess- 
ing the $\mathrm{pH}$ of the residual gastric juice. If radiological investigation suggests the presence of gastric ulcer or gastric cancer, endoscopy has still to be performed to obtain a histological diagnosis. Therefore, upper gastrointestinal endoscopy is generally considered the investigation of first choice and is mandatory for a precise diagnosis of dyspepsia ${ }^{34-36,50}$.

During the past decades there has been a dramatic escalation in demand for endoscopic examinations, especially since endoscopy units began to offer open access to general practitioners ${ }^{51-64}$. Scott and Atkinson showed ${ }^{58}$ that the annual number of upper gastrointestinal endoscopies had doubled to 7.6 per 1000 of the population from 1981 to 1986 . It has been speculated that the annual demand in the nineties could easily reach 12 per 1000 of the population ${ }^{60,61}$. Providing open access to endoscopy offers patients the opportunity of rapid diagnosis and treatment, while general practitioners retain control of the patients. In some centres, however, the demand for service has outstripped the available resources resulting in long waiting lists ${ }^{51,62,64}$. A nationwide survey in the United Kingdom has shown that $52 \%$ of the endoscopy units offering an open access service have had a waiting list exceeding six weeks at some time ${ }^{62}$. Whereas some studies have shown that the institution of an open access policy had resulted in a substantial fall in requests for barium meal examinations and in referrals to the gastroenterology outpatient department ${ }^{57.63}$, other studies failed to demonstrate these effects ${ }^{51,53,58}$. Moreover, in a large proportion of the patients endoscopy reveals no serious organic disease $51-53,57,59,65,66$.

The appropriate use of upper gastrointestinal endoscopy in patients with dyspepsia is thus crucial to avoid overloading the services and creating long waiting lists. However, no agreement has yet been reached about how to select dyspeptic patients for endoscopy. In this context, the opportunity of free access to endoscopic facilities has been debated, and it has been proposed to restrict the open access service only to patients above a certain age, for example 45 years $51,59,64,67,68$. Moreover the adoption of guidelines to select those patients with dyspepsia who really need endoscopy can probably enable a more appropriate use of this diagnostic technique. It still has to be established whether the clinical picture of dyspepsia can be used as a valid guideline to sustain endoscopy demand.

\section{Predictive value of dyspeptic symptoms: overview of the literature}

At the beginning of the $20^{\text {th }}$ century it was claimed that most patients with dyspepsia could be correctly diagnosed solely on the basis of their symptoms ${ }^{69}$. However, it has been demonstrated that up to half of all patients with dyspepsia emerge from the first outpatient contact without any firm diagnosis having been established ${ }^{70.71}$. Over the last 20 years several groups of investigators have systematically evaluated dyspeptic symptoms in an attempt to predict the probability of underlying organic disease and, thus, the need of further investigation and/or treatment.

The Leeds studies: Horrocks and de Dombal from Leeds, England, have developed a computer-aided diagnostic system, using a variant of Bayes' theorem ${ }^{70}$. The 
computer's diagnostic predictions (based solely on the data obtained by the house surgeon's interview), were compared with the final diagnoses in 212 patients admitted electively with dyspepsia, and coming eventually to surgery. In $85 \%$ of the patients the final postoperative diagnosis was correctly predicted by the system.

In another study the computer-aided system was supplied with data obtained at initial outpatient attendance (by means of a non-medically qualified assistant's interview) ${ }^{71}$. Of 154 patients presenting with dyspepsia to the surgical outpatient department, 93 were shown to have an organic lesion - such as peptic ulcer, cholecystitis, or gastric cancer - and were admitted to hospital. The computer correctly predicted the cause of dyspepsia in $81 \%$ of these patients.

The foregoing studies dealt with patients who attended the surgical outpatient clinic and all of whom proceeded eventually to surgery. It remained to be answered whether the computer-aided system used on patients coming to surgery could also be used on patients coming to endoscopy, and whether results equivalent to those in Leeds could be obtained in a different geographical (and socio-economic) environment. In an attempt to answer these questions, the computer-aided system used in Leeds in previous experiments was 'transferred" to a District General Hospital, and a series of 165 patients referred for upper gastrointestinal endoscopy were interviewed and analysed 72 . The system could predict the presence of serious organic lesions on endoscopy, i.e. peptic ulcers and cancers, with a sensitivity of $92 \%$ and a specificity of $63 \%$. The investigators suggested that a system of this type could be used to identify patients at high risk of having serious organic disease, who might then be referred for endoscopy.

Horrocks and de Dombal ${ }^{73}$ evaluated the clinical presentation of 360 patients with dyspepsia, and made some interesting observations concerning the discriminative value of various aspects of abdominal pain. The diagnostic outcome in this patient population was as follows: $28 \%$ had cholecystitis, $36 \%$ peptic ulcer, $22 \%$ gastric cancer, and $14 \%$ no organic lesion on operation. Pain localisation and pain radiation site were by no means as helpful as might be imagined in discriminating between the disease categories, this in contrast to the duration and pattern of pain. Furthermore, severity and progress of pain were of limited discriminative value. At variance with textbook descriptions, only $20 \%$ of the patients with duodenal ulcer and only $2 \%$ of the patients with gastric ulcer expressed that their pain was relieved by ingestion of food. Night pain appeared to be a good discriminative feature: $70 \%$ of the patients with duodenal ulcer claimed that their pain woke them at night. The authors concluded that opinions in the literature about the symptomatology of upper gastrointestinal disease consisted of clinical impressions or aphorisms rather than observed findings in large series of patients.

In 1985 de Dombal's group published the results on a total number of 1041 patients with dyspepsia who were interviewed (by a medical secretary) when seeing their general practitioner (201 patients), before undergoing a barium meal examination (344 patients), or before being seen at an endoscopy clinic (496 patients) ${ }^{74}$. The history data were analysed by the computer-aided system developed at Leeds, 
and, according to the results, patients were predicted to be at high, medium, or low risk of having serious organic disease. They were then followed up and the final diagnosis was compared with the risk predicted by the computer. The authors concluded that the computer-aided system was an effective method of preliminary screening of dyspeptic patients and that, if such a policy had been in force during the study, a fall of almost $30 \%$ in the number of investigations could have been achieved. As a consequence, the investigation of patients with organic disease in the low risk category (13\% of duodenal ulcers, $12 \%$ of gastric ulcers, and $4 \%$ of gastric cancers) would be deferred in the first instance. Another important conclusion was that the system obtained similar results in the referral setting as in the general practice setting.

The Glasgow studies: Crean and colleagues from the Diagnostic Methodology Research Unit in Glasgow, Scotland, have also worked towards the development of a diagnostic decision support system for dyspepsia ${ }^{75-79}$. They have collected detailed history data on 1200 patients referred from general practice to a gastroenterological clinic because of dyspepsia. Early on in the project, a structured questionnaire was used to elicit a large number of predefined symptoms in a standardised fashion. Later on, patients were interviewed by a simple computer system. A final diagnosis has been established for each patient by means of radiological and/or endoscopic investigations. The data on these patients and the final diagnoses have been analysed with a Bayesian approach using multiple logistic regression to adjust for dependency of symptoms and multiple diagnoses, resulting in the 'adjusted weights of symptoms' for each of these diagnoses ${ }^{76,78,79}$. The investigators emphasized the importance of making explicit definitions of the symptoms and diagnoses relevant to dyspepsia ${ }^{77.78}$, and concluded that computerised interviewing is the best way to ensure consistent questioning ${ }^{76}$.

Symptoms reported to be predictive of peptic ulcer disease were (in descending order): frequent night pain relieved by food or antacids, complaints worse in winter, history longer than four years, pointing sign, family history of peptic ulcer, and pain relieved by food ${ }^{75}$. Patient characteristics and symptoms predictive of gastric cancer were (in descending order): dark vomitus, age above 55 years, interscapular pain radiation, daily pain, history shorter than one year, and weight loss ${ }^{75}$.

Lindberg et al. ${ }^{80}$ tested the Glasgow diagnostic decision system in 467 Swedish patients referred for upper gastrointestinal endoscopy because of dyspeptic symptoms. The discriminative performance of this system for peptic ulcers was rather disappointing when the statistics based on British patients were applied to Swedish patients, but classification of the Swedish patients based on statistics from their own data base showed promising results. This observation may reflect a true geographical variation in the clinical picture of peptic ulcer disease or may be a result of the selection of patients included in the data bases or definitions used.

The Southampton studies: Holdstock's group from Southampton, England, has developed a scoring system to assess the individual risk of finding serious endoscopic disease in patients attending an open access endoscopy unit ${ }^{81}$. A total of 235 
patients referred for upper gastrointestinal endoscopy by their general practitioner were asked to complete a standard questionnaire. On the basis of the subsequent endoscopy results, the patients were divided into two groups: 48 patients with serious disease (peptic ulcers; cancers;" oesophageal strictures) and 187 patients without. The technique of stepwise discriminant analysis was used to select those variables that best discriminate between these two groups. In order of importance, these were age above 55 years, vomiting, male gender, smoking, and past history of peptic ulcer or hiatus hernia. The scoring system derived from these six variables has been prospectively assessed in a further 356 patients, undergoing endoscopy in two hospitals with different endoscopy practice. The results showed that by utilising this scoring system, it would be possible to reduce the number of examinations by $33 \%$, still detecting $98 \%$ of serious disease.

In another study ${ }^{82}$ the scoring system could also be successfully used in 1279 patients undergoing endoscopy (439 patients directly referred from general practice and 840 hospital outpatients), and in 321 patients undergoing radiological examination. In this population a $26 \%$ reduction in endoscopic workload with $3 \%$ of serious disease missed could have been possible, when the system would have been used to select patients. All 55 patients with carcinoma included in this study would be diagnosed. Similar results applied to patients attending for radiology. The investigators concluded that the scoring system is better at excluding serious disease than actually predicting it.

The Trondheim studies: researchers at the University of Trondheim, Norway, have also investigated the ability of dyspeptic symptoms to predict endoscopic findings ${ }^{83-86}$. A recent study included 930 dyspeptic outpatients attending for their first upper gastrointestinal endoscopy who completed a detailed, self-administered questionnaire ${ }^{86}$. Three diagnostic categories were evaluated: organic dyspepsia (endoscopic evidence of malignancy; peptic ulcer; oesophagitis, 270 patients); peptic ulcer (154 patients); and oesophagitis (131 patients). A forward stepwise logistic regression analysis was used to identify the best predictors for each of these diagnostic categories, and score models for individual predictions were devised by applying Bayes' theorem on the observed material.

Pain relieved by antacids, age above 40 years, previous peptic ulcer disease, male gender, symptoms provoked by berries, and night pain relieved by antacids or food were found to predict organic dyspepsia with a sensitivity and specificity of approximately $70 \%$. A history of peptic ulcer disease was the single best predictor of actual peptic ulcer, followed by pain relieved by antacids, age above 40 years, smoking, and pain relieved by food. The score model for peptic ulcer showed at best $60-70 \%$ sensitivity and specificity. Oesophagitis could be predicted by the following variables: heartburn, history of hiatus hernia, pain provoked by berries, male gender, and vomiting. The predictive score model for oesophagitis based on these symptoms similarly showed a sensitivity and specificity of $60-70 \%$.

The authors confirmed the findings of Holdstock and colleagues ${ }^{82}$ that the main impact of predictive models in dyspepsia should be to reduce the number of negative 
endoscopies rather than predict positive findings, because of the rather low prevalence of organic diseases. However, they also emphasized the value of reassurance from a negative endoscopy, since $41 \%$ of the patients in their study indicated a fear of malignant disease.

The Sydney / Rochester studies: in 1987 Talley et al. from Sydney, Australia, reported a study on whether dyspeptic symptoms can discriminate between the following diagnostic categories: essential dyspepsia (113 patients); peptic ulcer (55 patients), and cholelithiasis (53 patients) ${ }^{87}$. All patients completed a structured history questionnaire. Patients in the first two categories were all examined endoscopically, and patients in the latter had biliary pain and radiologically confirmed gall stones. Stepwise logistic regression analysis was used to identify the symptoms that could predict each of the diagnostic categories. A diagnosis of peptic ullceration was more likely if there was night pain, pain relieved by food or antacids, and pain episodes of shorter duration. The results suggested that certain symptoms may be of diagnostic value in dyspepsia, but many are not.

In 1993 Talley's group from the Mayo Clinic in Rochester, Minnesota, published a study about the discriminative value of individual dyspeptic symptoms and symptom subgroups in a consecutive sample of 820 outpatients referred for upper gastrointestinal endoscopy ${ }^{88}$. All patients completed a validated questionnaire concerning 46 dyspeptic symptoms. Based on the questionnaire responses, dyspeptic patients were classified in the following symptom subgroups: 'ulcer-like dyspepsia', 'dysmotility-like dyspepsia', 'reflux-like dyspepsia', and 'nonspecific dyspepsia'. Logistic regression analysis was used to evaluate the following diagnostic categories: functional dyspepsia (normal endoscopic findings, including gastric or duodenal erythema, 162 patients); peptic ulcers (96 patients); acute (erosive) gastritis and/or duodenitis ( 90 patients); reflux oesophagitis (1.18 patients); gastric cancer (28 patients); other diagnoses (326 patients).

There was a substantial overlap among the symptom subgroups in patients with functional dyspepsia; also, the dyspepsia subgroups were poor discriminators in the models comparing the diagnostic categories. The investigators concluded that classification of dyspepsia in subgroups based on symptom patterns appears not to be useful in identifying specific causes of dyspepsia.

The following dyspeptic symptoms were predictive of functional dyspepsia $v s$ all other diagnoses: frequent epigastric pain, no pain relief with antacid use, and infrequent vomiting. At a specificity of $80 \%$, the sensitivity of this model was $60 \%$. A diagnosis of functional dyspepsia us peptic ulcer was significantly more likely if patients had frequent epigastric pain and had no pain relief from $\mathrm{H}_{2}$ receptor antagonists. At a specificity of $80 \%$, the sensitivity of this model was $55 \%$. Functional dyspepsia was significantly more likely than reflux oesophagitis in patients with frequent epigastric pain, infrequent vomiting, and heartburn not relieved by antacids. At a specificity of $80 \%$, this model had a sensitivity of $80 \%$. 
It has to be remarked that the models were adjusted for age and gender. The results showed that symptoms are not very sensitive in discriminating functional dyspepsia from other diagnoses in patients undergoing endoscopy.

The Genoa studies: Mansi and colleagues from Genoa, Italy, studied 2000 dyspeptic patients attending the gastroenterology outpatient department ${ }^{89}$. History data were obtained by a personal interview using a structured questionnaire, and almost all patients underwent necessary investigations such as ultrasonography and/or upper gastrointestinal endoscopy. Patients were divided into the following dyspepsia-categories: 'organic-related dyspepsia' (cancers; peptic ulcers; oesophagitis; pancreatic and biliary disease, 572 patients), 'organic-associated dyspepsia" (hiatus hernia, gastritis; duodenitis; cholelithiasis without true biliary colics, 908 patients), and 'idiopathic dyspepsia' (no structural abnormality on investigation, 520 patients). With linear discriminant analysis approximately $70 \%$ of the patients could be correctly classified in all the pairs of categories considered.

More recently Mansi's group studied 2253 dyspeptic patients who were referred to an open access endoscopy service ${ }^{90}$. The aim of this study was to assess whether clinical patterns of dyspepsia can be considered as a valid guideline for the appropriate use of endoscopy. According to the symptom patterns, the patients were considered to have 'ulcer-like dyspepsia' (973 patients), 'reflux-like dyspepsia' (857 patients), and 'dysmotility-like dyspepsia' (423 patients). Ulcer-like dyspepsia was more common in peptic ulcer, whereas the reflux-like type predominated in oesophagitis and hiatus hernia. Patients with dysmotility-like dyspepsia had more often a normal endoscopy than patients belonging to the other dyspepsia subgroups, particularly in the age below 50 years. Because of the relatively low prevalence of patients younger than 50 years with dysmotility-like dyspepsia in the patient sample, only a small reduction in endoscopic service load could be obtained by not investigating them.

The Aberdeen study: Naji and colleagues from Aberdeen, Scotland, have addressed the important issue that a negative endoscopy not necessarily has to be inappropriate. They analysed a retrospective sample of 483 patients undergoing elective upper gastrointestinal endoscopy ${ }^{91}$. The endoscopic findings were divided into 'positive' (any pathology other than hiatus hernia, $\mathrm{n}=333$ ) and 'negative' (no pathology other than hiatus hernia alone, $n=150$ ). The endoscopies were also divided into 'helpful' $(n=404)$ and 'unhelpful' $(n=79)$, according to whether they were judged to have influenced patient management or not. Two-thirds of the negative endoscopies were considered to have been helpful in the sense of influencing management.

Stepwise logistic discriminant analysis was used to identify the variables that were predictive of the findings at endoscopy in terms of both criteria. The set of variables predictive of a positive endoscopy differed substantially from the variables discriminating between helpful and unhelpful findings. The investigators stressed that the value of a particular investigation cannot be fully assessed by merely recor- 
ding a proportion showing positive findings, since this does not indicate the effect of the findings on patient management.

The Utrecht studies: Numans studied 861 patients who were firstly referred for upper gastrointestinal endoscopy by their general practitioner to one of the nine participating hospitals in the Utrecht region. The Netherlands ${ }^{92}$. The determinants of relevant findings (cancers, $n=21$; peptic ulcers, $n=131$; oesophagitis, $n=162$ ) were obtained by logistic regression analysis. Cancers could be predicted with a sensitivity of $90 \%$ and a specificity of $80 \%$; most important determinants were age, male sex, smoking, dysphagia, and weight loss. The following variables were important determinants of peptic ulcers: previous ulcer, age, male sex, smoking, use of $\mathrm{H}_{2}$ receptor antagonists, and pain on an empty stomach (sensitivity $80 \%$ and specificity $60 \%$ ). Oesophagitis could be predicted with a sensitivity of $80 \%$ and a specificity of $60 \%$. Important determinants were: male sex, a history of hiatus hernia, smoking, heartburn during the night and when bending. Because of the rather high proportion of relevant findings in the study population, the author concluded that the general practitioners had adequately used the open access endoscopy service and that the predictive models would be of limited help in reducing the number of endoscopies revealing irrelevant findings.

The Maastricht studies: the studies to be presented in this thesis dealt with 2900 patients referred for their first upper gastrointestinal endoscopy to a single open access endoscopy unit. The aims of these studies and the thesis outline will be given in the following section. 


\section{Aims of the study and thesis outline}

The aims of the studies in this thesis are:

- to assess whether it is possible to predict the presence of clinically relevant endoscopic findings in patients referred for diagnostic upper gastrointestinal endoscopy and

- to assess whether it is possible to distinguish patients with specific endoscopic diagnoses from patients having a normal endoscopy by analysing pre-endoscopically collected patient characteristics and history data. In this context, we will also address the issue of multiple diagnoses and the influence of endoscopic copathology on the discrimination of these specific diagnoses.

We will use two different statistical methods on the same material which enables us to compare these techniques and determine the influence of the methods of analysis on the study results. The first technique, forward stepwise logistic regression, has been previously used by other investigators and results in a set of discriminative variables (Chapter VII). The second technique, a non-parametric partitioning algorithm (NPPA), has never been used before in this field of research and results in a classification tree (Chapter VIII).

In the first phase of the study, patients were offered a paper questionnaire containing 57 questions mainly concerning dyspeptic symptoms, with special attention to provoking and/or relieving factors. In the second phase, the patients used a computerised history taking system containing the same questions. Another aim of the study is

- to assess the applicability of such a computerised history taking system in routine clinical practice of an endoscopy unit (Chapter III).

The fact that we have systematically collected data such as patient age, referral source, indications for endoscopy, and previous drug treatment gives us the opportunity

- to determine the impact of patient age on the diagnostic yield of upper gastrointestinal endoscopy (Chapter IV).

- to evaluate the open access facility at our endoscopy unit by comparing the endoscopic outcome in patients referred directly by their general practitioner to the outcome in hospital in- and outpatients (Chapter IV).

- to assess the appropriateness of several indications for diagnostic upper gastrointestinal endoscopy, with special attention to patient age and previous empiric treatment as determinants for the endoscopic outcome in patients with dyspepsia as an isolated symptom (Chapter $\mathbf{V}$ ). 


\section{References}

1. Colin Jones DG, Bloom B, Bodemar G, Crean G, Freston I, Gugler R, et al. Management of dyspepsia: report of a working party. Lancet 1988; I: 576-579.

2. Barbara $L$, Camilleri $M$, Corinaldesi $\mathrm{R}_{\text {, Crean }} \mathrm{GP}$, Heading $\mathrm{RC}$, Johnson $\mathrm{AG}$, et al. Definition and investigation of dyspepsia. Consensus of an international ad hoc working party. Dig Dis Sci $1989 ; 34(8)$ : 1272-1276.

3. Colin-Jones DG. Practical guidelines for the management of dyspepsia. Lancet 1990; I: 301302 .

4. Drossman DA, Thompson $W_{\text {, Talley }} \mathrm{NJ}$, Funch-Jensen $P$, Janssens J, Whitehead WE. Identification of sub-groups of functional gastrointestinall disorders. Gastroenterol Int 1990; 3 (4): $159-172$.

5. Talley $\mathrm{NJ}$, Colin-Jones $\mathrm{D}_{*}$ Koch $\mathrm{KL}$, Koch $\mathrm{M}$, Nyrén O, Stanghellini V. Functional dyspepsia: a classification with guidelines for diagnosis and management. Gastroenterol Int $1991 ; 4$ (4): 145-160.

6. Heading RC. Definitions of dyspepsia. Scand J Gastroenterol 1991; 26 Suppl 182: 1-6.

7. Gustavsson S, Bates S, Adami H-O, Löóf L, Nyrén $O$. Definition and discussion of nomenclature. Scand J Gastroenterol 1985; 20 Supp $109: 11-13$.

8. Colin-Jones DG. The management of dyspepsia. Scand $J$ Gastroenterol 1988; 23 Suppl 155: 96-100.

9. Talley NJ. Spectrum of chronic dyspepsia in the presence of the irritable bowel syndrome. Scand $J$ Gastroenterol 1991; 26 Suppl 182: 7-10.

10. Talley NJ, Zinsmeister AR, Schleck CD, Melton LJ III. Dyspepsia and dyspepsia subgroups: a population-based study. Gastroenterology 1992;102; 1259-1268.

11. Talley NJ. Symptom patterms in functional dyspepsia. Eur $J$ Gastroenterol Hepatol 1992; 4 (8): 597-601.

12. Doll R, Avery Jones F, Buckatzsch MM. Occupational factors in the aetiology of gastric and duodenal ulcers, with an estimate of their incidence in the general population. MRC Special Repart Series no 276. London: HMSO, 1951

13. Weir RD, Backett EM. Studies of the epidemiology of peptic ulcer in a rural community: prevalence and natural history of dyspepsia and peptic ulcer. Gut 1968; 9: 75-83.

14. Tibblin G. Introduction to the epidemiology of dyspepsia. Scand J Gastroenteral 1985; 20 Supp $109: 29-33$.

15. Johnsen R. Straume B, Førde $O H$. Peptic ulcer and non-ulcer dyspepsia - a disease and a disorder. Scand I Prim Healh Care 1988; 6: 239-243.

16. Jones R, Lydeard S. Prevalence of symptoms of dyspepsia in the community. Br Med J 1989; 298: $30-32$.

17. Jones RH, Lydeard SE, Hobbs FDR, Kenkre JE, Williams EI, Jones SI, et al. Dyspepsia in England and Scotland. Gut 1990; 31: 401-405.

18. Bernersen B, Johnsen $R$, Straume B, Burhol PG, Jenssen TG, Stakkevold PA. Towards a true prevalence of peptic ulcer: the Sorreisa gastrointestinal disorder study. Gut 1990; 31: 989-992.

19. Agréus L, Svärdsudd K, Nyrén O, Tibblin G. The epidemiology of abdominal symptoms: prevalence and demographic characteristics in a Swedish adult population. Scand J Gastroenterol 1994; 29: 102-109.

20. Kay $\mathrm{L}$, Jørgensen T. Epidemiology of upper dyspepsia in a random population. Prevalence, incidence, natural history, and risk factors. Scand J Gastroenterol 1994; 29: 1-6.

21. Knill-Jones RP. Geographical differences in the prevalence of dyspepsia. Scand $J$ Gastroenterol 1991; 26 Suppl 182: 17-24. 
22. Jones R, Lydeard S. Dyspepsia in the community: a follow-up study. Br J Chin Pract 1992 : 46 (2): $95-97$.

23. Crean GP, Holden RJ, Knill-Jones RP, Beatrie AD, James WB, Marjoribanks FM, et al. A database on dyspepsia. Gut 1994; 35: 191-202.

24. Lydeard S, Jones R. Factors affecting the decision to consult with dyspepsia: comparison of consulters and non-consulters. IR Coll Gen Pract 1989; 39: 495-498.

25. Royall College of General Practitioners, Office of Population Censuses and Surveys, Department of Health and Social Security. Morbidity statistics from general practice $1981-82$. Third national study. London: HMSO, 1986.

26. Jones R. Self-care and primary care of dyspepsia: a review. Fam Pract 1987; 4 (1): 68-77.

27. Petersen H. Epidemiological and economic aspects of dyspepsia. In: Colin-Jones DG, ed. Practical approaches to the management of dyspepsia. The Medicine Group, Langhorne: 1989, 2-5.

28. Nederlands Instituut voor de Publieke Opinie en het Marktonderzoek (NIPO). Hoe gezond is Nederland? 1990.

29. Pötgens N. Gezondheidsenquête 1989. Een onderzoek naar de gezondheidssituatie van de bewolking in de regio Arnhem. Onderzoeksrapport. Dienst WVG regio Arnhem. Sector Algemene Zaken, epidemiologie, 1990.

30. Werkgroep Gezondheidsenquête Noordelijk Naord-Holland. Gezondheidsenquête in NoordHolland Noord. Basisgezondheidsdienst Kop van Noord-Holland, Westfriesland, Noord-Kennemerland, 1990.

31. Warndorff DK, Boom van den G, Ament AJHA, Evers SMAA. The cost of disorders associated with dyspepsia. Department of Health Economics, University of Maastricht. Maastricht, 1992.

32. Nyrén O, Adami H-O, Gustavsson S, Lööf L, Nyberg A. Social and economic effects of nonulcer dyspepsia. Scand J Gastroenterol 1985; 20 Suppl 109: 41-45.

33. Nyrén O, Adami H॰O, Gustavsson S, Lööf L. Excess sick-listing in nonulcer dyspepsia. $J$ Clin Gastroenterol $1986 ; 8(3): 339-345$.

34. Cotton PB, Shorvon PJ. Analysis of endoscopy and radiography in the diagnosis, follow-up and treatment of peptic ulcer disease. Clin Gastroenterol 1984; 13 (2):383-403.

35. Dooley CP, Larson AW, Stace NH, Renner IG, Valenzuela JE, Eliasoph J, et al. Double contrast barium meal and upper gastrointestinal endoscopy; a comparative study. Ann Intern Med 1984; 101: 538-845.

36. Colin-Jones DG. Endoscopy or radiology for upper gastrointestinal symptoms. Lancet 1986; I: $1022-1023$.

37. Chandie Shaw P, Romunde van LKJ, Griffioen S, Janssens AR, Kreuning J, Eilers GAM. Peptic ulcer and gastric carcinoma: diagnosis with biphasic radiography conipared with endoscopy. Radiology 1987; 163: 39-42.

38. Chandie Shaw P, Romunde van LKJ, Griffioen S, Janssens AR, Kreuning J, Lamers CBHW. Detection of gastric erosions: comparison of biphasic radiography with fiberoptic endoscopy. Radiology 1991; 178: 63-66.

39. DeLuca VA, Winnan GG, Sheahan DG, Sanders FJ, Greenlaw R, Marignani $\mathrm{P}$, er al. Is gastroduodenitis part of the spectrum of peptic ulcer disease? $J$ Cin Gastroenterol 1981; 3 Suppl 2: 17-22.

40. Joffe SN, Shiva Rao S. Symptoms of gastritis. Scand I Gastroenterol 1982; 17 Suppl 79: 6265 .

41. Joffe SN. Relevance of duodenitis to non-ulcer dyspepsia and peptic ulceration. Scand $J$ Gastroenterol 1982; 17 Suppl 79: 88-97.

42. Cheli R, Perasso A, Giacosa A. Dyspepsia and chronic gastritis. Hepato-gastroenterol 1983 : 30: $21-23$. 
43. Villako $\mathrm{K}$, Ihamaiki $\mathrm{T}$, Tamm $\mathrm{A}$, Tammur $\mathrm{R}$. Upper abdominal complaints and gastritis. Amn Clin Res: 1984; 16: 192-194.

44. Toukan AU, Kamal MF, Amr SS, Arnaout MA, Abu-Romiyeh AS. Gastroduodenal inflammation in patients with nonulcer dyspepsia. A controlled endoscopic and morphometric study. Dig Dis Sci 1985; $30(4): 313-320$.

45. Venables CW. Duodenitis. Scand J Gastroenterol 1985; 20 Suppl 109: 91-97.

46. Jonsson $\mathrm{K}-\mathrm{A}$, Gotthard $\mathrm{R}$, Bodemar $\mathrm{G}$, Brodin $\mathrm{U}$. The clinical relevance of endoscopic and histologic inflammation of gastroduodenal mucosa in dyspepsia of unknown origin. Scand $J$ Gastroenterol 1989; $24: 385-395$.

47. Dooley CP, Cohen H, Fitzgibbons PL, et al. Prevalence of Helicobacter pylori infection and histologic gastritis in asymptomatic persons. $N$ Engl $J$ Med 1989; 321: 1562-1566.

48. Tytgat GNJ, Noach LA, Rauws AJ. Is gastroduodenitis a cause of chronic dyspepsia? Scand $J$ Gastroenterol 1991; 26 Suppl 182: 33-39.

49. Johnsen R, Bernersen B, Straume B, Forde OH, Bostad L, Burhol PG. Prevalences of endoscopic and histological findings in subjects with and without dyspepsia. $\operatorname{Br}$ Med $J 1991 ; 302$ : 749-752.

50. Kahn KL, Greenfield S. The efficacy of endoscopy in the evaluation of dyspepsia. A review of the literature and development of a sound strategy. I Clin Gastroenterol 1986; 8 (3): 346-358.

51. Holdstock $\mathrm{G}$, Wiseman $\mathrm{M}$, Loehry $\mathrm{CA}$. Open-access endoscopy service for general practitioners. $\mathrm{Br} \mathrm{Med} J 1979 ; 1 ; 457-459$.

52. Gear MWL, Barnes RJ. Endoscopic studies of dyspepsia in a general practice. Br Med $J 1980$; 280: $1136-1137$.

53. Gear MWL, Ormiston MC, Barnes RJ, Rocyn-Jones J, Voss GC. Endoscopic studies of dyspepsia in the community: an "open-access" service. Br Med $J$ 1980; 280: 1135.

54. Cockel R, Colin-Jones DG, Schiller KFR Gastrointestinal endoscopy services - a review of the 70s with predictions for the 80s. Health Trends 1982; 14: 46 49.

55. Jones $\mathrm{R}$. Upper gastrointestinal endoscopy - a view from general practice. $J R$ Coll Gen Pract $1986 ; 36: 6-8$

56. Hungin AS. Use of an open-access gastroscopy serwice by a general practice: findings and subsequent referral rate. JR Coll Gen Pract 1987; 37: 170-171.

57. Gear MWL, Wilkinson SP. Open-access upper alimentary endoscopy. Br J Hosp Med 1989; 41: $438-444$.

58. Scott B. Atkinson M. Gastroenterology serwices: a regionall review of changes over a five year period (1981-86). Gut 1989; 30: 695-700.

59. Kerrigan DD, Brown SR, Hutchinson GH. Open access gastroscopy: Too much to swallow? Br Med J 1990; 300: 374-376.

60. Scott B. Endoscopic demands in the 90's. Gut 1990; 31: 125-126.

61. Working Party of the Clinical Services Committee of the British Society of Gastroenterology. Provision of gastrointestinal endoscopy and related services for a district general hospital. Gut $1991 ; 32: 95-105$.

62. Bramble MG. Open access endoscopy - a nationwide survey of current practice. Gut 1992; 33: 282-285.

63. Bramble $\mathrm{MG}_{3}$ Cooke WM, Corbett WA, Cann PA, Clarke D, Contractor B, et al. Organising unrestricted open access gastroscopy in South Tees. Gut 1993; 34: 422-427.

64. Williams B, Luckas M, Ellingham JHM, Dain A, Wicks ACB. Do young patients with dyspepsia need investigation? Lancet 1988; II: 1349-1351.

65. Harvey RF, Salih SY, Read AE. Organic and functional disorders in 2000 gastroenterology outpatients. Lancet 1983; I: $632-634$.

66. Richter JE. Dyspepsia: organic causes and differential characteristics from functional dyspepsia. Scand J Gastroenterol 1991; 26 Suppl 182: 11-16. 
67. Hansen JM, Bytzer P, Bondesen S, Schaffalitzky de Muckadell OB. Efficacy and outcome of an open access endoscopy service. Dan Med Bull 1991; 38: 288-290.

68. Jones R. Dyspeptic symptoms in the community. Gut 1989; $30 ; 893-898$.

69. Moynihan BGA. On duodenal ulcer: with notes of 52 operations. Lancet 1905; I: $340-346$.

70. Horrocks JC, de Dombal FT. Computer-aided diagnosis of "dyspepsia". Dig Dis 1975; 20 (5): $397-406$.

71. Horracks JC, de Dombal FT. Diagnosis of dyspepsia from data collected by a physician's assistant. Br Med J $1975 ; 3 ; 421-423$.

72. Horrocks JC, Lambert DE, McAdam WAF, Morgan AG, Pacsoo C, Darnborough A, et al. Transfer of computer-aided diagnosis of dyspepsia from one geographical area to another. Gut $1976 ; 17: 640-644$.

73. Horrocks JC, de Dombal FT. Clinical presentation of patients with 'dyspepsia'. Detailed symptomatic study of 360 patients. Gut 1978; 19: 19-26.

74. Davenport PM, Morgan AG, Darnborough A, de Dombal FT. Can preliminary screening of dyspeptic patients allow more effective use of investigational techniques? $\operatorname{Br}$ Med J 1985; 290: $217-220$.

75. Crean GP, Card WI, Beattie AD, Holden RJ, James WB, Knill-Jones RP, et al. "Ulcer-like dyspepsia". Scand J Gastroenterol 1982; 17 Suppl 79: 9-15.

76. Spiegelhalter DJ. Statistical methodology for evaluating gastrointestinal symptoms. Clin Gastroenterol 1985; 14: 489-515.

77. Knill-Jones RP. A formal approach to symptoms in dyspepsia. Clin Gastroenterol 1985; 14 : 517-529.

78. Knill-Jones RP. Diagnostic systems as an aid to clinical decision making. Br Med $J 1987$ : 295: 1392-1396.

79. Spiegelhalter DJ, Crean GP, Holden R, Knill-Jones RP. Taking a calculated risk: Predictive scoring systems in dyspepsia. Scand J Gastroenterol $1987 ; 22$ Suppl 128:152-160.

80. Lindberg G, Seensalu R, Nilsson LH, Forsell P, Kager L, Knill-Jones RP. Transferability of a computer system for medical history taking and decision support in dyspepsia. A comparison of indicants for peptic ulcer disease. Scand J Gastroenterol 1987; 22 Suppl 128: 190-196.

81. Mann J, Holdstock G, Harman M, Machin D, Loehry CA. Scoring system to improve cost effectiveness of open access endoscopy. $\mathrm{Br}$ Med $J$ 1983; 287: 937-940.

82. Holdstock G, Harman M, Machin D, Patel C, Lloyd RS. Prospective testing of a scoring system designed to improve case selection for upper gastrointestinal investigation. Gastroenterology 1986; 90; 1164-1169.

83. Petersen H, Fjesne U, Johannessen T, Kristensen P, Hafstad PE, Sandbakken P, et al. Clinical significance of upper abdominal symptoms. Scand J Gastroenterol 1985; 20 Suppl 109: 19-22.

84. Fjesne U, Kleveland PM, Waldum H, Halvorsen T, Petersen $H$. The clinical benefit of routine upper gastrointestinal endoscopy. Scand $J$ Gastroenterol 1986; 21: 433-440.

85. Petersen H, Johannessen T, Kleveland PM, Fjosne U, Dybdahl JH, Waldum HL. Do we need to listen to the patient? The predictive value of synptoms. Scand d Gastroenterol 1988; 23 Suppl 155: 30-34.

86. Johannessen T, Petersen $H$, Kleveland PM, Dybdahl JH, Sandvik AK, Brenna E, et al. The predictive value of history in dyspepsia. Scand J Gastroenterol 1990; 25: 689-697.

87. Talley NJ, McNeil D, Piper DW. Discriminant value of dyspeptic symptoms: a study of the clinical presentation of 221 patients with dyspepsia of unknown cause, peptic ulceration, and cholelithiasis. Gut 1987; $28: 40-46$.

88. Talley NJ, Weaver AL. Tesmer DL, Zinsmeister AR Lack of discriminant value of dyspepsia subgroups in patients referred for upper endoscopy. Gastroenterology 1993; 105: 1378-1386.

89. Mansi C, Mela GS, Pasini D, Grosso M, Corti L, Morett M, et al. Patterns of dyspepsia in patients with no clinical evidence of organic diseases. Dig Dis Sci 1990; 35 (12): 1452-1458. 


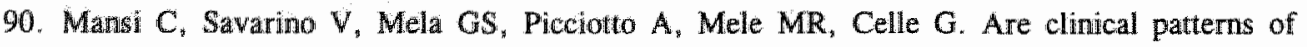
dyspepsia a valid guideline for appropriate use of endoscopy? A report on 2253 dyspeptic patients. Am J Gastroenterol 1993; 88 (7): 1011-1015.

91. Naji SA. Brunt PW, Hagen S, Mowat NAG, Russell IT, Sinclair TS, et al. Improving the selection of patients for upper gastrointestinal endoscopy. Gut 1993; 34: 187-191.

92. Numans ME. Determinants of relevant diagnoses in open access gastroscopy. [Thesis]. Utrecht. 1992. 
Methods of data acquisition and description of the study population 



\section{Introduction}

The studies presented in this thesis concern the discriminative value of patient characteristics and dyspeptic symptoms for upper gastrointestinal (GI) endoscopic diagnoses. The following data, which have been prospectively collected in a consecutive series of patients undergoing their first diagnostic upper GI endoscopy, form the basis for these studies: demographic patient characteristics, referral indications, pain localisations, previous drug treatment, and endoscopic diagnoses. In part of the study population, a detailed history concerning dyspeptic symptoms has been obtained by means of paper or computerised questionnaires.

In this chapter the methods of data acquisition will be described in detail. The data of the study population will be discussed in view of the literature, with special attention to the co-occurrence of endoscopic findings.

\section{Methods of data acquisition}

This study has been performed at the endoscopy unit of the University Hospital Maastricht between January 1989 and October 1990. The hospital serves an area of approximately 250,000 inhabitants, and functions as both the major teaching hospital associated with the University of Limburg and a district general hospital. Since 1981 the endoscopy unit offers an unrestricted open access service to hospital specialists and general practitioners (GPs) ${ }^{1,2}$ : a diagnostic upper GI endoscopy can be requested and is carried out without previous selection by the endoscopist ${ }^{3,4}$.

Data were prospectively collected during every day practice. The secretaries and endoscopists performed the additional, mainly administrative, study activities in addition to their regular work, and no extra personnel was contracted to support the study. The patient data were acquired by means of:

- Structured request forms

- Paper or computerised questionnaires

- A pre-endoscopic interview conducted by the endoscopists

- The endoscopic examination

A specially designed form ('study form") was used to record the data in a consistent and uniform manner (Appendix A); text in this chapter printed in italics refers to items on this study form. The data were coded and stored in a dBASE III PLUS data base file ${ }^{5}$. Missing values and incorrect coding were screened for using the dBASE STATS programme ${ }^{6}$. Part of these originally recorded data have been 'clustered' and recoded for further statistical analysis. The methods of data acquisition, the clustering procedure, and the data of the study population will be described in the following paragraphs. In the studies of this thesis predominantly the clustered data have been analysed, however, occasionally the originally recorded, more detailed data constituted the material for the analyses. 
All patients who were newly referred for a diagnostic upper GI endoscopy (besides an endoscopic retrograde cholangiopancreaticography) were included; patients who underwent a repeat investigation or an elective therapeutic endoscopy were excluded from the study. The secretaries of the endoscopy unit recorded the demographic characteristics such as age and gender, and whether patients were referred by a GP or a specialist. The latter were classified as: internist or gastroenterologist; surgeon; and other specialists.

\section{REQUEST FORMS}

At the time of the study structured request forms were routinely used by the GPs and hospital specialists. The request form contains a section in which the reason(s) for endoscopy were given by the referring doctor. This was interpreted by the endoscopist and recorded on the study form, which provides a list of predetermined referral indications. Indications not given on the request form were considered to be absent. The number of indications for each patient was unlimited and indications were recorded in a non-hierarchical manner.

Dyspepsia was rather broadly defined as episodic or persistent upper abdominal pain and/or discomfort considered to be attributable to the proximal alimentary tract 7.9. Previous peptic ulcer disease was recorded as a separate referral indication. Swallowing problems (proximal dysphagia) were originally recorded apart from symptoms suggesting an obstruction more distal in the oesophagus (distal dysphagia). Dysphagia together with retrosternal pain were clustered as 'oesophageal complaints'. Upper Gl bleeding can be considered in two categories: (a) active haemorrhage, which is usually manifested by haematemesis and/or melaena, and (b) chronic blood loss occurring over weeks or months, in which the manifestations are usually those of a positive faecal occult blood test (Haemoccult ${ }^{R}$ test) and/or iron deficiency anaemia. When a patient was referred because of haematemesis and/or melaena, their presence either could have been confirmed by the referring doctor or only had been presumed on the basis of anamnestic information. Haematemesis, melaena, faecal occult blood, and iron deficiency anaemia were clustered as 'signs of upper GI bleeding'. These signs as well as anorexia and weight loss are generally regarded as so-called 'alarm symptoms'.

\section{QUESTIONNAIRES}

The evaluation of the paper and computerised questionnaires with respect to their applicability in routine clinical practice of an open access endoscopy unit will be presented in Chapter III. In this section, some general characteristics of these questionnaires will be reviewed.

From January 1989 until May 1989 patients received a paper questionnaire while waiting for their endoscopic investigation. This questionnaire contains 57 multiplechoice questions within a branching structure, which divides the questions into 22 'main questions' and 35 'refinement questions'. A refinement question has to be answered only if a previous 'branching question' was answered affirmatively. For 
example, question 1: 'Do you have epigastric pain?", is a branching question. Question 3: "How long have you had this pain?", is a refinement question which only has to be answered if question 1 has been answered with option b 'yes'. Patients were asked to choose just one answer to each question.

From May 1989 to October 1990 a computerised history taking system, implemented on a PC network, was used to interrogate the patients ${ }^{10}$. This system contains the same questions and has the same branching structure as the paper questionnaire. However, each question has an additional 'escape answer': 'I don't know'; 'I don't understand'; 'The correct answer is not available'. Each single question together with its answer options was presented on a separate screen. A question could be answered by simply pressing the numeric key on the keyboard which corresponds to the number of the correct answer. Patients were obliged by the system to select a single answer to each question. The history taking system allowed the patients to correct their answer to the preceding question.

The questionnaires provided a detailed history concerning present dyspeptic complaints, with special attention to their duration, frequency, intensity, and provoking and/or relieving factors. Information on past medical history and nicotine and/or alcohol consumption has also been obtained with these questionnaires. A list of all questions with their answer options is presented in Appendix B. The responses to the questionnaires have been summarised in Appendix D. The code for the clustering procedure of the originally recorded history data is presented in Appendix E.

Patients were invited by the secretaries to answer the paper or computerised questionnaire; whenever a patient did not answer the questionnaire, the reason for not answering had to be recorded.

\section{PRE-ENDOSCOPIC INTERVIEW}

A pilot study demonstrated that it is difficult for patients to indicate precise pain localisation(s) on a paper questionnaire. It also appeared that many patients are unable to select drugs they had recently been taking from a list of predefined agents provided in such a questionnaire.

For that reason, patients were personally interviewed by the endoscopist as to whether pain had been a reason for consultation and subsequent referral. In this interview, conducted shortly before the endoscopy, patients were asked to indicate the pain localisation(s) and pain radiation site(s) on their own body. The localisation(s) were then recorded on the study form, which contains an illustration of the abdomen divided into nine parts by two horizontal and two vertical lines ". The radiation site(s) were recorded by selecting from a list of predetermined radiation sites.

Patients were also questioned as to whether they used non-steroidal anti-inflammatory drugs (NSAIDs), steroids, or anticoagulant agents, and whether they had recently been taking 'anti-peptic drugs' such as $\mathrm{H}_{2}$ receptor antagonists, antacids, cytoprotective drugs, or prokinetic agents. For each of these drugs the duration of 
treatment was recorded as: less than six weeks; six weeks to one year; more than one year.

\section{ENDOSCOPIC EXAMINATION}

The endoscopic examinations were carried out by experienced gastroenterologists/internists $(n=9)$ and by residents in gastroenterology/internal medicine $(n=5)$; the latter under supervision of an experienced endoscopist. Patients fasted overnight and were premedicated with xylocaine $2 \%$ throat spray. The investigations were performed with standard forward-viewing fibreoptic endoscopes.

\section{ENDOSCOPIC DIAGNOSES}

The endoscopic findings in oesophagus, stomach, and duodenum were separately recorded on the study form, which provides three lists of predefined endoscopic diagnoses (Appendix A). Definitions were agreed between the endoscopists in advance and were applied as consistently as possible. Only endoscopic diagnoses have been considered in our study and additional histopathological findings were not taken into account. The number of endoscopic diagnoses in each patient was unlimited, and the diagnoses were recorded in a non-hierarchical manner.

We focused on the following endoscopic diagnoses: hiatus hernia; oesophagitis; oesophageal cancer; endoscopic gastritis; gastric ulcer; gastric cancer; duodenitis/bulbitis; duodenal ulcer; and normal endoscopy. The definitions of these diagnoses will be briefly reviewed.

Oesophagitis, inflammation of the oesophageal mucosa (mainly) caused by gastro-oesophageal acid reflux, has been classified according to Savary-Miller ${ }^{12}$. Sliding hiatus hernia was diagnosed by endoscopically assessing the distance between the level of the lower oesophageal sphincter and the diaphragmatic impression. Oesophageal cancer may present as an irregular ulcerated mass with a raised edge, an encircling obstructive lesion, or a fungating obstructive mass. In the absence of these endoscopic appearances, a stenosis was considered to be benign.

Gastritis is mainly a histologic diagnosis. However, some endoscopic appearances are descriptively called 'gastritis'. When multiple haemorrhagic spots or small superficial erosions occur against the background of a hyperaemic gastric mucosa, this may be classified as haemorrhagic or erosive gastritis. Atrophic gastritis is endoscopically recognised by a thin mucosa with transparent submucosal vessels. Varioliform gastritis is characterised by small intramucosal vesicular lesions in the gastric mucosa. Hypertrophic gastritis is an uncommon condition in which there is an enlargement of the gastric folds, normally affecting the body of the stomach. In our study, these different types of gastritis together with postgastrectomy anastomositis were covered by the term 'endoscopic gastritis'. Gastric ulcers were primarily classified as benign in the absence of malignant stigmata, mainly when they had a flat edge and a uniform exudate at the base of the ulcer crater. Gastric cancers may have a variety of endoscopic appearances including 
overtly malignant ulcers with rolled edges, fungating or nodular tumours, and multiple or atypical localisations.

The endoscopic appearances of inflammation in the duodenal bulb or in the descending duodenum such as erythema alone or scattered reddened, slightly raised, non-eroded patches were described as bulbitis and duodenitis, respectively. A duodenal ulcer can be easily recognised at endoscopy as a round or oval, yellowishgrey crater with a hyperaemic wall, most commonly localised in the duodenal bulb. Unlike gastric ulcers, true duodenal ulcers are never malignant.

For the purpose of this study, the diagnoses that usually have direct therapeutic and/or prognostic consequences were classified as clinically 'relevant', i.e. oesophagitis, peptic ulcers, and oesophageal and gastric cancers. The remaining endoscopic findings were considered as 'irrelevant' or normal findings.

\section{STATISTICAL ANALYSES}

The two-samples t-test was used to test age differences between groups. The Chisquared test with continuity correction was used to assess a positive or negative association (co-occurrence) between endoscopic diagnoses. A p-value less than 0.05 was considered statistically significant.

\section{Study population}

\section{DEMOGRAPHIC CHARACTERISTICS}

All 2900 patients undergoing their first diagnostic upper GI endoscopy during the study period were included. This series of patients with a mean age 56 years $(\mathrm{SD}=17.6$, range $3-96$ years) consisted of $52.5 \%$ males and $47.5 \%$ females (Table I). Female patients were significantly older than male patients $(p<0.0001)$. The local GPs referred 1205 patients $(41.6 \%)$, and 1695 patients $(58.4 \%)$ were referred as in- or outpatients by hospital clinicians. Of the latter, $1386(81.8 \%)$ were referred by an internist or gastroenterologist, $179(10.6 \%)$ by a surgeon, and 130 patients $(7.7 \%)$ by other specialists. Specialist referrals were significantly older than GP referrals $(p<0.0001)$.

The originally recorded patient data are presented in Appendix $\mathrm{C}$. The clustered data are listed in Tables II-V, and will be briefly reviewed in the following paragraphs.

\section{REFERRAL INDICATIONS}

During the study period not more than three indications were recorded in each patient, resulting in 77 different combinations of referral indications in the study population. After clustering of the indications, a total number of 29 different combinations remained.

In 1562 patients (53.9\%) dyspepsia was a referral indication (Table II), and in 1344 of these patients $(86.0 \% ; 46.3 \%$ of the total study population) dyspeptic 
complaints were the only reason for doing an endoscopy. The remaining 218 patients $(14.0 \%)$ had one or more additional referral indications. Previous peptic ulcer disease was a referral indication in $5.8 \%$ of the patients, mostly in combination with dyspepsia. Oesophageal complaints were an indication in $14.6 \%$ of the patients, and in 335 patients $(11.6 \%)$ they were the only reason for referral. Signs of upper GI bleeding were present in 526 patients (18.1\%), and in 434 patients $(15.0 \%)$ they were the only reason for doing an endoscopy. Anorexia and weight loss were in $4.9 \%$ a referral indication. Only $1.0 \%$ of the endoscopies were performed as follow-up after an abnormal barium meal investigation (Appendix C (I)).

Table I The demographic characteristics of the study population as related to referral source.

\begin{tabular}{lrll}
\hline DEMOGRAPHIC CHARACTERISTICS & \multicolumn{2}{l}{ Number of patients $(\%)$} & Age $^{\text {(years) }}$ \\
\hline STUDY POPULATION & 2900 & $56 \pm 17.6$ \\
$\quad$ Male & 1522 & $(52.5)$ & $54 \pm 17.3$ \\
Female & 1378 & $(47.5)$ & $58 \pm 17.7$ \\
GP REFERRALS & 1205 & & $52 \pm 16.0$ \\
Male & 671 & $(55.7)$ & $50 \pm 15.7$ \\
Female & 534 & $(44.3)$ & $54 \pm 16.2$ \\
SPECIALIST REFERRALS & 1695 & & $59 \pm 18.1$ \\
Male & 851 & $(50.2)$ & $57 \pm 17.9$ \\
Female & 844 & $(49.8)$ & $61 \pm 18.0$ \\
\hline
\end{tabular}

${ }^{1}$ Age is expressed as mean $\pm \mathrm{SD}$.

Table II The referral indications in the study population.

\begin{tabular}{|c|c|}
\hline REFERRAL INDICATIONS & Number of patients $(\%){ }^{\prime}$ \\
\hline Dyspepsia & $1562(53.9)$ \\
\hline Prewious peptic ulcer & $168 \quad(5.8)$ \\
\hline Oesophageal complaints " & $424(14.6)$ \\
\hline Signs of upper GI bleeding & $526 \quad(18.1)$ \\
\hline Anorexia and weight loss & $143 \quad(4.9)$ \\
\hline Other referral indications ${ }^{\circ}$ & $396 \quad(13.7)$ \\
\hline
\end{tabular}

1 Total number exceeds $2900(100 \%)$, as multiple referral indications in individual patients occurred; "Dysphagia and retrosternal pain; "Haematemesis, melaena, faecal occult blood, and iron deficiency anaemia; "Including abnormal upper GI X-ray. 
Table III The pain localisations in the patients who were interviewed prior to endoscopy.

\begin{tabular}{lrc}
\hline PAIN LOCALISATIONS & \multicolumn{2}{c}{ Number of patients (\%)! } \\
\hline No pain & 1006 & $(34.4)$ \\
Retrosternal & 426 & $(15.0)$ \\
Epigastric & 1340 & $(47.1)$ \\
Right upper abdomen & 131 & $(4.6)$ \\
Left upper abdomen & 97 & $(3.4)$ \\
Mid abdomen & 49 & $(1.7)$ \\
Lower abdomen & 55 & $(1.9)$ \\
\hline
\end{tabular}

${ }^{1}$ Total number exceeds $2843(100 \%)$, as multiple pain localisations in individual patients occurred;

"Umbilical, right and left mid abdomen; " Right, mid and left lower abdomen.

Table IV Previous drug treatment in the patients who were interviewed prior to endoscopy.

\begin{tabular}{lccccc}
\hline \multirow{2}{*}{ DRUG TREATMENT } & \multicolumn{4}{c}{ Duration of treatment } & Number of patients (\%) \\
\cline { 2 - 5 } & $<6$ weeks & 6 weeks - 1 year & $>1$ year & \\
\hline Anti-peptic drugs & 700 & 213 & 130 & 1043 & $(36.6)$ \\
NSAIDs & 91 & 92 & 48 & 231 & $(8.1)$ \\
Steroids & 16 & 24 & 23 & 63 & $(2.2)$ \\
Anticoagulant agents & 16 & 15 & 31 & 62 & $(2.2)$ \\
\hline
\end{tabular}

" $\mathrm{H}_{2}$ receptor antagonists or proton pump inhibitors, antacids, cytoprotective drugs, and prokinetic agents.

\section{PAIN LOCALISATIONS}

Information on pain localisation(s) and radiation site(s) was obtained in 2843 patients $(98.0 \%$ ). Pain radiation occurred in $16.5 \%$ of those having pain (304 out of 1837 patients) (Appendix C (II)). At most three pain localisations and at most two radiation sites were reported by each patient, resulting in a total number of 98 different combinations of pain localisations and radiation sites. After clustering 26 different combinations of pain localisations remained.

The pre-endoscopic interview revealed that in $64.6 \%$ of the patients pain was involved in the process of consultation and subsequent referral for endoscopy (Table III). Almost $50 \%(\mathrm{n}=1340)$ of the referrals had epigastric pain and $15.0 \%$ had retrosternal pain. 


\section{PREVIOUS DRUG TREATMENT}

Of those 2850 patients $(98.3 \%$ ) interviewed concerning previous drug treatment, more than one-third $(n=1043)$ had been taking anti-peptic agents prior to referral for endoscopy (Table IV). Of the latter, $700(67.1 \%)$ had been empirically treated for less than six weeks, and $343(32.9 \%)$ during a period of more than six weeks. Use of potentially ulcerogenic drugs such as NSAIDs or steroids was reported by $8.1 \%$ and $2.2 \%$ of the patients respectively.

\section{ENDOSCOPIC DIAGNOSES}

A complete endoscopic investigation of the upper GI tract was carried out in 2817 patients $(97.1 \%)$, whereas 24 patients $(0.8 \%)$ had an oesophagogastroscopy and another 24 patients $(0.8 \%)$ an oesophagoscopy. In 35 patients $(1.2 \%)$ introduction of the endoscope was not possible.

Analysis of the data revealed that not more than three different endoscopic diagnoses in each part of the upper GI tract, i.e. oesophagus, stomach, and duodenum, were recorded in each patient. This resulted in 535 different single diagnoses or combinations of diagnoses. Most of them occurred in rather small mumbers of patients. When only considering the clustered endoscopic diagnoses as presented in Table $\mathrm{V}$, a total number of 62 single diagnoses or combinations of diagnoses occurred in 2484 patients; the remaining 381 patients had other abnormal findings. Hiatus hernia was diagnosed in $17.3 \%$ and oesophagitis in $13.9 \%$ of the patients. Grading oesophagitis according to the Savary-Miller criteria resulted in the following percentages: $53.1 \%$ grade I; $25.9 \%$ grade II; $11.6 \%$ grade III; and $9.3 \%$ grade IV (Appendix C (IV)). An endoscopically benign-looking oesophageal stenosis occurred in 20 patients $(0.7 \%)$, and endoscopic lesions suspect for oesophageal cancer were observed in $0.5 \%$ of the patients. Barrett epithelium, a rather typical replacement of the squamous oesophageal epithelium by gastric and/or intestinal type mucosa, was observed in 53 patients $(1.8 \%)$. Oesophageal varices were found in 41 patients $(1.4 \%)$. The varices were classified according to their extension into the lumen as grade I-IV.

The different types of diffuse gastric changes such as haemorrhagic, erosive, atrophic, varioliform, and hypertrophic gastritis, together with post-gastrectomy anastomositis, occurred in $17.5 \%$ of the patient population. Gastric ulcers were diagnosed in $7.8 \%$ of the patients, and the endoscopic diagnosis of gastric cancer was made in 55 patients $(1.9 \%)$. Overall, $5.5 \%$ of the study population had previous gastric surgery of various types (Appendix $\mathrm{C}(\mathrm{V})$ ), and in one-third of them anastomositis was diagnosed. Narrowing of the pyloric canal due to recurrent ulcer disease was diagnosed in 20 patients $(0.7 \%)$.

Duodenitis and/or bulbitis were diagnosed in $13.3 \%$, and duodenal ulcers in $8.3 \%$ of the patients. Bulbar deformation and stenosis as a result of recurrent duodenal ulceration was found in $1.3 \%$ of the patients (Appendix $\mathrm{C}$ (VI)). Only one papillary cancer was endoscopically diagnosed in the patient population. 
The endoscopic investigation was normal in 838 patients $29.7 \%$ of those having a complete endoscopy). Clinically relevant endoscopic disease, as defined in this study, occurred in 844 patients (29.1\% of the study population).

Table $\mathbf{V}$ The most important endoscopic diagnoses in the study population.

\begin{tabular}{|c|c|}
\hline ENDOSCOPIC DIAGNOSES & Number of patients (\%) \\
\hline Hiatus hernia * & $497 \quad(17.3)^{x}$ \\
\hline Oesophagitis ${ }^{*}$ & $397 \quad(13.9)^{*}$ \\
\hline Oesophageal cancer & $15 \quad(0.5)^{: a}$ \\
\hline Endoscopic gastritis & $496(17.5)^{b}$ \\
\hline Gastric ulcer *- & $221 \quad(7.8)^{b}$ \\
\hline Gastric cancer & $55 \quad(1.9)^{b}$ \\
\hline Duodenitis/bulbitis ${ }^{\infty}$ & $374 \quad(13.3)^{\circ}$ \\
\hline Duodenal ulcer ${ }^{* *}$ & $234(8.3)^{\circ}$ \\
\hline Normal endoscopy & $838(29.7)^{\circ}$ \\
\hline
\end{tabular}

"Percentages are given of those patients who had an aesophagoscopy $(n=2865)$, oesophagogastroscopy $(n=2841)$, or " oesophagogastroduodenoscopy $(n=2817)$; "Sliding hernia, paraoesophageal hernia, and combined hernia; "Oesophagitis grade I-IV; "Haemorrhagic, erosive, atrophic, varioliform and hypertrophic gastritis, and anastomositis; "” Active and healing gastric ulcer, and perforated ulcer; ${ }^{*}$ Gastric cancer and cancer in the resected stomach; ${ }^{*}$ Duodenitis and bulbitis; ${ }^{* *}$ Active and healing duodenal ulcer.

Table VI The most frequent single (or combinations of) diagnoses in the study population.

\begin{tabular}{|c|c|c|}
\hline \multirow{2}{*}{$\frac{\text { ENDOSCOPIC DIAGNOSES }}{\text { Normal endoscopy }}$} & \multicolumn{2}{|c|}{ Number of patients $(\%)^{\prime}$} \\
\hline & 838 & $(29.7)^{6}$ \\
\hline Endoscopic gastritis & 193 & $(6.8)^{b}$ \\
\hline Hiatus hernia & 154 & $(5.4)^{a}$ \\
\hline Duodenitis/bulbitis & 131 & $(4.7)^{\circ}$ \\
\hline Duodenal ulcer" & 103 & $(3.7)^{c}$ \\
\hline Gastric ulcer ${ }^{\text {"* }}$ & 98 & $(3.4)^{b}$ \\
\hline Oesophagitis & 87 & $(3.0)^{a}$ \\
\hline Oesophagitis ${ }^{\text {喟 }}+$ hiatus hermia & 87 & $(3.0)^{2}$ \\
\hline
\end{tabular}

${ }^{1}$ Percentages are given of those patients who had an "oesophagoscopy $(n=2865)$, ${ }^{b}$ oesophagogastroscopy $(n=2841)$, or ${ }^{c}$ pesophagogastroduodenoscopy $(n=2817)$; "Haemorrhagic, erosive, atrophic, varioliform and hypertrophic gastritis, and anastomositis; "Sliding hernia, paraoesophageal hernia, and combined hernia;" Active and healing duodenal ulcer; " Active and healing gastric ulcer, and perforated ulcer; ${ }^{\circ /}$ Oesophagitis grade I-IV. 


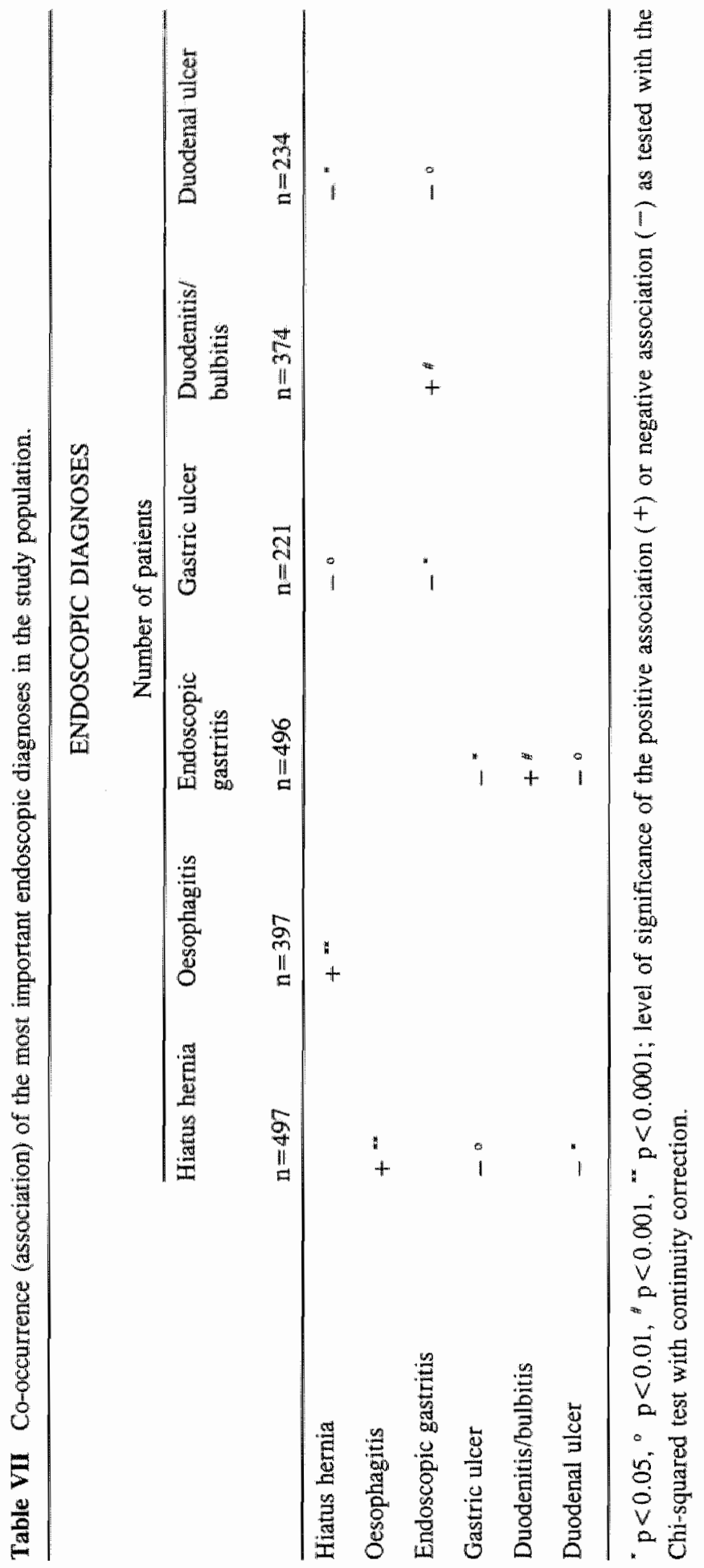


The most frequent single (clustered) diagnoses or combinations of (clustered) diagnoses are listed in Table VI. After normal endoscopy, endoscopic gastritis was the most frequent single diagnosis, followed by hiatus hernia and duodenitis/bulbitis. The combination of oesophagitis and hiatus hernia was the most frequent combined diagnosis.

\section{CO-OCCURRENCE OF ENDOSCOPIC DIAGNOSES}

The results of the analysis on the co-occurrence of endoscopic diagnoses are summarised in Table VII. Oesophagitis and hiatus hernia were significantly associated, the combination of these diagnoses occurred in 167 patients $(5.8 \%)$. Oesophagitis was diagnosed in $33.6 \%$ of the patients with a hiatus hernia and in $9.6 \%$ of those without. Hiatus hernia was diagnosed in $42.1 \%$ of the patients with oesophagitis and in $13.2 \%$ of those without.

Barrett epithelium occurred significantly more often in patients with oesophagitis $(\mathrm{n}=22 ; 5.5 \%)$ than in those without oesophagitis $(1.2 \%) \quad(\mathrm{p}<0.0001)$. Barrett epithelium was also diagnosed significantly more often in patients with a hiatus hernia $(\mathrm{n}=25 ; 5.0 \%)$ than in patients without $(1.2 \%)(\mathrm{p}<0.0001)$. This applied mainly for patients who had a hiatus hernia and oesophagitis $(n=13 ; 7.8 \%)$ $(p<0.0001)$, but also for patients with hiatus hernia without oesophagitis $(n=12$; $3.6 \%)(\mathrm{p}<0.05)$.

The findings of endoscopic gastritis and duodenitis/bulbitis were significantly associated; this combination occurred in 88 patients $(3.1 \%)$. Gastritis was observed in $23.5 \%$ of the patients with duodenitis/bulbitis and in $16.2 \%$ of those without. Duodenitis/bulbitis was diagnosed in $17.7 \%$ of the patients with endoscopic gastritis and in $11.9 \%$ of those without gastritis.

Regarding the subtypes of gastritis, it appeared that duodenitis/bulbitis was significantly more often diagnosed in patients with acute (haemorrhagic and/or erosive) gastritis $(\mathrm{n}=51 ; 18.3 \%)(\mathrm{p}<0.01)$, but not in patients with the other types of endoscopic gastritis $(n=37 ; 17.0 \%)(p=0.078)$.

The diagnosis of hiatus hernia was made significantly less often in patients with a gastric $(10.4 \%)$ or duodenal $(11.1 \%)$ ulcer than in patients without such an ulcer $(17.7 \%$ and $17.7 \%$, respectively).

Gastritis was also observed less often in patients with gastric $(11.8 \%)$ or duodenal $(10.7 \%)$ ulcers than in those without (17.5\% and $17.7 \%$, respectively). Acute gastritis was observed as often in patients with gastric $(\mathrm{n}=22 ; 10.0 \%)$ or duodenal $(\mathrm{n}=21 ; 9.0 \%)$ ulcers as in those without these ulcers $(9.6 \%$ and $9.6 \%$, respectively) $(p=0.940$ and $p=0.829$, respectively). The other types of endoscopic gastritis were all together diagnosed significantly less often in patients with a gastric $(n=4 ; 1.8 \%)$ or duodenal $(n=4 ; 1.7 \%)$ ulcer than in patients without these ulcers $(8.0 \%$ and $8.0 \%$, respectively) $(p<0.01$ and $p<0.001$, respectively). 


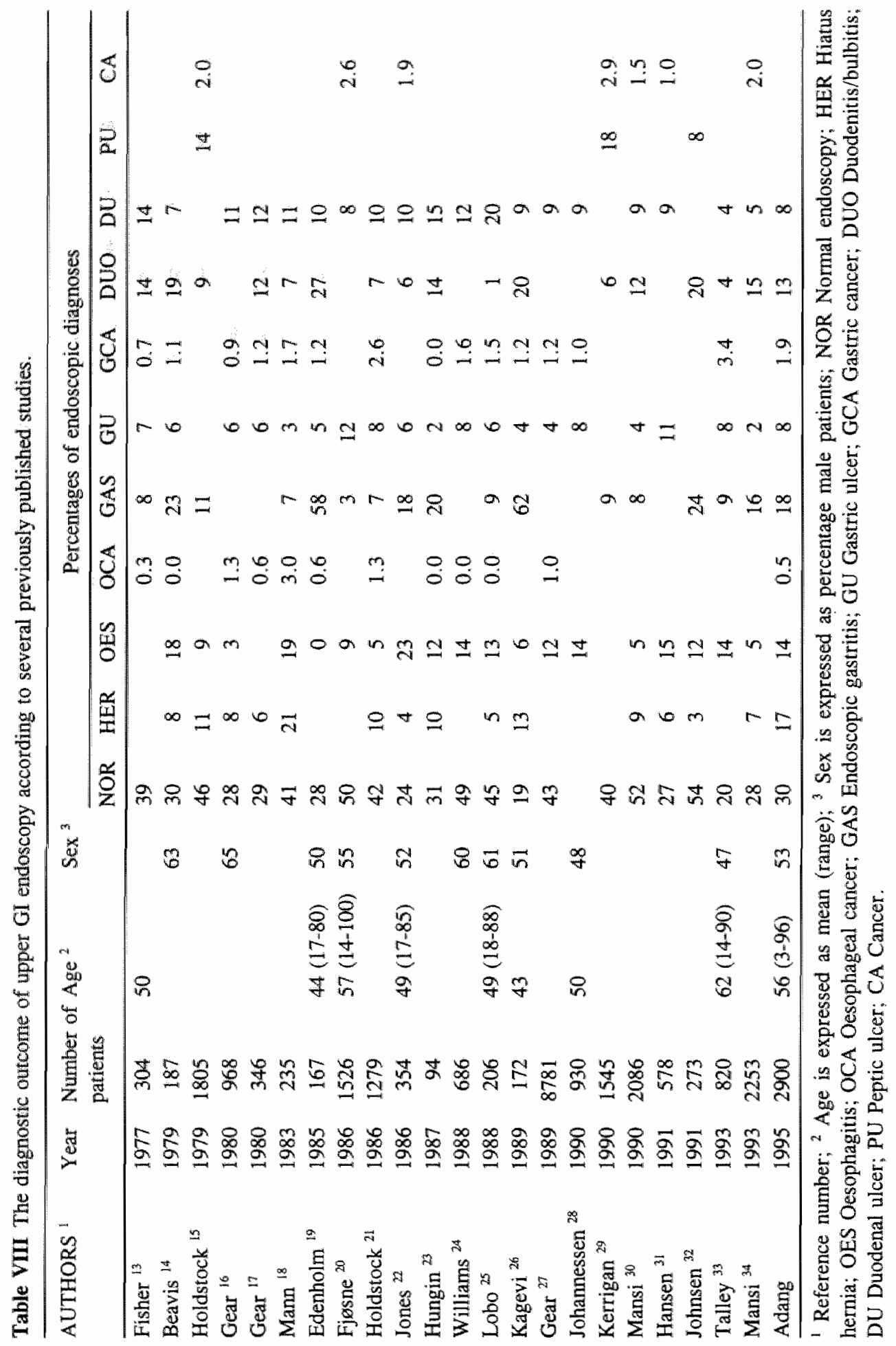




\section{Discussion}

This prospective study was performed at a single endoscopy unit of a teaching/general hospital and included 2900 consecutive patients undergoing their first diagnostic upper GI endoscopy for various reasons. The study population is, to our knowledge, the largest series of patients providing such detailed information on items as indications for endoscopy, previous drug treatment, dyspeptic symptoms including pain localisations, and endoscopic findings. These data, which form the basis for the studies to be presented in the next chapters, will be discussed and compared to data known from previous reports on this subject ${ }^{13-34}$.

The endoscopy unit of the University Hospital Maastricht offers an unrestricted open access service and, as a result, more than $40 \%$ of the patients were directly referred by a GP. The mean age of this group of patients was comparable to the mean age of other GP referred endoscopy populations ${ }^{13,22,25,28}$. Specialist referrals were older than the referrals from general practice. As in other endoscopy unit settings ${ }^{20,22.26}$, male patients constituted somewhat more than $50 \%$ of the referrals for diagnostic upper GI endoscopy.

Dyspepsia was by far the most frequent referral indication: in $54 \%$ of the study population it was a reason and in $46 \%$ it was the (only) reason for doing an endoscopy. On the other hand, a significant proportion of the patients were referred because of alarm symptoms such as dysphagia, signs of upper GI bleeding, and anorexia and weight loss.

The verbal interview conducted by the endoscopists revealed that almost $50 \%$ of the patients had epigastric pain and $15 \%$ had retrosternal pain. In about one-third of the patients apparently other symptoms than pain had been a reason for consultation and subsequent referral.

It is noteworthy that $37 \%$ of the patients had been empirically treated prior to referral for endoscopy. This is almost the same percentage as has been reported in a Swedish study by Edenholm et al. ${ }^{19}$ "Of these patients, about two-thirds had been taking anti-peptic agents for a period of less than six weeks. The waiting period for a regular endoscopy was in general not more than six weeks, which means that empiric treatment was started just before or during this waiting period in almost $25 \%$ of the patients. This may have influenced the symptoms and endoscopic findings.

With respect to the diagnostic outcome our study material compares well with other endoscopy populations which have been previously reported in literature (Table VIII). As in other studies ${ }^{14,18,22,24,27,28,31-33}$, oesophagitis was the most frequently diagnosed relevant acid-related disorder. Gastric and duodenal ulcers were almost equally frequent in our study population, this in contrast to other studies that reported about twice as many duodenal ulcers ${ }^{13,16-19,22-27,30,34}$. However, most of these reports involved only patients referred by GPs. Oesophageal and gastric cancer were endoscopically diagnosed and, as in most other studies $13,14,17,19,23-25,27$, they were found in less than $1 \%$ and in less than $2 \%$ of the patients, respectively. Over- 
all, clinically relevant endoscopic disease, as defined in this study, was diagnosed in $29 \%$ of the patients referred for endoscopy.

As in many other studies ${ }^{14,16,17,19,23,31.34,35}$, about $30 \%$ of the patients had a normal endoscopy. In the publications summarised in Table VIII the proportion of normal investigations ranges from $19 \%$ to $54 \%$, depending on how 'normal' has been defined. In some of these studies the presence of endoscopic findings such as hiatus hernia, cardia insufficiency, chronic (atrophic) gastritis, or bile reflux did not rule out a normal endoscopy.

It has to be reminded that the presence of more or less serious organic disease in these so-called 'normal' but symptomatic patients can not be excluded by only an endoscopy. These patients have to be followed and, depending on clinical and biochemical parameters, additional investigations have to be performed for further evaluation of their symptoms.

In a study about the discriminative value of symptoms for upper GI endoscopic diagnoses, it is important to be informed about the co-occurrence of these diagnoses. Most previous studies have not addressed this subject. The high co-prevalence of hiatus hernia and oesophagitis most probably reflects a causal relationship between these diagnoses: pathological gastric acid reflux in hiatus hernia causes damage of the distal oesophageal mucosa ${ }^{36}$. The demonstration of Barrett epithelium was associated with the presence of oesophagitis and, to a lesser degree, with hiatus hernia. Hereby, the role of gastro-oesophageal reflux in the pathogenesis of this condition is underlined. The co-occurrence of acute (erosive or haemorrhagic) gastritis and duodenitis/bulbitis may suggest common etiologic factors in these disorders, for example use of NSAIDs. Duodenal ulcer and duodenitis/bulbitis are considered by many authors as parts of the spectrum of one disease ${ }^{37-41}$. One would expect a close association between these two diagnoses; this, however, has not been demonstrated in this study.

For the purpose of this study we focused on several major endoscopic diagnoses, whereas more subtle endoscopic findings have not been analysed separately. Histopathological findings were also not taken into account. For most endoscopic diagnoses which have been analysed in this study histopathology gives no extra diagnostic information. Oesophagitis and duodenal ulcers are generally regarded as endoscopic diagnoses, but biopsy specimens are routinely taken from gastric ulcers. In our study an ulcer in the stomach was classified as benign unless endoscopic features suggestive of malignancy were present. It has to be realised that a small number of these endoscopically benign-looking gastric ulcers may in fact represent gastric cancers. Similarly, a severe (histologically-proved) benign gastric ulcer may appear as an ulcerated carcinoma at endoscopy.

It has been demonstrated that there is only a weak correlation between the endoscopic picture of mucosal inflammation and histologic inflammatory changes of the gastric and duodenal mucosa ${ }^{39,42-44}$. Furthermore, there remains much debate about the clinical significance of endoscopic and histologic appearances of inflamma- 
tion in stomach and duodenum $32,38,39.43-49$. For the purpose of this study, we only considered the endoscopic diagnoses of gastritis and duodenitis/bulbitis.

Though relevant for clinical practice, we have not considered additional diagnostic endoscopic procedures such as: $\mathrm{pH}$ measurement of the residual gastric juice, duodenal biopsies, gastric antral biopsies to detect infestation with Helicobacter pylori, etc.

In conclusion, our study material consists of a large, representative series of patients undergoing their first diagnostic upper GI endoscopy at a single open access unit. This patient population provides consistently collected and detailed information on referral indications, pre-endoscopic treatment, dyspeptic symptoms including pain localisations, and endoscopic findings. It therefore forms a solid base for studies concerning the predictability of endoscopic diagnoses by patient characteristics and symptoms. 


\section{References}

1. Pop P. Endoscopisch onderzoek voor de huisarts. Med Contact $1982 ; 37$ : 1125-1128.

2. Pop P. Endoscopie en de huisartsenpraktijk. Gastro-Enterologisch Consult 1986; 16: 1-32.

3. Bramble MG. Open access endoscopy - a nationwide survey of current practice. Gut 1992; 33: $282-285$.

4. Bramble MG, Cooke WM, Corbett WA, Cann PA, Clarke D, Contractor B, et al. Organising unrestricted open access gastroscopy in South Tees. Gut 1993; 34: 422-427.

5. Tsu-der Chou G. dBASE III PLUS handbook. Indianapolis: Que Corporation, 1986.

6. Norusis MJ dBASE STATS. The power of statistical analysis for dBASE III PLUS and ABASE IV users. Torrance: Tate Publishing, 1989.

7. Colin-Jones DG, Bloom B, Bodemar G, Crean G, Freston J, Gugler R, et al. Management of dyspepsia: report of a working party. Lancet $1988 ;$ I: $576-579$.

8. Barbara $L$, Camilleri $M$, Corinaldesi $R$, Crean GP, Heading $\mathrm{RC}$, Johnson AG, et al. Definition and investigation of dyspepsia. Consensus of an international ad hoc working party. Dig Dis Sci 1989; 34: 1272-1276.

9. Heading RC. Definitions of dyspepsia. Sicand J Gastroenterol 1991; 26 Suppl 182: 1-6.

10. Adang RP, Vismans F-JFE, Ambergen AW, Talmon JL, Hasman A, Flendrig JA. Evaluation of computerised questionnaires designed for patients referred for gastrointestinal endoscopy. Int $J$ Biomed Comp 1991; $29: 31-44$.

11. Kang JY, Tay HH, Guan $R$. Chronic upper abdominal pain: Site and radiation in various structural and functional disorders and the effect of various foods. Gut 1992; 33: 743 748 .

12. Savary M, Miller G. The esophagus - handbook and atlas of endoscopy. Solothurn: Verlag. Gassmann AG, 1977.

13. Fisher JA, Surridge JG, Vartan CP, Loehry CA. Upper gastrointestinal endoscopy - a GP service. $\mathrm{Br}$ Med J 1977; 2: 1199-1201.

14. Beavis AK, La Brooy S, Misiewicz JJ. Evaluation of one-visit endoscopic clinic for patients with dyspepsia. $\mathrm{Br}$ Med J 1979; 1: 1387-1389.

15. Holdstock G, Wiseman $M$, Loehry $C A$. Open-access endoscopy service for general practitioners. Br Med J 1979; 1: 457-459.

16. Gear MWL, Barnes RI. Endoscopic studies of dyspepsia in a general practice. $\mathrm{Br} M e d J 1980$; 280: $1136-1137$.

17. Gear MWL, Ormiston MC, Barnes RJ, Rocyn-Jones J, Voss GC. Endoscopic studies of dyspepsia in the community: an "open-access" service. Br Med J 1980; 280: 1135.

18. Mann J, Holdstock G, Harman M, Machin D, Loehry CA. Scoring system to improve cost. effectiveness of open access endoscopy. Br Med J 1983; 287; 937-940.

19. Edenholm M, Gustawsson R, Jansson $O$, Lingfors $H$, Nilsson $O$, Söderlind $T$, et al. Endoscopic findings in patients with ulcer-like dyspepsia. Scand $J$ Gastroenterol 1985; 20 Suppl 109: 163-167.

20. Fjosne U, Kleveland PM, Waldum H, Halvorsen T, Petersen H. The clinical benefit of routine upper gastrointestinal endoscopy. Scand $J$ Gastroenterol 1986; 21 : 433-440.

21. Holdstock G, Harman M, Machin D, Patel C, Lloyd RS. Prospective testing of a scoring system designed to improve case selection for upper gastrointestinal investigation. Gastroenterology 1986: 90: 1164-1169.

22. Jones $\mathrm{R}$. Upper gastrointestinal endoscopy - a view from general practice. $J R$ Coll Gen Pract $1986 ; 36: 6-8$.

23. Hungin AS. Use of an open-access gastroscopy service by a general practice: findings and subsequent referral rate. $J R$ Coll Gen Pract $1987 ; 37: 170-171$. 
24. Williams B, Luckas M, Ellingham JHM, Dain A, Wicks ACB. Do young patients with dyspepsia need investigation? Lancet 1988; II: 1349-1351.

25. Lobo $A$. Dickinson $R$. Managing the dyspeptic patient: experience of a single-visit dyspepsia clinic. J $R$ Soc Med 1988; 81: 212-213.

26. Kagevi 1, Löfstedt S, Persson L-G. Endoscopüc findings and diagnoses in unselected dyspeptic patients at a primary health care center. Scand J Gastroenterol 1989; 24: 145 150.

27. Gear MWL, Wilkinson SP. Open-access upper alimentary endoscopy. Br $\$ Hosp Med 1989; 41: $438-444$.

28. Johannessen T, Petersen H, Kleveland PM, Dybdahl JH, Sandvik AK, Brenna E, et al. The predictive value of history in dyspepsia. Scand J Gastroenterol 1990; 25; 689-697.

29. Kerrigan DD, Brown SR, Hutchinson GH. Open access gastroscopy: Too much to swallow? Br Med J 1990; 300: 374-376.

30. Mansi C, Mela GS, Pasini D, Grosso M, Corti L, Moretti M, et al. Patterns of dyspepsia in patients with no clinical evidence of organic diseases. Dig Dis Sci 1990; 35 (12): 1452 1458.

31. Hansen JM, Bytzer P, Bondesen S, Schaffalitzky de Muckadell OB. Efficacy and outcome of an open access endoscopy service. Dan Med Bull 1991; 38: 288-290.

32. Johnsen R, Bernersen B, Straume B, Forde OH, Bostad L, Burhol PG. Prevalences of endoscopic and histological findings in subjects with and without dyspepsia. $\operatorname{Br~Med~} J 1991 ; 302$ : 749-752.

33. Talley NJ, Weaver AL, Tesmer DL, Zinsmeister AR. Lack of discriminant value of dyspepsia subgroups in patients referred for upper endoscopy. Gastroenterology 1993; 105: 1378-1386.

34. Mansi C, Savarino V, Mela GS, Picciotto A, Mele MR, Celle G. Are clinical patterns of dyspepsia a valid guideline for appropriate use of endoscopy? A report on 2253 dyspeptic patients. Am J Gastroenterol 1993; 88 (7); 1011-1015.

35. Naji SA, Brunt PW, Hagen S, Mowat NAG, Russell IT, Sinclair TS, et at. Improving the selection of patients for upper gastrointestinal endoscopy. Gut 1993; 34: 187-191.

36. Zhu H, Pace F, Trape E, Sangaletti O, Bianchi Porro G. Prevalence of hiatal hernia and its influence on gastro-oesophageal reflux. Eur J Gastroenterol Hepatol 1994; 6: 393-397.

37. Greenlaw R, Sheahan DG, De Luca V, Miller D, Myerson D, Myerson P'. Gastroduodenitis. A broader concept of peptic ulcer disease. Dig Dis Sci 1980; 25: 660-672.

38. Deluca VA, Winnan GG, Sheahan DG, Sanders FJ, Greenlaw R, Marignani P, et al. Is gastroduodenitis part of the spectrum of peptic ulcer disease? I Clim Gastroenterol 1981; 3 Suppl 2: 17-22.

39. Joffe SN. Relevance of duodenitis to non-ulcer dyspepsia and peptic ulceration. Scand J Gastroenterol 1982; 17 Suppl 79: 88-97.

40. Anonymous. Duodenitis - Any progress? Lancet 1985; 1: 1222-1223.

41. Venables C. Duodenitis. Scand J Gastroenterol 1988; 23 Suppl 155: 61-65.

42. Cheli R. Symptoms in chronic non-specific duodenitis. Scand J Gastroenterol $1982 ; 17$ Suppl 79: 84-86.

43. Joffe SN, Shiva Rao S. Symptoms of gastritis. Scand J Gastroenterol 1982; 17 Suppl 79: 6265.

44. Toukan AU, Kamal MF, Amr SS, Arnaout MA, Abu-Romiyeh AS. Gastroduodenal inflanmation in patients with nonulcer dyspepsia. A controlled endoscopic and morphometric study.

Dig Dis Sci 1985; 30 (4): 313-320

45. Cheli $R$, Perasso A, Giacosa A. Dyspepsia and chronic gastritis. Hepato-gastroenterol 1983: 30: $21-23$.

46. Villako $\mathrm{K}$, Thamäki $\mathrm{T}$, Tamm $\mathrm{A}$, Tammur $\mathrm{R}$. Upper abdominal complaints and gastritis. Ann Clin Res 1984; 16: 192-194.

47. Venables CW. Duodenitis. Scand J Gastroenterol 1985; 20 Suppl 109: 91-97. 
48. Jonsson $\mathrm{K} A$, Gothand $\mathrm{R}$, Bodemar $\mathrm{G}$, Brodin $\mathrm{U}$. The clinical relevance of endoscopic and histologic inflammation of gastroduodenal mucosa in dyspepsia of unknown origin. Scand $J$ Gastroenterol 1989; $24: 385-395$.

49. Tytgat GNJ, Noach LA, Rauws AJ. Is gastroduodenitis a cause of chronic dyspepsia? Scand $\lambda$ Gastroenterol 1991; 26 Suppl 182: 33-39. 


\section{Evaluation of the computerised history taking system: a comparison between paper and computerised questionnaires}

Published as 'Evaluation of computerised questionnaires designed for patients referred for gastrointestinal endoscopy' in

Int J Biomed Comput 1991; 29: 31-44.

R.P. Adang, F.-J. F.E. Vismans, A.W. Ambergen, J.L. Talmon, A. Hasman, J.A. Flendrig 



\section{Abstract}

The aim of this study was to assess the applicability of a computerised history taking system in routine clinical practice of an open access endoscopy unit. We evaluated feasibility, acceptability and reproducibility of the computerised questionnaires designed for either the upper or lower gastrointestinal tract, partly in comparison to paper questionnaires. The paper questionnaires were answered by $73 \%$ of the referrals, and the computerised questionnaires were answered by $64 \%(p<0.001)$. Gender was not related to the ability to answer either type of questionnaires. A significant age dependency was observed in the ability to answer the paper and computerised questionnaires, both for the upper and lower gastrointestinal tract $(p<0.0001$ for all four questionnaires). The average completion time of each of the computerised questionnaires was 11 minutes. The completion times did not depend on gender, but there was a slightly positive correlation with age $(r=0.27$ with $p<0.0001$ in case of the questionnaire for the upper gastrointestinal tract and $r=0.12$ with $p=0.0593$ in case of the questionnaire for the lower gastrointestinal tract). Answering the history taking system was consistently reported to be interesting and easy. The computer-based interrogation did not last too long according to the patients. After patients answered the computerised questionnaires, about $40 \%$ of them reported that the insight in their complaints had increased and almost $45 \%$ could put their complaints into words more easily. However, $25 \%$ of the patients had been unable to express all their complaints. The reproducibility of history data that were first obtained with the paper questionnaires and later by means of the history taking system was about $85 \%$.

In summary, the computerised history taking system can provide a consistently collected and detailed history of most patients referred for upper or lower gastrointestinal endoscopy. The computerised questionnaires are well accepted by the patients and can be completed within the regular waiting time for endoscopy. The history data as obtained with these questionnaires are highly reproducible.

\section{Introduction}

Computerised questionnaires can provide detailed and uniformly collected history data. This is particularly useful in restricted fields of medicine in which the history is of great importance, as in gastroenterology '.

Since Slack et al. in 1966 first reported their experiences with a computerised history taking system ${ }^{2}$, several other systems have been introduced in different fields of medicine. Before such a system eventually can be used in clinical practice, however, it has to be subjected to thorough evaluation ${ }^{3,4}$. Applicability of a computerised questionnaire depends on its feasibility and on its acceptability by patients. The responses also have to be reproducible, which means that questions repeatedly presented to the same patient must evoke the same answers. The history 
data as obtained with a computerised questionnaire are generally considered to be reliable, i.e. are comparable to data as obtained with conventional history taking. This has been demonstrated in previous studies, which either directly compared data obtained with the computerised questionmaire to data present in the conventional medical record ${ }^{2,5-11}$ or which compared the diagnostic hypotheses based upon data obtained with the computerised questionnaire to those generated by routine history taking ${ }^{12}$. The diagnostic value of history data is more difficult to establish, but can be indirectly tested by comparing the diagnostic hypotheses based upon these data to the final diagnosis ${ }^{13,14}$. The diagnostic value can also be tested by associating the history data with diagnoses ${ }^{3.15-17}$.

In this chapter we assessed the feasibility and acceptability of computerised questionnaires, partlly in comparison to paper questionnaires, and mainly as a function of patient age. We also determined the reproducibility of history data, initially obtained with paper questionnaires and several days later by means of the history taking system. The clinical relevance of the data as obtained with these questionnaires will not be discussed in this chapter, but will be the subject of the studies presented in Chapters VII and VIII.

\section{Methods of data acquisition}

\section{STUDY DESIGN AND QUESTIONNAIRES}

During the first period of the study, patients attending the endoscopy unit received a paper questionnaire (PQ). We used different questionnaires for the patients referred for either an upper or lower GI endoscopy. The paper questionnaire designed for the upper GI tract (PQ-UGT) contains 57 multiple-choice questions and has a 'branching structure $3,5,9,18-21$. Because of this branching structure, the questions can be divided into 22 'main questions' and 35 'refinement questions'. A refinement question has to be answered only if a previous 'branching question' was answered affirmatively (see Chapter II). The paper questionnaire designed for the lower GI tract (PQ-LGT) consists of 58 questions: 34 'main questions' and 24 'refinement questions'. The patients were requested to choose just one answer to each question.

In the second part of the study, the same questions within the same branching structure were implemented in a computerised history taking system (CQ), designed for either the upper or lower GI tract (CQ-UGT and CQ-LGT, respectively). However, each question has an additional 'escape answer' (I don't know; I don't understand; The correct answer is not available) besides the answer options of the paper questionnaires. Each question together with its numbered answer options was separately presented on the screen, and could be answered by simply pressing the numeric key on the keyboard which corresponds to the number of the correct answer. Patients were obliged by the system to select a single answer to each question. The history taking system allowed the patients to correct the answer to the preceding question. After they had completed the computerised questionnaire, 
patients were presented an opinion questionnaire consisting of five questions regarding their opinion on the history taking procedure.

Patients were invited by the secretaries to answer the paper or computerised questionnaire; whenever a patient did not answer the questionnaire, the reason for not answering had to be recorded.

\section{EQUTPMENT}

We chose a distributed implementation on a PC network consisting of Olivetti PCs and Novell network software. The programming language Turbo Pascal 5.5 was used for the computerised questionnaires.

Table I The characteristics of the patients referred for an endoscopy during the first part (paper questionnaires) and the second part (computerised questionnaires) of the study.

CHARACTERISTICS

Number of patients (\%)

$\begin{array}{ll}\frac{\text { Number of patients }(\%)}{\text { Paper questionnaires }} & \text { Computerised questionnaires } \\ 1134 & 537\end{array}$

\section{GENDER DISTRIBUTION}

Male

Female

AGE DISTRIBUTION

$<40$ years

40-50 years

50-60 years

60-70 years

$>70$ years

ENDOSCOPIC EXAMINATION

UGT

LGT

REFERRING DOCTORS

\section{GP}

Internist

Surgeon

Other specialists

$624 \quad(55.0)$

$510 \quad(45.0)$

$213 \quad(18.8)$

$201 \quad(17.7)$

$193 \quad(17.0)$

$240 \quad$ (21.2)

$287 \quad(25.3)$

$638 \quad(56.3)$

$496 \quad(43.7)$

$324(28.6)$

465 (41.0)

$284 \quad(25.0)$

$61 \quad(5.4)$
$288 \quad(53.6)$

$249 \quad(46.4)$

$110 \quad(20.5)$

$83 \quad(15.5)$

$93 \quad(17,3)$

$115 \quad(21.4)$

$136 \quad(25.3)$

$296 \quad(55.1)$

$241 \quad(44.9)$

$164 \quad(30.5)$

$213 \quad(39.7)$

$141 \quad(26.3)$

$19 \quad(3.5)$

Excluding the patients referred for an upper $(n=131)$ or lower $(n=95)$ GI endoscopy while the computerised history taking system was not operational. 


\section{SETTING}

The study was performed at the open access endoscopy unit of the University Hospital Maastricht during every day practice. The secretaries invited patients to participate in the study and familiarised them with the computer while doing their regular work. Patients answered the paper or computerised questionnaire while waiting for their endoscopy. Since we wanted to assess the applicability of the computerised history taking system in routine clinical practice, no extra personnel was contracted to support this study.

\section{PATIENTS AND STATISTICAL METHODS}

From 2 January 1989 until 16 May 1989,1134 patients were referred for either an upper $(n=638)$ or lower $(n=496)$ GI endoscopy. Of these patients, $446(70 \%)$ answered the PQ-UGT and $378(76 \%)$ answered the PQ-LGT, respectively.

Between 17 May 1989 and 1 September 1989, 763 patients were referred for an endoscopy of either the upper $(n=427)$ or lower $(n=336)$ GI tract. During this period, however, the computerised history taking system was several times not operational because of technical problems. The patients who were referred during these episodes have not been included in the analyses of this chapter, because they did not have the opportunity to answer the computerised questionnaire. Of the 296 patients referred for an upper GI endoscopy who were included, 190 (64\%) answered the CQ-UGT. Of the 241 patients referred for a lower GI endoscopy who were included, $152(63 \%)$ answered the CQ-LGT. The group of patients referred during the first period (PQ) did not significantly differ from those referred during the second period (CQ) regarding distribution of gender, age, upper or lower GI endoscopy, and referral source (Table I).

Data have been analysed with the Chi-squared test, logistic regression analysis, linear regression analysis, one proportion t-test and two proportion t-test.

Table II The percentages of patients who did not answer the paper (PQ) or computerised (CQ) questionnatres designed for the UGT and LGT, respectively.

\begin{tabular}{lcccc} 
REASONS FOR NOT ANSWERING & PQ-UGT & PQ-LGT & CQ-UGT & CQ-LGT \\
& $\mathrm{n}=192$ & $\mathrm{n}=118$ & $\mathrm{n}=106$ & $\mathrm{n}=89$ \\
\hline Mental disorders & $14 \%$ & $12 \%$ & $10 \%$ & $6 \%$ \\
Physical illness & $29 \%$ & $14 \%$ & $35 \%$ & $22 \%$ \\
Visual handicap & $20 \%$ & $22 \%$ & $15 \%$ & $12 \%$ \\
Motivational reasons & $3 \%$ & $3 \%$ & $5 \%$ & $5 \%$ \\
Language problems & $8 \%$ & $3 \%$ & $10 \%$ & $5 \%$ \\
Other reasons & $5 \%$ & $4 \%$ & $0 \%$ & $1 \%$ \\
No reason recorded & $21 \%$ & $42 \%$ & $25 \%$ & $49 \%$ \\
\hline
\end{tabular}




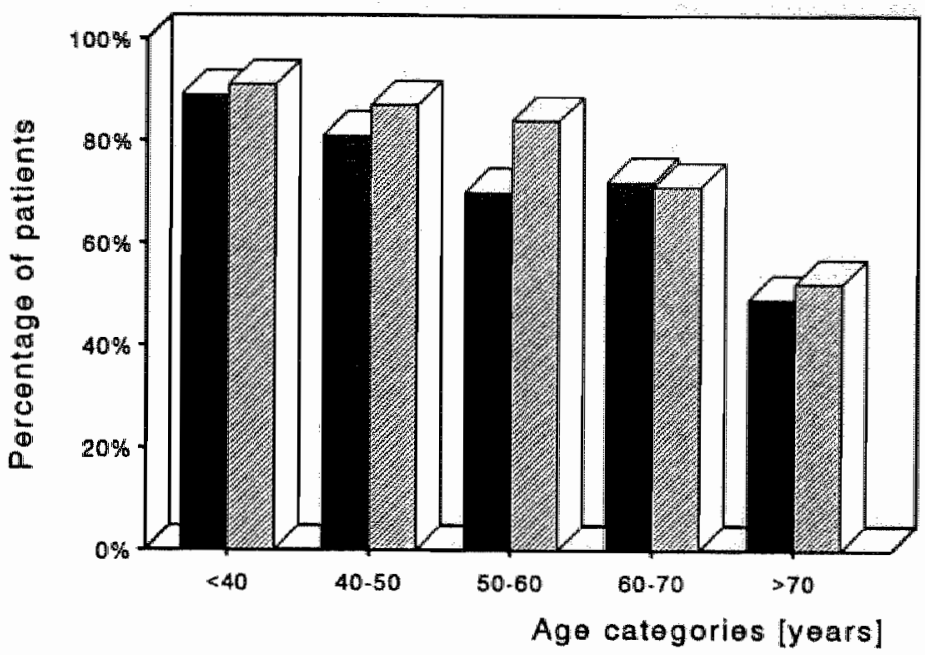

Figure I Percentages of patients who answered the paper questionnaires designed for the UGT ( $\mathbf{Q})$ and LGT ( $\square$ ) according to age categories.

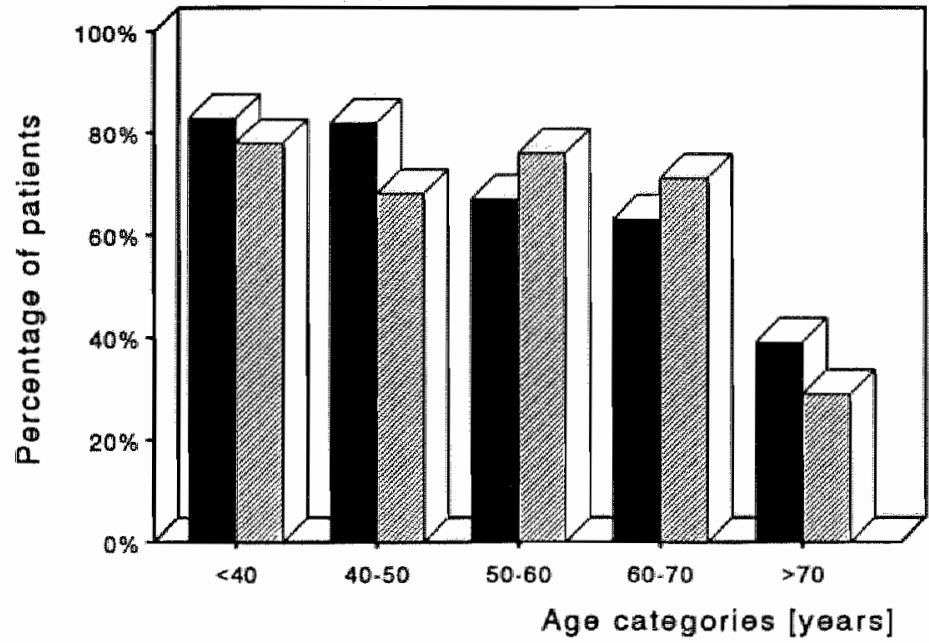

Figure II Percentages of patients who answered the computerised questionnaires designed for the UGT ( $)$ and LGT ( $\square$ ) according to age categories. 


\section{Results}

\section{FEASIBILITY}

The comparison between the paper and computerised questionnaires was performed separately for the questionnaires designed for the UGT and LGT, respectively. As mentioned before, $73 \%$ of the patients answered the paper questionnaire, as compared to $64 \%$ who answered the computerised questionnaire $(p<0.001)$. Of the 638 patients referred for an upper GI endoscopy during the first period, $70 \%$ answered the PQ-UGT; 64\% of 296 patients answered the CQ-UGT $(\mathrm{p}=0.095)$. The PQ-LGT was answered by $76 \%$ of 496 patients, as compared to $63 \%$ of 241 patients who answered the CQ-LGT $(p<0.001)$.

The reasons for not answering the questionnaires are presented in Table II. Unfortunately, these reasons were not recorded in almost $25 \%$ of the patients who did not answer the questionnaires designed for the UGT, and in about $45 \%$ of the patients who did not answer the questionnaires designed for the LGT. A small number of patients who started the history taking system were unable to complete it: eleven patients $(6 \%)$ in case of the CQ-UGT and seven patients $(5 \%)$ in case of the CQ-LGT.

No gender dependency was observed regarding the ability to answer both types of questionnaires $(p=0.685$ for the PQ-UGT; $p=0.916$ for the PQ-LGT; $p=0.403$ for the CQ-UGT; $p=0.056$ for the CQ-LGT). There was, however, a strong age dependency regarding the ability to answer these questionnaires $(p<0.0001$ for each of the four questionnaires). The mean age of the group of patients who answered the PQ-UGT was 53 years as compared to 65 years for those who did not answer this questionnaire. Comparable results were obtained for the PQ-LGT: 52 years as compared to 65 years. The percentage of patients who answered the paper questionnaire decreased from approximately $90 \%$ of those younger than 40 years to about $50 \%$ of the patients older than 80 years (Figure 1). The mean age of the group of patients who answered the CQ-UGT was 52 years, and the mean age of those who answered the CQ-LGT was 51 years. The mean ages of the groups of patients who did not answer these computerised questionnaires were 65 and 63 years, respectively. The percentage of patients who answered the computerised questionnaire decreased from about $80 \%$ of the patients younger than 40 years to less than $40 \%$ of the patients older than 80 years (Figure II).

Time measurements were automatically performed while patients were interrogated by the history taking system. Measurement started with the first question of the computerised questionnaire and ended after the last question of the opinion questionnaire. The 179 patients completed the CQ-UGT on average in 11 (range 227) minutes; also the CQ-LGT was completed by the 145 patients in on average 11 (range 3-37) minutes. For both questionnaires the completion time did not depend on gender. The completion times only slightly increased with increasing age $(r=0.27$ with $p<0.0001$ in case of the CQ-UGT and $r=0.12$ with $p=0.0593$ in case of the CQ-LGT). This is also apparent from Figures III and IV, presenting the 


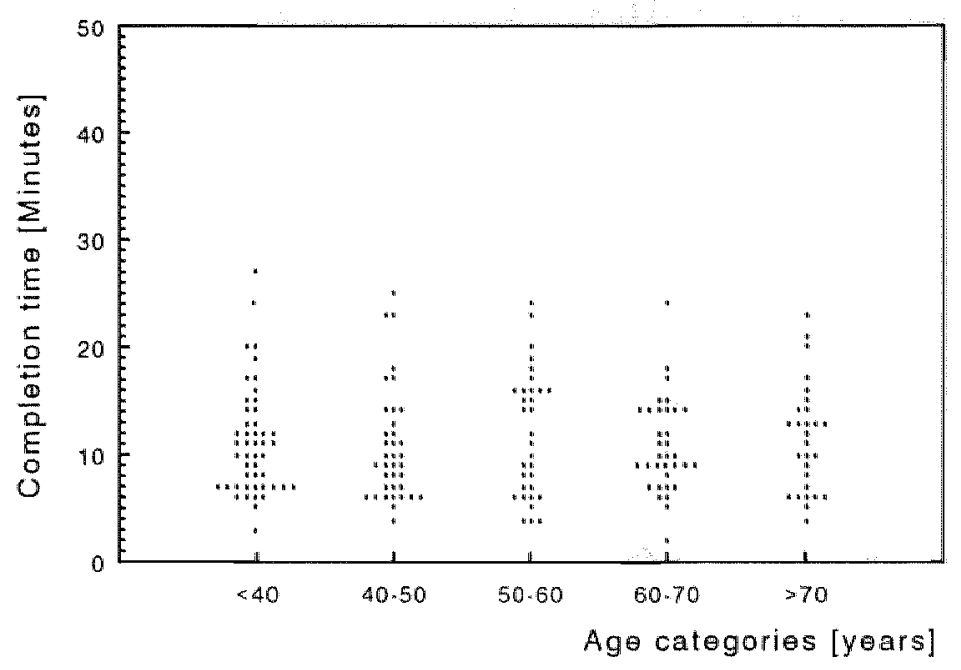

Figure III Completion times of the computerised questionnaire designed for the UGT according to age categories.

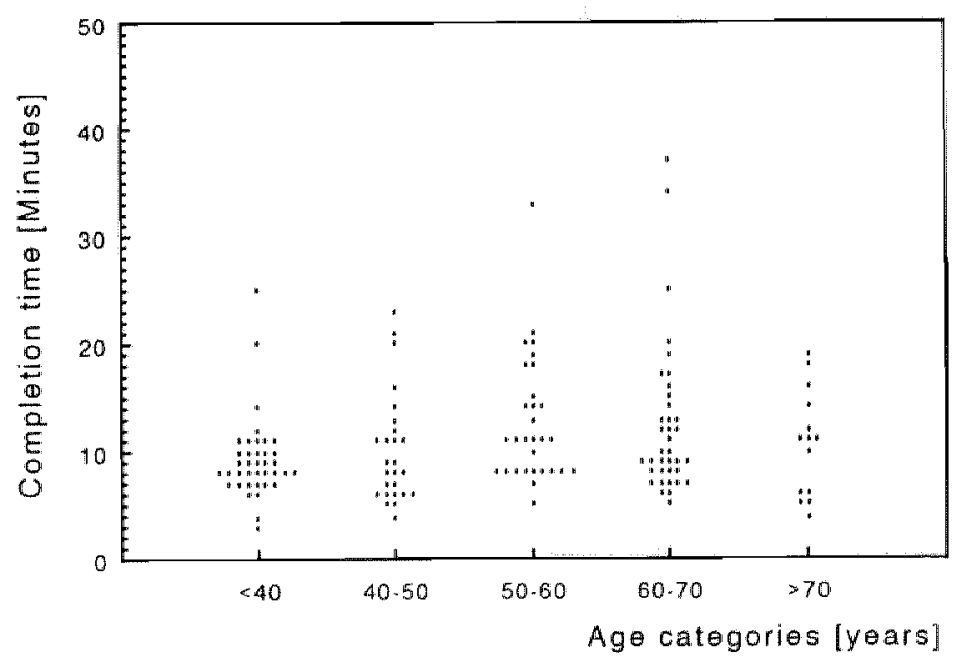

Figure IV Completion times of the computerised questionnaire designed for the LGT according to age categories. 
completion times of five age categories. Because of the branching structure of the computerised questionnaire not every question was presented to each patient. Patients referred for an upper GI endoscopy on average answered 42 of the possible 57 questions (74\%), and patients referred for a lower GI endoscopy answered on average 49 of the possible 58 questions ( $84 \%$ ). The number of questions answered did not depend on patient age.

Table III The results of the opinion questionnaire presented to the patients who answered the computerised questionnaires designed for the UGT and LGT, respectively.

\begin{tabular}{lll}
\hline OPINION QUESTIONNAIRE & UGT & LGT \\
& $n=180$ & $\mathrm{n}=148$ \\
\hline
\end{tabular}

Have you got more insight in your complaints after answering the computerised questionnaire?

Yes

$\begin{array}{ll}45 \% & 40 \% \\ 39 \% & 46 \% \\ 16 \% & 14 \%\end{array}$

No $14 \%$

Can you put your complaints into words more easily after answering the computerised questionnaire?

Yes

No

I don't know; I don't understand; The correct answer is not available

Were you able to express all your complaints by answering the computerised questionnaire?

Yes

No

I don't know; I don't understand; The correct answer is not available

Do you think answering the computerised questionnaire lasted too long?

Yes

$\begin{array}{rr}6 \% & 1 \% \\ 91 \% & 96 \% \\ 3 \% & 3 \%\end{array}$

I don't know; I don't understand; The correct answer is not available What is your personal opinion on being interrogated by a computer?

Interesting

$46 \%$

$42 \%$

Annoying

$3 \%$

$2 \%$

Easy

$34 \%$

$49 \%$

Difficult

$9 \%$

$3 \%$

I don"t know; I don't understand; The correct answer is not available 


\section{ACCEPTABILITY}

The results of the opinion questionnaire are presented in Table III. The opinions of the patients who answered the CQ-UGT were quite similar to those of the patients who answered the CQ-LGT, and did not depend on age and gender.

\section{REPRODUCIBILITY}

Whilst making an appointment at the endoscopy unit, two series of 25 consecutive patients referred for either an upper or lower GI endoscopy were asked by the secretaries to answer the paper questionnaire at home. Of these two groups, 20 and 16 patients, respectively, returned the paper questionnaire and answered the computerised questionnaire while attending for the endoscopic investigation. The number of questions that could be evaluated with respect to their reproducibility varied for each patient, depending on how the branching questions in both types of questionnaires were answered. The 20 patients answered 792 questions in both types of questionnaires designed for the UGT, and to $18 \%$ (range $0-55 \%$ ) of these questions the answers in the paper questionnaire differed from those in the computerised questionnaire. Thus, on average 7 out of 40 questions were answered differently in both types of questionnaires designed for the UGT. The 16 patients answered 665 questions in both questionnaires designed for the LGT; 11\% (range 3-21\%) of the answers differed between the paper questionnaire and the computerised questionnaire. This means that on average 5 out of 42 questions were answered differently in the paper and computerised questionnaires designed for the LGT.

It has to be realised that these two types of questionnaires can be handled differently by the patients. In the paper questionnaire patients have the opportunity to select multiple answers to a question or to skip one or more questions. On the other hand, patients can only proceed with the history taking system by selecting a single answer, either one of the answer options also present in the paper questionnaire or the escape answer. In this context, different types of inconsistency can be observed (Table IV). One may speculate that $63 \%$ of the inconsistencies between PQ-UGT and CQ-UGT and $37 \%$ of the inconsistencies between PQ-LGT and CQ-LGT are a result of the different ways these two types of questionnaires can be handled.

\section{INDIVIDUAL QUESTIONS}

The fact that first paper questionnaires were used and later computerised questionnaires permitted the evaluation of each single question under two different circumstances. It was possible to analyse how often a question was skipped or was answered with multiple answers in the paper questionnaire, and how often the same question was answered with the escape answer in the computerised questionnaire.

In addition, some patients provided written comments on questions and/or answer options on the paper questionnaires. As Logie et $a l$, we used these comments to evaluate the questions and answer options ${ }^{22}$. The results of the evaluation of the individual questions will not be presented in this chapter. 
Table IV The different types of inconsistency observed between paper ( $P Q$ ) and computerised (CQ) questionmaires designed for the UGT and LGT, respectively.

\begin{tabular}{lllll}
\hline \multicolumn{2}{c}{ Types of inconsistency } & & \multicolumn{2}{c}{ Proportions } \\
\cline { 1 - 1 } PQ & CQ & & UGT & LGT \\
\hline Regular answer & Regular answer & & $37 \%$ & $63 \%$ \\
Regular answer & Escape answer & & $32 \%$ & $20 \%$ \\
No answer & Regular answer & & $17 \%$ & $13 \%$ \\
No answer & Escape answer & & $5 \%$ & $3 \%$ \\
Multiple answers & Regular answer & & $7 \%$ & $1 \%$ \\
Multiple answers & Escape answer & & $2 \%$ & $0 \%$ \\
\hline
\end{tabular}

\section{Discussion}

Structured history taking remains a time-consuming and often unrewarding task. First, the recall of necessary questions and the writing down of the answers are monotonous and tedious. Secondly, the types of questions and answers vary between individual history takers and the results are often incomplete, inconsistent and illegibly written ${ }^{21,23}$.

The application of questionnaires in medical practice has the advantage that questions are presented to patients in a structured and uniform manner. The history data as obtained with these questionnaires are in general complete and detailed, consistent, mutually comparable, and can be stored in a data base for subsequent analysis $2,6,9-11,24-32$. Computerised questionnaires with a branching structure have the additional advantages that history taking is individualised and that data can be presented in a summarised form for immediate use or can be stored in a data base for later use without the interference of other persons ${ }^{5,33,34}$. Computerised questionnaires, however, must not be considered as competitive with routine history taking but rather as complementary ${ }^{35}$. Before a computerised questionnaire can be used in every day practice, it has to be evaluated under working conditions.

The computerised questionnaires were introduced at our endoscopy unit to provide a detailed and consistently collected history of patients referred for either upper or lower GI endoscopy. Thereby, several conditions needed for the clinical application of a history taking system, i.e. usage within a restricted field of medicine (gastroenterology) and close to the diagnostic stage (endoscopy), were fulfilled 1.21.36-38. However, some other conditions have to be fulfilled in order to guarantee the application of such a system in clinical practice. The accessibility for patients has to be comparable to a paper questionnaire, and the use of the history taking system should not disturb the routine work at the endoscopy unit. This means that the secretaries must have the opportunity to familiarise patients with the 
computerised questionnaire while doing their regular work. The patients must be able to answer the system during the normal waiting time of about a quarter of an hour. This study is the first to evaluate paper and computerised questionnaires answered by a large number of patients in a clinical setting.

Feasibility: the proportion of patients who answered the computerised questionnaire was somewhat lower than the proportion of patients who answered the paper questionnaire. The ability to answer both types of questionnaires did not depend on gender, but significantly decreased with increasing age. These results are comparable to those reported by Quaak et al, who described a computerised questionnaire which was completed by about two-thirds of the patients. They observed a similar age dependency regarding the ability to answer the questionnaire ${ }^{39}$.

As far as is recorded, the reasons for not answering were similar for paper and computerised questionnaires. Comparable to the results of Trell ${ }^{34}$, only a few patients refused to answer the questionnaire due to lack of motivation. Most of the patients who did not answer the questionnaires had visual or other physical handicaps that made reading, writing and typing impossible. About $10 \%$ of the patients were unable to answer the questionnaire because of (mainly age-related) mental deterioration. It is reasonable to assume that a large number of the patients who did not answer the paper or computerised questionnaire because of mental disorders, physical illness, or language problems, would also have been unable to answer a doctor during routine history taking. The fact that the reasons for not answering the questionnaires were not recorded in a substantial proportion of the patients makes interpretation very difficult and somewhat speculative.

An average completion time of eleven minutes is acceptable in every respect and makes answering the computerised questionnaires during the regular waiting time possible. We observed a slight positive correlation between age and completion time, as did Quaak et al. ${ }^{14,39}$. Also Coombs et al. $(\mathrm{r}=0.27 \text { with } \mathrm{p}<0.005)^{40}$ and Slack et al. $(\mathrm{r}=0.41 \text { with } \mathrm{p}<0.001)^{41}$ reported that the time required to answer their computer-based questionnaire increased with age.

Acceptability: previous studies have shown patient attitudes towards computerised questionnaires to be uniformly favourable. Although these studies have been done with computerised questionnaires which were different with regard to structure and number of questions, answering these questionnaires was consistently reported to be interesting, enjoyable, easy and sometimes even preferable to routine history taking $1,2,5.6,8-10,16,18,34,42-47$.

The last two questions of the opinion questionnaire demonstrated that, independent of patient age and gender, answering our history taking system was interesting and easy, and did not last too long according to the patients. By contrast, Lucas ${ }^{45}$ demonstrated that male and younger patients had a more favourable attitude towards computerised history taking than female and older patients, respectively. The first three questions of the opinion questionnaire were apparently more difficult to answer, which was reflected in the higher percentage of escape answers. At the onset of the study we had the idea that presenting questions in a structured and 
logical way would provide patients with more insight in their complaints, and consequently would enable them to put their complaints into words more easily. Indeed, about $40 \%$ of the patients answered that the insight in their problem had increased after answering the computerised questionnaire, which is superior to the $10 \%$ as reported by Quaak et al. ${ }^{47}$. About $45 \%$ of the patients could put their complaints into words more easily after answering the history taking system. Comparable to other reports $6.9 .10 .22 .47,25 \%$ of the patients were unable to express all their complaints.

Reproducibility: a reproducibility of $85 \%$ between paper and computerised questionnaires is quite acceptable and comparable to the results presented in other studies, especially when we take into account that these two types of questionnaires can be handled differently by the patients $6,28,48$.

In conclusion, with the help of the computerised history taking system a detailed and uniformly collected history of most patients referred for either upper or lower GI endoscopy can be obtained. Patients are able to answer the computerised questionnaires during the regular waiting time before endoscopy, and they consider answering these questionnaires as interesting and easy. The history data as obtained with both paper and computerised questionnaires are highly reproducible. The value of these data for the prediction of endoscopic diagnoses, however, still has to be established and this will be the subject of the studies presented in Chapters VII and VIII.

Table $\mathbf{V}$ Comparison of the reasons for not answering the paper (PQ) and computerised $(\mathrm{CQ})$ questionnaires designed for the UGT as presented in Chapter III (A) and as they eventually have been recorded for the remaining studies in this thesis (B).

REASONS FOR NOT ANSWERING

Number of patients (\%)

PQ-UGT (A) PQ-UGT (B) CQ-UGT (A) CQ-UGT (B)

\begin{tabular}{lrrrrrrrrr} 
& 192 & \multicolumn{1}{c}{173} & \multicolumn{3}{c}{106} & \multicolumn{3}{c}{248} \\
\hline Mental disorders & 27 & $(14.1)$ & 18 & $(10.4)$ & 11 & $(10.4)$ & 6 & $(2.4)$ \\
Plyysical illness & 56 & $(29.2)$ & 48 & $(27.7)$ & 37 & $(34.9)$ & 23 & $(9.3)$ \\
Visual handicap & 39 & $(20.3)$ & 39 & $(22.5)$ & 16 & $(15.1)$ & 16 & $(6.5)$ \\
Motivational reasons & 5 & $(2.6)$ & 5 & $(2.9)$ & 5 & $(4.7)$ & 2 & $(0.8)$ \\
Other reasons * & 25 & $(13.0)$ & 25 & $(14.5)$ & 10 & $(9.5)$ & 32 & $(12.9)$ \\
Computer-related reasons & & & & & & & 131 & $(52.8)$ \\
No reason recorded & 40 & $(20.8)$ & 38 & $(22.0)$ & 27 & $(25.4)$ & 38 & $(15.3)$ \\
\hline
\end{tabular}

"Including language problems such as illiteracy, foreign language, etc. 


\section{Epilogue}

The number of patients presented in this chapter differs from those as they eventually have been recorded for the remaining studies in this thesis. This has also affected the distribution of the reasons for not answering the questionnaires, as demonstrated in Table $V$. The differences will be explained in this epilogue.

A re-evaluation of the paper questionnaires designed for the upper GI tract revealed that in 34 cases, the patients were referred for a follow-up endoscopy. These cases were excluded from the remainder of the studies which, therefore, describe 604 patients undergoing their first diagnostic upper GI endoscopy between January 1989 and May 1989. Of these patients, 431 answered the questionnaire (response rate $=71.4 \%$ ).

Between May 1989 and september 1989, 427 patients were referred for their first diagnostic upper GI endoscopy. Of these patients, 190 have been interviewed by the history taking system. The 131 patients who were referred while the computerised questionnaire was not operational because of technical problems have been excluded from the analyses in Chapter III, but were included in the remaining studies in this thesis. There are two other changes in the analysis responsible for the fact that the number of patients who did not answer the computerised questionnaire for various reasons as given in Chapter III differs from the figures used later. First, 11 patients who started but did not complete the history taking system were considered to have answered the computerised questionnaire in the analyses in Chapter III. However, since the history data of these patients have not been stored by the system, they were regarded as not having answered the computerised questionnaire in the remainder of the studies. Secondly, the 32 patients who did not answer the computerised questionnaire because of so-called 'other reasons', could be assigned to specific categories with the help of some clarifying comments recorded by the secretaries as follows: mental disorders $(n=5)$, physical illness $(n=14)$, motivational reasons $(n=3)$, and language problems $(n=10)$. 


\section{References}

1. Card WI, Lucas RW. Computer interrogation in medical practice. Int J Man-Machine studies 1981; 14: 49-57.

2. Slack WV, Hicks GP, Reed CE, Van Cura LJ. A computer-based medical-history system. $N$ Engl J Med 1966; 274 (4): 194-198.

3. Collen MF. Self-admimistered questionnaire. J Clin Comput 1977; 7: 35-52.

4. Chisholm EM, de Dombal FT, Giles GR. Validation of a self administered questionnaire to licit gastrointestinal symptoms. Br Med J 1985; 290: 1795-1796.

5. Mayne JG, Weksel W, Sholtz PN. Toward automating the medical history. Mayo Cin Proc 1968; $43: 1-25$.

6. Grosiman $\mathrm{JH}$, Barnett GO, McGuire MT, Swedlow DB. Evaluation of computer-acquired patient histories. JAMA 1971; 215 (8): 1286-1291.

7. Simmons EM, Miller OW. Automated patient history-taking. Hospitals 1971; 45: 56-59.

8. Rockart JF, McLean ER, Hershberg PI, Bell GO. An automated medical history system. Arch Intern Med 1973; 132: 348-358.

9. Lilford RJ, Glyn-Evans $\mathrm{D}$, Chard $T$. The use of a patient-interactive microcomputer system to obtain histories in an infertility and gynecologic endocrinology clinic. Am J Obstet Gymecol $1983 ; 146: 374-379$.

10. Bingham $P$, Lilford RI, Chard T. Strengths and weaknesses of direct patient interviewing by a microcomputer system in specialist gynaecological practice. Europ I Obster Gynec reprod Biol 1984; 18: 43-56.

11. Quaak MJ, Westerman RF, Schouten JA, Hasman A, van Bemmel JH. Computerization of the patient history - Patients answers compared with medical records. Methods Inf Med 1986; 25: 222-228.

12. Quaak MJ, Westerman RF, Schouten JA, Hasman A, van Bemmel JH. Appraisal of computerized medical histories: Comparison between computerized and conventional records. Comput Bioned Res 1986; 19: 551-564.

13. Mayne JG, Martin MJ, Taylor WF, O'Brien PC, Fleming PJ. A health questionnaire based on paper-and-pencil medium, individualized and produced by computer. III. Usefulness and acceptability to physicians. Ann of Int Med 1972; 76: 923-930.

14. Quaak MJ, Westerman RF, van Bemmel JH Comparisons between written and computerised patient histories. Br Med I 1987; 295: 184-190.

15. Hershberg PI, Englebardt C. Harrison R, Rockart JF, McGandy RB. The medical history question as a health screening test: An assessment of validity. Arch Interm Med 1971; 127: $266-272$

16. Seelos HJ. Evaluation of a computer-assisted screening method for medical history records. Meth Inform Med 1984; $23: 189-194$.

17. Haug PI, Warner HR, Clayton PD, Schmidt CD, Pearl JE, Farney RI, et al. A decisiondriven system to collect the patient history. Comput Biomed Res 1987; 20 (2): 193-207.

18. Slack WV, Van Cura LJ. Patient reaction to computer-based medical interviewing. Comp Bioned Res 1968; 1: 527-531

19. Gottlieb GL, Beers RF, Bernecker C, Samter M. An approach to automation of medical interviews. Comp Bionted Res 1972; 5: 99-107.

20. Bevan N, Pobgee P, Somerville S. MICKIE - A microcomputer for medical interviewing. Im J Man-Machine studies 1981; 14: 39-47.

21. Houzliaux MO, Lefebvre PJ. Historical and methodological aspects of computer-assisted medical history-taking. Med Inform 1986; 11 (2): 129-143. 
22. Logie AR, Madirazza JA, Webster IW. Patient evaluation of a computerised questionnaire. Comp Biomed Res 1976; 9: 169-176.

23. Wong WS, Lee $\mathrm{KH}_{\text {, }}$ Chang $\mathrm{MZ}$. A microcomputer based interview system for antenatal clinic. Comput Biol Med 1986; 16 (6): 453-463.

24. Brodman K, Erdmann AJ, Lorge 1, Wolff HG. Cornell Medical Index: adjunct to medical interview. JAMA 1949; 140: 530-534.

25. Barnett GO. Computers in patient care. N Engl I med 1968; 279: 1321-1327.

26. Kanner IF. Programmed medical history-taking with or without computer. JAMA 1969; 207 : 317-321.

27. Mayne JG, Martin MJ. Computer-aided history acquisition. Med Clin N Amer 1970; 54: 825833.

28. Mellner C. The self-administered medical history. Acta Chir Scand Suppl 1970; 406: 5-93.

29. Robinson DW, Walmsley GL, Horrocks JC, Milson P, Jenkins DM, de Dombal FT, et al. Histories obtained by two-stage questionnaire with automated transcript in specialist gynaecological practice. Br Med J 1975; IV: 510-513.

30. Lilford $\mathrm{RJ}$, Chard T. Microcomputers in antenatal care: a feasibility study in the booking interview. Br Med J 1981; 283: 533-536.

31. Lilford RJ, Bourne $G$, Chard $T$. Comparison of information obtainable by computerized and manual questionnaires in an antenatal clinic. Med Inform 1982; 7: 315-320.

32. Glen ES, Small DR, Morrison LM, Pollack K. Urological history-taking and management recommendations by microcomputer. BrJ Urol 1989; 63: 117-121.

33. Komaroff AL. The variability and inaccuracy of medical data. Proceedings of the IEEE 1979; $67(9): 1196-1207$.

34. Trell E. Interactive computer program for self-distributed medical questionnaires: Notes on technical implementation and use. Med Inform 1983; 8 (2): $139-143$.

35. Pringle M. Using computers to table patient histories. Br Med $J$ 1988; 297: 697-698.

36. Blois MD. Clinical judgement and computers. N Engl J Med 1980; 303: 192-197.

37. Rozen P. Computer assistance in Gastroenterology: A review. J Clin Gastroenterol 198 ; 4 $403-413$.

38. Lilford RJ. Comparisons between written and computerised patient histories. $\mathrm{Br}$ Med J 1987; 295: 503 .

39. Quaak MJ, wan der Voort PJG, Westerman RF, Hasman A, van Bemmel JH. Automation of the patient history - Evaluation of ergonomic aspects. Int J Biomed Comput 1987; 21: 287-298.

40. Coombs GJ, Murray WR, Krahn DW. Automated medical histories: Factors determining patient performance. Comp Biomed Res 1970; 3: 178-181.

41. Slack WV, Leviton A, Bennett SE, Fleischmann KH, Lawrence RS. Relation between age, education, and time to respond to questions in a computer-based medical interview. Comput Biomed Res 1988; 21 : 78-84.

42. Lucas RW, Card WI, Knill-Jones RP. Watkinson G, Crean GP. Computer interrogation of patients. $\mathrm{Br} \mathrm{Med} J 1976 ; 2$ : 623-625.

43. McLean ER, Rockart JF, Chaney JHG. Questionnaire becomes preadmission tool. Hospitals $1973 ; 47: 56-59$.

44. Card WI, Nicholson M, Crean GP, Watkinson G, Evans CR, Wilson J, el al. A comparison of doctor and computer interrogation of patients. In J Biomed Comp 1974; 5: 175-187.

45. Lucas RW. A study of patients' attitudes to computer interrogation. Int J Man-Machine studies 1977; 9: 69-86.

46. Millstein SG, Irwin CE. Acceptability of computer-acquired sexual histories in adolescent girls. J Pediatr 1983; 103: 815-819.

47. Quaak MJ, Westerman RF, Schouten JA, Hasman A, van Bemmel JH. Patient appreciations of computerized medical interviews. Med Inform 1986; 11:339-350. 
48. Collen $\mathrm{MF}$, Cutler $\mathrm{L}_{*}$ Siegelaub $\mathrm{AB}$, Cella $\mathrm{RL}$. Reliability of a self-administered medical questionnaire. Arch Intern Med 1969; 123: 664-681. 


\section{The diagnostic outcome of upper gastrointestinal endoscopy: are referral source and patient age determining factors?}

Eur J Gastroenterol Hepatol 1994; 6: 329-335.

R.P. Adang, F.-J.F.E. Vismans, J.L. Talmon, A. Hasman, A.W. Ambergen, R.W. Stockbrügger 



\section{Abstract}

The aim of this study was to assess the diagnostic outcome of upper gastrointestinal endoscopy at an open access service for general practitioners and specialists, with special attention to the importance of referral source and patient age as determining factors. All 2900 patients $(52.5 \%$ men; mean age $56 \pm 17.6$ years) who underwent their first diagnostic upper gastrointestinal endoscopy between January 1989 and October 1990 were included. General demographic characteristics, referral indications, pain localisation, previous drug treatment, and endoscopic diagnoses were compared by means of the two-samples t-test or Chi-squared test. Patients referred by general practitioners (42\%) were younger than specialist referrals $(58 \%)$ with mean ages of 52 and 59 years respectively. Compared with specialists, general practitioners referred their patients significantly more often because of dyspepsia $(72 \%$ vs $41 \%)$ and less often because of signs of upper gastrointestinal bleeding (6\% vs $27 \%$ ) or anorexia and weight loss $(4 \%$ vs $6 \%)$. Patients referred by their general practitioner reported epigastric $(62 \%$ vs $36 \%)$ or retrosternal pain $(18 \%$ vs $13 \%)$ significantly more often and had been treated more frequently with anti-peptic drugs prior to endoscopy (51\% vs 26\%). The proportion of relevant endoscopic findings did not differ between the two groups. The proportion of normal endoscopic investigations was lower in patients aged over 45 years than in those under 45 years: $25 \%$ $v s 42 \%$, respectively. No malignant disorders were found in patients under 45 years of age.

In summary, our results provide strong evidence in favour of continuing the open access endoscopy service for both general practitioners and specialists, if the aim of the diagnostic activity is the discovery of treatable disease. The expected proportion of relevant diagnoses is considerable in patients below 45 years of age. In those aged over 45 years, dyspeptic symptoms should be regarded as alarm symptoms.

\section{Introduction}

Dyspeptic symptoms are common in the general population, but the prevalence of serious disorders associated with these symptoms is rather low ${ }^{1-4}$. Over the last ten years, endoscopy has become the most important diagnostic procedure for diseases of the upper gastrointestinal (GI) tract. Consequently, the referral rate of dyspeptic patients for upper Gl endoscopy has increased considerably, especially since endoscopy units began to offer an open access service to general practitioners (GPs) 5.15. In some centres, the demand for service has outstripped the available resources resulting in long waiting lists ${ }^{6,15,16}$. Unfortunately, despite the increased use of upper GI endoscopy in Europe, there is no convincing increase in the diagnostic rate of (early) gastric cancer and peptic ulcer disease ${ }^{6,11,12,17,18}$. The need for open access endoscopy has been questioned, therefore, and criteria for referral 


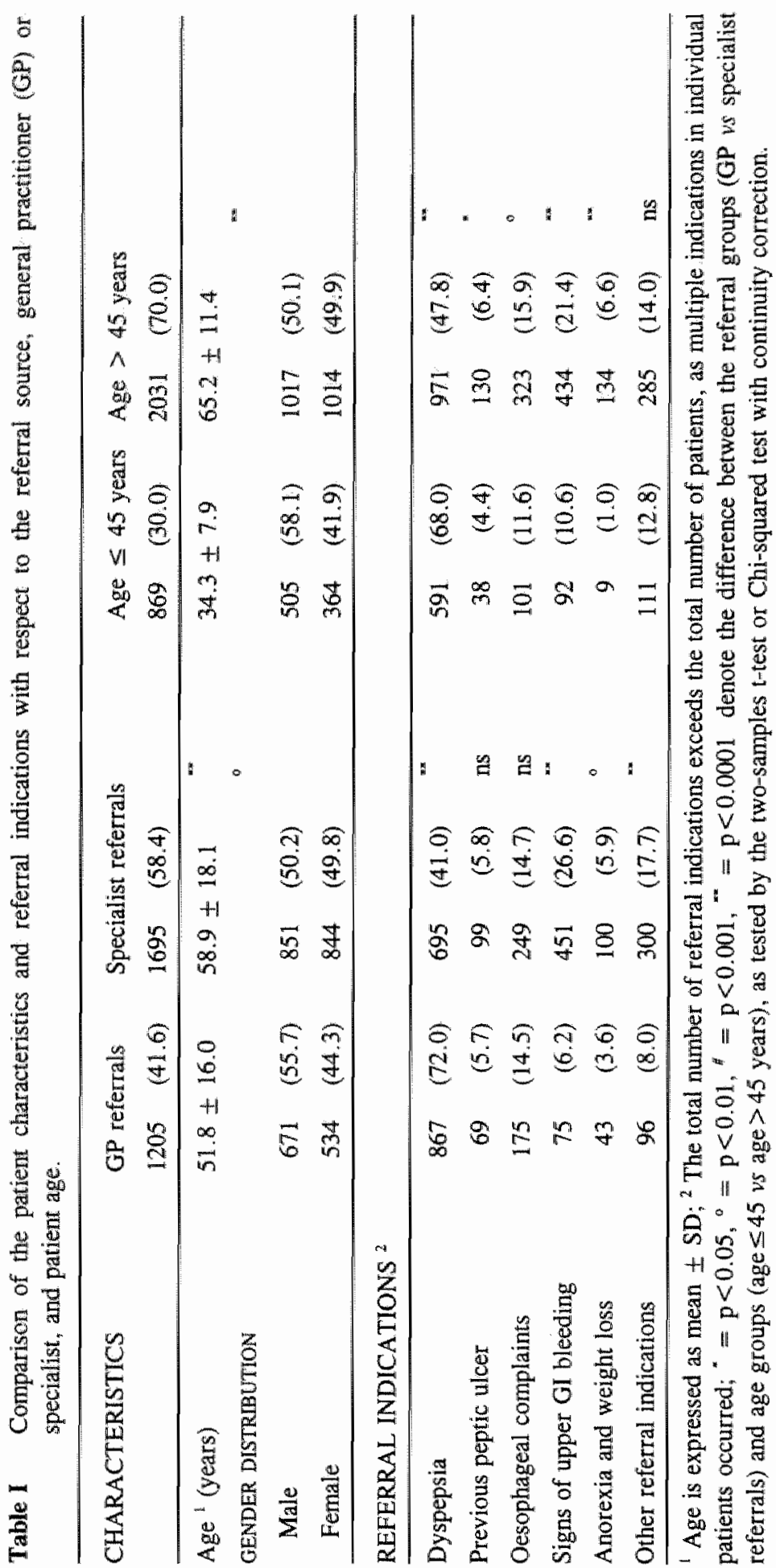


selection have been suggested ${ }^{6,19-26}$, such as the refusal to investigate short-lasting uncomplicated dyspepsia in young patients ${ }^{16,27,28}$.

The aim of this study was to compare indications and endoscopic findings in patients referred by GPs or hospital specialists. Furthermore, we studied the impact of patient age as a determinant for the diagnostic yield of upper GI endoscopy.

\section{Patients and methods}

This prospective study was performed at a single endoscopy unit from January 1989 to October 1990. The endoscopy unit of the University Hospital Maastricht serves a population of approximately 250,000 and has offered an unrestricted 'true' open access service to GPs since $1981^{15,29}$. Hospital specialists and their assistants also refer patients from in- and outpatient departments without prior selection by endoscopists. All 2900 patients who underwent their first diagnostic upper GI endoscopy were included. The study population, 1522 men $(52.5 \%)$ and 1378 women $(47.5 \%$ ), had a mean age (SD) of 56 (17.6) years (range 3-96 years). A standardised study form was used to record the patient data in a consistent and uniform manner. The methods of data acquisition have been extensively described in Chapter II and, therefore, will be summarised only briefly in the following paragraphs.

The secretarial staff of the endoscopy unit recorded the demographic characteristics and whether patients were referred by a GP or by a hospital specialist, both of whom used structured request forms for endoscopy. The request form contains a section in which the indication for the endoscopic investigation was given.

Before the endoscopic investigation was carried out, the patients were interviewed by the endoscopists as to whether retrosternal or epigastric pain had been a reason for consultation and subsequent referral for endoscopy. Patients were also asked whether they had recently been taking 'anti-peptic drugs" such as $\mathrm{H}_{2}$ receptor antagonists, antacids, cytoprotective agents, or prokinetics, and whether they used non-steroidal anti-inflammatory drugs (NSAIDs) or steroids.

The endoscopic examinations were carried out using standard forward-viewing fibreoptic endoscopes. For the purpose of this study, only endoscopic diagnoses have been considered and additional histopathological findings were not taken into account. Oesophagitis was graded according to the Savary-Miller classification ${ }^{30}$. Ulcers in the stomach were classified as benign, when endoscopic features traditionally suggestive of malignancy were absent. The term 'endoscopic gastritis' was used for different types of diffuse gastric changes such as erosive, haemorrhagic, atrophic, varioliform, and hypertrophic appearances. Post-gastrectomy anastomositis was also covered by endoscopic gastritis. Endoscopic appearances of inflammation in the duodenal bulb and/or descending duodenum were summarised as a diagnosis of bulbitis/duodenitis. Those diagnoses which usually have direct therapeutic and/or prognostic consequences were regarded as clinically 'relevant' such as cancers, peptic ulcers, and oesophagitis. 


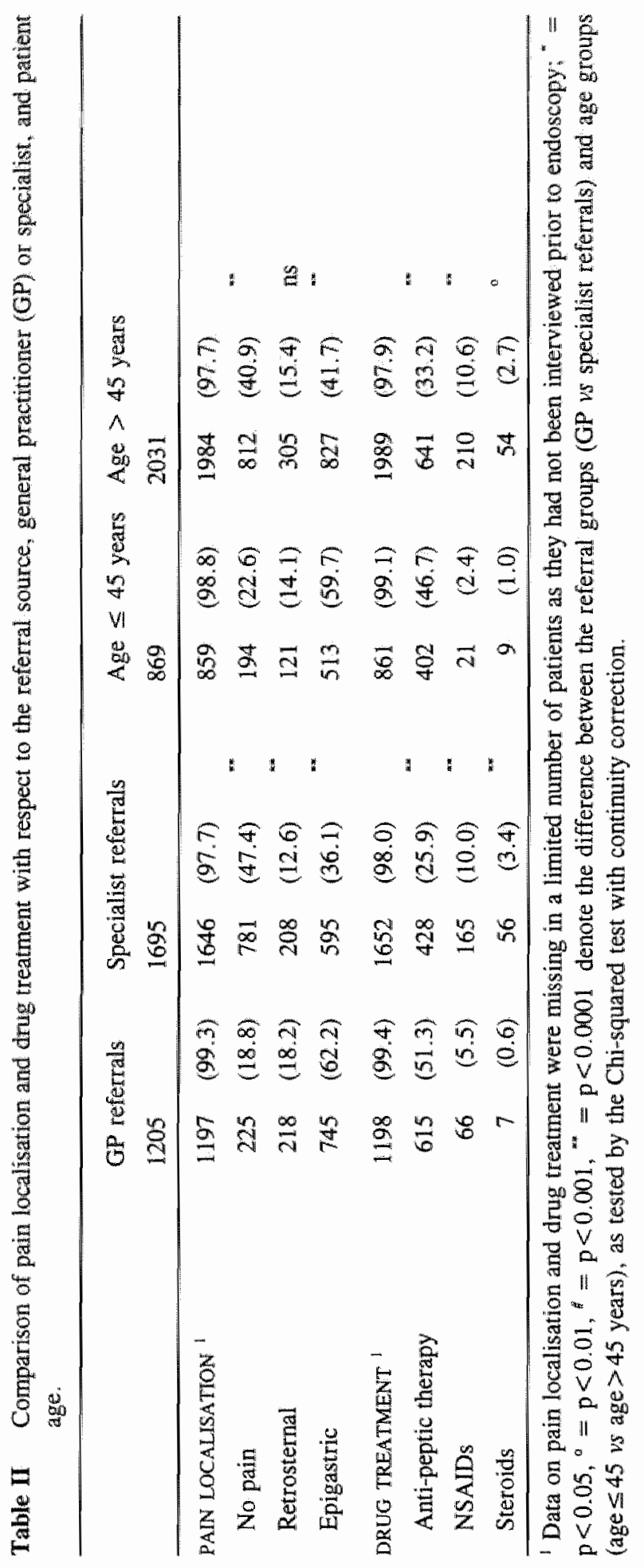




\section{STATISTICAL ANALYSES}

The two-samples t-test and Chi-squared test with continuity correction were used to test differences between groups. Significance was set at the $5 \%$ level. GP and specialist referrals were regarded as two distinct groups. To evaluate the influence of the age of the patient on the endoscopic outcome, a continuum of seven age groups as well as subdivision into two age groups, $\leq 45$ and $>45$ years, were chosen. This latter threshold was selected in accordance with previous studies ${ }^{16,31-34}$.

\section{Results}

GP referrals $(n=1205)$ were significantly younger than specialist referrals $(n=1695$; Table I, Figure I); $30 \%$ of the patients were less than 45 years of age, with a higher proportion of male patients than in the group over 45 years of age.

Dyspepsia, defined as episodic or persistent upper abdominal pain and/or discomfort, was an indication for referral in $72 \%$ of those patients referred by GPs, but was the reason for endoscopy in only $41 \%$ of the specialist population. Specialists referred more than one-quarter of their patients because of signs of upper GI bleeding such as haematemesis, melaena, faecal occult blood, or iron deficiency anaemia; by contrast, these were the reasons for referral in only $6 \%$ of the GP population. Anorexia and weight loss were seen more frequently in specialist referrals. Patients under 45 years of age were generally referred because of dyspepsia and less frequently because of 'alarm symptoms' such as signs of upper GI bleeding or anorexia and weight loss.

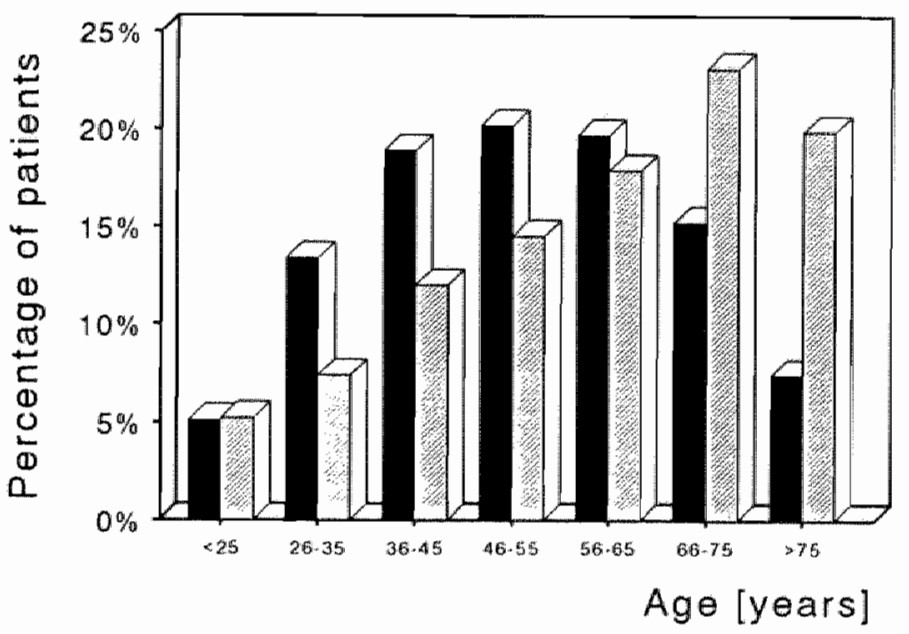

Figure I Age distribution of GP ( $\square$ ) and specialist ( $\square$ ) referrals. 


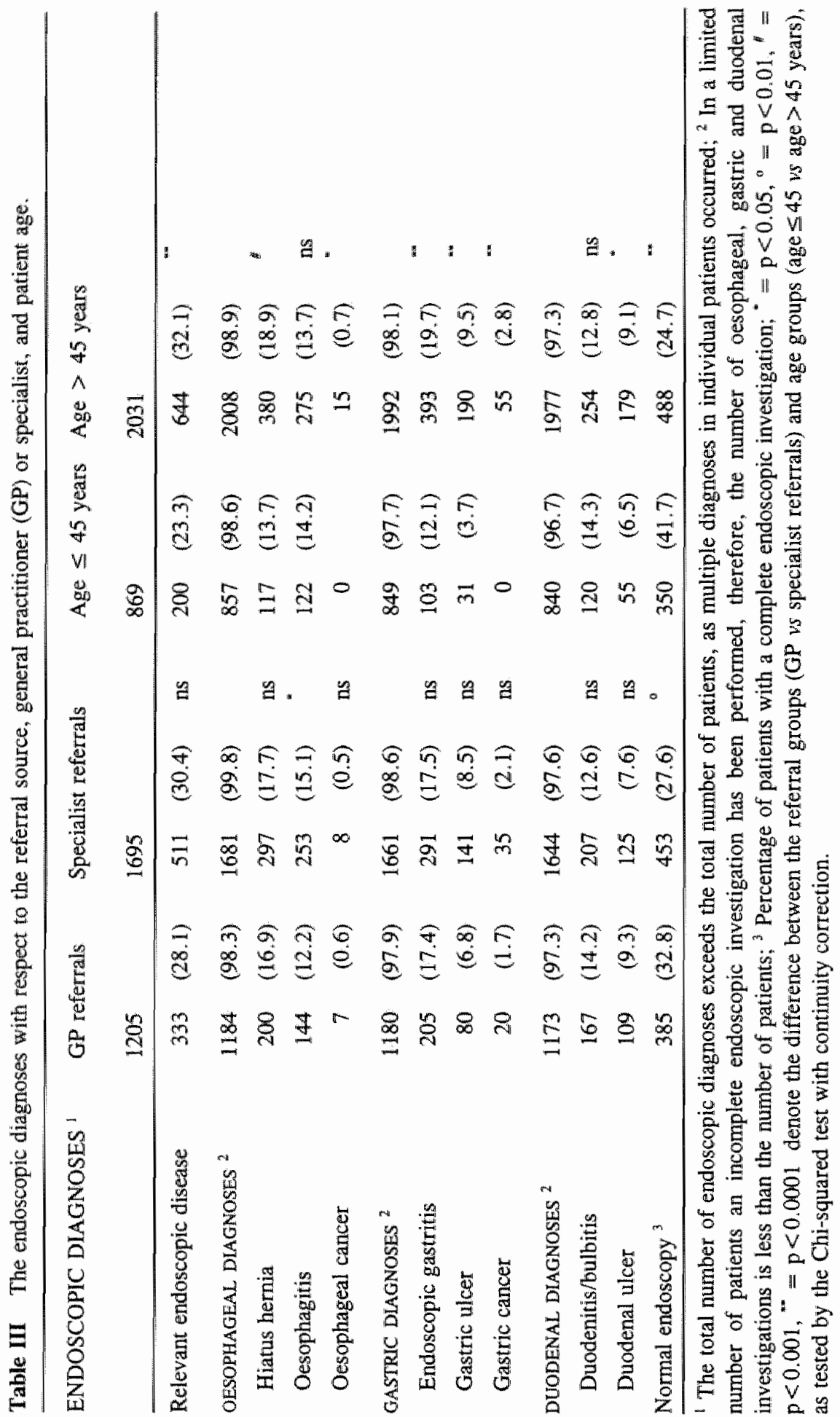


More than $60 \%$ of the GP referrals reported epigastric pain and less than $20 \%$ had not experienced abdominal or retrosternal pain (Table II). By contrast, only $36 \%$ of the patients referred by specialists reported epigastric pain and nearly $50 \%$ did not have any pain at all. While GPs had treated more than $50 \%$ of the patients prior to referral for endoscopy, specialists had started anti-peptic therapy in only one-quarter of their patients. Specialist referrals had been taking potentially ulcerogenic drugs such as NSAIDs and steroids more frequently.

Patients under 45 years of age reported epigastric pain more often compared with the older patient group, but reported retrosternal pain less often. About $40 \%$ of the patients aged over 45 years did not experience any pain; this was the case in less than one-quarter of the younger age group. Anti-peptic therapy was started more frequently prior to the endoscopic investigation in younger patients and potentially ulcerogenic drugs were used more often by older patients.

The endoscopic findings in patients referred by a GP were almost similar to those in specialist referrals (Table III). Peptic ulcers were equally common in both groups, although duodenal ulcers tended to predominate in patients referred by GPs and gastric ulcers in specialist referrals. Patients referred by a specialist were more likely to have oesophagitis and the prevalence of hiatus hernia was about $17 \%$ in both populations.

The proportion of relevant endoscopic disease increased in both referral populations with increasing age (Figure II). The percentages of several relevant endoscopic diagnoses and the relation to age and referral source are presented in Figures IIla-d.

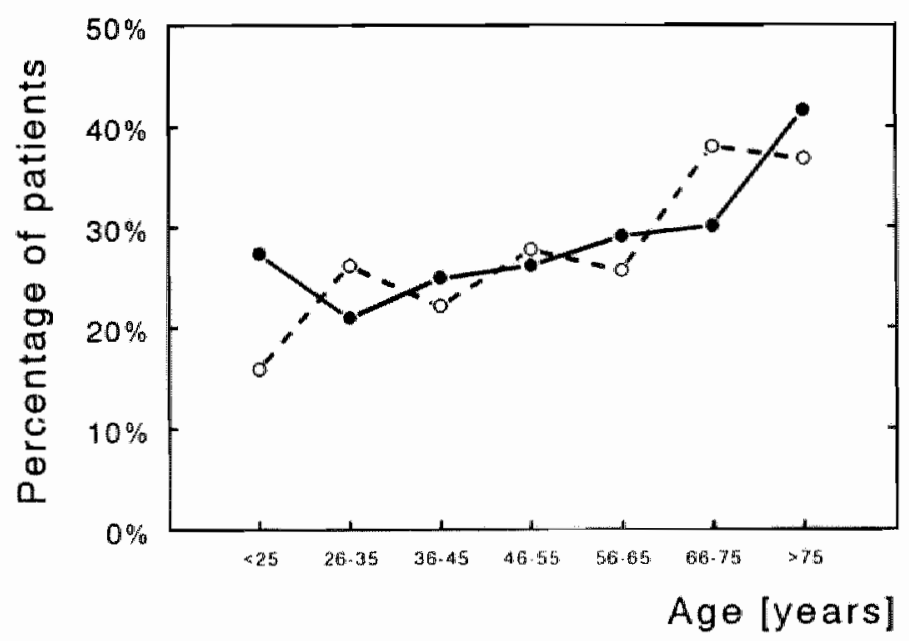

Figure II Relewant endoscopic findings in GP (•) and specialist (o) referrals according to age. 


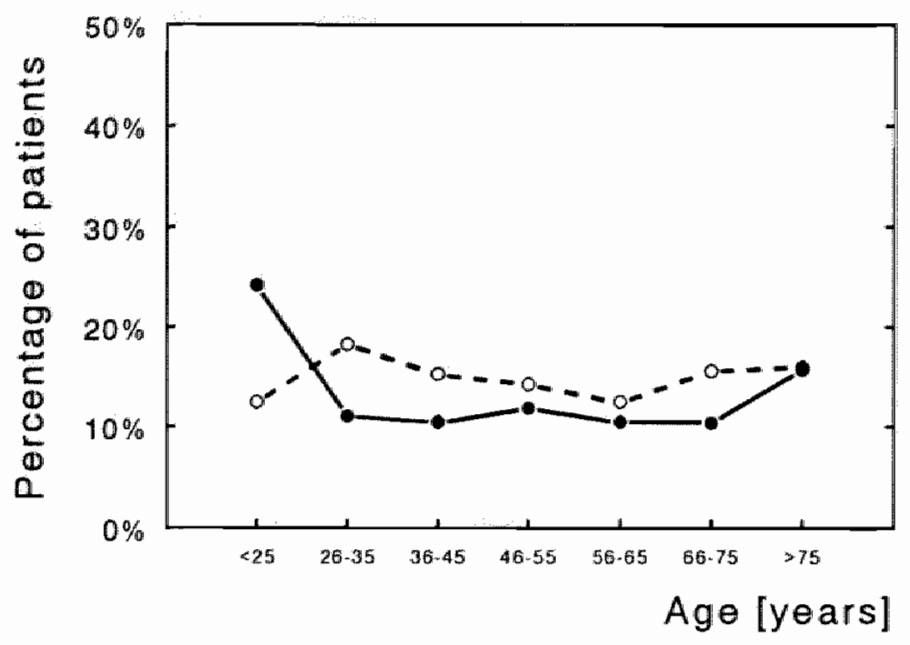

Figure IIIa Oesophagitis in GP $(\bullet)$ and specialist (O) referrals according to age.

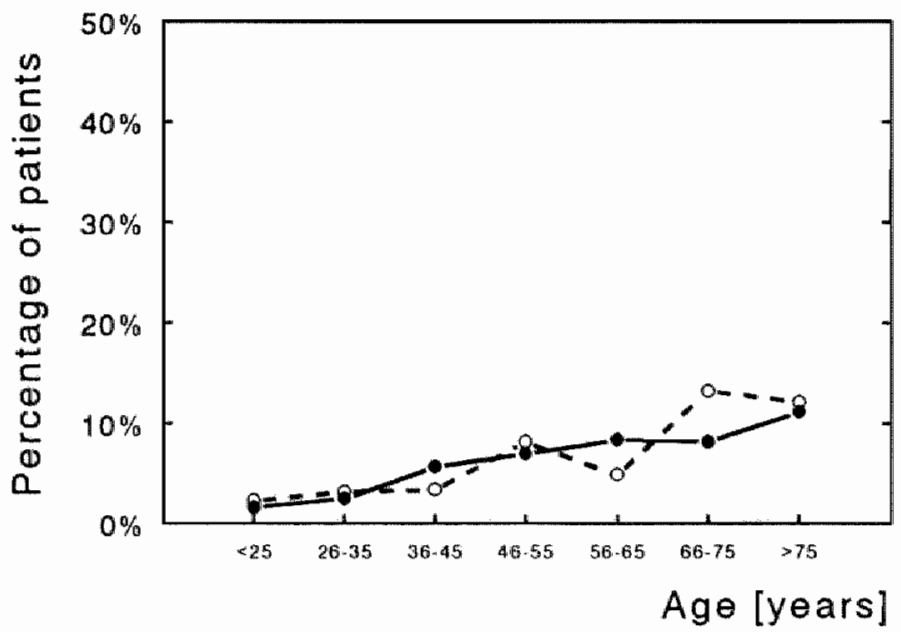

Figure IIIb Gastric ulcer in GP (๑) and specialist (O) referrals according to age. 


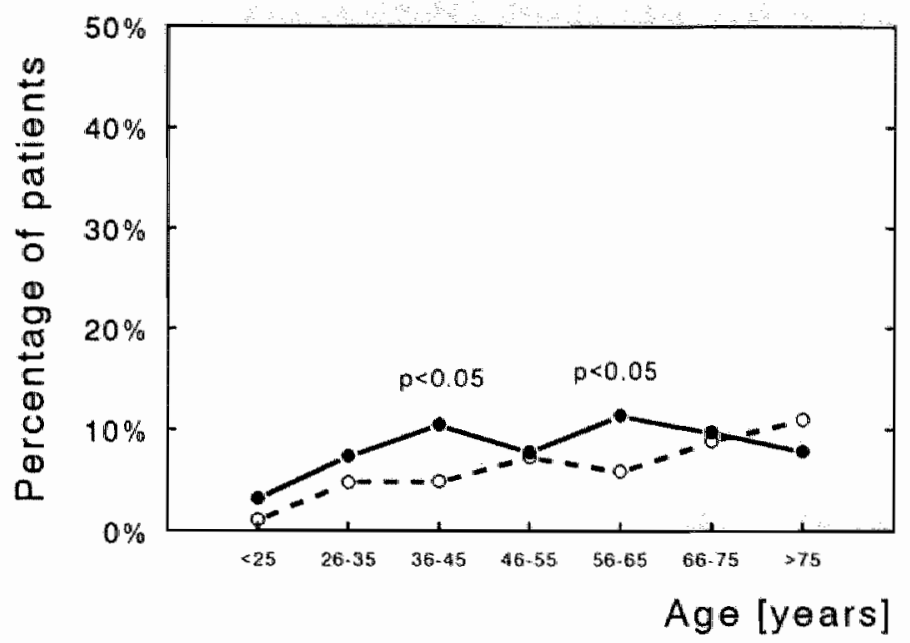

Figure IIIc Duodenal ulcer in GP (•) and specialist (O) referrals according to age.

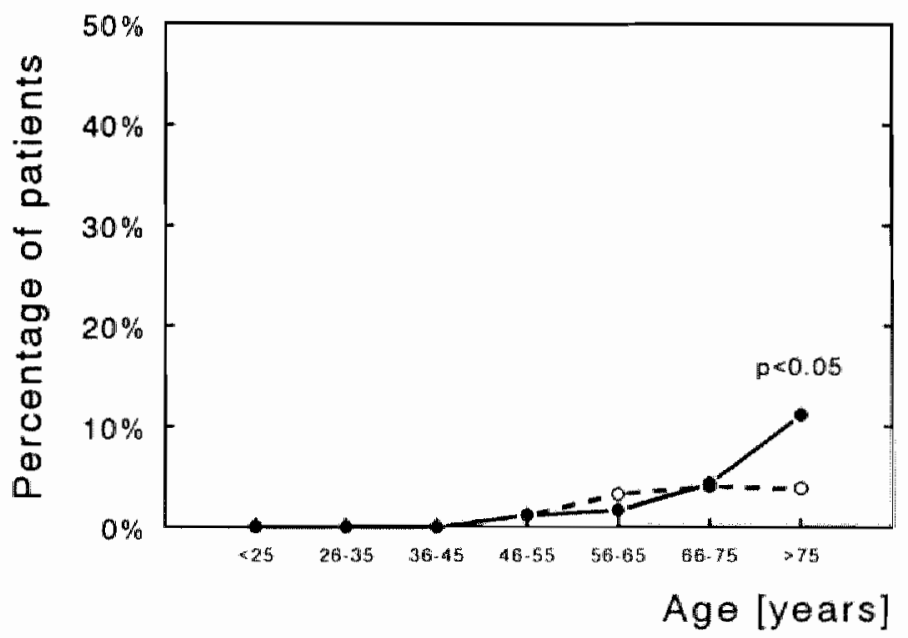

Figure IIId Oesophageal or gastric cancer in GP (•) and specialist (O) referrals according to age. 
Duodenal ulcers were more common in GP referrals than in specialist referrals for those patients aged from 35-45 and from 55-65 years. Malignant disorders were diagnosed more often in GP referrals above 75 years of age than in specialist referrals from the same age range.

The percentage of relevant endoscopic disease was significantly higher in patients aged above 45 years than in those below (Table III). No malignant disorder of the upper GI tract was found in patients under 45 years of age. Peptic ulcers were diagnosed significantly more often in the older age group. The incidence of oesophagitis did not increase with age despite the increased prevalence of hiatus hernia.

\section{Discussion}

This study evaluated the open access endoscopy service by comparing 2900 referrals from both GPs and specialists, with special attention to the age of the patient as a factor determining outcome $4,5,7,10,12,16,20,31,32,35$. The overall diagnostic outcome of upper GI endoscopy in patients referred by a GP was similar to that observed in patients referred by specialists, although these two patient populations differed with respect to age and gender distribution, referral pattern, pain presentation and previous drug treatment.

Similar to Kerrigan et al. ${ }^{33}$, we found that hospital clinicians generally refer older patients. GPs are regularly consulted by patients with rather indeterminate dyspeptic complaints, whereas specialists from in- and outpatient departments presumably deal with patients with long-standing, severe, and/or alarming symptoms more often ${ }^{6}$. Although an open access service should prevent patients with dyspepsia being treated empirically over a protracted period of time with expensive anti-peptic drugs, this form of treatment occurred still in about half of the GP referrals and in one-quarter of the specialist referrals at this endoscopy centre.

The prevalence of relevant endoscopic disease did not differ significantly between the GP and specialist population despite the age differences between the two groups. This observation conflicts with the results of Kerrigan et al. ${ }^{33}$, which showed an increased prevalence of malignant disease in patients referred from within the hospital. NSAIDs and steroids were more frequently used by patients in the specialist group than in the GP group. Hence, one would expect a higher prevalence of peptic ulcer disease in the former. However, both duodenal and gastric ulcers were equally represented in each group. Oesophagitis was a more common finding in the specialist than in the GP referrals, although oesophageal-type symptoms did not occur predominantly in this referral group. In accordance with previously published reports $7 \cdot 10,29,31,32,35-37$, the proportion of normal endoscopic investigations was about $30 \%$ in both GP and specialist referrals.

What are the practical implications of our observations? As the diagnostic yield of upper GI endoscopy is almost identical in GP and specialist referrals, our results 
provide strong evidence in favour of an unrestricted open access policy. All the more, since it has been demonstrated that the availability of an open access endoscopy service may result in a decreased demand for barium meal examinations and a reduced workload in the gastroenterology outpatient department $5,11,12,29,38,3 \%$.

We found, as did others $9.16,22,31-34,36$, that the frequency of clinically relevant endoscopic findings was much lower in the younger than in older patient group and that none of the patients under 45 years of age had a malignant disorder. These results are largely compatible with those from studies assessing the efficacy of barium meal investigations ${ }^{40-42}$. On the other hand, $14 \%$ of the gastric ulcers, $24 \%$ of the duodenal ulcers, and $31 \%$ of oesophagitis were diagnosed in patients below 45 years of age.

The benefit of upper GI endoscopy, when defined as the ability to disclose clinically significant disease, is lower in younger patients. Indeed, there is a trend towards administration of empiric therapy as an initial approach to patients below the age of 45 years and to reserve early investigation for patients suspected of having serious disease and for patients with persistent or recurrent dyspeptic complaints 16,27,28,34,42-46. Advocates of this strategy are supported by the fact that oesophageal and gastric cancers are rarely found in patients under 45 years of age 16,32,34. Following this strategy, many patients with oesophagitis or peptic ulcer disease would still be diagnosed at a later date because of symptom recurrence; there is no firm evidence that patients with acid-related diseases have a higher complication rate when endoscopy is delayed several weeks in favour of empiric treatment ${ }^{47}$.

On the other hand, the importance of a normal endoscopic investigation in patients with fear of malignancy, which is a major determinant for consulting in dyspepsia ${ }^{48}$, should not be underestimated. The majority of patients are reassured by a normal endoscopy, resulting in fewer symptoms, avoidance of unnecessary treatment and a decreased consultation rate ${ }^{12.32 .49}$. Therefore, more than two-thirds of the normal endoscopic investigations influence patient management ${ }^{37}$.

In conclusion, in view of the literature and of our own data, there is no reason to reconsider the availability of open access endoscopy services for GPs and specialists. It still seems sensible to treat patients with dyspepsia and without alarm symptoms by a limited course of acid-reducing therapy, provided that they are seen for re-evaluation within six weeks. Patients with insufficient therapeutic response or recurrent symptoms should be promptly referred for endoscopy together with those with alarm symptoms. In this context, first symptoms in patients aged above 45 years should be regarded as alarm symptoms per se. Obviously, only the referring doctor is able to assess the value of documenting a normal endoscopic finding in his symptomatic patient, which can be either reassuring or a reason for further investigation. The endoscopist should, therefore, not interfere unnecessarily with the management strategy of the referring GP or specialist. 


\section{References}

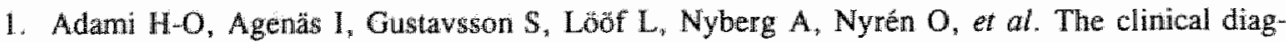
nosis of 'gastritis'. Aspects of demographic epidemiology and health care consumption based on a nationwide sample survey. Scand J Gastroenterol 1984; 19: 216-219.

2. Jones $\mathrm{R}$, Lydeard $\mathrm{S}$. Prevalence of symptoms of dyspepsia in the community. Br Med J 1989 ; 298: $30-32$.

3. Jones R, Lydeard S. Dyspepsia in the community: a follow-up study. Br J Clin Pract 1992; 26 (2): $95-97$

4. Kagevi $I$, Löfstedt $S$, Persson $L-G$. Endoscopic findings and diagnoses in unselected dyspeptic patients at a primary health care center. Scand J Gastroenterol $1989 ; 24$ : 145-150.

5. Fisher JA, Surridge JG, Vartan CP, Loehry CA. Upper gastrointestinal endoscopy - a GP service. Br Med J 1977; 2: 1199-1201.

6. Holdstack $G$, Wiseman $M$, Loehry $C A$. Open-access endoscopy service for general practitioners. $\mathrm{Br} \mathrm{Med} \mathrm{J} \mathrm{1979;} \mathrm{1:} \mathrm{457-459.}$

7. Gear MWL, Barnes RJ. Endoscopic studies of dyspepsia in a general practice. $\mathrm{Br}$ Med $J 1980$; 280: $1136-1137$.

8. Gear MWL, Ormiston MC, Barnes RJ, Rocyn-Jones J, Voss GC. Endoscopic studies of dyspepsia in the community: an "open-access" service. Br Med $J$ 1980; 280: 1135.

9. Jones $\mathrm{R}$. Upper gastrointestinal endoscopy - a view from general practice. $J R$ Coll Gen Pract $1986 ; 36: 6-8$.

10. Hungin AS. Use of an open-access gastroscopy service by a general practice: findings and subsequent referral rate. $J R$ Coll Gen Pract 1987; 37: 170-171.

11. Gear MWL, Barnes RJ, Rocyn-Jones $J$, Voss GC, Wilkinson SP. The Gloucester general practitioner open-access endoscopy service. [Abstract] Postgraduate Medical Journal 1988; 64 Suppl 1: 78 .

12. Gear MWL, Wilkinson SP. Open-access upper alimentary endoscopy. Br J Hosp Med 1989; 41: $438-444$.

13. Scott B, Atkinson M. Gastroenteralogy services: a regionall review of changes over a five year period (1981-86). Gut 1989; 30: 695-700.

14. Working Party of the Clinical Services Committee of the British Society of Gastroenterology. Provision of gastrointestinal endoscopy and related services for a district general hospital. Gut $1991 ; 32 ; 95-105$.

15. Bramble MG. Open access endoscopy - a nationwide survey of current practice. Gut 1992; 33 : 282-285.

16. Willians $B$, Luckas $M$, Ellingham JHM, Dain A, Wicks ACB. Do young patients with dyspepsia need investigation? Lancet 1988; II: 1349-1351.

1.7. Holdstock GE. Open-access endoscopy. Br Med J 1980; 281: 1617.

18. Holdstock G, Bruce S. Endoscopy and gastric cancer. Gut 1981; 22: 673-676.

19. Jones R. Open access endoscopy. Br Med J 1985; $291: 424-426$.

20. Lobo A, Dickinson R. Managing the dyspeptic patient: experience of a single-visit dyspepsia clinic. I $R$ Soc Med 1988; 81: 212-213.

21. Mamn $J$, Holdstock $G$, Harman $M$, Machin D, Loehry CA. Scoring system to improve cost effectiveness of open access endoscopy. $\mathrm{Br} \mathrm{Med} J$ 1983; 287: 937-940.

22. Davenport PM, Morgan AG, Damborough A, De Dombal FT. Can preliminary screening of dyspeptic patients allow more effective use of investigational techniques? $\mathrm{Br}$ Med J 1985; 290 : 217-220.

23. Sutton GC. Can preliminary screening of dyspeptic patients allow more effective use of investigational techniques? $\mathrm{Br}$ Med $J$ 1985; 290: 553-554. 
24. Holdstock $G$, Harman M, Machin D, Patel C, Lloyd RS. Prospective testing of a scoring system designed to improve case selection for upper gastrointestinal investigation. Gastroenterology 1986; 90: 1164-1169.

25. Venables C. Endoscopy: Its diagnostic role in dyspepsia. Scond J Gastroenteral 1988; 23 Suppl 155: 44-49.

26. Scott B. Endoscopic demands in the 90 's. Gut 1990; 31: 125-126.

27. Kahn KL, Greenfield S. The efficacy of endoscopy in the evaluation of dyspepsia. A review of the literature and development of a sound strategy. J Clin Gastroenterol 1986, 8 (3): 346-358.

28. Brown C, Rees WDW. Dyspepsia in general practice. Try empirical treatment first and investigate patients who do not respond. $\operatorname{Br} M e d J$ 1990; 300: 829-830.

29. Bramble $\mathrm{MG}_{x}$ Cooke WM, Corbett WA, Cann PA, Clarke D, Contractor B, et al. Organising unrestricted open access gastroscopy in South Tees. Gut 1993; 34: 422 427 .

30. Savary M, Miller G. The esophagus - handbook and atlas of endoscopy. Solothurn: Verlag Gassmann AG; 1977.

31. Edenholm $M$, Gustavsson $\mathbb{R}$, Jansson $O$, Lingfors $H$, Nilsson $O$, Söderlind $T$, et al. Endoscopic findings in patients with ulcer-like dyspepsia. Scand $J$ Gastroenterol 1985; 20 Suppl 109: 163-167.

32. Hansen JM, Bytzer P, Bondesen S, Schaffalitzky de Muckadell OB. Efficacy and outcome of an open access endoscopy service. Dan Med Bull 1991; 38: 288-290.

33. Kerrigan DD, Brown SR, Hutchinson GH. Open access gastroscopy: Too much to swallow? Br Med J 1990; 300: 374-376.

34. Fjesne U, Kleveland PM, Waldum $H$, Halvorsen $T$, Petersen $H$. The clinical benefit of routine upper gastrointestinall endoscopy. Scand $J$ Gastroenterol 1986; 21: 433-440.

35. Beawis AK, La Brooy S, Misiewicz JJ. Evaluation of one-visit endoscopic clinic for patients with dyspepsia. $\mathrm{Br}$ Med J 1979; 1: 1387-1389.

36. Allum WH, Oakland DI. The detection of premalignant histology in patients with dyspepsia. European Journal of Surgical Oncology 1985; 11: 25-26.

37. Naji SA, Brunt PW, Hagen S, Mowat NAG, Russell IT, Sinclair TS, et al. Improving the selection of patients for upper gastrointestinal endoscopy. Gut 1993; 34: 187 191 .

38. Overholt BF, Hargrove RL, Farris RK, Porter FR. Primary panendoscopy. Gastrointest Endosc $1987 ; 33: 1-3$.

39. Bramble MG, Cann PA. Open access gastroscopy. Br Med $J$ 1990; 300: 749-750.

40. Mead GM, Morris A, Webster GK, Langman MJS. Uses of barium theal examination in dyspeptic patients under 50. Br Med J 1977; 1: 1460-1461.

41. Marton $\mathrm{KI}$, Sox HC, Wasson J, Duisenberg CE. The clinical value of the upper gastrointestinal tract roentgenogram series. Arch Imtern Med 1980; 140: 191-195.

42. Goodson JD, Lehmann JW, Colditz GA, Atamian $S_{*}$ Hall D, Peltier-Saxe D, et al. The diagnostic value of upper gastrointestinal radiography. J Clin Gastroenterol 1990; 12 (2): 140. 144.

43. Jones R. Investigating patients with dyspepsia. The Practitioner 1987; 231: 155-160.

44. Conry BG, McLean AM, Farthing MJG. Diagnostic and therapeutic efficacy of barium mea! examination: a prospective evaluation in general practice. Br Med J 1989; 299: 1443-1445.

45. Johnsen R. Endoscopy: Why and when. Scand J Prim Health Care 1990; 8: 187-190.

46. Nyrén $O$. Therapeutic trial in dyspepsia: Its role in the primary care setting. Scand $\mathbb{J}$ Gastroenterol 1991; 26 Suppl 182: 61-69.

47. Schiller LR, Fordtran JS. Ulcer complications during short-term therapy of duodenal ulcer with active agents and placebo. Gastroenterology 1986; 90: 478-481.

48. Lydeard $S$, Jones R. Factors affecting the decision to consult with dyspepsia: comparison of consulters and non-consulters. J R Coll Gen Pract 1989; 39: 495-498. 
49. Jones $\mathrm{R}$. What happens to patients with non-ulcer dyspepsia after endoscopy? The Practitioner 1988; 232: 75-78. 


\section{Appropriateness of indications for diagnostic upper gastrointestinal endoscopy: association with relevant endoscopic disease}

Gastrointest Endosc 1995; 41: xx.

R.P. Adang, F.-J.F.E. Vismans, J.L. Talmon, A. Hasman, A.W. Ambergen, R.W. Stockbrügger 



\section{Abstract}

Since the institution of open access endoscopy units there has been a considerable increase of referrals for upper gastrointestinal examinations. Therefore, guidelines for the appropriate use of upper gastrointestinal endoscopy are needed. The outcome of first diagnostic upper gastrointestinal endoscopy was prospectively assessed for several referral indications in a consecutive series of 2900 patients. Indications were judged 'appropriate' when significantly $(p<0.01)$ associated with clinically 'relevant' endoscopic findings. The proportion of relevant disease for various indications was: signs of upper gastrointestinal bleeding (42.2\%); history of peptic ulcer (40.5\%); dysphagia (34.4\%); anorexia and weight loss (34.3\%); isolated dyspepsia with long-term (31.9\%), short-term (24.4\%), and without therapy (20.9\%). Relevant endoscopic findings were observed in $21.0 \%$ of dyspeptic patients aged 45 years or less, and in $25.3 \%$ of those above 45 years of age.

In summary, the generally approved alarm symptoms should be a reason to perform endoscopy without hesitation. Dyspeptic symptoms despite adequate empiric treatment as well as first dyspeptic symptoms in patients older than 45 years should also be a reason for endoscopic investigation. Our results support the strategy to treat patients younger than 45 years who have isolated dyspepsia by a limited course of anti-peptic agents, provided that they are seen for re-evaluation within four to six weeks.

\section{Introduction}

During the past two decades, the number of upper gastrointestinal (GI) endoscopic investigations being performed has increased, especially since open access services have become available to general practitioners (GPs) ${ }^{1-5}$. In many centres, this has resulted in long waiting lists ${ }^{6.7}$. Dyspeptic complaints, which have a high prevalence and incidence in the population, are the most frequent reason for requesting an endoscopy ${ }^{8,9}$.

Guidelines for the appropriate use of upper GI endoscopy may result in a more rational selection of patients ${ }^{10.11}$. In this context, a patient age of 45 years has been proposed as a cut-off point in regard to the question of whether or not to investigate dyspepsia as an isolated symptom ${ }^{7,12,13}$. Selection of dyspeptic patients for upper GI endoscopy, however, cannot be separated from the timing of this procedure; either initial endoscopy followed by rational therapy, or empiric medical treatment followed by endoscopy when needed ${ }^{14,15}$.

The aims of the present study were 1) to examine whether 'alarm symptoms' are associated with the endoscopic demonstration of serious disease; 2) to compare the outcome of endoscopy in dyspeptic patients aged 45 years or less to that in patients more than 45 years of age who have dyspepsia; and 3) to compare the yield of 
initial endoscopy to that of endoscopy after a trial of medical therapy for dyspeptic patients.

\section{Methods of data acquisition}

The study was performed between January 1989 and October 1990 at an endoscopy unit providing an unrestricted open access service to hospital specialists and GPs ${ }^{6}$. All 2900 patients referred for a diagnostic upper GI endoscopy were included; patients who were undergoing a follow-up investigation or an elective therapeutic endoscopy were excluded from the study. Data were prospectively collected in a consistent and uniform manner using a standardised study form. The methods of data acquisition have been extensively described in Chapter II and, therefore, will be only briefly reviewed in the next paragraphs.

\section{STRUCTURED REQUEST FORM}

The reason(s) for requesting an endoscopy were given on structured request forms, which were jointly used by hospital specialists and GPs. This information was interpreted by the endoscopist and transferred onto the study form, which contains a list of predetermined referral indications. Indications not given on the request form were considered to be absent.

Dyspepsia was defined as episodic or persistent upper abdominal pain and/or discomfort considered to be attributable to the proximal alimentary tract ${ }^{16-18}$. In this study, retrosternal pain was evaluated apart from the other dyspeptic complaints. A history of peptic ulcer was recorded separately, as we wanted to determine any association with present peptic disease. Signs of upper GI bleeding, anorexia and weight loss, and dysphagia were considered to be 'alarm symptoms'. Upper GI bleeding can be divided into two categories: (1) active haemorrhage manifested as haematemesis and/or melaena, and (2) chronic bleeding occurring during weeks or months, with the manifestations of stool positive for occult blood and/or iron deficiency anaemia. According to the definitions used in this study, patients referred because of haematemesis and/or melaena either presented with these signs of acute bleeding or had a recent history of them. Follow-up after abnormal findings on barium meal examination could also be a reason for requesting an endoscopy. The reasons for referral were recorded for all patients included. Each patient could have more than one referral indication.

\section{SHORT PRE-ENDOSCOPIC INTERVIEW}

Before the endoscopy was carried out, patients $(n=2843 ; 98.0 \%)$ were asked by the endoscopist whether retrosternal or abdominal pain had been a reason for consultation and subsequent referral. Pain localisations were recorded on the study form, which contains an illustration of the abdomen divided into nine parts by two horizontal and two vertical lines ${ }^{19}$. Patients $(\mathrm{n}=2850 ; 98.3 \%)$ were also asked whether 
they used ulcerogenic drugs, such as non-steroidal anti-inflammatory drugs (NSAIDs) or steroids, and whether they had been taking 'anti-peptic agents", such as $\mathrm{H}_{2}$ receptor antagonists, antacids, cytoprotective drugs, or prokinetic agents. For each of these drugs, the duration of treatment was recorded as less than six weeks, six weeks to one year, or more than one year. Empiric medical therapy for less than six weeks was classified as short-term treatment. Whenever an anti-peptic agent was continued for more than six weeks, it was considered as long-term treatment. In a limited number of patients, the interview could not be conducted because of more or less severe mental or physical disability.

\section{ENDOSCOPIC EXAMINATION}

Endoscopic examination was carried out using standard forward-viewing tibreoptic endoscopes by experienced gastroenterologists/internists $(n=9)$ or by trainees in gastroenterology/internal medicine $(n=5)$, the latter under supervision of an experienced endoscopist. Only endoscopic diagnoses were considered; additional histopathologic findings were not taken into account. The diagnosis of oesophageal or gastric cancer was thus based on the presence of endoscopic features traditionally suggestive of malignancy. Oesophagitis was diagnosed according to criteria of Savary and Miller ${ }^{20}$. In the absence of endoscopic stigmata of malignancy, ulcers in the stomach were classified as benign.

Almost all of the patients included $(n=2817 ; 97.1 \%)$ had a complete upper GI endoscopy. In the remaining patients, the examination was limited to the oesophagus and stomach $(n=24 ; 0.8 \%)$ or to the oesophagus $(n=24 ; 0.8 \%)$, or introduction of the endoscope was not possible $(n=35 ; 1.2 \%)$.

\section{CRITERIA OF EVALUATION AND STATISTICAL ANALYSES}

Endoscopic diagnoses that usually have direct therapeutic and/or prognostic consequences were classified as 'relevant', i.e. oesophagitis, peptic ulcers, and cancers. For the purpose of this study, indications were judged 'appropriate' if they turned out to be significantly associated with the demonstration of relevant endoscopic disease.

In order to assess this association, patients with a certain symptom or referral indication were compared with those not having such symptom or indication in regard to the prevalence of relevant endoscopic findings. The two-samples t-test and Chi-squared test with continuity correction were used to test differences between groups. Differences with a p-value of less than 0.01 were considered statistically significant. 
Table 1 The referral indications in the study population.

\begin{tabular}{lrc}
\hline REFERRAL INDICATIONS & \multicolumn{2}{c}{ Number of patients $(\%){ }^{\prime}$} \\
\hline Dyspepsia & 1562 & $(53.9)$ \\
Retrosternal pain & 263 & $(9.1)$ \\
Previous peptic ulcer & 168 & $(5.8)$ \\
Haematemesis & 226 & $(7.8)$ \\
Melaena & 164 & $(5.7)$ \\
Faecal occult blood & 23 & $(0.8)$ \\
Iron deficiency anaemia & 155 & $(5.3)$ \\
Anorexia and weight loss & 143 & $(4.9)$ \\
Dysphagia & 183 & $(6.3)$ \\
Abnormal upper GI X-ray & 30 & $(1.0)$ \\
Other referral indications & 368 & $(12.7)$ \\
\hline
\end{tabular}

1 Total number exceeds $2900(100 \%)$, as some patients thad multiple referral indications.

Table II The pain localisations in the study population.

\begin{tabular}{lrc}
\hline PAIN LOCALISATIONS & \multicolumn{2}{c}{ Number of patients (\%) ${ }^{1}$} \\
\hline No pain & 1006 & $(35.4)$ \\
Retrosternal & 426 & $(15.0)$ \\
Epigastric & 1340 & $(47.1)$ \\
Right upper abdomen & 131 & $(4.6)$ \\
Left upper abdomen & 97 & $(3.4)$ \\
Umbilical & 31 & $(1.1)$ \\
Right mid abdomen & 14 & $(0.5)$ \\
Left mid sbdomen & 8 & $(0.3)$ \\
Mid lower abdomen & 30 & $(1.1)$ \\
Right lower abdomen & 21 & $(0.7)$ \\
Left lower abdomen & 14 & $(0.5)$ \\
\hline
\end{tabular}

Total number exceeds $2843(100 \%)$, as some patients had multiple pain localisations. 


\section{Results}

\section{STUDY POPULATION}

The study population consisted of 1522 men $(52.5 \%)$ and 1378 women $(47.5 \%)$, with a mean age of 56 years ( $S D=17.6$ years; range $3-96$ years). The local GPs referred 1205 patients $(41.6 \%)$; the remaining $1695(58.4 \%)$ were referred as hospital in- or outpatients.

Dyspeptic symptoms were by far the most frequent reason for performing an endoscopic examination; dyspepsia was a referral indication in 1562 patients (54\%, Table I), and in 1344 patients ( $46 \%$ ) it was the only indication. Retrosternal pain was a reason for doing an endoscopy in $9 \%$ of the patients. Six percent of the referralls had a history of peptic ulcer disease. Signs of upper GI bleeding were as a whole present in $18 \%$ of the endoscopy population. Anorexia and weight loss and dysphagia, other alarm symptoms, occurred in $5 \%$ and $6 \%$ respectively. Only $1 \%$ of the endoscopic investigations were performed as follow-up after abnormal findings on barium meal examination. In $13 \%$ of the patients, upper GI endoscopy was performed for other, not separately recorded, indications.

Almost $50 \%$ of the patients had epigastric pain, whereas $35 \%$ did not have any pain at all (Table II). Retrosternal pain was reported by $15 \%$. The other pain localisations occurred in limited numbers of patients.

More than one-third of the patients $(n=1043)$ had been empirically treated with an anti-peptic agent before referral for endoscopy. Of these patients, 67\% $(n=700)$ had short-term therapy and $33 \%(n=343)$ long-term therapy (Table III). The majority of the patients with anti-peptic treatment had been taking $\mathrm{H}_{2}$ receptor antagonists $(\mathrm{n}=847 ; 81 \%)$.

Table III Drug regimens in the study population.

\begin{tabular}{|c|c|c|c|c|c|}
\hline \multirow{3}{*}{$\begin{array}{l}\text { DRUG TREATMENT } \\
\text { Anti-peptic therapy }\end{array}$} & \multicolumn{3}{|c|}{ Duration of treatment } & \multirow{2}{*}{\multicolumn{2}{|c|}{$\begin{array}{l}\text { Number of } \\
\text { patients }(\%)\end{array}$}} \\
\hline & \multirow{2}{*}{$\frac{<6 \text { woeks }}{700}$} & \multirow{2}{*}{$\frac{6 \text { weeks - I year }}{213}$} & \multirow{2}{*}{$\frac{>1 \text { year }}{130}$} & & \\
\hline & & & & 1043 & $(36.6)$ \\
\hline $\mathrm{H}_{2}$ receptor antagonists ${ }^{2}$ & 546 & 185 & 116 & 847 & $(29.7)$ \\
\hline Antacids & 119 & 25 & 15 & 159 & (5.6) \\
\hline Cyloprotective drugs & 91 & 12 & 3 & 106 & (3.7) \\
\hline Prokinetic agents & 62 & 13 & 3 & 78 & $(2.7)$ \\
\hline NSAIDs & 91 & 92 & 48 & 231 & $(8.1)$ \\
\hline Steroids & 16 & 24 & 23 & 63 & $(2.2)$ \\
\hline
\end{tabular}

${ }^{1}$ Percentage of the patients who were interviewed concerning drug treatment $(n=2850) ;{ }^{2}$ Including proton pump inhibitors. 


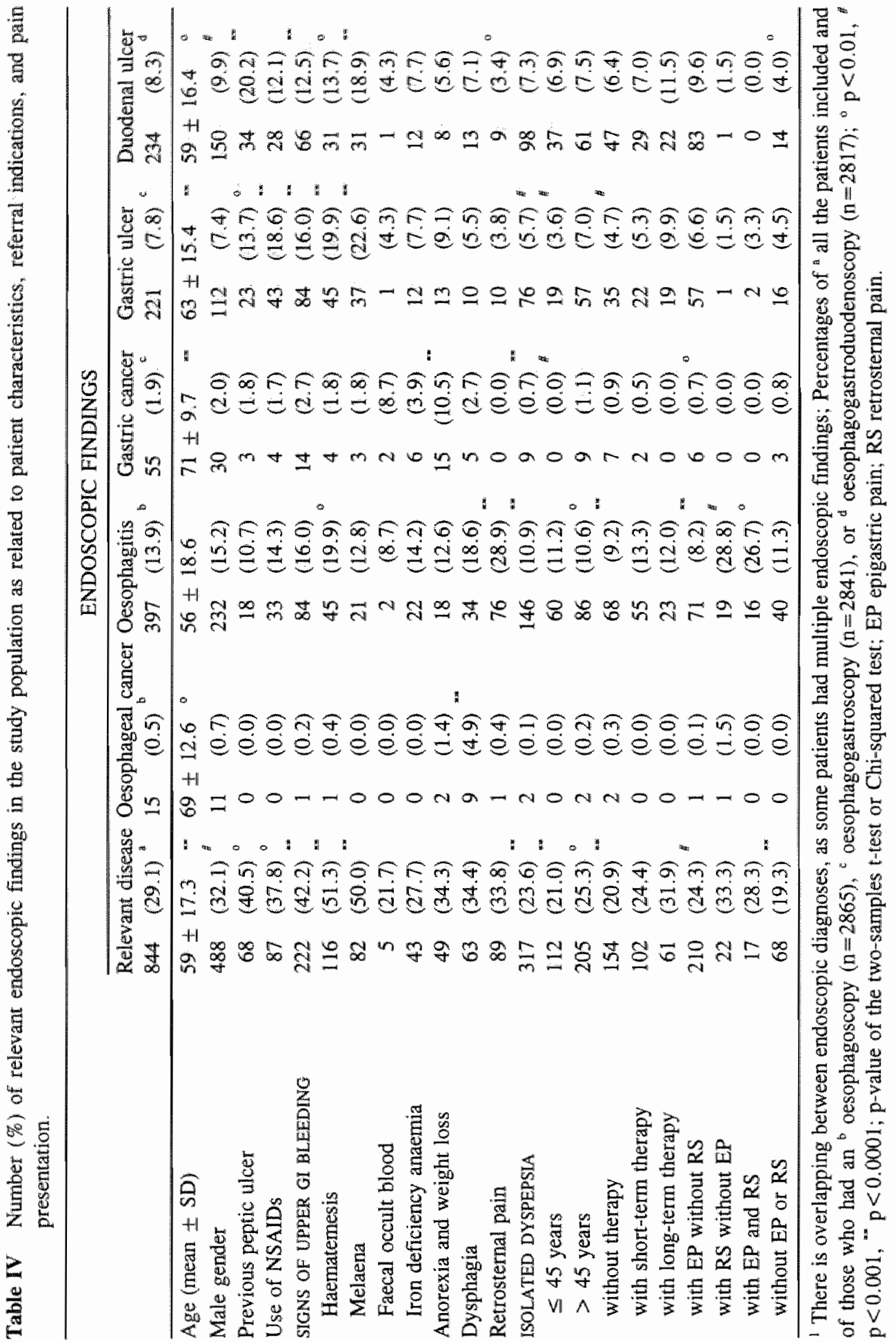




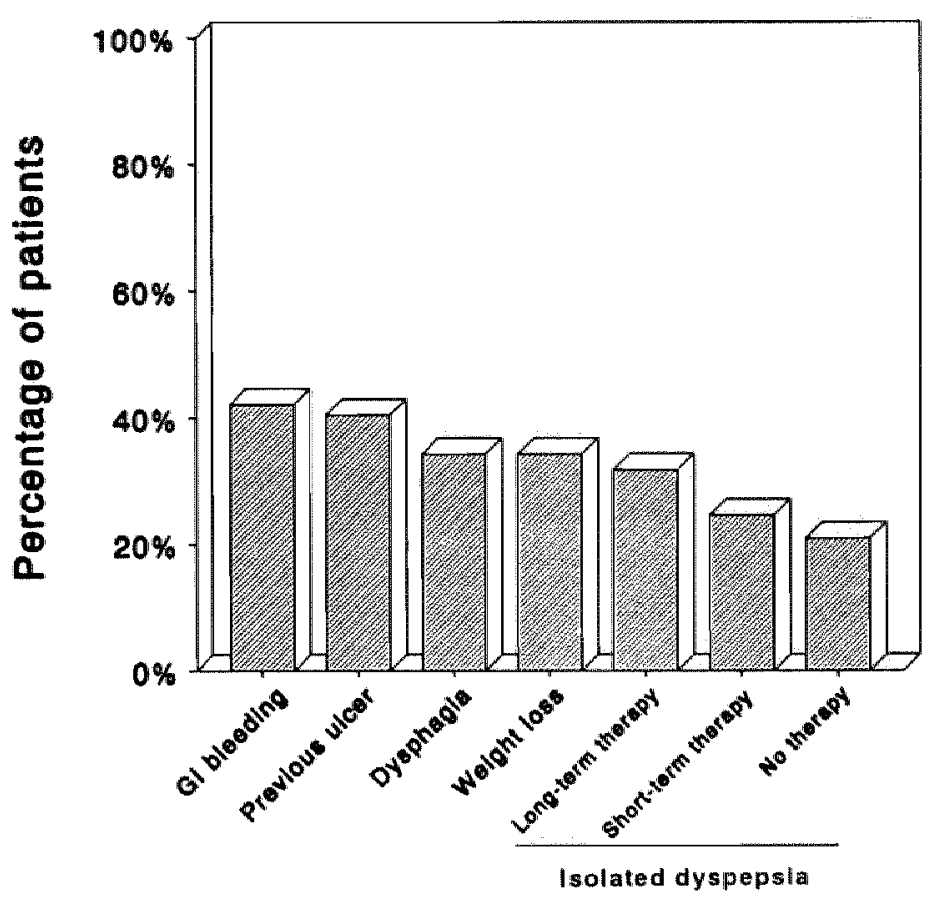

Figure I Rates of relevant endoscopic disease for several referral indications.

Findings were normal in $29.7 \%(n=838)$ of the patients who had a complete upper GI endoscopy. Relevant endoscopic disease, as defined in this study, was demonstrated in approximately $30 \%$ of the patients (Table IV). Oesophagitis was the most frequent acid-related disorder, followed by duodenal and gastric ulcers. Gastric cancer was diagnosed in $2 \%$, and in fewer than $1 \%$ of the patients the diagnosis of oesophageal cancer was made.

\section{ENDOSCOPIC YIELD IN PATIENTS WITH 'ALARM SYMPTOMS'}

The yield of upper GI endoscopy was the highest in patients referred because of signs of upper GI bleeding, with a more than $40 \%$ rate of relevant endoscopic findings in this group of patients (Table IV, Figure I). Particularly, the manifestations of active GI bleeding were significantly associated with acid-related disorders, such as oesophagitis and peptic ulcers. When analysed separately, the signs of chronic GI blood loss were not significantly related to any relevant finding.

The proportion of relevant findings was about one-third in patients with anorexia and weight loss and in those with dysphagia (Table IV, Figure I). Gastric cancer was significantly more often diagnosed in patients referred because of anorexia and 
weight loss than in the remaining patients, and oesophageal cancer was significantly associated with dysphagia.

Although a history of peptic ulcer and NSAID use are not alarm symptoms, it must be stressed here that of patients with these factors, relevant endoscopic disease could be found in a considerable percentage (Table IV, Figure I). A history of peptic ulcer was significantly related to present peptic disease: $14 \%$ had a gastric ulcer and $20 \%$ had a duodenal ulcer. The use of NSAIDs was significantly associated with the demonstration of gastric ullcers: $19 \%$ of those taking NSAIDs had gastric ulcers, irrespective of other symptoms or referral indications.

\section{ENDOSCOPIC YIELD IN PATIENTS WITH DYSPEPSIA AS AN ISOLATED SYMPTOM}

Of the patients with dyspepsia as an isolated symptom $(\mathrm{n}=1344), 31 \%$ had been taking anti-peptic agents for less than six weeks, $9 \%$ during a period of six weeks to one year, and $5 \%$ for more than one year. The remaining 735 patients $(55 \%)$ had not been treated before endoscopy (Table V). Forty percent $(n=534)$ were 45 years of age or less, and $60 \%(n=810)$ were more than 45 years of age. Epigastric pain was reported by $64 \%(n=865), 5 \%$ reported retrosternal pain $(n=66)$, and $4 \%$ reported both epigastric and retrosternal pain $(n=60)$. More than $25 \%(n=353)$ did not report any epigastric or retrosternal pain during the pre-endoscopic interview.

Clinically significant endoscopic disease was demonstrated in fewer than $25 \%$ of the patients referred because of isolated dyspepsia (Table IV); oesophagitis (11\%), gastric ulcer $(6 \%)$, and gastric cancer $(0.7 \%)$ were less often diagnosed in this category of patients than in those with other referral indications.

Endoscopic findings related to patient age: of the dyspeptic patients aged 45 years or less, $21 \%$ had relevant endoscopic disease, whereas $25 \%$ of those older than $\mathbf{4 5}$ years had clinically significant findings (Table IV).

Table $\mathbf{V}$ Number (\%) of relevant endoscopic findings (printed in italics) in 1344 patients with dyspepsia as an isolated symptom as related to patient age and prior drug treatment.

\begin{tabular}{|c|c|c|c|c|c|c|c|}
\hline \multicolumn{2}{|c|}{ PATIENT AGE } & \multicolumn{6}{|c|}{ DRUG TREATMENT } \\
\hline & & \multicolumn{2}{|c|}{ No therapy } & \multicolumn{2}{|c|}{ Short-term therapy } & \multicolumn{2}{|c|}{ Long-term therapy } \\
\hline & & 735 & $(54.7)$ & 418 & $(31,1)$ & 191 & $(14.2)$ \\
\hline \multirow[t]{2}{*}{$>45$ years } & $810(60.3)$ & 476 & & 204 & & 130 & \\
\hline & & 108 & $(22.7)$ & 58 & $(28.4)$ & 39 & $(30.0)$ \\
\hline \multirow[t]{2}{*}{$\$ 45$ years } & $534(39.7)$ & 259 & & 214 & & $6 \mathbb{1}$ & \\
\hline & & 46 & $(17.8)$ & 44 & $(20.6)$ & 22 & $(36.1)$ \\
\hline
\end{tabular}


Endoscopic findings related to prior treatment: the proportion of relevant findings was $21 \%$ in dyspeptic patients who had initial endoscopy, $24 \%$ in those with short-term therapy, and $32 \%$ in those with long-term therapy (Table IV, Figure 1). Oesophagitis $(9 \%)$ and gastric ulcers $(5 \%)$, but not duodenal ulcers $(6 \%)$, were found significantly less often in patients with dyspepsia who had an initial endoscopy than in the remaining patients undergoing endoscopy.

Endoscopic findings related to patient age and prior treatment: in dyspeptic patients aged 45 years or less, the percentage of relevant disease was $18 \%$ in those without empiric treatment and $36 \%$ in those with long-term treatment (Table V). In the age group of more than 45 years, those percentages were $23 \%$ and $30 \%$ respectively.

Endoscopic findings related to pain presentation: the presence of retrosternal pain was positively associated with the finding of oesophagitis, whether or not epigastric pain was also present $(27 \%$ and $29 \%$, respectively, Table IV). On the other hand, epigastric pain (without retrosternal pain) was negatively associated with the finding of oesophagitis $(8 \%)$, and also of gastric cancer $(0.7 \%)$. Whereas the proportion of relevant disease was less than $20 \%$ in those who had neither epigastric nor retrosternal pain, it was $24 \%$ in those with epigastric pain (without retrosternal pain) and $33 \%$ in those with retrosternal pain (without epigastric pain).

The relationship between retrosternal pain and oesophagitis was also observed in the whole study population: in almost $30 \%$ of the patients with retrosternal pain as a referral indication, oesophagitis was diagnosed at endoscopy (Table IV).

\section{Discussion}

In this study, the appropriateness of indications for diagnostic upper GI endoscopy has been evaluated by assessing their association with 'relevant' disease, i.e. endoscopic findings generally considered to have direct therapeutic and/or prognostic consequences.

We found that generally recognised 'alarm symptoms' are indeed associated with the demonstration of relevant endoscopic disease, such as manifestations of active upper GI bleeding with acid-related disorders, anorexia and weight loss with gastric cancer, and dysphagia with oesophageal cancer. By contrast, the yield of endoscopy is rather low in patients referred because of isolated dyspepsia, particularly in those younger than 45 years, in those who have not been empirically treated, and in those who do not report epigastric or retrosternal pain.

The approach in this study differs from that in some previous studies, gathering a panel of experts to rate more or less detailed indications for upper GI endoscopy. In 1984, the RAND/UCLA Health Services Utilization (RAND) Study was the first to assess the appropriateness of indications for diagnostic upper GI endoscopy in a large patient population. The results were based on detailed literature studies and an analysis of 1069 clinical scenarios for diagnostic upper GI endoscopy, using a 
modified Delphi technique ${ }^{21.22}$. In 1985, the Standards of Training and Practice Committee of the American Society for Gastrointestinal Endoscopy (ASGE) rated 38 indications for upper GI endoscopy based on critical review of the available literature, committee discussion and interchange, and expert input ${ }^{23}$. In a recently published report of the Upper Gastrointestinal Endoscopy Audit Committee ${ }^{24}$, a panel of seven gastroenterologists examined the appropriateness of indications in a consecutive series of 390 cases referred for upper GI endoscopy. The same cases were also rated by software that incorporated the RAND criteria. As Park et al. ${ }^{25}$ have demonstrated that many of the indications formulated are seldom or never used in practice, we focused on the major and most frequent indications in newly referred patients, omitting the more specific and less frequent ones.

Whereas not more than $15 \%$ of the patients were referred because of dyspeptic symptoms in the study of the RAND Corporation ${ }^{21,22}$, dyspepsia was the far most frequent reason for requesting an endoscopy in our study. This may be explained in several ways. First, the present study was performed almost ten years later than the RAND study, and more than $40 \%$ of the patients were directly referred by GPs. It has been shown that GPs more often than hospital specialists refer patients because of dyspeptic complaints rather than alarm symptoms ${ }^{26}$. Secondly, the RAND study did not exclude repeat investigations and evaluated only endoscopic examinations performed in patients older than 65 years. Older patients, however, are referred more often because of alarm symptoms and less often because of dyspepsia than are younger patients ${ }^{26}$.

In this study, the prevalence of clinically relevant endoscopic disease was about $30 \%$, similar to what others have found ${ }^{1,7,27-32}$, with oesophagitis $(14 \%)$, duodenal ulcer $(8 \%)$, and gastric ulcer $(8 \%)$ being the most frequent findings.

As in other surveys, age was an important determining factor for the diagnostic yield of upper GI endoscopy. Patients with oesophageal or gastric cancer had the highest mean ages, and in accordance with previous studies ${ }^{1.7 .27-32}$, we found no malignant disorders in patients under 45 years of age.

Relevant findings were observed significantly more often in men than in women; particularly, duodenal ulcers were found in $10 \%$ of the men but in only $6 \%$ of the women.

As has been demonstrated by others ${ }^{33}$, a history and/or signs of haematemesis and melaena were significantly associated with the detection of peptic ulcers, and they should therefore be a reason to perform an endoscopy without hesitation. This corresponds with the recommendations of the RAND Corporation ${ }^{21.22}$ and of the ASGE ${ }^{2.3}$. As in the RAND study ${ }^{21,22}$, about $6 \%$ of the patients were referred because of signs of chronic GI bleeding. In contrast to the manifestations of active GI haemorrhage, these were not significantly associated with the demonstration of relevant endoscopic disease. Like others ${ }^{34}$, we found peptic ulcers to be the most common relevant lesions identified in the upper GI tract of patients with iron deficiency anaemia. 
In more than $10 \%$ of the patients with anorexia and weight loss, gastric cancer was diagnosed. On the other hand, gastric cancer was rarely diagnosed in patients with isolated dyspepsia, whether they reported epigastric pain or not. The presence of anorexia and weight loss therefore seems to be an adequate reason to perform upper GI endoscopy, even in the absence of dyspeptic complaints.

Of the 15 patients with oesophageal cancer, $60 \%$ presented with dysphagia. Although these nine patients constituted only $5 \%$ of all patients investigated because of dysphagia, endoscopy is certainly indicated in patients with symptoms of upper GI tract obstruction ${ }^{23}$.

A history of previous ulcer disease and recent use of NSAIDs were related to the demonstration of peptic ulcers; this should be considered in the management of a dyspeptic patient.

Recommendations regarding the appropriate use of upper GI endoscopy in cases of uncomplicated dyspepsia vary widely and are mainly based on the patient's age at onset of symptoms and on the response of symptoms to a presumably useful course of medical treatment ${ }^{24,35,36}$. In accordance with what has been suggested by others ${ }^{21,37}$, our study demonstrated that dyspepsia as an isolated symptom and without a previous attempt of medical therapy is a rather weak indication for diagnostic upper GI endoscopy. The percentage of subjects with relevant endoscopic disease in this category was $18 \%$ in patients aged 45 years or less and $23 \%$ in those more than 45 years of age. By contrast, the yield of endoscopy in patients with uncomplicated dyspeptic complaints that persisted or recurred during or after long-term empiric treatment was considerable: $36 \%$ of those 45 years or younger and $30 \%$ of those older than 45 years had one or more relevant endoscopic findings. Obviously, it is important for patients with persistent or recurrent symptoms despite anti-peptic therapy to undergo endoscopic examination, even when aged 45 years or less. The rate of relevant disease in patients with uncomplicated dyspepsia was less than $20 \%$ in those who did not report any epigastric or retrosternal pain. On the other hand, about one-third of the dyspeptic patients who had retrosternal pain appeared to have relevant disease, mostly oesophagitis.

If in this study endoscopy had not been done in patients who had dyspepsia as an isolated symptom, had no previous empiric treatment, and were 45 years of age or younger, 259 endoscopies could have been saved with the failure to discover relevant disease in 46 patients. We are aware of the fact that the definition 'relevant' vs 'irrelevant' disease is arbitrary and may differ between various health care systems. Of special interest is a recent study by Sonnenberg and Townsend ${ }^{38}$, which showed any diagnostic test with a probability of $20 \%$ to discover treatable disease to be cost-effective. In view of this and in the context of our setting, uncomplicated dyspepsia without previous empiric treatment in patients under 45 years of age should be regarded as an 'inappropriate' indication for diagnostic upper GI endoscopy.

There is no firm evidence showing that patients with peptic ulcers have a higher complication rate when endoscopy is delayed several weeks in favour of empiric 
treatment ${ }^{39}$. Cancers are rarely found in patients under 45 years, and in addition, it seems reasonable to assume that patients with gastric cancer will continue to be symptomatic or have recurrence of symptoms when medical treatment is ended ${ }^{40}$. Empiric treatment therefore seems justified in this situation. Limiting the duration of the empiric trial to six weeks prevents the chronic usage of unnecessary medication, and allows quick diagnostic pursuit in the relatively small group of patients whose symptoms have persisted despite such treatment.

Based on the literature and our own observations, it seems appropriate to refer patients with alarm symptoms for early endoscopic investigation. Newly occurring dyspeptic symptoms in patients older than 45 years and particularly dyspeptic symptoms that persist or recur during or after adequate empiric treatment should also be a reason for requesting an endoscopy, as relevant disease can be demonstrated in a considerable percentage of the patients with these indications. Our observations tend to support the strategy, proposed by others ${ }^{7,12-15,23,37,41}$, to treat patients younger than 45 years with dyspepsia as an isolated symptom by a limited course of anti-peptic agents, provided that they are seen for re-evaluation within four to six weeks.

Hitherto, little has been said about the impact that normal endoscopic findings may have on the patient and the referring doctor. The reassurance afforded by normal findings may result in fewer symptoms, avoidance of unnecessary treatment, and a decreased consultation rate ${ }^{3,27,42}$. A recent study by Naji et al. ${ }^{43}$ has shown that more than two-thirds of endoscopic investigations with normal results are likely to influence patient management, either as a basis for terminating treatment with anti-peptic agents or as a means of providing direction to further investigation. Obviously, only the referring doctor is able to assess the value of documenting a normal endoscopic linding in a symptomatic patient.

One has to realise that the criteria for appropriate use of diagnostic endoscopy as formulated in this study are based on cross-sectional data extrapolated from a consecutive series of cases in a referral setting; thereby, comparison with other criteria, for example those formulated by the RAND Corporation or the ASGE, is difficult. Mai et al. ${ }^{44}$ demonstrated that adherence to the guidelines of the ASGE decreased the inappropriate use of upper Gl endoscopy. Whether this is also true for the criteria outlined in this study has to be evaluated in future studies. 


\section{References}

1. Jones $R$. Upper gastrointestinal endoscopy - a view from general practice. I $R$ Coll Gen Pract 1986; 36: 6-8.

2. Hungin AS. Use of an open-access gastroscopy service by a general practice: findings and subsequent referral rate. J R Call Gen Pract 1987; 37: 170-171.

3. Gear MWL, Wikinson SP. Open-access upper alimentary endoscopy. Br J Hosp Med 1989; 41: 438-444.

4. Scott B. Atkinson M. Gastroenterology services: a regional review of changes over a five year period (1981-86). Gut 1989; 30: 695-700.

5. Working Party of the Clinical Services Committee of the British Society of Gastroenterology. Provision of gastrointestinal endoscopy and related services for a district general hospital. Gut $1991 ; 32: 95-105$.

6. Bramble MG. Open access endoscopy - a nationwide survey of current practice. Gut 1992; 33 : 282-285.

7. Williams. B, Luckas M, Ellingham JHM, Dain A, Wicks ACB. Do young patients with dyspepsia need investigation? Lancet 1988; II: 1349-1351.

8. Jones RH, Lydeard SE, Hobbs FDR, et a!. Dyspepsia in England and Scotland. Gut 1990; 31: 401 -405.

9. Jones R, Lydeard S. Dyspepsia in the community: a follow-up study. Br J Clin Pract 1992; 26 (2): $95-97$.

10. Morrissey IF. The problem of the inappropriate endoscopy. Ann Intern Med 1988; 109: 605606.

11. Jones $\mathbb{R}$. When is endoscopy appropriate in dyspepsia? Am J Gastroenterol 1993; 88: 981-982.

12. Jones R. Investigating patients with dyspepsia. The Practitioner 1987; 231: 155-160.

13. Johnsen R. Endoscopy: Why and when. Scand I Prim Health Care 1990; 8: 187-190.

14. Brown $C$, Rees WDW. Dyspepsia in general practice. Try enpirical treatment first and investigate patients who do not respond. $\mathrm{Br}$ Med $J$ 1990; 300: 829-830.

15. Nyrén $O$. Therapeutic trial in dyspepsia: Its role in the primary care setting. Scand J Gastroenterol 1991; 26 Suppl 182: 61-69.

16. Colin-Jones DG, Bloom B, Bodemar G, Crean G, Freston J, Gugler R, et al. Management of dyspepsia: report of a working party. Lancet 1988; I: $576-579$.

17. Barbara L, Camilleri $\mathrm{M}$, Corinaldesi $\mathrm{K}$, et al. Definition and investigation of dyspepsia. Consensus of an international ad hoc working party. Dig Dis Sci 1989; 34: 1272-1276.

18. Heading RC. Definitions of dyspepsia. Scand J Gastroenrerol 1991; 26 Suppl 182: 1-6.

19. Kang JY, Tay HH, Guan R. Chronic upper abdominal pain: Site and radiation un various structural and functional disorders and the effect of various foods. Gut 1992; 33: 743 748.

20. Savary M, Miller G. The esophagus - Handbook and atlas of endoscopy. Solothurn: Verlag Gassmam AG, 1977.

21. Kahn KL. Kosecoff J, Chassin MR, Solomon DH, Brook RH. The use and misuse of upper gastrointestinal endoscopy. Amm Intern Med 1988; 109: 664-670.

22. Kahn KL, Roth CP, Kosecoff J, et al. Indications for selected medical and surgical procedures - A literature review and ratings of appropriateness. Diagnostic upper gastrointestinal endoscopy. Santa Monica, California: The RAND Corporation, May 1986.

23. Statements and guidelines developed by the Standards of Training and Practice Committee of the American Society for Gastrointestinal Endoscopy. Gastrointest Endosc 1988; 34 (3) Suppl: $1 \mathrm{~S}-40 \mathrm{~S}$.

24. Quine MA, Bell GD, MoCloy RF, Devlin HB, Hopkins A. Appropriate use of upper gastrointestinal endoscopy - a prospective audit. Gut 1994; 35: 1209-1214. 
25. Park RE, Fink A, Brook RH, et al. Physician ratings of appropriate indications for three procedures: Theoretical indications vs indications used in practice. Am J Public Healh 1989; 79: $445-447$.

26. Adang RP, Vismans JF-JFE, Talmon JL, Hasman A, Ambergen AW, Stockbrügger RW. The diagnostic outcome of upper gastrointestinal endoscopy: are referral source and patient age determining factors? Eur J Gastroenterol Hepatol 1994; 6:329-335.

27. Hansen JM, Bytzer $\mathbb{P}$, Bondesen S, Schaffalitzky de Muckadell OB. Efficacy and outcome of an open access endoscopy service. Dan Med Bull 1991; 38: 288-290.

28. Edenholm $M$, Gustavsson R, Jansson $O$, Lingfors $H$, Nilsson $O$, Söderlind $T$, Titusson $L$, Thulin A. Endoscopic findings in patients with ulcer-like dyspepsia. Scand $J$ Gastroenterol 1985; 20 Suppl 109: 163-167.

29. Allum WH, Oakland DJ. The detection of premalignant histology in patients with dyspepsia. European Journal of Surgical Oncology 1985; 11: 25-26.

30. Davenport PM, Morgan AG, Darnborough $A_{v}$ De Dombal FT. Can preliminary screening of dyspeptic patients allow more effective use of investigational techniques? $\mathrm{Br}$ Med $J 1985 ; 290$ : $217-220$.

31. Fjosne U, Kleveland PM, Waldum $H$, Halvorsen $T$, Petersen $H$. The clinical benefit of routine upper gastrointestinal endoscopy. Scand $J$ Gastroenterol 1986; 21 : 433-440.

32. Kerrigan DD, Brown SR, Hutchinson GH. Open access gastroscopy: Too much to swallow? Br Med $J$ 1990; 300: 374-376.

33. Dolmans WMV, Mbaga IM, Mwakyusa DH. Diagnostic yield of endoscopy in upper gastrointestinal bleeding. Trop Geogr Med 1983; 35: 173-178.

34. Rockey DC, Cello JP. Evaluation of the gastrointestinal tract in patients with iron-deficiency anaemia. N Engl J Med 1993; 329: 1691-1695.

35. Tedesco FJ. Endoscopy in the evaluation of patients with upper Gl symptoms: Indications, expectations and interpretation. J Clin Gastroenterol 1981; 3 Suppl 2: 67-71.

36. Grant AK, Harley HAJ. Gastrointestinal endoscopy: Some perspectives. Br Med J 1982; 285: 868-870.

37. Kahn KL, Greenfield S. The efficacy of endoscopy in the evaluation of dyspepsia. A review of the literature and development of a sound strategy. J Clin Gastroenterol 1986; 8 (3): $346-358$.

38. Sonnenberg A, Townsend WF. A cost-benefit analysis of performing diagnostic tests in dyspepsia [Abstract]. Proceedings Digestive Disease Week May 1993 Boston, United States: A489.

39. Schiller LR, Fordtran JS. Ulcer complications during short-term therapy of duodenal ulcer with active agents and placebo. Gastroenterology 1986; 90: 478-481.

40. Read L, Pass TM, Komaroff AL. Diagnosis and treatment of dyspepsia, a cost-effectiveness analysis. Med Decis Making 1982; 2 (4): 416-438.

41. Health and Public Policy Committee, American College of Physicians. Endoscopy in the evaluation of dyspepsia. Ann Intern Med 1985; 102: 266-269.

42. Jones $\mathbf{R}$. What happens to patients with non-ulcer dyspepsia after endoscopy? The Practitioner 1988; 232: 75-78.

43. Naji SA, Brunt PW, Hagen S, Mowat NAG, Russell IT, Sinclair TS, Tang TMH. Improving the selection of patients for upper gastrointestinal endoscopy "Gut 1993; 34: 187-191.

44. Mai HD, Sanowski RA, Waring JP. Improved patient care using the ASGE guidelines on quality assurance: A prospective comparative study. Gastrointest Endosc 1991; 37: 597-599. 


\section{Intermezzo}




\section{Introduction}

In Chapters IV and V we have presented results on 2900 patients who were referred for their first diagnostic upper gastrointestinal (GI) endoscopy. In the following chapters we will analyse data of 1147 patients who answered either the paper $(n=431)$ or the computerised $(n=716)$ questionnaire. In the present chapter we will discuss a number of issues related to the fact that these 1147 patients are a subset of our initial study population.

First, the reasons why 1753 patients did not answer a questionnaire will be discussed. Secondly, the group of patients who answered the questionnaires will be compared to the patients who did not. The aim of this comparison is to assess whether there is a selection bias regarding the studies to be presented in Chapters VII and VIII, which are based only on patients who answered the questionnaires.

A third issue that will be dealt with in this chapter are the differences in pain localisations as reported by the patients in the questionnaires and as reported in the interview by the endoscopist.

\section{Reasons for not answering the questionnaires}

During the first part of the study in which paper questionnaires were used (January 1989 - May 1989), 604 patients underwent their first diagnostic upper GI endoscopy. Of these patients, 431 answered such a questionnaire (response rate $=71.4 \%$ ). In the second part of the study in which the computerised history taking system was used (May 1989 - October 1990), 2296 patients were newly referred for a diagnostic upper GI endoscopy. Of these patients, 716 were interrogated by the history taking system (response rate $=31.2 \%$ ).

Thus, 173 patients did not answer the paper questionnaire and 1580 patients did not answer the computerised questionnaire. In the following paragraphs the various reasons for not answering these questionnaires will be discussed.

The reasons that can be attributed to characteristics of the patients have been summarised as 'patient-related reasons'. Mental disorders that hindered answering the questionnaires included severe psychiatric disorders, mental retardation, dementia, etc. Physical illness was the main reason not to answer the questionnaires for hospitalised patients. Moreover, bedridden patients were unable to use the history taking system, because the computers were located in a small room which co'sld not be entered by a hospital bed. A severe visual handicap obviously formed a hindrance for answering either type of questionnaires. Also the patients who did not have their reading-glasses (while visiting the endoscopy unit) were unable to answer the questionnaires. Motivational reasons were recorded in only a small proportion of the patients who did not answer a questionnaire. Most of these patients expressed that they were too nervous to answer the paper or computerised questionnaire while waiting for their endoscopic examination. Language problems such as 
illiteracy or "foreign language" have been recorded as a separate reason for not answering the questionnaires in Chapter III. In this chapter language problems constitute part of 'other reasons'.

Whereas 135 patients $(78.0 \%)$ did not answer the paper questionnaire because of patient-related reasons, 38.8 patients $(24.5 \%$ ) did not answer the history taking system because of these reasons. The distribution of the various 'patient-related reasons' was almost similar for paper and computerised questionnaires (Table I).

Unfortunately, the reasons for not answering the questionnaire have not been recorded ('no reason recorded') in rather large numbers of patients: 38 (22.0\% of those who did not answer the paper questionnaire) and $420(26.6 \%$ of those who did not answer the computerised questionnaire), respectively. The 420 patients included those 60 patients who started with the history taking system but did not complete it.

During the first months after the installation of the computerised history taking system, some technical problems repeatedly inhibited the interrogation of the patients. These obstacles were caused by hardware defects and network software errors, and were not due to flaws in the history taking programme. Eventually, 208 patients $(13.2 \%$ ) could not answer the history taking system because of these socalled 'computer-related reasons'.

During the last months of the study, there was a shortage of secretarial personnel at the endoscopy unit because of reasons such as sick-leave, pregnancy-leave, holidlays, etc. During the periods of understaffing the secretaries had no time to instruct patients how to answer the computerised questionnaire and, therefore, it was agreed that the history taking system would not be used during such periods. Thus, on the days when patients did not answer the computerised questionnaire because of so-called 'personnel-related reasons', the history taking system was not operational at all. As a result, 564 patients $(35.7 \%)$ had no opportunity to answer the computerised questionnaire.

The percentages of patients who answered the paper or computerised questionnaire and the percentages of those who did not answer these questionnaires for

Table I Patient-related reasons * for not answering the paper or computerised questionnaires.

RFASONS FOR NOT ANSWERING
Number of patients $(\%)$

\begin{tabular}{ll}
\begin{tabular}{ll} 
Paper questionnaires & Computerised questionnaires \\
135 & 388 \\
\hline
\end{tabular} \\
\hline
\end{tabular}

\begin{tabular}{lrrrr}
\hline Mental disorders & 18 & $(13.3)$ & 37 & $(9.5)$ \\
Physical illness & 48 & $(35.6)$ & 102 & $(26.3)$ \\
Visual handicap & 39 & $(28.9)$ & 120 & $(30.9)$ \\
Motivational reasons & 5 & $(3.7)$ & 4 & $(1.0)$ \\
Other reasons & 25 & $(18.5)$ & 125 & $(32.2)$ \\
\hline
\end{tabular}


various reasons are presented in Figure I for monthly periods. The proportion of patients who answered the history taking system decreased drastically towards the end of the study. This was mainly due to personnel-related reasons. The proportion of patients who did not answer the paper or computerised questionnaire because of adverse mental or physical conditions remained rather constant throughout the study. The percentage of patients. whose reasons for not answering the questionnaires had not been recorded gradually increased during the study. It is possible that these patients were in fact not invited by the secretaries to answer the paper or computerised questionnaire because of pressure of work at the endoscopy unit, and that the reasons for not answering have therefore not been recorded.

In Chapter III the computerised questionnaires designed for the upper and lower GI tract have been evaluated with respect to their applicability in every day practice of an open access endoscopy unit. The evaluation was performed at the time that the questionnaires were in use for a period of 5 months (May 1989 - September 1989). The computerised history taking system was used, however, during a total period of 17 months (May 1989 - October 1990). In the next paragraphs the feasibility and acceptability of the computerised questionnaire designed for the upper GI tract over this 17 -month period will therefore be presented.

Feasibility: time measurements were automatically performed when patients were interrogated by the computerised questionnaire. Time measurement started with the first question of the computerised questionnaire and ended after the last question of the opinion questionnaire (see Chapter III). The history taking system was completed by the 716 patients on average in 10 minutes $(S D=6$, range 2-41 minutes). Thus, computer-based interrogation seems possible during the regular waiting time for endoscopy.

Acceptability: at the end of the computerised questionnaire designed for the upper GI tract, patients were presented an opinion questionnaire consisting of five questions regarding their opinion about the history taking procedure (see Chapter III). The results of the opinion questionnaire are presented in Table II. When considering the opinion of all 716 patients who completed the history taking system, interrogation by such a system appeared to be interesting and easy. Further, answer ing the computerised questionnaire did not last too long according to the patients. About $40 \%$ of the patients expressed that they had more insight in their complaints and could put their complaints into words more easily after answering the computerised questionnaire. However, about $25 \%$ of the patients were unable to express all their complaints. 


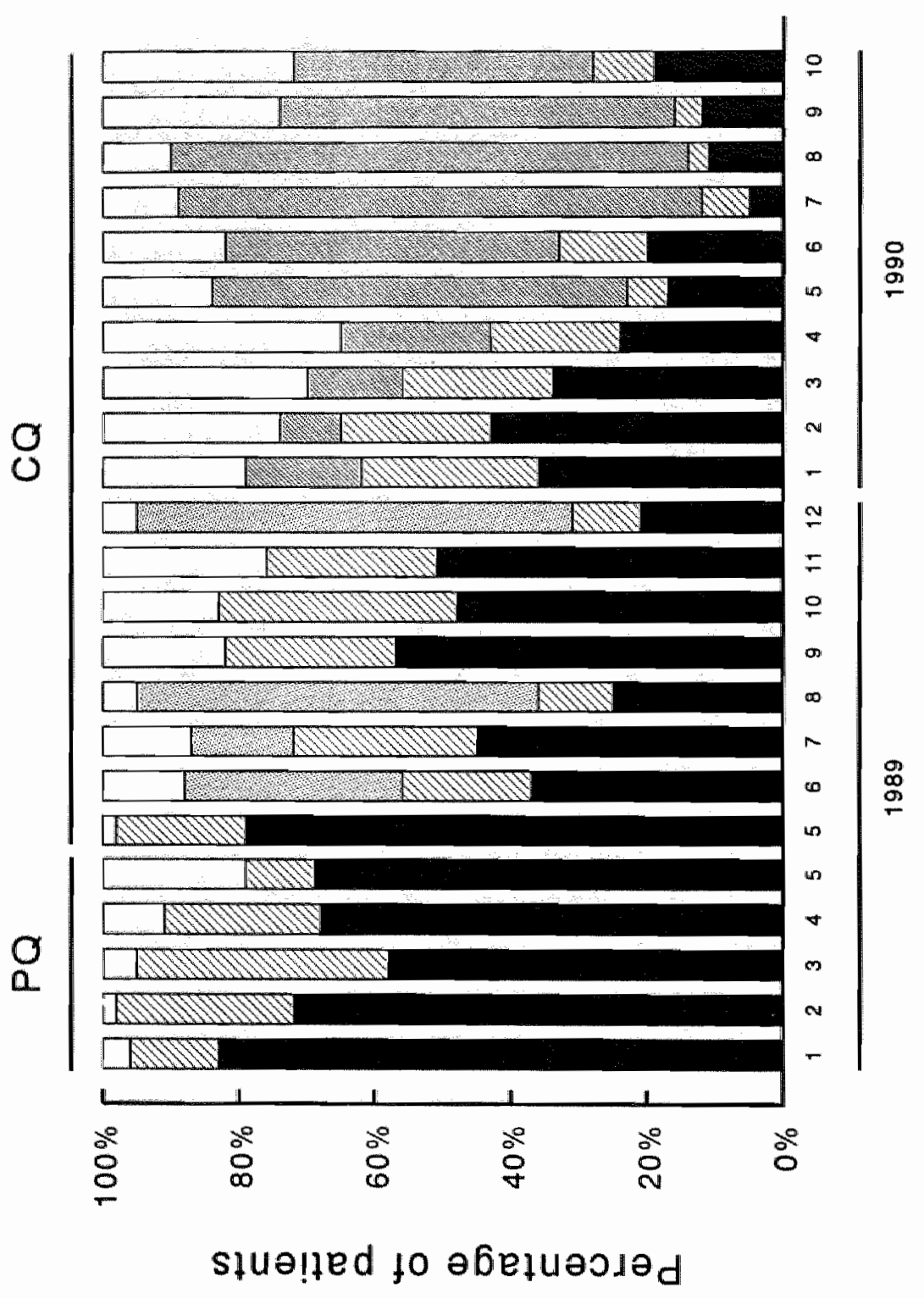

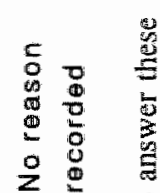

29

$\square \quad \frac{9}{3}$

$\stackrel{4}{5}$

욛ㄴ

-

0.

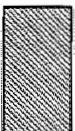

$\frac{\frac{1}{2}}{\frac{2}{3}} \frac{0}{0}$

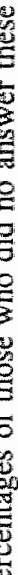

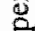

물

量

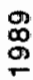

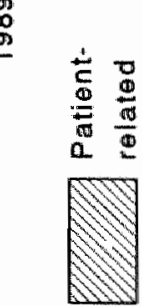

प

용

0 
Table II The results of the opinion guestionnaire presented to the patients who completed the computerised questionnaire designed for the upper GI tract.

\section{OPINION QUESTIONNAIRE}

Number of

patients $(\%)$

716

Have you got more insight in your complaints after answering the computerised questionnaire?

Yes

305

No

299

I don't know; I don't understand; The correct answer is not available

$112 \quad(15.6)$

Can you put your complaints into words more easily after answering the computerised questionnaire?

Yes 296

No

I don't know; I don't understand; The correct answer is not available

Were you able to express all your complaints by answering the computerised questionnaire?

Yes

No

I don't know; I don't understand; The correct answer is not available

Do you think answering the computerised questionnaire lasted too long?

Yes

No

I don't know; I don"t understand; The correct answer is not available

What is your personal opinion on being interrogated by a computer?

Interesting

Annoying

Easy

Difficult 


\section{Comparison between responders and non-responders}

The differences between the group of patients who answered the questionnaires ('responders") and those who did not ('non-responders') with respect to age, gender, referral source, referral indications, pain localisations, previous drug treatment, and endoscopic outcome are presented in Tables III-V.

The two-samples t-test and Chi-squared test with continuity correction were used to test differences between groups. Differences with a p-value less than 0.05 were considered statistically significant. Only 'clustered" data (see Chapter II) have been analysed, since these data form the basis for the studies to be presented in the following chapters.

Responders were younger (Figure II) and more often of the male gender than non-responders (Table III). They were also more often referred by a general practitioner (GP). Responders, as compared to non-responders, were more often referred because of dyspepsia and less often because of so-called 'alarm symptoms' such as signs of upper GI bleeding (haematemesis; melaena; positive faecal occult blood test; iron deficiency anaemia) or anorexia and weight loss. The patients who answered the questionnaires had more often a history of peptic ulcer disease than those who did not.

Tablle III Comparison of the patient characteristics and referral indications of the patients who answered the questionnaires (responders) to those who did not (non-responders).

\begin{tabular}{lrrrrr}
\hline CHARACTERISTICS & \multicolumn{2}{c}{ Responders } & Non-responders & p-value ' \\
& 1147 & & 1753 & \\
\hline Age ${ }^{2}$ (years) & $50 \pm 15.7$ & $60 \pm 17.9$ & $*$ \\
Malle gender & 634 & $(55.3)$ & 888 & $(50.7)$ & $*$ \\
GP referrals & 635 & $(55.4)$ & 570 & $(32.5)$ & $*$ \\
\hline REFERRAL INDICATIONS & & & & & \\
\hline Dyspepsia & 745 & $(65.0)$ & 817 & $(46.6)$ & $*$ \\
Previous peptic ulcer & 86 & $(7.5)$ & 82 & $(4.7)$ & $*$ \\
Oesophageal complaints & 170 & $(14.8)$ & 254 & $(14.5)$ & ns \\
Signs of upper GI bleeding & 81 & $(7.1)$ & 445 & $(25.4)$ & $*$ \\
Anorexia and weight loss & 37 & $(3.2)$ & 106 & $(6.0)$ & $*$ \\
Other referral indications & 157 & $(13.7)$ & 239 & $(13.6)$ & ns \\
\hline
\end{tabular}

'P-value of the two-samples t-test and Chi-squared test with continuity correction $(=p<0.05$; $\left.=p<0.01 ;^{*}=p<0.001 ;^{* *}=p<0.0001\right) ;^{2}$ Age is expressed as mean $\pm S D ;{ }^{3}$ The total number of referral indications exceeds the number of patients, as multiple indications in individual patients accurred. 


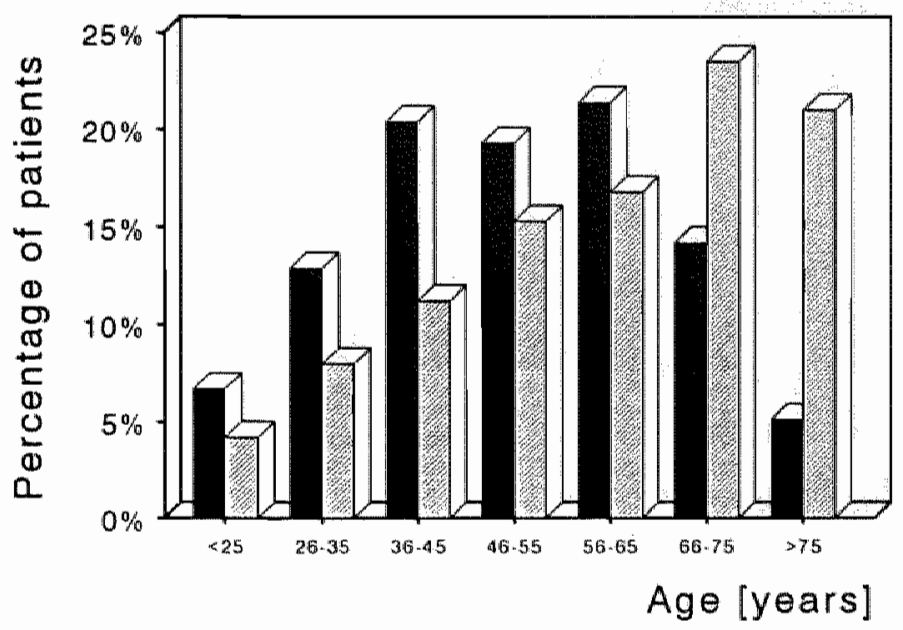

Figure II Age distribution of the patients who answered the questionnaires (responders) ( $\square$ ) and of those who did not (non-responders) ( $\square$ ).

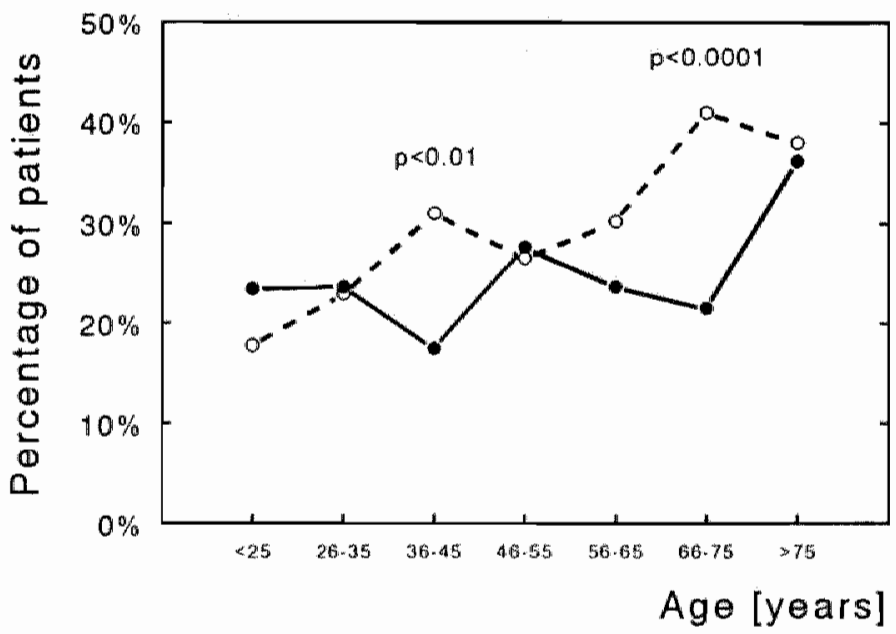

Figure III Relevant endoscopic findings in the patients who answered the questionnaires (responders) ( $\bullet$ ) and in those who did not (nonresponders) (O) according to several age categories. 
Table IV Comparison of the interwiew data of the patients who answered the questionmaires (responders) to those who did not (non-responders).

\begin{tabular}{|c|c|c|c|c|c|}
\hline & \multicolumn{2}{|c|}{ Responders } & \multicolumn{2}{|c|}{ Non-responders } & \multirow[t]{2}{*}{ p-value : } \\
\hline & 1147 & & 1753 & & \\
\hline PAN LOCALISATTONS ${ }^{2}$ & 1135 & & 1708 & & \multirow[b]{2}{*}{ *ì } \\
\hline Epigastric pain & 612 & $(53.9)$ & 728 & $(42.1)$ & \\
\hline Retrosternal pain & 213 & $(18.8)$ & 213 & $(12.5)$ & \multirow{2}{*}{$\begin{array}{l}* * \\
* *\end{array}$} \\
\hline No pain & 288 & $(25.4)$ & 718 & $(42.0)$ & \\
\hline PREVIOUS DRUG TREATMENT ${ }^{2}$ & 1139 & & 1711 & & \multirow{4}{*}{$* *$} \\
\hline Anti-peptic drugs ${ }^{3}$ & 497 & $(43.6)$ & 546 & $(31.9)$ & \\
\hline NSAIDs & 73 & $(6.4)$ & 158 & $(9.2)$ & \\
\hline Steroids & 11 & $(1.0)$ & 52 & $(3.0)$ & \\
\hline
\end{tabular}

Responders reported more often epigastric and retrosternal pain in the preendoscopic interview than non-responders (Table IV). A larger proportion of the responders had been empirically treated prior to referral for endoscopy, as compared to the group of non-responders. Responders had been taking less often potentially ulcerogenic drugs than non-responders.

Relevant endoscopic findings, as defined in this study, were diagnosed less frequently in the patients who answered the questionnaires than in those who did not (Table V). When considering several age categories, relevant endoscopic disease was diagnosed more often in non-responders than responders for those aged 36-45 and 66-75 years (Figure III). Whereas oesophagitis was equally prevalent in responders and non-responders, gastric and - to a lesser degree - duodenal ulcers were found less often in responders than in non-responders. The endoscopic diagnosis of gastric cancer was also made less often in the patients who answered the questionnaires than in those who did not. The proportion of normal investigations was about one-third in the group of responders and about one-quarter in the group of nonresponders. 
Table $\mathrm{V}$ Comparison of the endoscopic outcome in the patients who answered the questioniaires (responders) to those who did (non-responders).

\begin{tabular}{|c|c|c|c|c|c|}
\hline \multirow[t]{2}{*}{ ENDOSCOPIC DIAGNOSES } & \multicolumn{2}{|c|}{ Responders } & \multicolumn{2}{|c|}{ Non-responders } & $\mathrm{p}_{\text {-value }}{ }^{\prime}$ \\
\hline & 1147 & & 1753 & & \\
\hline Relevant endoscopic findings & 269 & $(23.5)$ & 575 & $(32.8)$ & $*$ \\
\hline OESOPHAGEAL DIAGNOSES ${ }^{2 a}$ & 1131 & & 1734 & & \\
\hline Hiatus hernia & 186 & $(16.4)$ & 311 & (17.9) & ns \\
\hline Oesophagitiss & 141 & $(12.5)$ & 256 & $(14.6)$ & ns \\
\hline Oesophageal cancer & 3 & $(0.3)$ & 12 & $(0.7)$ & ns \\
\hline GASTRIC DIAGNOSES ${ }^{2 b}$ & 1126 & & 1715 & & \\
\hline Endoscopic gastritis & 167 & $(14.8)$ & 329 & $(19.2)$ & 0 \\
\hline Gastric ulcer & 56 & $(5.0)$ & 165 & $(9.6)$ & 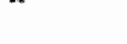 \\
\hline Gastric cancer & 10 & $(0.9)$ & 45 & $(2.6)$ & 0 \\
\hline DUODENAL DIAGNOSES ${ }^{2 C}$ & 1118 & & 1699 & & \\
\hline Duodenitis/bulbitis & 152 & $(13.6)$ & 222 & $(13,1)$ & ns \\
\hline Duodenal ulcer & 78 & $(7.0)$ & 156 & $(8.9)$ & \\
\hline Normal endoscopy ${ }^{2 c}$ & 390 & $(34.9)$ & 448 & $(26.4)$ & $*$ \\
\hline
\end{tabular}

"P-value of the Chi-squared test with continuity correction ${ }^{*}=p<0.05 ;{ }^{\circ}=p<0.01 ; "=$ $\left.p<0.001 ;{ }^{*}=p<0.0001\right) ;^{2}$ Percentages are given of those patients who had an ${ }^{2}$ oesophagoscopy, ${ }^{b}$ oesophagogastroscopy, or ${ }^{\circ}$ oesophagogastroduodenoscopy.

\section{Comparison between pain report in questionnaires and interview}

A pilot study demonstrated that it is difficult for patients to indicate precise pain localisation(s) on a paper questionnaire. For that reason, patients were personally interviewed by the endoscopist as to whether pain had been a reason for consultation and subsequent referral and - if so - where this pain was localised. The localisation(s) were recorded on the study form, which contains an illustration of the abdomen divided in nine parts by two horizontal and two vertical lines (see Appendix A).

The questionnaires contain the following two questions: 'Do you have epigastric pain?' and 'Do you have retrosternal pain?'. These questions could be answered with 'yes' or 'no'. The computerised questionnaire offered an additional 'escape answer' (see Appendix B).

Of the 1147 patients who answered the questionnaires, only 12 patients were not interviewed by the endoscopist. As a result, for 1135 patients the presentation of epigastric and/or retrosternal pain in the questionnaires could be compared to the report of these pain localisations in the pre-endoscopic interview (Table VI). The 
Table VI Comparison of the parn presentation in the questionnaires to the report of pain in the pre-endoscopic interview by the endoscopist.

PRE-ENDOSCOPIC INTERVIEW

Number of patients (\%)

\begin{tabular}{|c|c|c|c|c|c|}
\hline \multicolumn{2}{|c|}{ QUESTIONNAIRES } & \multirow{2}{*}{$\begin{array}{l}\text { EP } \\
551 \quad(48.5)\end{array}$} & EP/RS & \multirow{2}{*}{$\begin{array}{l}\text { RS } \\
152(13.4)\end{array}$} & \multirow{2}{*}{$\begin{array}{l}-\mathrm{EP} / \text { RS } \\
371 \quad(32.7)\end{array}$} \\
\hline & & & $61 \quad(5.4)$ & & \\
\hline EP & $307(27.0)$ & 203 & 7 & 15 & 82 \\
\hline EP/RS & $339(29.9)$ & 194 & 47 & 49 & 49 \\
\hline RS & $148(13.0)$ & 53 & 6 & 57 & 32 \\
\hline$-\mathrm{EP} / \mathrm{RS}$ & $341 \quad(30.0)$ & 101 & 1 & 31 & 208 \\
\hline
\end{tabular}

EP Epigastric pain; RS Retrosternal pain; EP/RS Epigastric and retrosternal pain; -EP/-RS No epigastric and no retrosternal pain.

Chi-squared test with continuity correction was used to test differences between groups, and a p-value less than 0.05 was considered statistically significant.

There were marked differences in pain localisations as assessed by these two methods: patients reported more often epigastric pain $(\mathrm{p}<0.0001)$ and less often combined epigastric and retrosternal pain $(\mathrm{p}<0.0001)$ in the interview than in the questionnaires.

Of the 307 patients who had only epigastric pain according to the questionnaires, $82(26.7 \%)$ did not report epigastric or retrosternal pain in the interview. Of these 82 patients, $36(43.9 \%)$ reported pain in other abdominal regions such as the right $(n=20)$ or left $(n=9)$ upper abdomen, or the umbilical region $(n=7)$. The remaining 46 patients $(56.1 \%)$ indicated that they had no pain at all. Of the 148 patients who reported only retrosternal pain in the questionnaires, $53(35.8 \%)$ had epigastric pain and $32(21.6 \%)$ had neither epigastric nor retrosternal pain according to the interview. Of the 339 patients who reported combined epigastric and retrosternal pain in the questionnaires, only $47(13.9 \%)$ expressed both pain localisations in the interview. However, 194 patients $(57.2 \%)$ reported only epigastric pain to the endoscopist. Of the 341 patients without retrosternal or epigastric pain according to the questionnaires, $101(29.6 \%)$ reported epigastric pain in the pre-endoscopic interview.

The variations in pain localisation as assessed by these two methods can be explained by the fact that the interview, in contrast to the questionnaires, is an interactive process. The endoscopist could assist the patients in determining the exact pain localisation(s) and, because of this, some patients might have reconsidered the pain localisation(s) previously presented in the questionnaires. Moreover, the term 'pain' could be differently interpreted by the patients and the endoscopist. For example, a patient with an uncomfortable sensation in the stomach region might 
not have reported this as epigastric pain in the questionnaire, although the endoscopist could interpret this sensation as pain localised in the epigastric region. Furthermore, while the questionnaires strictly enquired about the presence of epigastric and retrosternal pain, patients had the opportunity to express other pain localisations in the interview.

\section{Concluding remarks}

During the study period 2900 patients were referred for their first diagnostic upper GI endoscopy. About $40 \%$ of these patients answered either the paper questionnaire or the computerised history taking system. Technical problems and secretarial understaffing inhibited interrogation by the history taking system in almost $50 \%$ of the patients referred during the second part of the study. Unfortunately, the reasons for not answering the paper or computerised questionnaire have not been recorded in a considerable proportion of the patients. This makes interpretation of the "patient-related reasons' difficult and somewhat speculative.

The 'computer-related reasons' as well as the 'personnel-related reasons' did not depend on patient characteristics and will, therefore, not have caused any selection bias. In contrast, it is not unlikely that the 'patient-related reasons' and 'no reason recorded' have generated some bias with respect to the selection of patients for the studies to be presented in the next chapters.

Indeed, the group of patients who answered the questionnaires (responders) differed in several aspects from the patients who did not (non-responders). Responders were younger, had a male preponderance, and were more often referred directly from general practice. Dyspeptic and oesophageal complaints were by far the most frequent reason for undergoing an endoscopy, whereas alarm symptoms occurred in not more than $10 \%$ of these patients. The fact that more than $40 \%$ had been treated with anti-peptic agents prior to referral may also have influenced symptoms and endoscopic findings.

Not only the pre-endoscopic characteristics but also the endoscopic outcome differed markedly between the groups of responders and non-responders. Whereas oesophagitis was equally prevalent in both groups, peptic ulcers were diagnosed more often in the group of non-responders. Relevant endoscopic findings, as defined in this study, were diagnosed in less than one-quarter of the responders but in about one-third of the non-responders.

The pain presentation in the questionnaires differed from the report of pain localisations in the interview by the endoscopist. The patients reported more often epigastric pain and less often a combination of epigastric and retrosternal pain in the pre-endoscopic interview. The pain localisations as assessed by each of both methods, however, have been considered in the studies about the predictability of endoscopic diagnoses by patient characteristics and symptoms. 
In conclusion, the studies to be presented in Chapters VII and VIII deal with a selected group of patients who answered the questionnaires and who in various aspects differ from those who did not. Although it is important to realise that the results are based on this selected group of patients, it is these younger, dyspeptic, GP referred patients, who begin to overload the open access endoscopy services. Under this aspect, such a population is very attractive for studies that aim at the discrimination between patients with or without relevant endoscopic disease by analysing pre-endoscopic characteristics and symptoms. Furthermore, since the studies to be presented in the following chapters concern specific endoscopic diagnoses the representativeness of the whole sample is less important as long as the patients belonging to the different diagnostic categories are representative for that category, as far as sensitivity and specificity are concerned. 


\section{Are upper gastrointestinal endoscopic findings predictable? The use of logistic regression analysis}

Submitted for publication as 'The discriminative value of patient characteristics and dyspeptic symptoms for upper gastrointestinal endoscopic findings: a study on the clinical presentation of 1147 patients'

R.P. Adang, A.W. Ambergen, J.L. Talmon, A. Hasman, F.-J.F.E. Vismans, R.W. Stockbrügger 


\section{Abstract}

The discriminative value of patient characteristics and dyspeptic symptoms for upper gastrointestinal endoscopic findings was prospectively assessed in 1147 patients attending for their first diagnostic endoscopy who answered paper $(n=431)$ or computerised $(n=716)$ questionnaires. The questionnaires provided detailed information concerning present dyspeptic symptoms, with special attention to provoking and/or reliewing factors, and smoking and/or drinking habits. In logistic regression models each of a number of 'specific endoscopic diagnoses' was contrasted to normal endoscopy $(n=390)$, and 'relevant endoscopic disease' (oesophagitis; peptic ulcers; cancers, $n=269$ ) was contrasted with 'irrelevant' and normal endoscopic findings $(n=878)$. From the regression model a Receiver Operating Characteristic (ROC) curve could be constructed, and the Area Under the ROC Curve (AUC) was calculated to summarise the discriminative power of the regression model.

The best discrimination from patients with a normal endoscopy was achieved for patients with gastric $(A U C=0.86)$ or duodenal $(A U C=0.85)$ ulcers, followed by patients with hiatus hernia $(A U C=0.78)$ or oesophagitis $(A U C=0.77)$. The discriminative performance of the regression models was somewhat less for duodenitis/bulbitis (AUC=0.75) and endoscopic gastritis $(A U C=0.73)$. In an open access endoscopy unit setting, the value of pre-investigation history taking for the prediction of clinically relevant endoscopic disease was very limited $(A U C=0.63)$.

Patients with gastric ulcer are afraid to eat, but those with duodenal ulcer are afraid not to eat

Anonymous !

\section{Introduction}

Dyspeptic symptoms are frequent in the population ${ }^{2-4}$ and have important socioeconomic consequences, as they are a common reason for absence from work and medical consumption ${ }^{5-7}$. Upper gastrointestinal (GI) endoscopy is considered the investigation of first choice in patients with dyspepsia ${ }^{8.9}$. It is mandatory for a precise diagnosis and may give direction to further patient management. There has been a dramatic escalation in demand for endoscopic examinations, especially since endoscopy units began to offer an open access service to general practitioners (GPs) ${ }^{10-14}$. In many centres this resulted in long waiting lists ${ }^{14,16-18}$.

Although endoscopy may reveal serious organic disorders, such as oesophagitis, peptic ulcers, or cancer, in a considerable proportion of patients no specific lesion emerges on investigation ${ }^{3,4,19}$. With shrinking medical resources it is not possible to investigate all patients with dyspepsia; criteria for the appropriate use of upper GI 
endoscopy in those patients is crucial to avoid overloading the services ${ }^{8,16.20-23}$. In 1905 Lord Moynihan declared that most patients with dyspepsia could be correctly diagnosed by their symptoms alone ${ }^{24}$. If the clinical picture of dyspepsia could be used as a valid guideline to select those patients who really need endoscopy, this would probably favour a more efficient use of this technique $1,7,25-28$.

The aims of the present study were to assess 1) whether patients with a specific endoscopic diagnosis have a typical symptom profile, which distinguishes them from symptomatic patients with a normal endoscopy, and 2) whether it is possible to discriminate patients with clinically relevant endoscopic disease from those without by analysing patient characteristics and present dyspeptic symptoms.

\section{Methods}

This prospective study was performed between January 1989 and October 1990 at a single endoscopy unit providing unrestricted open access to hospital specialists and GPs ${ }^{14}$. Only patients attending for their first diagnostic upper GI endoscopy and who answered a detailed questionnaire were included in this study. Data were collected in a consistent and uniform way using a standardised study form, providing lists of predetermined referral indications, pain localisations, drug regimens, and endoscopic findings (Appendix A). The methods of data acquisition have been extensively described in Chapter II and, therefore, will be only briefly summarised in the following paragraphs.

\section{METHODS OF DATA ACQUISITION}

Request forms: the indication(s) for endoscopy were extracted from request forms, which were routinely used by the referring doctors, and they were recorded by the endoscopist on the study form by selecting from a list of predefined referral indications. The following indications have been used in the analysis in this study: dyspepsia; previous peptic ulcer; retrosternal pain and/or dysphagia; signs of upper GI bleeding; anorexia and weight loss; and miscellaneous, covering all other possible referral indications.

Dyspepsia was defined as episodic or persistent upper abdominal pain and/or discomfort considered attributable to the proximal alimentary tract 9,15 . Previous peptic ulcer was selected as a reason for referral whenever a history of ulcer disease was mentioned on the request form. Signs of upper GI bleeding included both acute (haematemesis; melaena) and chronic (positive faecal occult blood test; iron deficiency anaemia) manifestations of GI blood loss.

Questionnaires: in the first part of the study, patients received a paper questionnaire while waiting for their endoscopy. This questionnaire consists of $57 \mathrm{mul}-$ tiple-choice questions enquiring about past medical history, present dyspeptic symptoms, with special attention to their duration, frequency, intensity, and provoking and/or relieving factors, and alcohol and/or nicotine consumption (Appendix B). 
The questionnaire has a branching structure, so that a patient has to answer at least 22 questions; the remaining 35 questions have to be answered only if the preceding 'branching questions' were answered affirmatively. Patients were requested to choose just one answer to each question.

In the second part of the study, the same questions with the same branching structure were implemented in a computerised history taking system. However, each question has an additional 'escape answer' (I don't know; I don't understand; The correct answer is not available) besides the answer options of the paper questionnaire. Patients were obliged by the system to select a single answer to each question. The paper and computerised questionnaires have been evaluated with respect to their feasibility and acceptability in routine clinical practice (see Chapter III) ${ }^{29}$.

Short personal interview: a pilot study demonstrated that it is difficult for patients to indicate precise pain localisation(s) on a paper questionnaire. It also appeared that many patients are unable to select drugs they have recently been taking from a list of predefined agents provided in such a questionnaire. Patients were therefore interviewed by the endoscopist as to whether pain had been a reason for consultation and subsequent referral for endoscopy. If so, the pain localisation(s) were recorded on the study form, which contains an illustration of the abdomen divided into nine regions by the intersection of two horizontal and two vertical lines 30. The following pain localisations have been analysed: retrosternal; epigastric; right upper abdominal; left upper abdominal; mid abdominal; lower abdominal. Patients were also asked about the recent use of 'anti-peptic drugs' $\left(\mathrm{H}_{2}\right.$ receptor antagonists; antacids; cytoprotective drugs; prokinetic agents), non-steroidal antiinflammatory drugs (NSAIDs), steroids, and anticoagulant agents.

Endoscopic examination: the endoscopic examinations were carried out by trained endoscopists. For the purpose of this study, we focused on the following endoscopic diagnoses: hiatus hernia; oesophagitis; endoscopic gastritis; gastric ulcer; duodenitis/bulbitis; duodenal ulcer; and normal endoscopy. Oesophageall and gastric cancer were not separately analysed because of the small number of patients with these endoscopic diagnoses. A patient could have more than one diagnosis, except for normal endoscopy. Diagnostic criteria were agreed in advance between the endoscopists and were applied as consistently as possible. Only endoscopic diagnoses have been considered, and additional histopathological findings were not taken into account.

Oesophagitis was diagnosed using the Savary-Miller grading system ${ }^{31}$. The term 'endoscopic gastritis' was used for different types of diffuse gastric changes such as erosive, haemorrhagic, atrophic, varioliform, and hypertrophic appearances. Postgastrectomy anastomositis was also covered by endoscopic gastritis. Gastric ulcers were classified as benign when endoscopic features suggestive of malignancy were absent. Endoscopic appearances of inflammation in the duodenal bulb and/or descending duodenum were summarised as a diagnosis duodenitis/bulbitis. 


\section{METHODOLOGICAL APPROACH: PREDICTION MODELS}

For each of the diagnostic categories a logistic regression model was developed to determine whether patients with such 'specific endoscopic diagnoses' can be discriminated from symptomatic patients having a normal endoscopy. A logistic regression model was also developed to predict the presence of 'relevant endoscopic disease' with the help of patient characteristics and symptoms.

Prediction models for 'specific endoscopic diagnoses': a model was developed for each of the following endoscopic diagnoses: hiatus hernia; oesophagitis; endoscopic gastritis; gastric ulcer; duodenitis/bulbitis; duodenal ulcer. Each diagnostic category consisted of those patients having at least that specific endoscopic diagnosis. Therefore, patients may belong to more than one diagnostic category simultaneously. In the logistic regression models a particular diagnostic category was contrasted with a control group, which consisted of the patients having a normal endoscopy.

Prediction model for 'relevant endoscopic disease': the endoscopic diagnoses which usually have direct therapeutic and/or prognostic consequences were regarded to be clinically relevant. By this definition, patients with oesophagitis or peptic ulcers, and those who were endoscopically judged to have a malignant disorder, were classified as having 'relevant endoscopic disease'. In the regression model they were contrasted with the remaining patients who had either 'irrelevant' endoscopic finding(s) or a normal endoscopy.

\section{STATISTICAL ANALYSIS}

A total number of 73 (independent) variables have been analysed (number of different variables between brackets): age, gender, referral indications [6], pain localisations [6], drug regimens [4], and symptom variables [55]. Age was treated as a continuous variable; male gender, referral indications, pain localisations and drugs were dealt with as dichotomous categorical variables (present/absent); the multiplechoice questions of the questionnaires resulted in multi-categorical symptom variables.

A categorical variable can have a number of values. One of them is used as the reference category. For example, in 'Duration of heartburn' the value 'No heartburn' is taken as the reference category. The other values form the non-reference categories. Each non-reference category is translated into a design variable. The coding scheme for the design variables is as follows: the non-reference category obtains a one for the corresponding design variable, and a zero for the other (noncorresponding) design variables (Figure I). The reference category obtains zeros for all the design variables. Hence, the number of design variables for each categorical variable is equal to the number of categories minus one. In this way 


\begin{tabular}{|llll|}
\hline & \multicolumn{3}{c|}{ Design variables } \\
\hline Reference category & $\mathbf{1}$ & $\mathbf{2}$ & $\mathbf{3}$ \\
Non-reference category 1 & 0 & 0 & 0 \\
Non-reference category 2 & 1 & 0 & 0 \\
Non-reference category 3 & 0 & 1 & 0 \\
\hline
\end{tabular}

Figure I Coding scheme for the categorical symptom variables.

the discriminative influence of each design variable can be determined with respect to the reference category.

A two-step statistical procedure was performed for each prediction model. In step one data were analysed by univariate techniques (two-samples t-test or Chisquared test) to identify the variables that occurred more frequently in the diagnostic category than in the control group (an arbitrary difference in probability of 0.25 was chosen for inclusion of the variable). These variables were in step two included in a forward stepwise logistic regression analysis, to identify which combination of variables best discriminated between the diagnostic category and the control group ${ }^{32}$. First, the entry limit was a p-value less than 0.25 on the Score test, and remove limit was a p-value less than 0.15 on the likelihood ratio test. The set of variables obtained in this way was used in a second analysis. In this analysis, the above mentioned limits were set both to 0.05 . The variables were ranked by the step number by which they were selected in the analysis (Tables I-VII). The first variable thus provides the best discrimination between the two categories compared. The second variable offers the most additional discrimination given the information from the first variable, and this procedure continued until none of the remaining variables added significantly to the discrimination.

The discriminative value of the regression models was assessed by the $-2 \log$ likelihood test and the goodness of fit test ${ }^{32}$.

The above-mentioned coding scheme of the categorical variables is such that the odds ratios (OR) of the non-reference categories as related to the reference category can be calculated from the logistic regression coefficients as follows:

$\mathrm{OR}=\mathrm{e}^{\text {coefficient }}$

Note that these odds ratios are in fact adjusted odds ratios. They are computed by the logistic regression progranme for models with a number of covariates. The adjustment is for these covariates. 
The non-adjusted odds ratios of the categories of a particular categorical variable can be obtained from the frequencies of occurrence of each of the categories of the variable in the diagnostic category and its control group. The probability of a true negative test result and the probability of a true positive test result are often used in this context:

$$
\mathrm{OR}=\frac{\text { probability true positive } \mathrm{x} \text { probability true negative }}{\text { probability false positive } \mathrm{x} \text { probability false negative }}
$$

or

$$
\mathrm{OR}=\frac{\mathrm{P}(\mathrm{D}+\mid \mathrm{T}+) \times \mathrm{P}(\mathrm{D}-\mid \mathrm{T}-)}{\mathrm{P}(\mathrm{D}+\mid \mathrm{T}-) \times \mathrm{P}(\mathrm{D}-\mid \mathrm{T}+)}
$$

If the regression coefficient is positive then the odds ratio is greater than 1 , which means that the probability of having a particular diagnosis is increased for that variable category. If the regression coefficient is negative then the odds ratio is less than 1 , which means that the probability of having a particular diagnosis is decreased for that variable category.

This logistic regression analysis results in a prediction model with a reduced number of variables, and from this model a Receiver Operating Characteristic (ROC) curve can be constructed ${ }^{33-36}$. A ROC curve gives an impression of the discriminative ability of a test by plotting its sensitivity (proportion of subjects correctly classified as diseased) against 100-specificity (proportion of subjects correctly classified as non-diseased) for a range of cutoff points ${ }^{37}$.

The Area Under the Curve (AUC) of a ROC curve summarises the overall

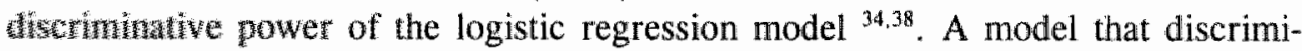
nates pertecty has an AUC of 1; a model without discriminative power has an AUC art 0

\section{Results}

\section{STOW MATERAL}

Data of 1147 newly referred patients could be analysed because they had filled in the paper questionnaire $(n=431 ; 37.6 \%)$ or had used the computerised history taking system $(n=716 ; 62.4 \%)$. A detailed description of this group of patients has been presented in Chapter VI.

The patients, 634 men $(55.3 \%)$ and 513 women (44.7\%), had a mean age of 50 years $(\mathrm{SD}=15.7$ years, range $15-88$ years). The local GPs referred 635 patients 


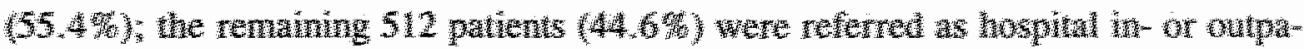

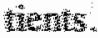

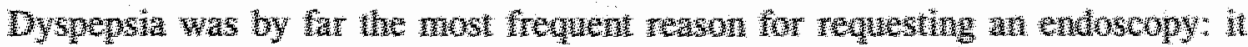

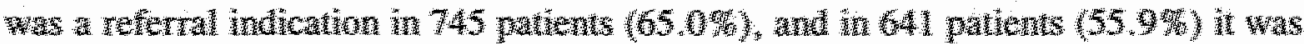

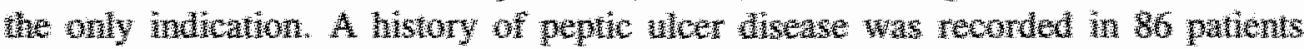

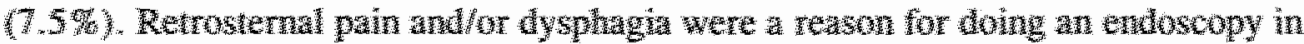

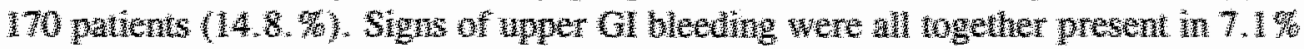

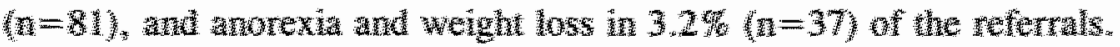

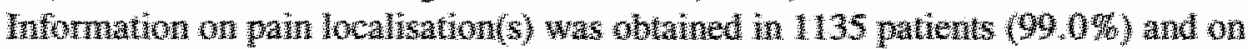

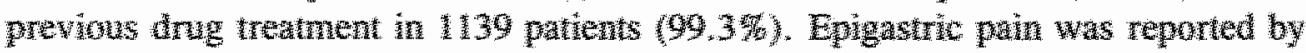
62 prients $(53.9 \%)$ and retrosternal pain by 213 patents $(18.8 \%$, the other pan

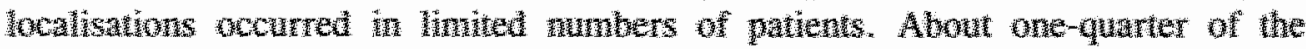

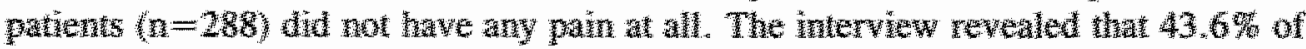
the referas $(n=497)$ had been empirtcally treated with anti-peptic agents prior to ewioscopy. Recent use of NSADs was reported by 73 pretents $(6,4 \%)$, of stervids

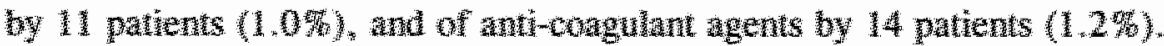

In 1118 patients $(97.5 \%)$ a complete oesophagogastroduodenoscopy was per-

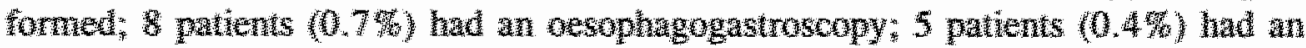
ceswenagoscopy: and in 16 patients $\left(1.4 x^{2}\right.$ ) introdwction of the endoscope was not possbib. The frequencies of the "specinc endoscopic diagnoses" were torcentages

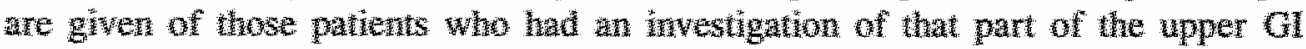
rrac in which the specific dagnosis is localised): hatus themia $(n=186 ; 16.4 \%)$

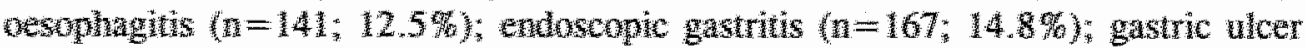

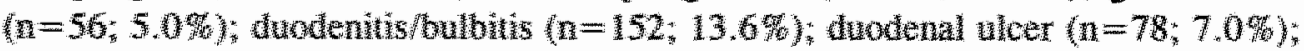
and womal endoscopy ( $(n=390,34,9 \%$ of those who had a complete endoscopy).

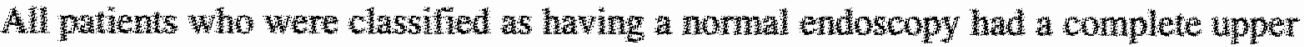

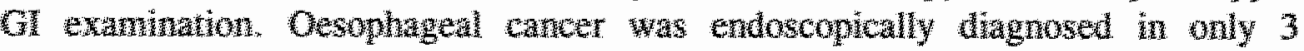
patients $(0.3 \%)$, and gastric cancer in 10 patients $(0.9 \%)$.

The 'specific endoscopic diagnoses' occurred in 44 different combinations in 972 patients; the majority of the patients had one endoscopic diagnosis $(\mathrm{n}=792 ; 81.5 \%)$; 150 patients $(15.4 \%)$ had two diagnoses, 29 patients $(3.0 \%)$ had three diagnoses, and 1 patient $(0.1 \%)$ had four of the above listed endoscopic diagnoses. The remaining 159 patients had other abnormal endoscopic findings.

According to our definition, 269 patients $(23.5 \%)$ had clinically 'relevant endoscopic disease' and the remaining 878 patients (76.5\%) had 'irrelevant' or normal endoscopic findings.

\section{PREDICTION MODELS}

The results of the logistic regression prediction models are presented in Tables IVII. A general impression of their discriminative performance is given by the corresponding ROC curves (Figures IIa-f and III) and by the areas under these curves (Tables I-VII). 
The best discrimination from patients with a normal endoscopy was achieved for patients with peptic ulcers (Figures IId and IIf), followed by patients with hiatus hernia or oesophagitis (Figures IIa and IIb). The regression models had the lowest discriminative value for duodenitis/bulbitis and endoscopic gastritis (Figures IIc and IIe). It was hardly possible to predict the presence of clinically relevant findings in patients undergoing endoscopy by analysing their symptoms (Figure III).

The discriminative value of a selected variable for a particular diagnosis can be presented as the odds ratio. The most remarkable findings regarding the discriminative value of individual characteristics and symptoms will be briefly reviewed in the subsequent paragraphs.

Hiatus hernia: a diagnosis of hiatus hernia was predicted by heartburn during a period of years or months and by retrosternal pain (Table I). This retrosternal pain, however, could be absent for days or even for a period of several weeks to months. As compared to patients having a normal endloscopy, patients with hiatus hernia were older and hiatus hernia more often occurred in males.

Oesophagitis: the following variables were significantly predictive of oesophagitis: heartburn during a period of years, retrosternal pain, and dysphagia for soft food or liquids (Table II). Also oesophagitis predominantly occurred in male patients.

Endoscopic gastritis: heartburn during a period of years increased the probability of having endoscopic gastritis, in contrast to left upper abdominal pain (Table III). Endoscopic gastritis more often occurred with increasing age, in males, and in patients who had undergone gastric surgery.

Gastric ulcer: in the model comparing gastric ulcer to normal endoscopy, eight variables appeared to be significantly associated with a gastric ulcer (Table IV). Most of these variables were patient characteristics: age, smoking, empiric treatment, and a history of ulcer disease. Signs of upper GI bleeding and epigastric pain arising and/or increasing before meal ('hunger pain') were also predictive of gastric ulcers. As for endoscopic gastritis, left upper abdominal pain decreased the probability of having a gastric ulcer.

Duodenitis/bulbitis: five patient characteristics were selected as variables predictive of duodenitis/bulbitis: age, male gender, smoking, empiric treatment, and previous gastric surgery (Table V). Furthermore, heartburn lasting for several years increased the probability of having duodenitis/bulbitis.

Duodenal ulcer: as for duodenitis/bulbitis, age and smoking were predictive of duodenal ulcer (Table VI). Signs of upper GI bleeding and epigastric pain were significantly associated with duodenal ulcers. Whereas vomiting increased the probability of having a duodenal ulcer, the opposite was true for nausea. Duodenal ulcer was the only diagnosis that appeared to be significantly associated with stress. 
Table I Discriminative variables selected by the logistic regression analysis of hiatus hernia $\left(\mathrm{n}_{\text {hermia }}=186\right)$ vs normal endoscopy $\left(\mathrm{n}_{\text {risarmal }}=390\right)$.

\begin{tabular}{|c|c|c|c|c|c|c|c|c|}
\hline SELECTED VARIABLES & $\mathrm{n}_{\text {lutmis }}$ & $(\%)$ & $\mathrm{n}_{\text {martenal }}$ & $(\%)$ & B & SE & OR & $p$-value \\
\hline Duration of heartburn (Q33) & 116 & & 160 & & & & & 0.0000 \\
\hline Years & 65 & $(34.9)$ & 35 & $(9.0)$ & 1.72 & 0.28 & 5.60 & \\
\hline Months & 27 & $(14.5)$ & 50 & $(12.9)$ & 0.60 & 0.30 & 1.83 & \\
\hline Days - weeks & 16 & $(8.6)$ & 60 & $(15.4)$ & 0.01 & 0.34 & 1.01 & \\
\hline$?$ & 8 & $(4.3)$ & 15 & $(3,8)$ & 0.58 & 0.49 & 1.79 & \\
\hline No heartburn * & 70 & $(37.6)$ & 230 & $(59.0)$ & & & & \\
\hline Age & 186 & & 390 & & 0.04 & 0.01 & 1.04 & 0.0000 \\
\hline Gender & 186 & & 390 & & & & & \\
\hline Male & 109 & $(58.6)$ & 1,82 & $(46.7)$ & 0.81 & 0.22 & 2.24 & 0.0002 \\
\hline Female * & 77 & $(41.4)$ & 208 & $(53.3)$ & & & & \\
\hline Retrosternal pain & 186 & & 390 & & & & & 0.0112 \\
\hline Yes & 62 & (33.3) & 67 & $(17.2)$ & 0.58 & 0.25 & 1.79 & \\
\hline $\mathrm{No} \cdot$ & 120 & $(64.5)$ & 321 & $(82.3)$ & & & & \\
\hline Missing & 4 & $(2.2)$ & 2 & $(0.5)$ & 2.06 & 0.98 & 7.87 & \\
\hline Recent troublesome time (Q56) & 186 & & 390 & & & & & 0.0484 \\
\hline Yes & 65 & $(34.9)$ & 184 & $(47.2)$ & -0.49 & 0.22 & 0.61 & \\
\hline $\mathrm{No}^{*}$ & 95 & $(51.1)$ & 170 & $(43.6)$ & & & & \\
\hline$?$ & 26 & $(14.0)$ & 36 & $(9.2)$ & 0.13 & 0.34 & 1.14 & \\
\hline Periods no retrosternal pain $(\mathrm{Q} 22)$ & 96 & & 160 & & & & & 0.0300 \\
\hline Never & 26 & $(14.0)$ & 52 & $(13.3)$ & -0.04 & 0.32 & 0.96 & \\
\hline Several days & 46 & $(24.8)$ & 55 & (14.1) & 0.87 & 0.28 & 2.39 & \\
\hline Several weeks - months & 22 & $(11.8)$ & 46 & $(11.8)$ & 0.24 & 0.34 & 1.27 & \\
\hline$?$ & 2 & (1.1) & 7 & $(1.8)$ & -0.26 & 0.94 & 0.77 & \\
\hline No retrostermal pain & 90 & $(48.4)$ & 230 & $(59.0)$ & & & & \\
\hline Constant & & & & & -3.29 & 0.55 & & 0.0000 \\
\hline
\end{tabular}

AUC

0.78

$n_{\text {ternin }}$ Number of patients with hiatus hernia; $n_{\text {nomal }}$ Number of patients with a normal endoscopy; $B$ Logistic regression coefficient; SE Standard error; OR Adjusted odds ratio; p-value $P$-value of the Wald test for removal; "Symptom variable not necessarily present in all patients because of the branching structure of the questionnaires; " Reference category; ? Unresponded question or escape answer; AUC Area under the Receiver Operating Characteristic curve. 
Table II Discriminative wariables selected by the logistic regression analysis of oesophagitis

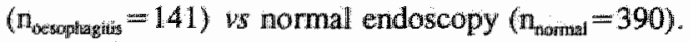

\begin{tabular}{|c|c|c|c|c|c|c|c|c|}
\hline SELECTED VARIABLES & $\mathrm{n}_{\text {actangenthe }}$ & (\%) & $\mathrm{n}_{\text {nommal }}$ & $(\%)$ & $\mathrm{B}$ & SE & OR & $\mathrm{p}$-value \\
\hline Duration of heartburn (Q33) & 100 & & 160 & & & & & 0.0000 \\
\hline Years & 45 & $(31.9)$ & 35 & $(9.0)$ & 1.65 & 0.30 & 5.19 & \\
\hline Months & 27 & $(19.1)$ & 50 & $(12.8)$ & 1.00 & 0.31 & 2.71 & \\
\hline Days - weeks & 22 & $(15.6)$ & 60 & $(15.4)$ & 0.64 & 0.32 & 1.89 & \\
\hline$?$ & 6 & $(4.3)$ & 15 & (3.8) & 0.62 & 0.54 & 1.86 & \\
\hline No heartburn * & 41 & $(29.1)$ & 230 & $(59.0)$ & & & & \\
\hline Retrosternal pain & 141 & & 390 & & & & & 0.0001 \\
\hline Yes & 58 & $(41.1)$ & 67 & $(17.2)$ & 1.03 & 0.24 & 2.81 & \\
\hline No ${ }^{*}$ & 82 & $(58.2)$ & 321 & $(82.3)$ & & & & \\
\hline Missing & 1 & $(0.7)$ & 2 & $(0.5)$ & 0.58 & 1.43 & 1.78 & \\
\hline Gender & 141 & & 390 & & & & & \\
\hline Male & 94 & $(66.7)$ & 182 & $(46.7)$ & 0.86 & 0.23 & 2.36 & 0.0002 \\
\hline Pemale & 47 & (33.3) & 208 & $(53.3)$ & & & & \\
\hline Dysphagia (Q42) & 141 & & 390 & & & & & 0.0220 \\
\hline Never " & 59 & $(41.8)$ & 217 & $(55.6)$ & & & & \\
\hline Only in case of solid food & 30 & $(21.3)$ & 77 & $(19.7)$ & 0.12 & 0.29 & 1.13 & \\
\hline Even in case of soft food / liquids & 32 & $(22.7)$ & 43 & $(11.0)$ & 0.93 & 0.31 & 2.52 & \\
\hline$?$ & 20 & $(14.2)$ & 53 & $(13.6)$ & 0.44 & 0.34 & 1.55 & \\
\hline $\begin{array}{l}\text { Course of epigastric pain during the } \\
\text { day (Q6) }\end{array}$ & 72 & & 227 & & & & & 0.0423 \\
\hline Continuous & 32 & $(22.7)$ & 135 & $(34.6)$ & -0.63 & 0.27 & 0.53 & \\
\hline Intermittent & 36 & $(25.5)$ & 78 & $(20.0)$ & 0.20 & 0.28 & 1.23 & \\
\hline$?$ & 4 & (2.8) & 14 & $(3.6)$ & .0 .38 & 0.66 & 0.96 & \\
\hline No epigastric pain & 69 & $(48.9)$ & 163 & $(41.8)$ & & & & \\
\hline Constant & & & & & -2.51 & 0.29 & & 0.0000 \\
\hline AUC & \multicolumn{8}{|c|}{0.77} \\
\hline
\end{tabular}

$n_{\text {oxweptugitus }}$ Number of patients with oesophagitis; $n_{\text {numal }}$ Number of patients with a normal endoscopy; B Logistic regression coefficient; SE Standard error; OR Adjusted odds ratio; $p$-value P-value of the Wald test for removal; "Symptom variable not necessarily present in all patients because of the branching structure of the questionnaires; "Reference category; ? Unresponded question or escape answer; ALC Area under the Receiver Operating Characteristic curve. 
Table III Discriminative variables selected by the logistic regression analysis of endoscopic gastritis ( $\left.\mathrm{n}_{\text {gastrilis }}=167\right)$ ws normal endoscopy $\left(\mathrm{n}_{\text {Rormas }}=390\right)$.

\begin{tabular}{|c|c|c|c|c|c|c|c|c|}
\hline SELECTED VARIABLES & $\mathrm{n}_{\text {Egascratio }}$ & $(\%)$ & $\mathrm{n}_{\text {hormit: }}$ & $(\%)$ & B & $\mathrm{SE}$ & OR & $\mathrm{p}$-value \\
\hline Age & 167 & & 390 & & 0.04 & 0.01 & 1.04 & 0.0000 \\
\hline Previous stomach surgery (Q52) & 167 & & 390 & & & & & 0.0002 \\
\hline Yes & 22 & $(13.2)$ & 8 & $(2.1)$ & 1.68 & 0.47 & 5.37 & \\
\hline No ${ }^{*}$ & 443 & $(85.6)$ & 373 & $(95.6)$ & & & & \\
\hline$?$ & 2 & $(1.2)$ & 9 & $(2.3)$ & -1.77 & 0.96 & 0.17 & \\
\hline Duration of heartburn (Q33) & 72 & & 160 & & & & & 0.0028 \\
\hline Years & 33 & $(19.8)$ & 35 & $(9.0)$ & 1.01 & 0.29 & 2.74 & \\
\hline Monthis & 13 & $(7.8)$ & 50 & $(12.8)$ & -0.47 & 0.37 & 0.62 & \\
\hline Days - weeks & 22 & $(13.2)$ & 60 & $(15,4)$ & 0.21 & 0.30 & 1.24 & \\
\hline$?$ & 4 & $(2.4)$ & 15 & $(3.8)$ & -0.31 & 0.62 & 0.73 & \\
\hline No heartburn " & 95 & $(56.9)$ & 230 & $(59.0)$ & & & & \\
\hline Gender & 167 & & 390 & & & & & \\
\hline Male & 95 & $(56.9)$ & 182 & $(46.7)$ & 0.47 & 0.21 & 1.60 & 0.0271 \\
\hline Female * & 72 & $(43.1)$ & 208 & $(53.3)$ & & & & \\
\hline Left upper abdominal pain & 167 & & 390 & & & & & 0.0580 \\
\hline Yes & 2 & $(1.2)$ & 22 & $(5.6)$ & -1.26 & 0.76 & 0.28 & \\
\hline No ${ }^{*}$ & 161 & $(96.4)$ & 366 & $(93.8)$ & & & & \\
\hline Missing & 4 & $(2.4)$ & 2 & $(0.5)$ & 1.62 & 0.96 & 5.03 & \\
\hline Known with gallstones (Q54) & 167 & & 390 & & & & & 0.0504 \\
\hline Yes & 17 & $(10.2)$ & 18 & $(4.6)$ & 0.52 & 0.40 & 1.68 & \\
\hline No* & 137 & $(82.0)$ & 358 & $(91.8)$ & & & & \\
\hline$?$ & 13 & $(7.8)$ & 14 & $(3.6)$ & 1.26 & 0.58 & 3.52 & \\
\hline Constant & & & & & -3.19 & 0.44 & & 0.0000 \\
\hline AUC & \multicolumn{8}{|c|}{0.73} \\
\hline
\end{tabular}

$\mathrm{n}_{\text {gastritio }}$ Number of patients with endoscopic gastritis; $\mathrm{n}_{\text {thomal }}$ Number of patients with a normal endoscopy; B Logistic regression coefficient; SE Standard error; OR Adjusted odds ratio; p-value P-value of the Wald test for removal; "Symptom wariable not necessarily present in all patients because of the branching structure of the questionnaires; "Reference category; ? Unresponded question or escape answer; AUC Area under the Receiver Operating Characteristic curve. 
Table IV Discriminative variables selected by the logistic regression analysis of gastric ulcer $\left(\mathrm{n}_{\mathrm{Gu}}=56\right) \mathrm{ws}$ normal endoscopy $\left(\mathrm{n}_{\mathrm{Bus}}=390\right)$.

\begin{tabular}{|c|c|c|c|c|c|c|c|c|}
\hline SELECTED VARIABLES & $\mathrm{n}_{\mathrm{gu}}$ & $(\%)$ & $\mathbf{n}_{\text {rocornala }}$ & $(\%)$ & $\mathrm{B}$ & $\mathrm{SE}$ & OR & $\mathrm{p}^{\text {-value }}$ \\
\hline Age & 56 & & 390 & & 0.05 & 0.01 & 1.06 & 0.0000 \\
\hline Smoking (Q51) & 56 & & 390 & & & & & 0.0018 \\
\hline No & 18 & $(32.1)$ & 213 & $(54.6)$ & & & & \\
\hline$<15$ cigarettes & 24 & $(42.9)$ & 90 & $(23.1)$ & 1.39 & 0.40 & 4.02 & \\
\hline$\geq 15$ cigarettes & 14 & $(25.0)$ & 75 & $(19.2)$ & 1.52 & 0.47 & 4.56 & \\
\hline$?$ & 0 & $(0.0)$ & 12 & $(3.1)$ & -7.32 & 26.22 & 0.00 & \\
\hline Signs of upper GI bleeding & 56 & & 390 & & & & & \\
\hline Yes & 8 & $(14.3)$ & 21 & $(5.4)$ & 1.87 & 0.54 & 6.46 & 0.0005 \\
\hline No * & 48 & $(85.7)$ & 369 & $(94.6)$ & & & & \\
\hline Anti-peptic therapy & 56 & & 390 & & & & & 0.0015 \\
\hline Yes & 32 & $(57.1)$ & 155 & $(39.7)$ & 1.33 & 0.37 & 3.78 & \\
\hline No & 24 & $(42.9)$ & 234 & $(60.0)$ & & & & \\
\hline Missing & 0 & $(0.0)$ & 1 & $(0.3)$ & -8.27 & 99.64 & 0.00 & \\
\hline Epigastric pain before meal (Q9) & 34 & & 227 & & & & & 0.0053 \\
\hline Yes & 13 & $(23.2)$ & 33 & $(8.5)$ & 1.44 & 0.51 & 4.20 & \\
\hline No & 16 & $(28.6)$ & 165 & $(42.3)$ & -0.44 & 0.41 & 0.65 & \\
\hline$?$ & 5 & $(8.9)$ & 29 & $(7.4)$ & 0.30 & 0.67 & 1.36 & \\
\hline No epigastric pain " & 22 & $(39.3)$ & 163 & $(41.8)$ & & & & \\
\hline Retrosternal pain before meal (Q26) & 26 & & 160 & & & & & 0.4015 \\
\hline Yes & 5 & $(8.9)$ & 20 & $(5.1)$ & 0.23 & 0.65 & 1.26 & \\
\hline No & 21 & $(37.5)$ & 122 & $(31.3)$ & 0.63 & 0.38 & 1.88 & \\
\hline$?$ & 0 & $(0.0)$ & 18 & $(4.6)$ & -7.56 & $2 \| .17$ & 0.00 & \\
\hline No retrosternal pain & 30 & $(53.6)$ & 230 & $(59.0)$ & & & & \\
\hline Left upper abdominal pain & 56 & & 390 & & & & & 0.5912 \\
\hline Yes & 0 & $(0.0)$ & 22 & $(5.6)$ & -7.42 & 18.33 & 0.00 & \\
\hline No & 55 & $(98.2)$ & 366 & $(93.8)$ & & & & \\
\hline Missing & 1 & $(1.8)$ & 2 & $(0.5)$ & 1.44 & 1.53 & 4.22 & \\
\hline Previous peptic ulcer & 56 & & 390 & & & & & \\
\hline Yes & 12 & $(21.4)$ & 22 & $(5.6)$ & 1.09 & 0.49 & 2.97 & 0.0262 \\
\hline No ${ }^{*}$ & 44 & $(78.6)$ & 368 & $(94,4)$ & & & & \\
\hline Constant & & & & & -6.70 & 0.94 & & 0.0000 \\
\hline $\mathrm{AUC}$ & \multicolumn{8}{|c|}{0.86} \\
\hline
\end{tabular}

$\mathrm{n}_{\text {Git }}$ Number of patients with gastric ulcer; $\mathrm{n}_{\text {nomal }}$ Number of patients with a normal endoscopy; $B$ Logistic regression coefficient; SE Standard error; OR Adjusted odds ratio; p-value P-value of the Wald test for removal; "Symptom variable not necessarily present in all patients because of the branching structure of the questionnaires; "Reference category; ? Unresponded question or escape answer; AUC Area under the Receiver Operating Characteristic curve. 
Table $\mathbf{V}$ Discriminative variables selected by the logistic regression analysis of duodenitis/bulbitis ( $\mathrm{n}_{\text {duadenius }}=152$ ) ws normal endoscopy $\left(\mathrm{n}_{\mathrm{sax} m \mathrm{~m}}=390\right)$.

\begin{tabular}{|c|c|c|c|c|c|c|c|c|}
\hline SELECTED VARIABLES & $\mathbb{m}_{\text {thioder }}$ & nimis $(\%)$ & $\mathrm{n}_{\text {nagrnal }}$ & $(\%)$ & $\mathrm{B}$ & $\mathrm{SE}$ & OR & p-value \\
\hline Gender & 152 & & 390 & & & & & \\
\hline Male & 110 & $(72.4)$ & 182 & $(46.7)$ & 0.98 & 0.22 & 2.66 & 0.0000 \\
\hline Female * & 42 & $(27.6)$ & 208 & $(53.3)$ & & & & \\
\hline Smoking (Q5i) & 152 & & 390 & & & & & 0.0004 \\
\hline No ${ }^{*}$ & 48 & $(31.6)$ & 213 & $(54.6)$ & & & & \\
\hline$<15$ cigarettes & 50 & $(32.9)$ & 90 & $(23.1)$ & 0.84 & 0.26 & 2.31 & \\
\hline$\geq 15$ cigarettes & 48 & (31.6) & 75 & $(19.2)$ & 1.07 & 0.27 & 2.92 & \\
\hline$?$ & 6 & $(3.9)$ & 12 & (3.1) & -0.22 & 1.33 & 0.80 & \\
\hline Age & 152 & & 390 & & 0.03 & 0.01 & 1.03 & 0.0000 \\
\hline Anti-peptic therapy & 152 & & 390 & & & & & 0.0061 \\
\hline Yes & 82 & (53.9) & 155 & $(39.7)$ & 0.68 & 0.22 & 1.97 & \\
\hline No & 69 & $(45.4)$ & 234 & $(60.0)$ & & & & \\
\hline Missing & 1 & $(0.7)$ & 1 & $(0.3)$ & 1.55 & 1.44 & 4.70 & \\
\hline Previous stomach surgery (Q52) & 152 & & 390 & & & & & 0.0281 \\
\hline Yes & 11 & $(7.2)$ & 8 & $(2.1)$ & 1.33 & 0.52 & 3.80 & \\
\hline No ${ }^{*}$ & 135 & $(88.8)$ & 373 & $(95.6)$ & & & & \\
\hline$?$ & 6 & $(3.9)$ & 9 & $(2.3)$ & 1.12 & 1.34 & 3.06 & \\
\hline Duration of heartburn (Q33) & 77 & & 160 & & & & & 0.0268 \\
\hline Years & 34 & $(22.4)$ & 35 & $(9.0)$ & 0.93 & 0.30 & 2.55 & \\
\hline Months & 20 & $(13,2)$ & 50 & $(12.8)$ & 0.18 & 0.33 & 1.19 & \\
\hline Days - weeks & 19 & $(12.5)$ & 60 & $(15.4)$ & 0.00 & 0.33 & 1.00 & \\
\hline$?$ & 4 & (2.6) & 15 & (3.8) & -0.28 & 0.63 & 0.76 & \\
\hline No heartburn : & 75 & $(49.3)$ & 230 & $(59.0)$ & & & & \\
\hline Constlant & & & & & -4.27 & 0.53 & & 0.0000 \\
\hline$\overline{A U C}$ & \multicolumn{8}{|c|}{0.75} \\
\hline
\end{tabular}

$\mathrm{n}_{\text {chrodentias }}$ Number of patients with duodenitis/bulbitis; $\mathrm{n}_{\text {twormal }}$ Number of patients with a normal endoscopy; B Logistic regression coefficient; SE Standard error; OR Adjusted odds ratio; p-value P-value of the Wald test for removal; "Symptom wariable not necessarily present in all patients because of the branching structure of the questionnaires; "Reference category; ? Unresponded question or escape answer; AUC Area under the Receiver Operating Characteristic curve. 
Table VI Discriminative yariables selected by the logistic regression analysis of duodenal ulcer $\left(n_{\text {vu }}=78\right)$ ys notmal endoscopy $\left(n_{\text {normal }}=390\right)$.

\begin{tabular}{|c|c|c|c|c|c|c|c|c|}
\hline SELECTED VARLABLES & $n_{\text {DU }}$ & $(\%)$ & $\mathrm{n}_{\text {Rormail }}$ & $(\%)$ & B & $\mathrm{SE}$ & OR & p-value \\
\hline Epigastric pain & 78 & & 390 & & & & & 0.0001 \\
\hline Yes & 65 & $(83.3)$ & 209 & $(53,6)$ & 1.70 & 0.38 & 5.50 & \\
\hline No & 13 & $(16.7)$ & 179 & $(45.9)$ & & & & \\
\hline Missing & 0 & $(0.0)$ & 2 & $(0.5)$ & -4.81 & 41.16 & 0.01 & \\
\hline Age & 78 & & 390 & & 0.03 & 0.01 & 1.04 & 0.0010 \\
\hline $\begin{array}{l}\text { Retrostermal pain decteasing after } \\
\text { meal }(\mathrm{Q} 27)^{\prime}\end{array}$ & 24 & & 160 & & & & & 0.0022 \\
\hline Yes & 14 & $(17.9)$ & 29 & $(7.4)$ & 0.38 & 0,43 & 1.46 & \\
\hline $\mathrm{No}$ & 7 & $(9.0)$ & 114 & $(29.2)$ & -1.60 & 0.46 & 0.20 & \\
\hline$?$ & 3 & $(3.8)$ & 17 & $(4.4)$ & -0.19 & 0.71 & 0.82 & \\
\hline No retrosternal pain " & 54 & $(69.2)$ & 230 & $(59.0)$ & & & & \\
\hline Nausea (Q37) & 78 & & 390 & & & & & 0.0017 \\
\hline Yes & 17 & $(21.8)$ & 1.56 & $(40,0)$ & -1.17 & 0.35 & 0.31 & \\
\hline No * & 59 & $(75.6)$ & 211 & $(54.1)$ & & & & \\
\hline$?$ & 2 & $(2.6)$ & 23 & (5.9) & -1.46 & 0.89 & 0.23 & \\
\hline $\begin{array}{l}\text { Epigastric pain increasing with lying } \\
\text { or bending (Q16) }\end{array}$ & 50 & & 227 & & & & & 0.0011 \\
\hline Yes & 9 & $(11.5)$ & 95 & (24.4) & -0.92 & 0.48 & 0.40 & \\
\hline No & 35 & $(44.9)$ & 109 & $(27.9)$ & 0.82 & 0.35 & 2.27 & \\
\hline$?$ & 6 & $(7.7)$ & 23 & $(5.9)$ & 1.04 & 0.62 & 2.83 & \\
\hline No epigastric pain " & 28 & $(35,9)$ & 163 & $(41.8)$ & & & & \\
\hline Smoking (Q51) & 78 & & 390 & & & & & 0.0336 \\
\hline $\mathrm{No}^{\circ}$ & 28 & $(35.9)$ & 213 & $(54.6)$ & & & & \\
\hline$<15$ cigarettes & 26 & $(33,3)$ & 90 & $(23.1)$ & 0.82 & 0.35 & 2.28 & \\
\hline$\geq 15$ cigarettes & 21 & $(26.9)$ & 75 & $(19.2)$ & 1.03 & 0.40 & 2.81 & \\
\hline$?$ & 3 & $(3.8)$ & 12 & $(3.1)$ & 0.43 & 0.85 & 1.54 & \\
\hline Signs of upper GI bleeding & 78 & & 390 & & & & & \\
\hline Yes & 8 & $(10.3)$ & 21 & $(5.4)$ & 1.19 & 0.54 & 3.30 & 0.0264 \\
\hline No & 70 & $(89.7)$ & 369 & $(94.6)$ & & & & \\
\hline
\end{tabular}

$n_{\mathrm{P}, \mathrm{i}}$ Number of patients with duodenal ulcer: $\mathrm{n}_{\mathrm{namal}}$ Number of patients with a normal endoscopy; $\mathrm{B}$ Logistic regression coefficient; SE Standard error; OR Adjusted odds ratio; p-value P-value of the Wald test for removal; "Symptom variable not necessarily present in all patients because of the branching structure of the questionnaires; "Reference category; ? Unresponded question or escape answer; AUC Area under the Receiver Operating Characteristic curve. 
continuation Table VI

\begin{tabular}{|c|c|c|c|c|c|c|c|c|}
\hline SELECTED VARIABLES & $n_{\text {pus }}$ & $(\%)$ & $\mathrm{n}_{\text {nommal }}$ & $(\%)$ & B & SE & OR & p-value \\
\hline $\begin{array}{l}\text { Vomiting after the ingestion of food } \\
\text { (Q41) }\end{array}$ & 7 & & 37 & & & & & 0.0380 \\
\hline Yes & 7 & $(9.0)$ & 18 & $(4.6)$ & 1.67 & 0.58 & 5.29 & \\
\hline Not related to ingestion of food & 0 & $(0.0)$ & 16 & $(4.1)$ & -5.60 & 13.90 & 0.00 & \\
\hline$?$ & 0 & $(0.0)$ & 3 & $(0.8)$ & -4.64 & 33.48 & 0.01 & \\
\hline No vomiting * & 71 & $(91.0)$ & 353 & $(90.5)$ & & & & \\
\hline $\begin{array}{l}\text { Complaints increasing with stress } \\
(Q 57)\end{array}$ & 78 & & 390 & & & & & $0.02 \| 2$ \\
\hline Yes & 48 & $(61.5)$ & 180 & $(46.2)$ & 0.83 & 0.38 & 2.30 & \\
\hline No ${ }^{*}$ & 15 & (19.2) & 119 & $(30.5)$ & & & & \\
\hline$?$ & 15 & $(19.2)$ & 91 & $(23.3)$ & -0.06 & 0.46 & 0.94 & \\
\hline Constant & & & & & -5.19 & 0.81 & & 0.0000 \\
\hline
\end{tabular}

AUC

0.85

$\mathrm{n}_{\mathrm{pu}}$ Number of patients with duodenal ulcer; $\mathrm{n}_{\text {nefnal }}$ Number of patients, with a normal endoscopy; $\mathrm{B}$ Logistic regression coefficient; SE Standard error; OR Adjusted odds ratio; p-value P-value of the Wald test for removal; "Symptom variable not necessarily present in all patients because of the branching structure of the questionnaires; "Reference category; ? Unresponded question or escape answer; AUC Area under the Receiver Operating Characteristic curve. 
Table VII Discriminative variables selected by the logistic regression analysis of "relevant endoscopic disease" $\left(n_{\text {retevan }}=269\right)$ ws "irrelevant" and normal endoscopic findings $\left(n_{\text {ifrelevinil }}=878\right)$.

\begin{tabular}{|c|c|c|c|c|c|c|c|c|}
\hline SELECTED VARIABLES & $n_{\text {rekevarit }}$ & $(\%)$ & $\mathrm{n}_{\text {irselerval }}$ & $(\%)$ & B & SE & $\mathrm{OR}$ & $\mathrm{p}$-value \\
\hline Duration of heartburn (Q33)" & 153 & & 382 & & & & & 0.0004 \\
\hline Years & 66 & $(24.5)$ & 121 & $(13.8)$ & 0.80 & 0.19 & 2.22 & \\
\hline Months & 37 & $(13.8)$ & 113 & (12.9) & 0.40 & 0.22 & 1.50 & \\
\hline Days - weeks & 41 & $(15.2)$ & 112 & $(12.8)$ & 0.47 & 0.21 & 1.60 & \\
\hline$?$ & 9 & $(3.3)$ & 36 & $(4.1)$ & 0.05 & 0.39 & 1.05 & \\
\hline No heartburn * & 116 & $(43,1)$ & 496 & $(56.5)$ & & & & \\
\hline Gender & 269 & & 878 & & & & & \\
\hline Male & 170 & $(63.2)$ & 464 & $(52.8)$ & 0.36 & 0.15 & 1.44 & 0.0135 \\
\hline Female ${ }^{*}$ & 99 & $(36.8)$ & 414 & $(47.2)$ & & & & \\
\hline Previous peptic ulcer & 269 & & 878 & & & & & \\
\hline Yes & 29 & $(10.8)$ & 57 & $(6.5)$ & 0.58 & 0.25 & 1.78 & 0.0202 \\
\hline No " & 240 & $(89.2)$ & 821 & $(93.5)$ & & & & \\
\hline Left upper abdominal pain & 269 & & 878 & & & & & 0.0378 \\
\hline Yes & 3 & (1.1) & 42 & $(4.8)$ & -1.49 & 0.61 & 0.22 & \\
\hline No * & 264 & $(98.1)$ & 826 & $(94.1)$ & & & & \\
\hline Missing & 2 & $(0.7)$ & 10 & $(1.1)$ & -0.57 & 0.79 & 0.57 & \\
\hline Constant & & & & & -1.67 & 0.14 & & 0.0000 \\
\hline AUC & \multicolumn{8}{|c|}{0.63} \\
\hline
\end{tabular}

$n_{\text {relevant }}$ Number of patients with relevant endoscopic disease; $n_{\text {irrelevan }}$ Number of patients with irrelevant or normal endoscopic findings; B Logistic regression coefficient; SE Standard error; OR Adjusted odds ratio; p-value P-value of the Wald test for removal; "Symptom variable not necessarily present in all patients because of the branching structure of the questionnaires; " Reference category; ? Unresponded question or escape answer; AUC Area under the Receiver Operating Characteristic curve.

Relevant endoscopic disease: the logistic regression analysis resulted in only four variables significantly contributing to the discrimination of patients with "relevant endoscopic disease" from those without: heartburn during a period of several years, male gender, a history of peptic ulcer, and absence of left upper abdominal pain (Table VII). 


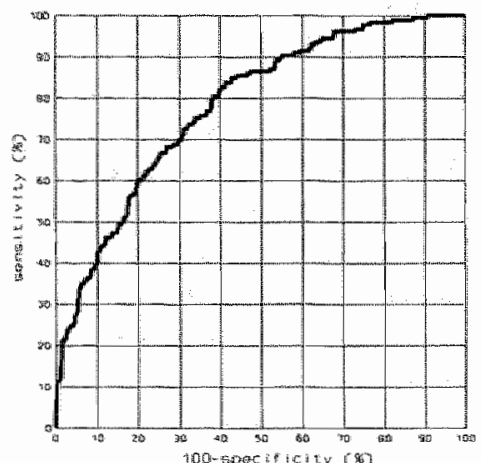

a Hiatus hernia

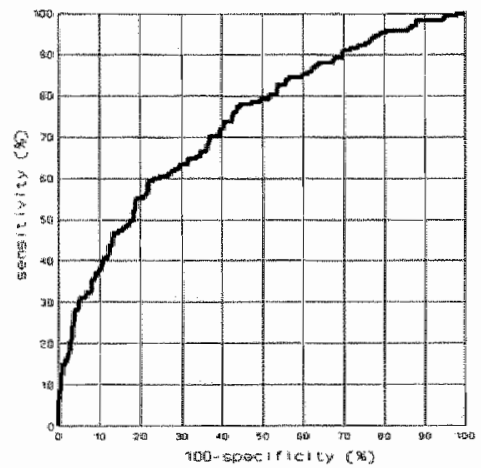

c Endoscopic gastritis

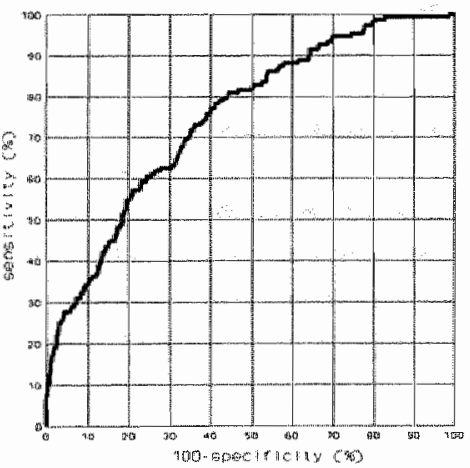

e Duodenitis/bulbitis

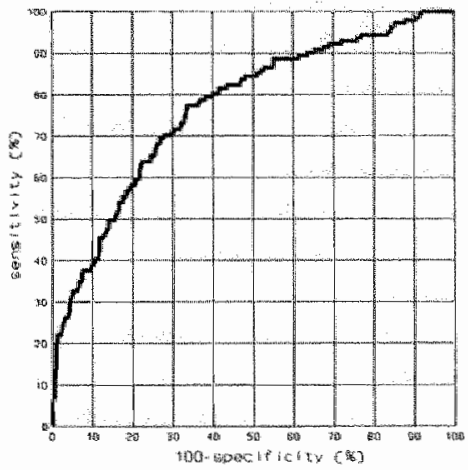

b Oesophagitis

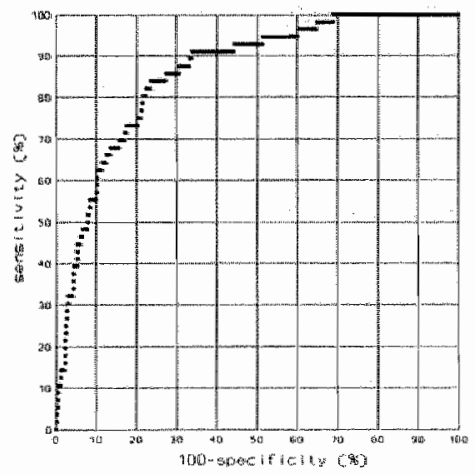

d Gastric ullcer

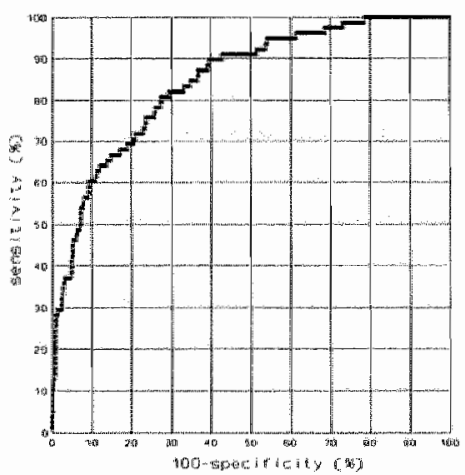

f Duodenal ulcer

Figure II ROC curves of the logistic regression (prediction) models. 


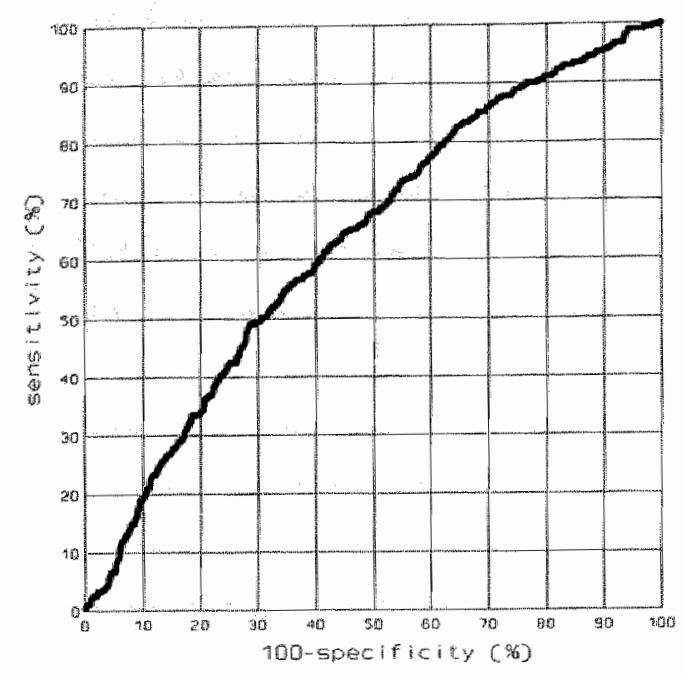

Figure III ROC curve of the logistic regression (prediction) model for relevant endoscopic disease.

\section{Discussion}

Until now, the diagnostic value of dyspeptic symptoms for upper GI endoscopic findings has remained an area of controversy. In some studies $25-27,35,36,39-41$ the importance of a limited number of symptoms for making a diagnosis of dyspepsia has been stressed, whereas others required attention for the large number of nondiscriminating symptoms ${ }^{42-47}$.

In this study patient data were prospectively collected in a consistent and uniform manner. A large number of symptom variables were systematically elicited using structured paper or computerised questionnaires, a method which improves the reliability of history taking ${ }^{48.51}$. The endoscopic diagnoses were obtained by endoscopists unaware of the questionnaire data.

The present study has confirmed the limited value of symptom recording for the prediction of clinically relevant disease in patients undergoing endoscopy $35,36,40,42,46,47,52$. Of all 73 variables studied, only four significantly contributed to the discrimination of patients with clinically relevant findings from those without. Like others ${ }^{25.27 .36}$, we found male gender and history of peptic ulcer to be predictive of relevant endoscopic disease. The other two variables were presence of heartburn and absence of left upper abdominal pain. The latter seems to be of limited value, since this pain localisation occurred in only a small proportion of the referralls. Whereas other investigations have emphasised the association between patient age and the 
demonstration of relevant endoscopic disease $7,25,27,36,46$, this was not found in the present study.

Theoretically, symptom-based prediction modeis can be used to select patients for upper GI endoscopy, accepting only those with 'scores above a certain threshold' $25-28,33,34$. Although such models must be proved in prospective trials, their impact can be tested by applying them on the observed material ${ }^{33}$. If in our material a sensitivity of $90 \%$ was used as the cutoff point, the number of endoscopic procedures could be reduced by the number of correctly classified patients with 'irrelevant' findings (specificity; 20\%), and the number of falsely classified patients with 'relevant findings' (100-sensitivity; 10\%) (Figure III). This implies that $87 \%$ of the patients 'with a score below the cutoff' (the negative predictive value) were correctly classified as having irrelevant findings, and that only $26 \%$ of those 'with a score above the cutoff' (the positive predictive value) were correctly predicted to have a relevant endoscopic diagnosis.

The main impact of prediction models in dyspepsia seems to be their high negative predictive value, mainly because of the relatively low prevalence of clinically relevant endoscopic diseases ${ }^{27,36}$. Therefore, the possible clinical application of these symptom-based models would be to exclude relevant findings rather than actually predict them ${ }^{37}$.

The prediction models for various endoscopic diagnoses used in this study distinguish themselves in several aspects from those described by others $35,36,40,44$. Firstly, gastric ulcer and duodenal ulcer were analysed as separate diagnostic categories in order to possibly identify a patient characteristic and symptom profile typical for each of both diagnoses. Secondly, patients with endoscopic signs of gastroduodenal inflammation only were not assigned to the control group. Hiatus hernia also formed a separate diagnostic category instead of being included in the control group ${ }^{35,36}$.

Both gastric and duodenal ulcers could be predicted with a sensitivity of $90 \%$ and a specificity of about $60 \%$. In contrast to Talley et al. ${ }^{40}$, we found that patient characteristics and symptoms are more useful in discriminating patients with peptic ulcers from patients with a normal endoscopy than in separating patients with clinically relevant endoscopic findings from those without.

Age, smoking and previous ulcer disease have been identified as predictors of peptic ulcer disease ${ }^{35.36,39,53.54}$. Furthermore, in this study, patient age and smoking (together with signs of upper GI bleeding) were significantly related to the presence of peptic ulcers. The more so, we found that the probability of having an ulcer increased with increasing cigarette consumption. In the present study, a history of peptic ulcer and empiric medical treatment were significantly associated with the detection of a gastric ulcer, but not of a duodenal ulcer. Although use of NSAIDs is a well-recognised risk factor for peptic ulcer disease, this was not selected as a predictive variable in the logistic regression models, probably due to the fact that only a small number of patients used these ulcerogenic drugs. 
A number of symptoms have been referred to as 'classical ulcer symptoms' in textbooks ${ }^{55.56}$ and previous publications ${ }^{4,9,40,41,44,57-59}$ : epigastric pain before meals or when hungry ("hunger pain'); 'night pain'; pain or discomfort relieved by food; pain or discomfort relieved by antacids; periodic pain or discomfort; well-localised abdominal pain or discomfort. Of these symptoms, 'hunger pain' and 'night pain' in particular have been reported as being typical features of duodenal ulcer disease $7,35,40,41,45,46,53,60$

We only found epigastric pain before meal ('hunger pain') to be significantly associated with gastric ulcer. The remaining 'classical ulcer symptoms' appeared to be of no discriminative value in patients referred for upper GI endoscopy. Our results did not confirm one of medicine's oldest adages - that 'the patient with gastric ulcer is afraid to eat and the patient with duodenal ulcer is afraid not to eat'.

Our results show that it is not possible to establish a reliable diagnosis of hiatus hernia and oesophagitis on the basis of patient history alone. Almost identical ROC curves were obtained for both diagnoses, reaching at a sensitivity of $80 \%$ a specificity of $60 \%$. Marked male preponderance, the presence of heartburn lasting for months to years, and retrosternal pain were clearly associated with both oesophagitis and hiatus hernia ${ }^{36,40,61}$. This observation may support the assumption that symptoms do not permit a differentiation between gastro-oesophageal reflux with or without endoscopic signs of inflammation ${ }^{62}$, the more so, since there is a close association between oesophagitis and hiatus hernia ${ }^{63}: 31 \%$ of the patients with hiatus hernia also had oesophagitis, and $40 \%$ of the patients with oesophagitis had a hiatus hernia.

In contrast to Talley et al. ${ }^{40}$, we found that the diagnostic accuracy of history taking was lower for oesophagitis than for peptic ulcers. Many patients with a normal examination will probably have symptomatic gastro-oesophageal reflux without evidence at endoscopy. Although heartburn is considered the leading symptom in gastro-oesophageal reflux disease ${ }^{62.64-66}$, we found that also patients with gastritis and those with duodenitis/bulbitis experienced heartburn more often than patients having a normal endoscopy. In a study by Johnsen $e t$ al. ${ }^{67}$, heartburn was even more often reported by patients with duodenitis than by those with oesophagitis.

Patients with endoscopic gastritis or duodenitis/bulbitis could harcly be discriminated from patients with a normal endoscopy. The logistic regression models gave a sensitivity of $80 \%$ and a specificity of not more than $50 \%$.

There remains considerable dispute as to whether dyspeptic symptoms correlate with the presence of endoscopic gastritis or duodenitis, and about the possible relationship between gastroduodenitis and peptic ulcers ${ }^{57,58,67-82}$. The fact that no symptom variable other than 'duration of heartburn' has been selected in the logistic regression models comparing patients with gastritis or duodenitis/bulbitis to patients with a normal investigation, supports the idea that the association between symptoms and diffuse inflammatory changes on endoscopy is questionable $58,69,76,77,79.83$. The present results suggest that the findings of endoscopic gastritis or duodenitis/bulbitis 
must not be accepted as the cause of dyspeptic complaints per se, since an almost similar symptom pattern occurs in endoscopically normal patients. However, it must be realised that 'endoscopic' gastritis and duodenitis/bulbitis as defined in this study include a wide range of endoscopic appearances of mucosal inflammation, and that a more differentiated grading might have given a better distinction.

Like others ${ }^{81,82}$, we found a significantly positive association between duodenitis/bulbitis and age, male gender, and smoking. In fact, age and cigarette consumption were identified as predictive variables for both duodenitis/bulbitis and duodenal ulcer; this tends to support the hypothesis that duodenitis/bulbitis is a part of the spectrum of duodenal ulcer disease and not a separate entity ${ }^{57,58,70-73,78,81}$.

Like many other studies in this field of research ${ }^{25,35,36,40,44,46,53}$, our study dealt with patients who were referred for endoscopy. It can be assumed that the observations of the relationship between symptoms and diseases are influenced by consultation and referral patterns. Valuable diagnostic information has been used in relation to the referral process and, therefore, the discriminative value of history taking may be somewhat decreased in patients selected for endoscopy ${ }^{84}$. The fact that more than $40 \%$ of the patients had been empirically treated before the endoscopy may also have influenced the symptoms and endoscopic findings. Anyhow, it was the aim of this study to explore whether it is possible to discriminate among referrals between those with or without clinically relevant endoscopic disease, but not to select patients in general practice for endoscopy.

For the purpose of this study, histopathological findings were not taken into account. It has been demonstrated that there is only a weak or no correlation between the histologic appearances of gastric or duodenal inflammation and symptoms ${ }^{67,73,77}$. For this reason, it seemed adequate to consider in this study only the endoscopic diagnoses of gastritis and duodenitis/bulbitis. In our study an ulcer in the stomach was classified as benign unless endoscopic features suggestive of malignancy were present. We realise that a small number of these endoscopically benignlooking gastric ulcers may in fact represent gastric cancers. Similarly, a histologically benign gastric ulcer may have appeared as an ulcerated carcinoma at endoscopy. However, the prediction model for relevant endoscopic disease has not been biased by disregarding the histopathological findings, since both gastric ulcers and gastric cancers were classified as relevant disorders.

No other investigations were performed to exclude organic or functional disease likely to explain the symptoms. Due to this, both patient and control group remain heterogeneous populations including subjects with increased gastro-oesophageal reflux but without oesophagitis, subjects with symptomatic gallstones, subjects with symptoms of the irritable bowel syndrome, and subjects with other disorders that may cause dyspepsia ${ }^{35,47}$. These undiagnosed organic or functional disorders cause a "background murmur of symptoms", possibly influencing the discriminative performance of the prediction models.

The appreciation of the relationship between a symptom and a disease is mostly based upon a semi-quantitative experience with patients having the disease and the 
symptom. This study demonstrates the value of obtaining objective symptom data on disorders associated with dyspepsia instead of relying on clinical impressions or aphorisms handed down from one textbook to another. Our data suggest that symptom models for predicting a diagnosis in patients referred for endoscopy are not sensitive enough to be useful in clinical practice. Symptom-based models are certainly not transferable from one gastroenterology unit to another without corrections for differences in the populations studied ${ }^{39,85}$. 


\section{References}

1. Anonymous. Data base on dyspepsia [Editorial]. Br Med J 1978; 1: 1163-1164.

2. Krag E. Non-ulcer dyspepsia. Introduction: epidemiological data. Scand J Gastroenterol 1982; 17 Suppl 79: 6-8.

3. Jones R, Lydeard S. Prevalence of symptoms of dyspepsia in the community. $B r$ Med J 1989; 298: $30-32$.

4. Talley $\mathrm{NJ}$, Zinsmeister $A R_{n}$ Schleck $C D$, Melton LJ. Dyspepsia and dyspepsia subgroups: a population-based study. Gastroenterology 1992; 102: 1259-1268.

5. Nyrén O, Adami H-O, Gustassson S, Löóf L, Nyberg A. Social and economic effects of nonulcer dyspepsia. Scand J Gastroenterol 1985; 20 Suppl 109: 41-45.

6. Nyrén $\mathrm{O}$, Adami H-O, Gustavsson S, Lööf L. Excess sick-listing in nonulcer dyspepsia. J Clin Gastroenterol 1986; 8 (3): 339-345.

7. Crean GP, Holden RJ, Knill-Jones RP, Beattie AD, James WB, Marjoribanks FM, et al. A database on dyspepsia. Gut 1994; 35: 191-202.

8. Kahn KL, Greenfield S. The efficacy of endoscopy in the evaluation of dyspepsia. A review of the literature and development of a sound strategy. $J$ Clin Gastroenterol 1986; 8 (3): 346-358.

9. Colin-Jones DG, Bloom B, Bodemar G, Crean G, Freston J, Gugler R, et al. Management of dyspepsia: report of a working party. Lancet 1988; I: 576-579.

10. Hungin AS. Use of an open-access gastroscopy service by a general practice: findings and subsequent referral rate. J $R$ Coll Gen Pract 1987; 37: 170-171.

11. Gear MWL, Wilkinson SP. Open-access upper alimentary endoscopy. Br J Hosp Med 1989; 41: $438-444$.

12. Scott $B$, Atkinson $M$. Gastroenterology services: a regional review of changes over a five year period (1981-86). Gut 1989; 30: 695-700.

13. Working Party of the Clinicall Services Committee of the British Society of Gastroenterology. Provision of gastrointestinal endoscopy and related services for a district general hospital. Gut 1991; 32: 95-105.

14. Bramble MG. Open access endoscopy - a nationwide survey of current practice. Gut 1992; 33: 282-285.

15. Barbara $L$, Camilleri $M$, Corinaldesi $R$, Crean GP, Heading RC, Johnson $A G$, et al. Definition and investigation of dyspepsia. Consensus of an international ad hoc working party. Dig Dis Sci 1989; 34: 1272-1276.

16. Williams B, Luckas M, Ellingham JHM, Dain A, Wicks ACB. Do young patients with dys ${ }^{-}$ pepsia need investigation? Lancet 1988; II: 1349-1351.

17. Newton M, Jamieson CP, Middleton S, Skinner AC, Kamm MA, Burnham WR. Open access endoscopy: how is a developing service viewed by general practitioners (GPS) [Abstract]? Gut 1994; 35 Suppl 2; F237.

18. Johnston DA, Lopez M, Goudie BM, McCollum R. Anderson JT, Pennington CR, et al. Open access endoscopy: satisfying general practitioners and reassuring patients, but increasing hospital worklload [Abstract]. Gut 1994; 35 Suppl 5: F310.

19. Jones R, Lydeard S. Dyspepsia in the community: a follow-up study. Br I Clin Pract 1992; 46 (2): $95-97$.

20. Venables C. Endoscopy: Its diagnostic role in dyspepsia. Scand J Gastroenterol $1988 ; 23$ Suppli 155: 44-49.

21. Morrissey JF. The problem of the inappropriate endoscopy. Ann Intem Med 1988; 109: 605606.

22. Scott B. Endoscopic demands in the 90's. Gut 1990; 31: 125-126. 
23. Cowan RE, Lerwill RI. Management strategies for dyspepsia and open access gastroscopy: A way of reducing the workload [Abstract]. Cut 1994; 35 Suppl 4: A87.

24. Moynitian BGA. On duodenal wilcer: with notes of 52 operations. Lancet 1905; 1: 340-346.

25. Mann J, Holdstock $G$, Harman M, Machin D, Loehry CA. Scoring system to improve cost effectiveness of open access endoscopy. Br Med $J 1983 ; 287: 937-940$.

26. Dawenport PM, Morgan AG, Darriborough A, de Dombal FT. Can prelimimary screening of dyspeptic patients allow more effective use of investigational techniques? $\mathrm{Br}$ Med J 1985; 290 : $217-220$.

27. Holdstock G, Harman M, Machin D, Patel C, Lloyd RS. Prospective testing of a scoring system designed to improve case selection for upper gastrointestinal investigation. Gastroenterology 1986; 90: 1164-1169

28. Knill-Jones RP. Diagnostic systems as an aid to clinical decision making. $\mathrm{Br}$ Med $J 1987$; 295: $1392-1396$.

29. Adang RP, Vismans F-JFE Ambergen AW, Talmon JL, Hasman A, Flendrig JA. Evaluation of computerised questionnaires designed for patients referred for gastrointestinal endoscopy. Int J Biomed Comp 1991; 29: 31-44.

30. Kang JY, Tay HH, Guan R. Chronic upper abdominal pain: site and radiation in various structural and functional disorders and the effect of various foods. Gut 1992; 33: 743-748.

31. Savary $M_{*}$ Miller $G$. The esophagus - handbook and atlas of endoscopy. Solothurn: Verlag Gassmann AG; 1977.

32. Hosmer DW, Lemeshow S. Applied logistic regression. 1st ed. New York: John Wiley and Sons. 1989.

33. Spiegelhalter DJ. Statistical methodology for evaluating gastrointestinal symptoms. Clin Gastroenterol 1985; 14: 489-515.

34. Spiegelhalter DJ, Crean GP, Holden R, Knill-Jones RP. Taking a calculated risk: Predictive scoring systems in dyspepsia. Scand J Gastroenterol 1987; 22 Suppl 128: 152 160.

35. Talley NJ, McNeil D. Piper DW. Discriminant value of dyspeptic symptoms: a study of the clinical presentation of 221 patients with dyspepsia of unknown cause, peptic ulceration, and cholelithiasis. Gut 1987; 28: 40-46.

36. Johannessen T, Petersen H, Kleveland PM, Dybdahl JH, Sandvik AK, Brenna E, et al. The predictive value of history in dyspepsia. Scand $J$ Gastroenterol 1990; 25: 689-697.

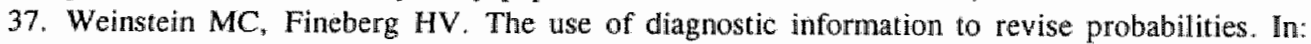
Clinical decision analysis. Philadelphia: WB Saunders Company, 1980: 114-127.

38. Hanley JA, McNeil BJ. The meaning and use of the area under a receiver operating charactertistic (ROC) curve. Radiology 1982; 143:29-36.

39. Petersen H. Johannessen T, Kleveland PM, Fjesne U, Dybdahl JH, Waldum HL. Do we need to listen to the parient? The predictive value of symptoms. Scand $J$ Gastroenterol 1988; 23 Suppl 155: 30-34...

40. Talley NJ, Weaver AL, Tesmer DL, Zinsmeister AR. Lack of discriminant value of dyspepsia subgroups in patients referred for upper endoscopy. Gastroenterology 1993; 105: 1378-1386.

41. Crean GP, Card WI, Beattie AD, Holden RJ, James WB, Knill-Jones RP, et al. "Ulcer-like dyspepsia". Scand J Gastroenterol 1982; 17 Suppl 79: 9-15.

42. Fjosne U, Kleveland PM, Waldum H, Halvorsen T, Petersen $H$. The clinical benefit of routine upper gastrointestinal endoscopy. Scand J Gastroenterol 1986; 21: 433-440.

43. Ross P, Dutton AM. Computer analysis of symptom complexes in patients having upper gastrointestinal examinations. Am J Dig Dis 197217 (3): 248-254.

44. Kudva MV, Zawawi M, Rafee N, Ismail $O$. Discriminant value of dyspeptic symptoms in peptic ulcer and non-ulcer dyspepsia. Med J Malcysia 1989; 44 (3): 236-242.

45. Horrocks JC, de Dombal FT. Clinical presentation of patients with 'dyspepsia', Detailed symptomatic study of 360 patients. Gut $1978 ; 19: 19-26$. 
46. Mansi C, Savarino V, Mela GS, Picciotto A, Mele MR, Celle G. Are clinical parterns of dyspepsia a valid guideline for appropriate use of endoscopy? A report on 2253 dyspeptic patients. Am J Gastroenterol 1993; 88 (7): 1011-1015.

47. Mansi C, Mela GS, Pasini D, Grosso M, Corti L, Moretti M, et al. Patterns of dyspepsia in patients with no clinical evidence of organtc diseases. Dig Dis Sici 1990; 35 (12): 1452-1458.

48. Horrocks $\mathrm{JC}$, de Dombal FT. Diagnosis of dyspepsia from data collected by a physician"s assistant. Br Med J 1975; 3: 421-423.

49. Horrocks JC, de Dombal FT. Computer-aided diagnosis of "dyspepsia". Dig Dis 1975; 20 (5): $397-406$.

50. Horrocks JC, Lambert DE, McAdam WAF, Morgan AG, Pacsoo C, Darnborough A, et at. Transfer of computer-aided diagnosis of dyspepsia from one geographical area to another. Gm 1976; 17: 640-644.

51. Knill-Jones RP. A formal approach to symptoms in dyspepsia. Clin Gastroenterol 1985; 14: 517-529.

52. Hallissey MT, Jewkes AJ, Allum WH, Ellis DJ, Fielding JWL. Clinical diagnosis in dyspepsia: a valueless exercise [Abstract]. Gut 1989; 30: A709.

53. Edenholm $M$, Gustavsson $R$, Jansson $O$, Lingfors $H$, Nilsson $O$, Söderlind $T$, et al. Endoscopic findings in patients with ulcer-like dyspepsia. Scand $J$ Gastroenterol $1985 ; 20$ Suppl 109: 163-167.

54. Johnsen R, Straume B, Forde OH. Peptic ulcer and non-ulcer dyspepsia - a disease and a disorder. Scand J Prim Health Care 1988; 6: 239-243.

55. Isenberg JI, McQuad KR, Laine L, Rubin W. Acid-peptic disorders. In: Yamada T, editor. Textbook of gastroenterology. Volume one. Philadelphia: J.B. Lippingcott company. 199》: $1263-1264$.

56. Thompson WG. Symptoms and signs of upper gastrointestinal disease. In: Gustavsson S, Kumar D, Graham DY, editors. The stomach. New York: Churchill Livingstone. 1992: 143156.

57. Greenlaw R, Sheahan DG, De Luca V, Miller D, Myerson D, Myerson P. Gastroduodenitis. A broader concept of peptic ulcer disease. Dig Dis Sci 1980; 25: 660-672.

58. Deluca VA, Winnan GG, Sheahan DG, Sanders FJ, Greenlaw R, Marignani $P$, et al. Is gastroduodenitis part of the spectrum of peptic ulcer disease? J Clin Gastroenterol 1981; 3 Suppl 2: 17-22.

59. Heading RC. Definitions of dyspepsia. Scand J Gastroenterol 1991; 26 Suppl 182: 1-6.

60. Petersen H, Fjosne U, Johamessen T, Kristensen P, Hafstad PE, Sandbakken P, et al. Clinical significance of upper abdominal symptoms. Scand J Gastroenterol 1985; 20 Suppl 1.09: 19-22.

61. Wienbeck M, Barnert J. Epidemiology of reflux disease and reflux esophagitis. Scand $J$ Gastroenterol 1989; 24 Suppl 156: 7-13.

62. Bennett JR. Oesophageal symptoms. Clin Gastroenterol 1985; 14: 591-598.

63. Berstad A, Weberg R, Frøyshov Larsen I, Hoel B, Hauer-Jensen M. Relationship of hiatus hernia to reflux oesophagitis. Sicand J Gastroenterol 1986; 21: 55-58.

64. Wienbeck M, Berges W. Esophageal disorders in the etiology and pathophysiology of dyspepsia. Scand J Gastroenterol 1985; 20 Suppl 109: 133-137.

65. Johnsson F, Joelsson B, Gudmundsson K, Greiff L. Symptoms and endoscopic findings in the diagnosis of gastroesophageal reflux disease. Scand J Gastroenterol 1987; 22: 714-718.

66. Klauser AG, Schindlbeck NE, Müller-Lissner SA. Symptoms in gastro-oesophageal reflux disease. Lancet 1990; 335: 205-208.

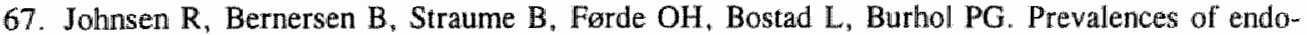
scopic and histological findings in subjects with and without dyspepsia. $\mathrm{Br} M$ Med $J 1991 ; 302$ : 749-752. 
68. Cheli $\mathbb{R}$. Symptoms in chronic non-specific duodenitis. Scand J Gastroenterol 1982; 17 Suppl 79 : $84-86$.

69. Toukan AU, Kamal MF, Amr SS, Amaout MA, Abu-Romiyeh AS. Gastroduodenal inflammation in patients with nonulcer dyspepsia. A controlled endoscopic and morphometric study. Dig Dis SCl 1985; 30 (4): 313-320.

70. Thomson WO, Robertson $\mathrm{AG}$, Imrie $\mathrm{CW}$, Joffe $\mathrm{SN}$, Lee $\mathrm{FD}$, Blumgart $\mathrm{LH}$. Is duodenitis a dyspeptic myth? Lancet 1977; I: 1197-1198.

71. Anonymous. Duodenitis - Any progress? Lancet 1985; 1: 1222-1223.

72. Joffe SN, Shiwa Rao S. Symptoms of gastritis. Scand J Gastroenterol 1982; 17 Suppl 79: 6265 .

73. Joffe SN. Relevance of duodenitis to non-ulcer dyspepsia and peptic ulceration. Scand $I$ Gastroenterol 1982; 17 Suppl 79: 88-97.

74. Talley NJ, Phillips SF. Non-ulcer dyspepsia: potential causes and pathofysiology. Ann Intern Med 1988; 108: 865-879.

75. Guslandi M. Non-ulcer dyspepsia [Letter]. Lancet 1986: 1: 113.

76. Villako K, Ihamäki T, Tamm A, Tammur R. Upper abdominal complaints and gastritis. Ann Clin Res 1984: 16: 192-194.

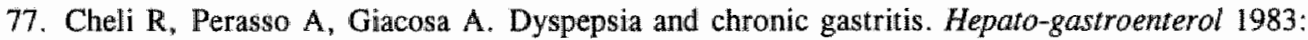
30: $21-23$.

78. Venables CW. Duodenitis. Scand J Gastroenterol 1985; 20 Suppl 109: 91-97.

79. Hojgaard L, Matzen P, Christoffersen P. Gastritis - A clinical entity? Scand J Gastroenterol 1987; 22 Suppl 128: 90-92.

80. Varis K. Gastritis - A misused term in clinical gastroenterology. Scand J Gastroenterol 1988; 23 Suppl 155: 53-58.

81. Venables C. Duodenitis. Scand J Gastroenterol 1988; 23 Suppl 155; 61-65.

82. Jönsson K-A, Gotthard R, Bodemar $G$, Brodin $U$. The clinical relevance of endoscopic and histologic inflammation of gastroduodenal mucosa in dyspepsia of unknown origin. Scand $J$ Gastroenteral 1989; 24: 385-395.

83. Akdamar K, Ertan A, Agrawal NM, McMahon FG, Ryan J. Upper gastrointestinal endoscopy in normal asymptomatic volunteers. Gastrointest Endosc 1986; 32 (2): 78-80.

84. Knottnerus JA. The effects of disease verification and referral on the relationship between symptoms and diseases. Med Decis Making 1987; 7: 139-148.

85. Lindberg G, Seensalu R, Nilsson LH, Forsell P, Kager L, Knill-Jones RP. Transferability of a computer system for medical history taking and decision support in dyspepsia. A comparison of indicants for peptic ulcer disease. Scand J Gastroenterol 1987; 22 Suppl 128: 190-196. 
Are upper gastrointestinal endoscopic findings predictable?

The use of a non-parametric partitioning algorithm. 



\section{Abstract}

The predictive value of patient characteristics and dyspeptic symptoms for upper gastrointestinal endoscopic findings was prospectively assessed in a series of 1147 patients undergoing their first diagnostic endoscopy by applying a non-parametric partitioning algorithm (NPPA). Detailed history data were obtained in a consistent and uniform manner by means of paper $(n=431)$ or computerised $(n=716)$ questionnaires. In 'two-class models', patients with a specific endoscopic diagnosis were contrasted with patients having a normal endoscopy $(n=390)$. In a 'multi-class model', patients with clinically 'relevant endoscopic disease' (oesophagitis; peptic ulcers; cancers, $n=269)$ were contrasted with those without $(n=878)$. NPPA resulted in a binary classification tree, from which a Receiver Operating Characteristic (ROC) curve was constructed. The Area Under the ROC Curve (AUC) summarises the predictive performance of the algorithm.

The best discrimination from patients with a normal endoscopy was achieved for patients with peptic ulcers, followed by patients with duodenitis/bulbitis. The models had similar discriminative value for hiatus hernia and for oesophagitis. Patients with endoscopic gastritis could hardly be discriminated from patients having a normal endoscopy. On the whole, it is not practical to predict the presence of clinically relevant endoscopic disease in patients referred for diagnostic upper gastrointestinal endoscopy by applying a symptom-based model, due to the high complexity of the classification tree.

\section{Introduction}

Dyspeptic complaints are very common and constitute a frequent reason for absence from work, self-medication, and health care consumption ${ }^{1.3}$. Upper gastrointestinal (GI) endoscopy is generally considered the investigation of first choice and is mandatory for a precise diagnosis of dyspepsia ${ }^{4-7}$. During the past two decades there has been a considerable increase of referrals for endoscopy, especially since the availability of open access services to general practitioners (GPs) ${ }^{8-11}$. In a large proportion of the patients, however, the endoscopic examination reveals no serious organic disorder ${ }^{1,12-14}$. Apparently, the clinical presentation of patients with dyspepsia provides only limited help when trying to select those patients who really need endoscopy ${ }^{15-18}$. It has been suggested that symptom-based prediction models can be used to achieve a more appropriate use of the available resources, accepting only patients with a significant probability of having relevant disease for upper GI endoscopy ${ }^{15,16,19-21}$.

The aims of this study were to assess 1) whether patients having a specific endoscopic diagnosis can be discriminated from patients with a normal endoscopy, and 2) whether it is possible to predict the presence of clinically relevant endoscopic disease in patients referred for a diagnostic upper GI endoscopy by analysing their 
characteristics and symptoms. The above-mentioned aims are similar to those presented in Chapter VII, however, in this chapter we will use a technique entirely different from that used in the foregoing chapter. This enables us to compare two distinct mathematical models applied to the same study material. As patients can have more than one endoscopic diagnosis, we also studied the influence of any copathology on the discrimination of a number of endoscopic diagnoses.

\section{Methods}

From January 1989 to October 1990, patients undergoing their first diagnostic upper GI endoscopy were asked to answer a detailed questionnaire concerning their previous medical history, actual dyspeptic symptoms, with special attention to provoking and/or relieving factors, and nicotine and/or alcohol consumption (Appendix B). In the first part of the study patients were offered a paper questionnaire, and in the second part they were requested to complete a computerised history taking system 22 . Both types of questionnaires have an identical branching structure, such that a patient has to answer at least 22 questions ('main questions'); the remaining 35 questions ('refinement questions') have to be answered only in case the preceding 'branching questions' were answered affirmatively. Patients were requested to choose a single answer to each question of the paper questionnaire; however, they were obliged to choose just one answer in order to proceed with the history taking system. Each question of the computerised questionnaire has an additional "escape answer' (I don't know; I don't understand; The correct answer is not available) besides the answer options of the paper questionnaire.

The methods of data acquisition have been extensively described in Chapter II; data were prospectively collected in a consistent and uniform manner by means of a standardised study form (Appendix A). The assessment of feasibility and acceptability of the computerised history taking system in clinical practice is presented in Chapter III.

A total number of 75 different variables were made available for statisticall analysis (number of different variables between brackets): age was treated as a continuous variable; male gender, referral indications [6], pain localisations [6], and drug regimens [4] were dealt with as dichotomous categorical variables (present/absent). The multiple-choice questions of the paper/computerised questionnaires resulted in 57 multi-categorical variables. For each of these questions the answer options were clustered and recoded in such a way that an ordinal ranking was obtained (Appendix E). For example, question 3 (Q3) enquired about the duration of epigastric pain; the coding scheme for the various answer options is given in Table I.

In this study we focused on the following diagnostic categories: hiatus hernia; oesophagitis; endoscopic gastritis; gastric uicer; duodenitis/bulbitis; duodenal ulcer; normal endoscopy; and the remaining endoscopic findings. Diagnostic criteria were 
agreed in advance and were applied as consistently as possible. Only endoscopic diagnoses have been considered; additional histopathological findings were not taken into account. Oesophageal and gastric cancer were not separately analysed, because of the limited number of patients with these disorders.

\section{METHODOLOGICAL APPROACH}

A non-parametric partitioning algorithm (NPPA) was used to create prediction models for several specific endoscopic diagnoses (two-class models) and a prediction model for clinically relevant endoscopic disease (multi-class model). The algorithm will be described in the following section of this chapter.

Non-parametric partitioning algorithm (NPPA): data analysis was performed with a non-parametric classification procedure designed for solving pattern recognition problems in which parametric techniques such as multivariant analysis or linear discriminant analysis are not suitable ${ }^{23.26}$. This procedure tries to find the variables that best discriminate between the classes in a sequential way. In general, NPPA tries to partition the high-dimensional variable space into regions such that in each region of that space (almost) only cases are present that belong to one class. Starting with the whole variable space, the most discriminative variable and a corresponding threshold is determined to split the set of cases into two subsets. The process is repeated for each of the subsets until a stop criterion is fulfilled. We use entropy reduction (ER) as a measure for the discriminative power

A more formal description of the algorithm is given in the addendum to this chapter. In this section an example for a two-class problem (classes ' $x$ ' and 'o') using two variables ( $\mathrm{v} 1$ and $\mathrm{v} 2$ ) will be presented. The vertical line in Figure I shows the first split of the set of example cases. The subset of cases with vl-values greater than $\lambda_{1}$ is further divided into two subsets by the horizontal line marked with a 3 (using variable $v 2$ with threshold $\lambda_{3}$ ). The subset of cases with v1-values less than $\lambda_{1}$ is further divided using variable $v_{2}$ with threshold $\lambda_{2}$; lastly, the subset of cases with values for v1 less than $\lambda_{1}$ and values for v2 greater than $\lambda_{2}$ is further divided using variable $v 2$ with threshold $\lambda_{4}$.

Table I Coding scheme for the answer options of question 3 (Q3): How long have you had epigastric pain?

\begin{tabular}{ll}
\hline ANSWER OPTIONS & Code \\
\hline Years & 3 \\
Months & 2 \\
Weeks - days & 1 \\
'Escape answer' & 0.5 \\
No epigastric pain & 0 \\
\hline
\end{tabular}




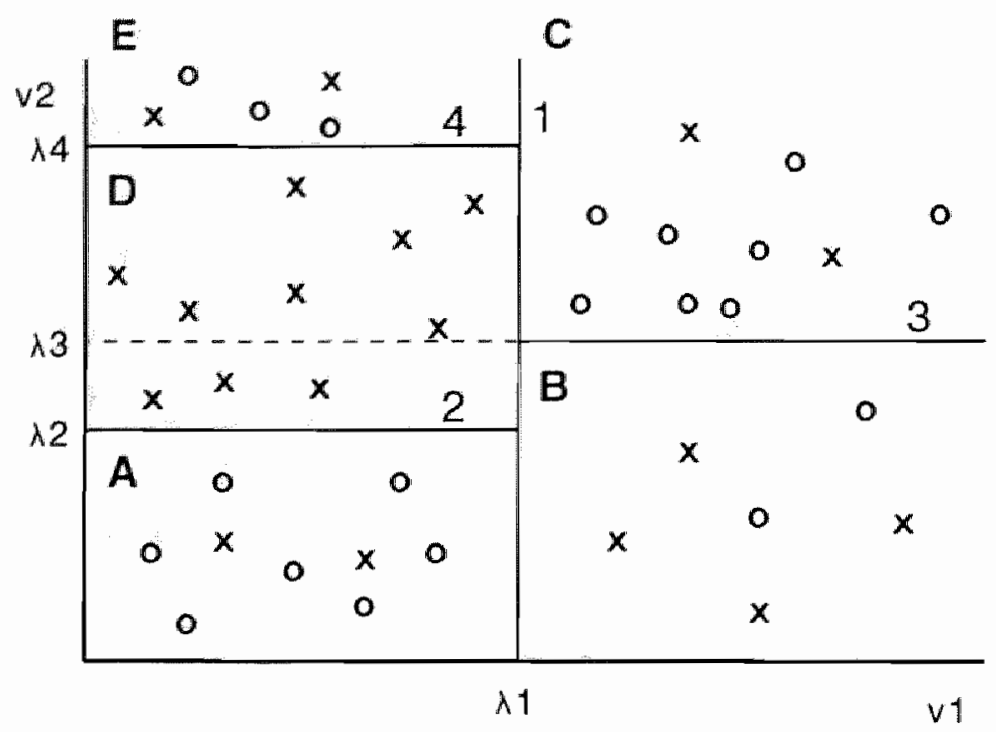

Figure I Example of NPPA for a two-class problem (classes " $x$ " and ' $a$ ')

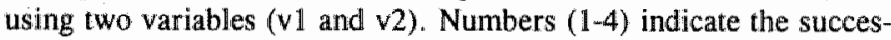
ive splits and capital letters (A-E) the final subregions of the variable space.

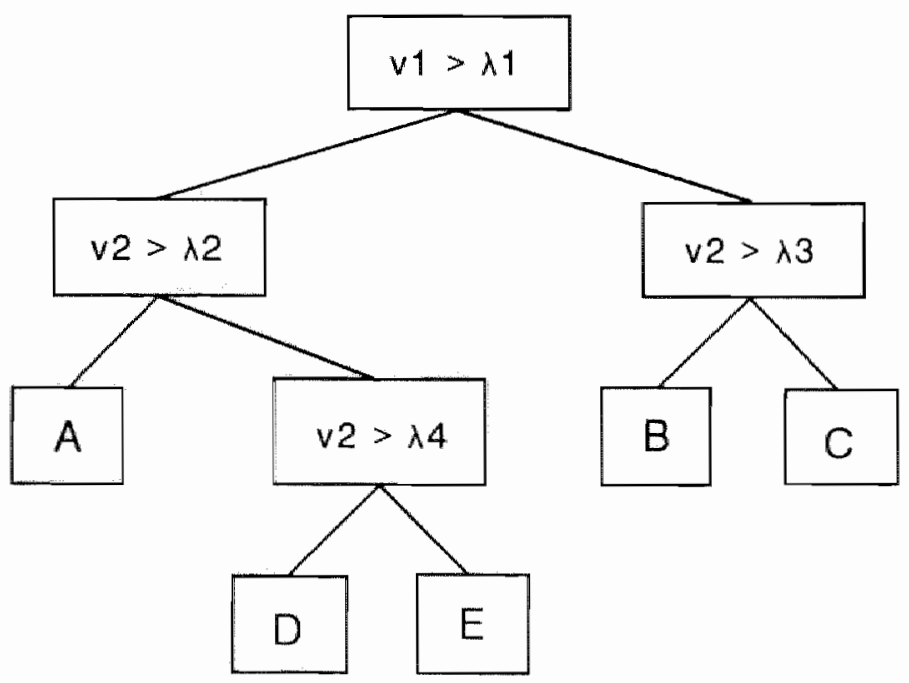

Figure II Binary classification tree of the NPPA analysis of the example cases using two variables ( $\mathrm{V} 1$ and $\mathrm{v} 2$ ) and resulting in five terminal nodes (A-E). 
Such a recursive partitioning of the variable space can be represented as a binary classification tree (Figure II). Starting at the top node (the root of the tree), a variable is compared with a threshold and dependent on the outcome of this test, the right or left subtree is traversed until a terminal node is encountered (here labelled with capital letters). A terminal node in the classification tree corresponds with a region of the variable space that is delimited by the tests at the nodes on the path from the terminal node to the root of the tree. For example, region $A$ in Figure $I$ is defined by $v 1<\lambda_{1}$ and $v 2<\lambda_{2}$. By 'and'-ing the tests along such a path, the condition part of a classification rule is created of which the conclusion is the class label assigned to the terminal node of the path.

When only cases with the same class label occur at a terminal node of a tree, the algorithm performs that labelling automatically. The cases that occur at a terminal node, however, do not necessarily belong to the same class; in such a situation the user has to decide what class label has to be assigned to this terminal node. This process is not trivial as the user may have requirements with respect to the sensitivity and specificity for a class or with respect to the predictive value of the classifier. In the example, the terminal node labelled with 'A' would represent the " $O$ ' class, while node D would represent the ' $x$ ' class.

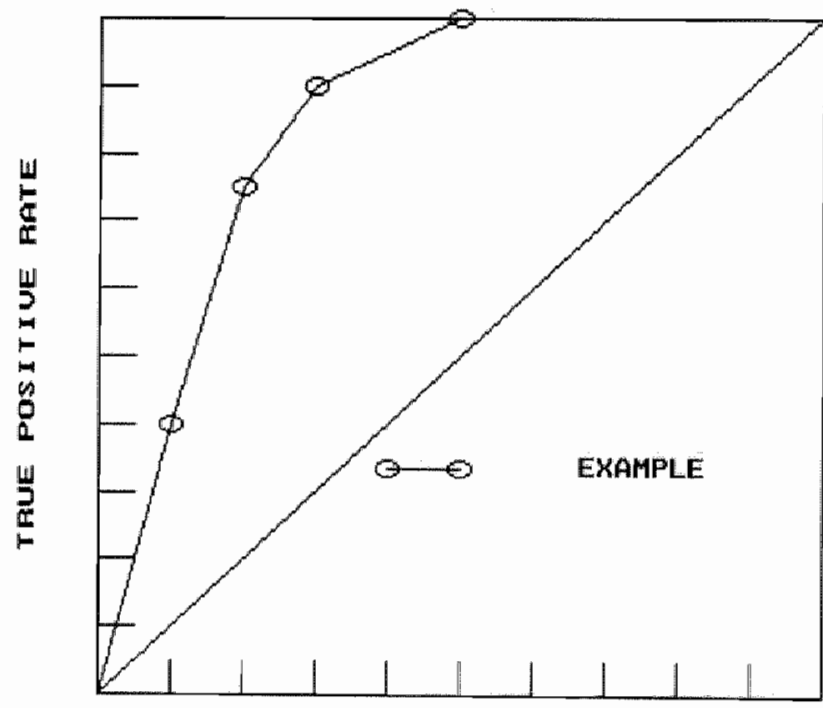

FALSE POSITIUE RATE

Figure III ROC curve of the two-class NPPA analysis given as an example. 
The clinical applicability of the classification tree depends on - among others the complexity of the induced rules. As the number of nodes increases, the number of criteria occurring in the classification rules also increases making the rules more specific. This implies that only a very small number of cases will meet de criteria specified in the rule (or formulated alternatively: will follow a certain path through the tree). Hence, applying such a tree in clinical practice without a support tool is not feasible as a large set of rules are to be remembered to cover the whole domain.

A Receiver Operating Characteristic (ROC) curve can be constructed from a classification tree for two-class problems to assist the user in gaining insight in the discriminative performance of the tree ${ }^{27-29}$. For each terminal node of a classification tree the fraction of 'normal' cases is determined (see Table II for the example given in this section, ' $x$ ' here being considered as 'normal'), and next the terminal nodes are ranked according to this fraction of normal cases in decreasing order (Table III). In this table also the sensitivity and specificity for the various thresholds on the fraction of ' $x$ ' used for labelling a terminal node as normal are provided. From this table, the ROC curve can be constructed (Figure III).

Table II Fraction of $\mathrm{x}$ for each terminal node of the classification tree given in the example.

\begin{tabular}{lcll}
\hline NODE & Number of $x$ & Number of $o$ & Fraction of $x$ \\
\hline A & 2 & 7 & 0.22 \\
B & 4 & 2 & 0.67 \\
C & 2 & 8 & 0.20 \\
D & 10 & 0 & 1.00 \\
E & 2 & 3 & 0.40 \\
\hline
\end{tabular}

Table III Sensitivity and specificity for the various threshlolds on the fraction of $\mathrm{x}$ used for labelling a terminal node as normal.

\begin{tabular}{llllll}
\hline NODE & Number of $x$ & Number of $o$ & Fraction of $x$ & Sensitivity & Specificity \\
\hline D & 10 & 0 & 1.00 & 0.00 & 1.00 \\
B & 4 & 2 & 0.66 & 0.50 & 1.00 \\
E & 2 & 3 & 0.40 & 0.70 & 0.90 \\
A & 2 & 7 & 0.22 & 0.80 & 0.75 \\
C & 2 & 8 & 0.20 & 0.90 & 0.40 \\
\hline
\end{tabular}


Hence, the quality of each NPPA analysis can be graphically represented in a ROC curve which plots the true-positive-rates (TPR, sensitivity) against the falsepositive-rates (FPR, 1-specificity) of the classification tree for various thresholds of the fraction of normal cases at the terminal nodes. The discriminative power of each analysis can be summarised by the Area Under the Curve (AUC) of the ROC curve. We used the ROC ANALYZER programme to construct the ROC curves and to calculate the areas under these curves ${ }^{30,31}$.

A maximum number of 45 variables can be handled simultaneously by the NPPA algorithm used in this study. The analyses were therefore performed in two steps. First, the patient characteristics (18 variables) together with the main questions (22 variables) were analysed. The variables that were selected as most discriminative at the non-terminal nodes of the classification tree were retained. The (non-selected) variables that gave an entropy reduction larger than half the entropy reduction of the selected variable at a certain node were also retained, provided that the entropy reduction of the variable was at least 4.0 . In the second step, the analysis was repeated with the retained variables completed with some of the 35 refinement questions to a total number of 45 variables.

When applying this algorithm to discriminate between patients with relevant endoscopic findings and those without, we used a multi-class approach rather than a two-class approach. Only at the level of the terminal nodes, the classes were merged into a relevant and a non-relevant category. The reason for this is that merging diagnostic categories into a relevant and a non-relevant class followed by a two-class analysis may result in a less accurate discrimination. It may well be that one relevant endoscopic finding is associated with high values for a variable while another (relevant) finding is associated with low values for the same variable. When these findings are combined into a relevant disease class, the discriminative power of the variable may be obscured. This argument holds when only binary trees are constructed. If the algorithm can create trees with nodes that can have more than two branches, a two-class formulation of the problem might also be a feasibility.

Two-class models: these models were designed to answer the question: Is it possible to discriminate between patients with a specific endoscopic diagnosis from those having a normal endoscopy based on patient characteristics and anamnestic data? For these analyses the endoscopic outcome was classified into the following diagnostic categories: hiatus hernia; oesophagitis; endoscopic gastritis; gastric ulcer; duodenitis/bulbitis; and duodenal ulcer.

In case patients had one of the above mentioned endoscopic diagnoses without any endoscopic co-pathology, they were classified as having a 'pure' endoscopic diagnosis. Those patients having one of these endoscopic diagnoses, irrespective of endoscopic co-pathology, were classified as having a 'mixed' endoscopic diagnosis. The group of patients with 'mixed gastric ulcer', for example, consists of those patients having at least a gastric ulcer, with or without endoscopic co-pathology. The group of patients classified as having 'pure gastric ulcer" comprises patients who had no endoscopic pathology other than gastric ulcer. 
In the analyses each specific endoscopic diagnosis was contrasted with a control group, which consisted of the patients with a completely normal endoscopy. We assessed the influence of any co-pathology on the discrimination of these endoscopic diagnoses as we performed the analyses for both the pure and the mixed diagnoses. As a result, 12 binary classification trees and their corresponding ROC curves were created.

Multi-class model: a multi-class model was designed to answer the question: Is it possible to predict the presence of clinically relevant endoscopic findings from pre-endoscopically collected data? The endoscopic diagnoses which usually have direct therapeutic and/or prognostic consequences were regarded to be clinically relevant. By this definition, patients with oesophagitis, gastric or duodenal ulcers, and those who were endoscopically judged to have a malignant disorder were classified as having 'relevant endoscopic findings'. In this model they were contrasted with the other patients who had either 'irrelevant' endoscopic findings or a normal endoscopy.

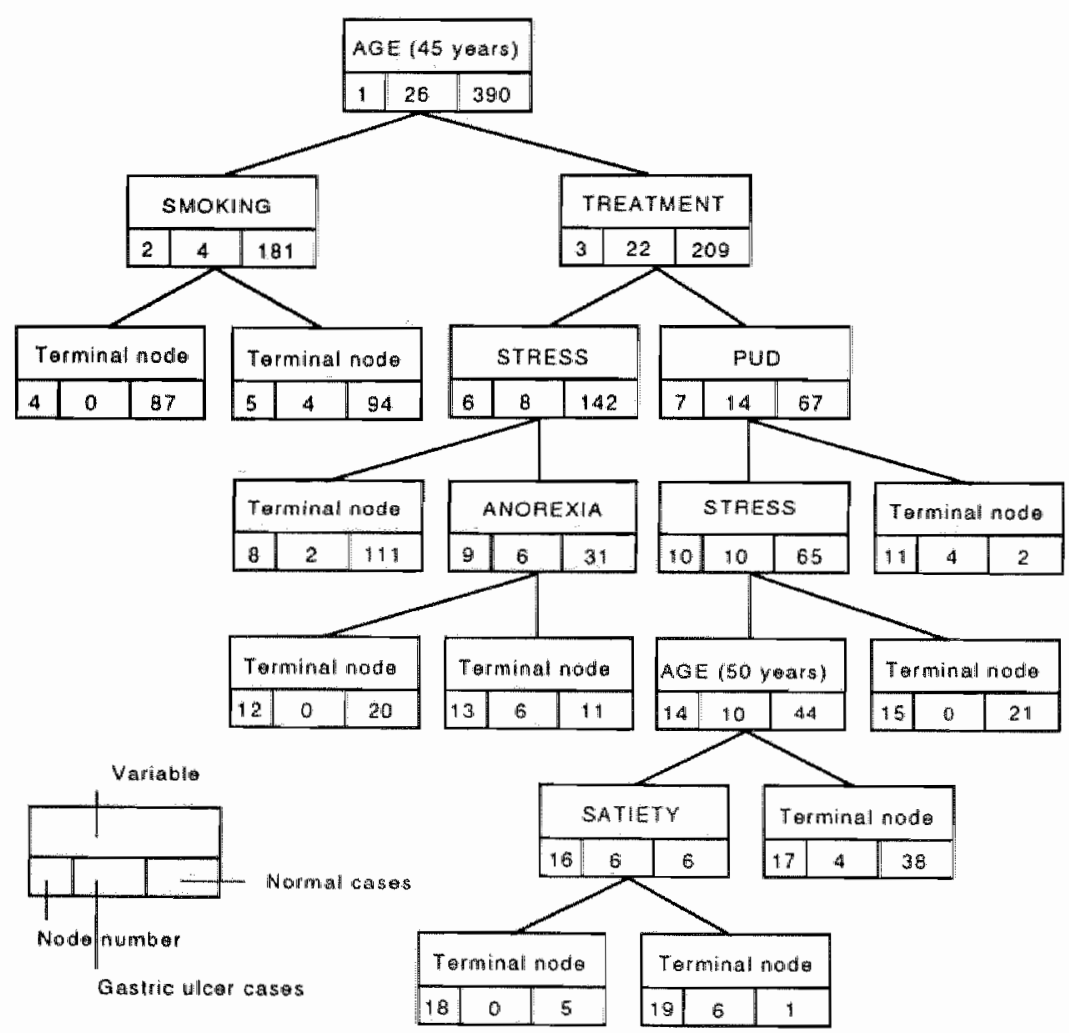

Figure IV Classification tree of the NPPA analysis for pure gastric ulcer. 
Table IV Most discriminative variables at nodes $1-3$ of the classification tree of pure gastric ulcer ws nomal endoscopy.

\begin{tabular}{lcllll}
\hline VARIABLES node 1 & ER $^{\prime}$ & VARIABLES node 2 & ER $^{\prime}$ & VARIABLES node 3 & ER \\
\hline Age (45 years) & 5.3 & Smoking & 2.6 & Anti-ulcer treatment & 4.1 \\
Previous peptic ulcer & 4.2 & Retrosternal pain & 2.2 & Previous peptic ulcer & 3.5 \\
Hunger pain & 3.7 & & & Hunger pain & 3.4 \\
Anti-ulcer treatment & 3.3 & & & & \\
\hline
\end{tabular}

${ }^{1}$ ER Entropy reduction.

The multi-class analysis involved eight diagnostic categories (in the following ranking order): gastric ulcer; duodenal ulcer; oesophagitis; duodenitis/bulbitis; endoscopic gastritis; hiatus hernia; normal endoscopy; and the remaining endoscopic findings. A patient with more than one of these diagnoses was assigned to the highest ranking category in the given order. Patients with gastric cancer were included in the gastric ulcer category, and patients with oesophageal cancer in the category of oesophagitis.

The ROC curve associated with the classification tree was generated by relabelling the terminal nodes as either relevant or non-relevant. Variables to be included in the analysis were selected on the basis of the results of the two-class models.

\section{AN EXAMPLE: PURE GASTRIC ULCER VS NORMAL ENDOSCOPY}

The classification tree resulting from the NPPA analysis comparing the group of patients with pure gastric ulcer $(n=26)$ to those having a normal endoscopy $(n=390)$, will be extensively discussed in this section (Figure IV). The entropy at the root of the tree was 140.3 ; the entropy reduction achieved by the most discriminative variables selected at the nine non-terminal nodes of the tree was not more than 5.5. The variables with the largest entropy reduction at node 1 are listed in Table IV. Age with a threshold of 45 years (AGE 45 years) was selected as most discriminative variable as it yielded the largest entropy reduction (5.3). Among the variables with a not too small entropy reduction that were not selected at this node were: previous peptic ulcer disease; epigastric pain arising or increasing before meal ('hunger pain'); and recent anti-ulcer treatment. The percentage of gastric ulcer cases was $6.3 \%$ at node $1(26 / 416 \times 100 \%)$, while it was only $2.2 \%(4 / 185 \times 100$ $\%$ ) in the younger subgroup (node 2 ). In the older subgroup (node 3 ) the percentage of gastric ulcer cases was $9.5 \%$ (22/231 x $100 \%)$. Smoking (SMOKING) was selected as most discriminative variable at node 2 (Table IV); the percentage of gastric ulcer disease was $4.1 \%(4 / 98 \times 100 \%)$ in patients younger than 45 who smoked. Previous drug therapy (TREATMENT) was the most discriminative variable in patients older than 45 years (Table IV), increasing the percentage of gastric ulcer cases from $9.5 \%$ to $17.3 \%(14 / 81 \times 100 \%)$. Previous ulcer disease (PUD, node 7 ) increased the 
percentage of gastric ulcer cases to $66.7 \%(4 / 6 \times 100 \%)$ in the group of patients aged above 45 years who had been treated prior to referral. Whether a strenuous life (STREss) increased (node 6) or decreased (node 10) the percentage of gastric ulcer cases in a subgroup apparently depended on the localisation within the classification tree and, therefore, on the presence and/or absence of other variables. Loss of appetite (ANOREXIA, node 9) and early satiety (SATTETY, node 16) increased the fraction of gastric ulcer cases in certain subgroups of patients. Age below 50 years (AGE 50 years, node 14) was selected as a variable favouring gastric ulcer disease in the subgroup of patients aged above 45 years with previous empiric treatment, but without previous peptic ulcer disease and without a strenuous life. This is an illustration of the selection of a variable based upon the probably accidental association between this variable and the endoscopic diagnosis under study in a subgroup of patients.

The following classification rules resulted in the terminal nodes with the highest predictive value for gastric ulcer:

1) Age $>45$ years + anti-ulcer treatment - previous peptic alcer - strenuous life + age $<50$ years + early satiety (6 gastric ulcer cases; $86 \%$ )

2) Age > 45 years + anti-alcer treatment + previous peptic alcer (4 gastric ulcer cases; $67 \%$ )

3) Age $>45$ years - anti-ulcer treatment + strenuous life + loss of appetite (6 gastric wlcer cases: $35 \%)$

If these terminal nodes were labelled as 'pure gastric ulcer' and the remaining terminal nodes as 'normal endoscopy', application of the classification rules would result in a prediction of gastric ulcer cases with a TPR of $62 \%(16 / 26 \times 100 \%)$ and a FPR of $4 \%(14 / 390 \times 100 \%)$ (black square in Figure Vd). The positive-predictivevalue (PPV) and negative-predictive-value (NPV) of this prediction would be $53 \%$ $(16 / 30 \times 100 \%)$ and $96 \%(376 / 390 \times 100 \%)$, respectively.

The ROC curve associated with the classification tree of Figure IV had an AUC of 0.90 .

\section{Results}

\section{STUDY POPULATION}

The characteristics of the study population have been comprehensively described in Chapter VI. This series of 1147 patients had a mean age of 50.4 years (SD 15.7, range 15-88) and consisted of 634 males (55.3\%) and 513 females (44.7\%). In the first part of the study, 431 patients $(37.6 \%)$ filled in a paper questionnaire; in the second part, $716(62.4 \%)$ answered the computerised history taking system. In 1118 patients $(97.5 \%$ ) a complete oesophagogastroduodenoscopy (OGD) was performed. The remaining 29 patients $(2.5 \%)$ had for several reasons an incomplete investigation: 8 patients had an oesophagogastroscopy, 5 patients had an oesophagoscopy, and in 16 patients introduction of the endoscope was not possible. The frequencies of the pure and mixed endoscopic diagnoses are presented in Table V. There was 
some overlap between the relevant (mixed) endoscopic diagnoses and their irrelevant counterparts: 57 patients had oesophagitis and hiatus hernia, 8 patients had a gastric ulcer and endoscopic gastritis, and 17 patients had both a duodenal ulcer and duodenitis/bullbitis. Almost $50 \%$ of the patients with a gastric or duodenal ulcer did not have other endoscopic pathology. Three patients $(0.3 \%)$ had an oesophageal cancer and gastric cancer was diagnosed in ten patients $(0.9 \%)$. Overall, 269 patients $(23.5 \%)$ were considered to have a relevant endoscopic diagnosis and the remaining 878 patients $(76.5 \%$ ) had either irrelevant or normal endoscopic findings.

Table $\mathbf{V}$ Frequencies of the specific endoscopic diagnoses in the study population.

\begin{tabular}{|c|c|c|c|c|c|c|}
\hline \multirow{2}{*}{$\begin{array}{l}\text { ENDOSCOPIC DIAGNOSES } \\
\text { Hiatus hernia }\end{array}$} & \multicolumn{3}{|c|}{$\begin{array}{l}\text { MIXED } \\
\text { Number of patients }(\%)\end{array}$} & \multicolumn{3}{|c|}{$\begin{array}{l}\text { PURE } \\
\text { Number of patients }(\%)\end{array}$} \\
\hline & 186 & $(16.4)$ & a & 68 & $(6.0)$ & is \\
\hline Oesophagitis & 141 & $(12.5)$ & a & 41 & $(3.6)$ & 日 \\
\hline Endoscopic gastritis & 167 & $(14.8)$ & $b$ & 67 & $(6.0)$ & th \\
\hline Gastric ulcer & 56 & $(5.0)$ & b & 26 & $(2.3)$ & $b$ \\
\hline Duodenitis/bulbitis & 152 & $(13.6)$ & c & 57 & $(5.1)$ & s \\
\hline Duodenal ulcer & 78 & $(7.0)$ & c & 37 & $(3.3)$ & c \\
\hline Normal endoscopy & & & & 390 & $(34.9)$ & " \\
\hline
\end{tabular}

Percentage of those patients who had an "oesophagoscopy $(n=1131)$, an "oesophagogastroscopy $(n=1126)$, or an ${ }^{c}$ oesophagogastroduodenoscopy $(n=1118)$.

Table VI Characteristics of the two-class NPPA analyses: the number of nodes of the binary classification trees and the areas under the corresponding ROC curves are listed for both mixed and pure endoscopic diagnoses.

\begin{tabular}{|c|c|c|c|c|c|}
\hline \multirow[t]{2}{*}{ ENDOSCOPIC DIAGNOSES } & \multicolumn{2}{|c|}{ MIXED } & \multicolumn{2}{|c|}{ PURE } & \multirow[b]{2}{*}{ p-value } \\
\hline & $\mathrm{n}_{\text {nodes. }}$ & $\mathrm{AUC} \pm \mathrm{SE}(\%)$ & $\mathrm{n}_{\text {twades }}$ & $\mathrm{AUC} \pm \mathrm{SE}(\%)$ & \\
\hline Hiatus Hernia & 35 & $80.18 \pm 1.83$ & 21 & $79.38 \pm 3.08$ & 0.41 \\
\hline Oesophagitis & 37 & $82.15 \pm 2.11$ & 21 & $80.95 \pm 3.56$ & 0.39 \\
\hline Endoscopic gastritis & 41 & $80.56 \pm 1.96$ & 19 & $75.37 \pm 2.77$ & 0.06 \\
\hline Gastric ulcer & 37 & $93.74 \pm 1.79$ & 19 & $90.21 \pm 3.09$ & 0.16 \\
\hline Duodenitis/bulbitis & 57 & $88.39 \pm 1.51$ & 31 & $85.84 \pm 2.31$ & 0.18 \\
\hline Duodenal ulcer & 47 & $93.93 \pm 1.32$ & 33 & $93.82 \pm 1.67$ & 0.48 \\
\hline
\end{tabular}

$\mathbb{n}_{\text {radcs }}$ Number of nodes; ${ }^{2}$-value of the comparison of the areas under the ROC curves as calculated by the non-parametric method as described by Centor. 


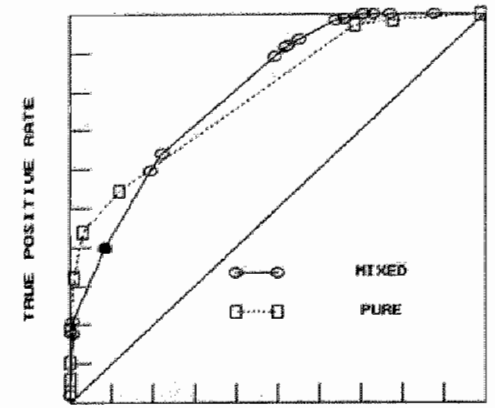

a

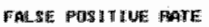

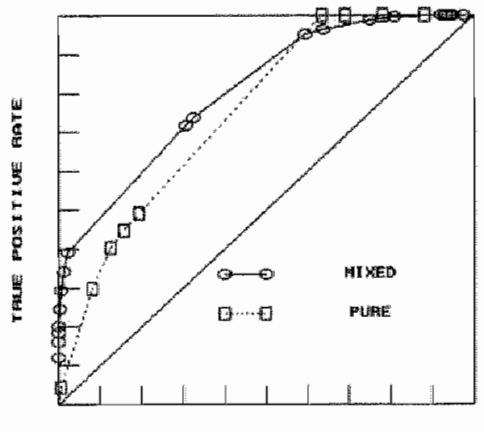

c

FALSE POSITTUE PATE

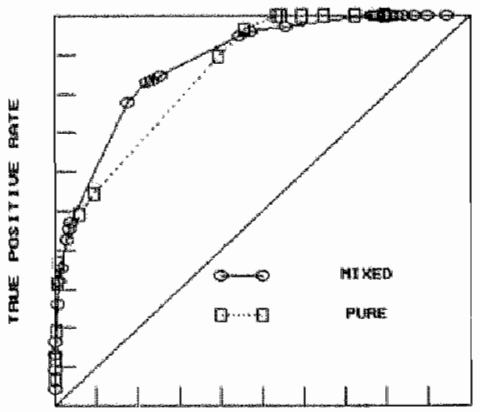

e

FA. SE POESTISUE PATIE

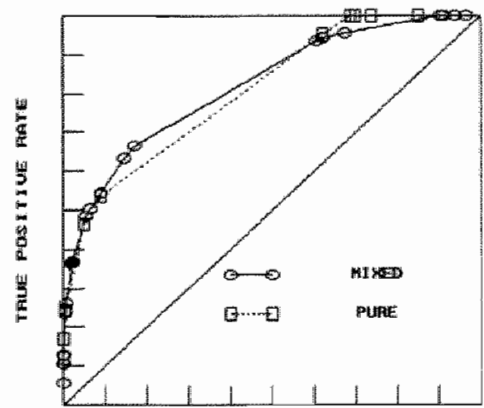

b

FALSE POS I I IUE RATE

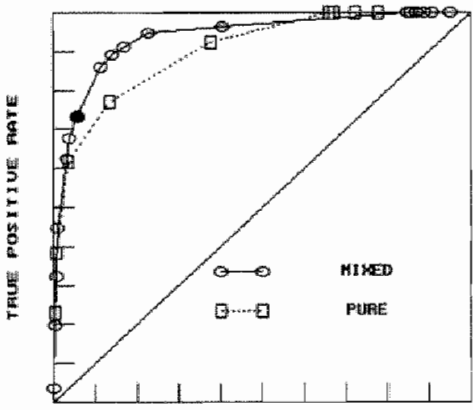

d

Fall. SE ProS I I I UE RATE

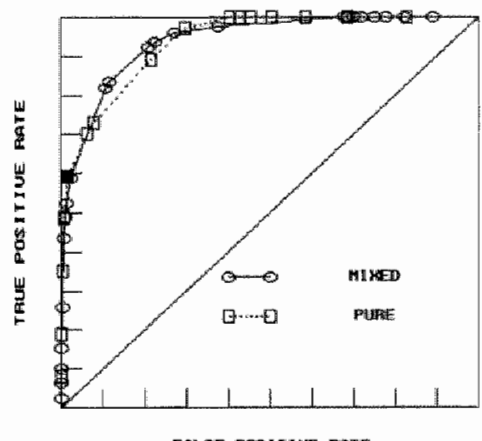

FALSE POSIIIUE FATE

Figure $V$ ROC curves of the NPPA analyses for: a Hiatus hernia; b Oesophagitis; $c$ Endoscopic gastritis; d Gastric ulcer; e Duodenitis/bulbitis; f Duodenall ulcer. 


\section{TWO-CLASS PREDICTION MODELS}

General remarks: the discriminative performance of the NPPA models was the same for the pure and the mixed endoscopic diagnoses. This is illustrated by the almost identical shape of the ROC curves for pure and mixed diagnoses (Figures Va-f). None of the pairs of ROC curves of pure and mixed diagnoses turned out to be statistically different, using the non-parametric method described by Cantor (Table VI) $(30,31,32)$. Therefore, the presence of any endoscopic co-pathology seems not to hinder the prediction of several endoscopic diagnoses.

The best discrimination from patients with a normal endoscopy was achieved for patients with peptic ulcers (Figures Vd and Vf), followed by patients with duodenitis/bulbitis (Figure Ve). The models had about the same discriminative value for hiatus hernia and for oesophagitis (Figures $\mathrm{Va}$ and $\mathrm{Vb}$ ). Patients with endoscopic gastritis could hardly be discriminated from patients having a normal endoscopy (Figure Vc).

The classification trees for both pure and mixed duodenal ulcer were more complex than those for pure and mixed gastric ulcer (Table VI). Also the trees for duodenitis/bulbitis were larger than those for endoscopic gastritis.

Comparison of the areas under the ROC curves by means of the non-parametric method demonstrated that gastric ulcer can be predicted more accurately than its irrelevant counterpart gastritis $(p<0.001$ for the pure diagnoses and $p<0.0001$ for the mixed diagnoses). Duodenal ulcer can be predicted more accurately than duodenitis/bulbitis ( $p<0.005$ for the pure and mixed diagnoses). On the other hand, oesophagitis cannot be predicted more accurately than hiatus hernia $(p=0.37$ for the pure diagnoses and $p=0.24$ for the mixed diagnoses).

In the following, the variables that play a prominent role in the discrimination of each of the specific endoscopic diagnoses from normal endoscopy will be summarised. The classification rules that result in terminal nodes with the highest predictive values for these endoscopic diagnoses will also be presented for some of the diagnoses.

Hiatus hernia: the most discriminative variables for pure and mixed hiatus hernia were so-called 'reflux-like symptoms': heartburn, especially when increasing with lying and/or bending or existing during several months or years, and retrosternal pain during several years. Also age was selected several times with different thresholds.

The following classification rules lead to terminal nodes in the trees with the highest percentages of mixed hiatus hernia cases:

1) Heartburn during days to months + age $<46$ years + heartburn during months to years + age $<42$ years + age $>26$ years - belching (4 hiatus hemia cases; $100 \%$ )

2) Heartburn during years + retrosternal pain (daily or without pain for at most several days) - epigastric pain (29 hiatus hernia cases; $94 \%$ )

3) Heartburn during days to months + age < 46 years + heartburn during days to weeks + retrosternal pain during the night + retrosternal pain in periods of less than one hour - first episode of epigastric pain (6 hiatus hernia cases; $86 \%$ ) 
4) Hearibum during years + remosternal pain (without pain for several weeks or months) (35 hians hernia cases; $54 \%$ )

Application of these rules when labelling the corresponding terminal nodes as 'mixed hiatus hernia' and the remaining terminal nodes as 'normal endoscopy' would result in a prediction of hiatus hernia with a TPR of $40 \%(74 / 186 \times 100 \%)$ and a FPR of $8 \%(33 / 390 \times 100 \%)$ (black dot in Figure Va).

Oesophagitis: as for hiatus hernia, reflux-like symptoms were important for the discrimination of oesophagitis. These were for pure oesophagitis: heartburn, especially when increasing with lying and/or bending; retrosternal pain during several years; and retrosternal pain causing severe hinder. For mixed oesophagitis, these were: heartburn, especially when increasing with lying and/or bending or existing for at least several months; retrosternal pain, especially when occurring during the night; and dysphagia.

The following classification rules resulted in terminal nodes with the highest percentages of mixed oesophagitis:

1) Heartbum during months to years + retrostemal pain during the night + gallstones 8 oesophagitis cases: 100\%)

2) Heartburn during months to years - revrosternal pain during the night + dysphagia - epigastric pain arising or increasing after meal + retrosternal pain arising or increasing after meal 7 oesophagitis cases; $100 \%$ )

3) Hearburn during months to years + retrosternal pain during the night - gallstones + retrosternal pain in periods during the day - retrosternal pain arising or increasing before meal (16 oesophagitis cases; $89 \%$

4) Heartburn during months to years - retrostemal pain during the night \& dysphagia - epigastric pain arising or increasing after meal - retrosternal pain arising or increasing after meal + retrosternal pain during days to months + heartburn during years (15 oesophagitis cases; $75 \%$ )

5) Heartburn during months to years - retrosternal pain during the night + dysphagia + epigastric pain arising or increasing after meal - early satiety (3 oesophagitis cases; $75 \%$

If only these terminal nodes were labelled as 'mixed oesophagitis', application of the classification rules would result in a prediction of oesophagitis with a TPR of $35 \%$ $(49 / 141 \times 100 \%)$ and a FPR of $2 \%(8 / 390 \times 100 \%)$ (black dot in Figure Vb).

Endoscopic gastritis: age with different thresholds is used at several non-terminal nodes of the classification trees for pure and mixed endoscopic gastritis. None of the symptom variables contributes significantly to the discrimination between endoscopic gastritis and normal endoscopy. Previous gastric surgery was selected as a variable favouring mixed endoscopic gastritis because anastomositis was included in this diagnostic category.

Gastric ulcer: the classification trees for pure gastric ulcer has been presented before as an example (Figure IV). Age was selected several times as the most discriminative variable in the tree for mixed gastric ulcer. At the root of this tree age with a threshold of 45 years $(\mathrm{ER}=7.9)$ was the second most discriminative variable after previous peptic ulcer $(E R=8.5)$. Other important discriminative variables were: signs of upper GI bleeding; smoking; and the presence of black 
stool. Of the so-called 'classical ulcer symptoms', only epigastric pain arising or increasing before meal (hunger pain) turned out to have any predictive value for gastric ulcer disease.

The following classification rules lead to terminal nodes with the highest predictive values for mixed gastric ullcer:

1) No previous peptic ulcer + smoking - increase of complaints with stress + age $<74$ years + hunger pain + increase of epigastric pain with certain foods ( 2 gastric ulcer cases; $100 \%$ )

2) Previous peptic ulcer + age $>50$ years ( 9 gastic ulcer cases; $90 \%$ )

3) No previous peptic ulcer + smoking + increase of complaints with stress + age $>31$ years + hunger pain - increase of epigastric pain with lying and/or bending ( 7 gastric wher cases; $88 \%$ )

4) No previous peptic ulcer + smoking + increase of complaints with stress + age $>31$ years - hunger pain + black stool + nausea during days (7 gastric ulcer cases; $78 \%$ )

5) No previous peptic ulcer - smoking + black staol + age $>45$ years - decrease of epigastric pain after meal - heartburn increasing with lying and/or bending (10 gastric ulcer cases; $56 \%$ )

6) No previous peptic ulcer + smoking - increase of complaints with stress + age $>74$ years $(3$ gastric ulcer cases; $50 \%$ )

7) No previous peptic ulcer + smoking + increase of complaints with stress + age $>31$ years + hunger pain + increase of epigastric pain with lying and/or bending ( 3 gastric wlcers. $30 \%$ )

If these terminal nodes were labelled as 'mixed gastric ulcer', application of the rules would result in a prediction of gastric ulcer disease with a TPR of $73 \%$ (41/56 $\times 100 \%)$ and a FPR of $6 \%(22 / 390 \times 100 \%)$ (black dot in Figure Vd).

Duodenitis/bulbitis: the NPPA analyses with respect to duodenitis/bulbitis resulted in large classification trees (with a small number of cases in most terminal nodes). Male gender was the most discriminative variable at the root of the trees for pure and mixed duodenitis/bulbitis, and age with different thresholds was selected as variable for splitting at several non-terminal nodes of both trees. Smoking was another important variable for the discrimination of duodenitis/bulbitis. Although several symptom variables were selected in the classification trees, it was not possible to indicate one or more symptoms significantly predictive of duodenitis/bulbitis.

Duodenal ulcer: as for duodenitis/bulbitis, the analyses on duodenal ulcer resulted in large classification trees. Absence of retrosternal pain was selected as the most discriminative variable at the root of the tree for pure duodenal ulcer; the presence of epigastric pain was selected as most discriminative variable at the root of the tree for mixed duodenal ulcer. In both trees age with different thresholds was selected as variable for splitting at several non-terminal nodes. In contrast with duodenitis/bulbitis, malle gender and smoking were not selected as variables important for the discrimination of duodenal ulcer. Epigastric and retrosternal pain continuous or episodical, and with or without relieving and/or provoking factors were selected as variables for splitting throughout both classification trees. This is illustrated by the following classification rules resulting in terminal nodes with the highest percentages of pure duodenal ulcer cases: 


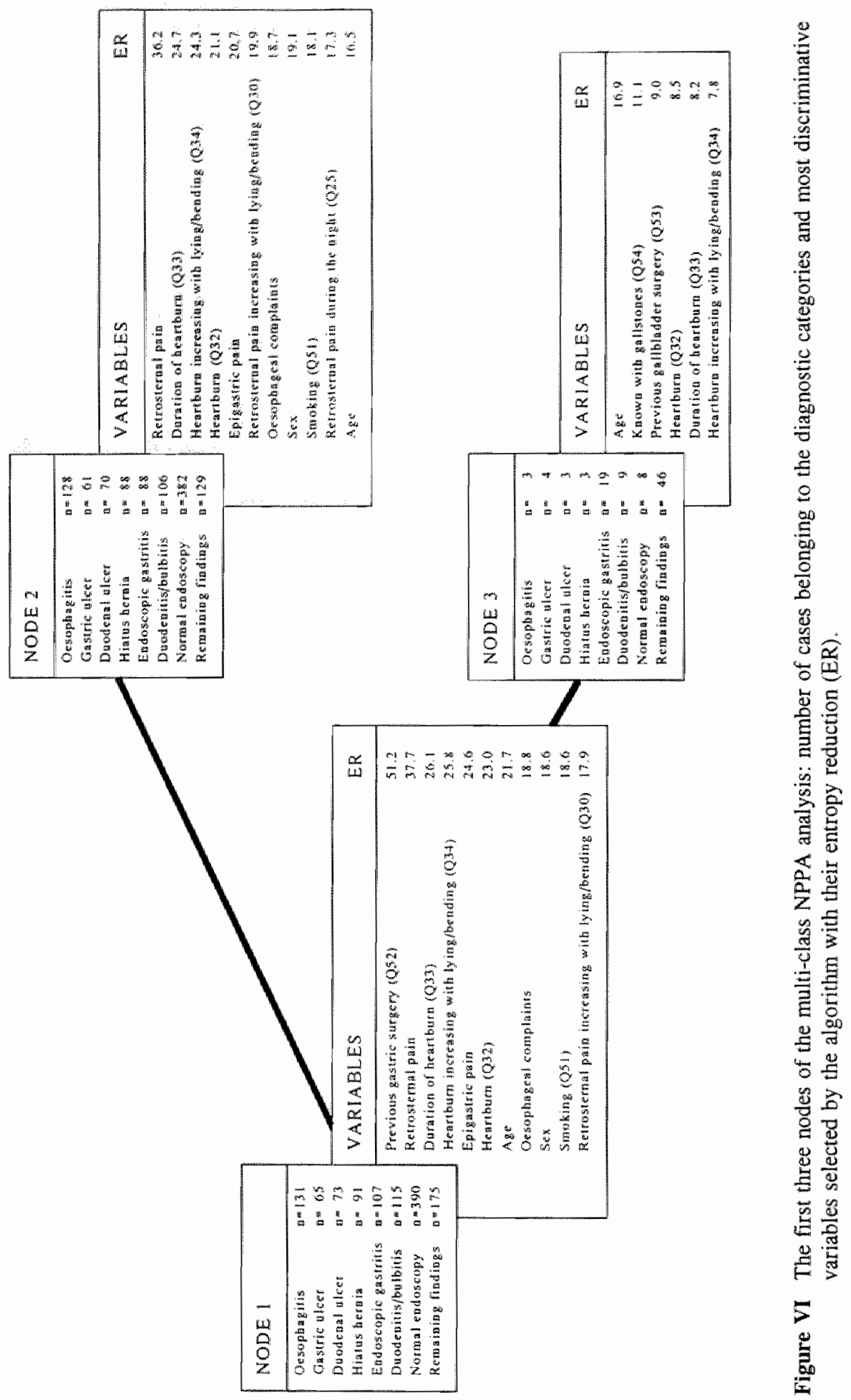


1) No retrosternal pain - nausea - retrosternal pain decreasing after meal + retrostemal pain in penods of less than one hour - epigastric pain increasing with lying and for bending + epigastric pain + epigastric pain in periods during the day + epigastric pain during years (4 duodenal ulcer cases; $100 \%$ )

2) No retrostemal pain - nausea - retrosternal pain decreasing after weal + retrostemal pain in periods of less than one hour - epigastric pain increasing with lying and/or bending + epigastric pain + epplgastric pain in periods during the doy + epigastric pain during days to months + age $>70$ years 13 duodenal ulcer cases; $100 \%$ )

3) No retrosternal pain - nausea - retrostemal pain decreasing after meal + retrostemal pain in periods of more thon one hour or during the whole day - retrostemal pain arising and/or increasing after meal (6 duodenal ulcer cases; $86 \%$,

4) No retrostemal pain - nausea - retrostemal pain decreasing after meal + retrostemal pain in periods of less than one hour - epigastric pain increasing with lying and/or bending + epigastric pain + epigastric pain in periods during the day + epigastric pain during days to months + age $<70$ years + age $<57$ years + age $>55$ years (5 duodenal ulcer cases; $83 \%$ )

5) No retrasternal pain + nausea + epigastric pain + retrosternal pain in periods of less than one hour epigastric pain increasing with lying and/or bending + epigastric pain during the night (4 duodenal ulcer cases; $50 \%$ )

If these terminal nodes were labelled as 'pure duodenal ulcer", application of the former classification rules would result in a prediction of duodenal ulcers with a TPR of $59 \%(22 / 37 \times 100 \%)$ and a FPR of $2 \%(6 / 390 \times 100 \%)$ (black square in Figure Vf).

\section{MULTI-CLASS PREDICTION MODEL}

The following eight classes were used in this analysis: oesophagitis or oesophageal cancer $(n=131)$; gastric ulcer or gastric cancer $(n=65)$; duodenal ulcer $(n=73)$; hiatus hernia $(n=91)$; endoscopic gastritis $(n=107)$; duodenitis/bulbitis $(n=115)$; normal endoscopy $(n=390)$; and the remaining endoscopic diagnoses $(n=175)$. Altogether 269 patients $(23.5 \%$ ) were classified as having a relevant endoscopic diagnosis and 878 patients $(76.5 \%)$ had one or more irrelevant findings or a normal endoscopy. The multi-class analysis resulted in a complex binary classification tree

Table VII The most frequently selected variables in the multi-class NPPA analysis.

\begin{tabular}{ll} 
VARIABLES & Number of nodes \\
\hline Age & 18 \\
Duration of heartburn (Q33) & 6 \\
Belching (Q35) & 5 \\
Nausea (Q37) & 5 \\
Abdominal rumblings (Q47) & 5 \\
Epigastric pain & 4 \\
Duration of retrosternal pain (Q20) & 4 \\
Decreased appetite (Q43) & 4 \\
Strenuous life (Q55) & 4 \\
\hline
\end{tabular}


of 108 terminal nodes. The area under the corresponding ROC curve was $83.70 \pm$ 1.30 .

The number of times that a variable is selected in a classification tree as the most discriminative variable can be considered as a measure of the importance of that variable in separating the classes. The nine most frequently selected variables in the multi-class analysis are listed in Table VII. Eight other variables were selected three times, nine variables twice, and ten variables at one non-terminall node.

Furthermore the variables with the largest entropy reduction at the first nodes of a classification tree can be regarded as important in discriminating between the classes. The variables with the largest entropy reduction at the first three nodes of the multi-class analysis are presented in Figure VI.

\section{Discussion}

A non-parametric partitioning algorithm (NPPA) has been used to predict upper GI endoscopic findings by means of analysing patient characteristics and symptoms. In contrast to other statistical techniques that have been used in this field of research, for example Bayes' theorem ${ }^{33.34}$, NPPA does not require independency of the variables that are analysed. The binary classification tree renders insight to what extent combinations of variables are important for the discrimination between disease classes. The ROC curve that can be generated from such classification tree represents the overall diagnostic accuracy of the predictive algorithm.

Prediction of clinically relevant disease in patients referred for diagnostic upper GI endoscopy was possible with a moderate accuracy. Moreover, this prediction was achieved by applying a large number of rather complex classification rules. Since the population was too small to divide into a training and a test set, the results oblained may be rather optimistic. Prospective application of this algorithm in another population than the patient population on which it has been developed would probably further reduce the predictive power ${ }^{35}$.

If the number of times a variable has been selected in the tree is considered to be a criterion for its predictive value, then age would be by far the most important predictor for relevant endoscopic disease. This has also been shown by others $15,19,21,36,37$

The clinical applicability of the predictive algorithm can be illustrated by two arbitrary situations, assuming that only those patients who are predicted to have relevant endoscopic disease will be accepted for endoscopy. In situation $A$, it is necessary that all patients with a relevant endoscopic diagnosis should be investigated: the sensitivity (TPR) should therefore be $100 \%$ and the specificity (1-FPR) is only $25 \%$ (black dot in Figure VIla). This implies that in our population 928 endoscopic examinations ( $81 \%$ of 1147 ) would have been performed, $269(29 \%)$ in patients with relevant findings and $659(71 \%)$ in patients without. Thus, the number of endoscopic examinations can only be reduced with approximately $20 \%$ without 


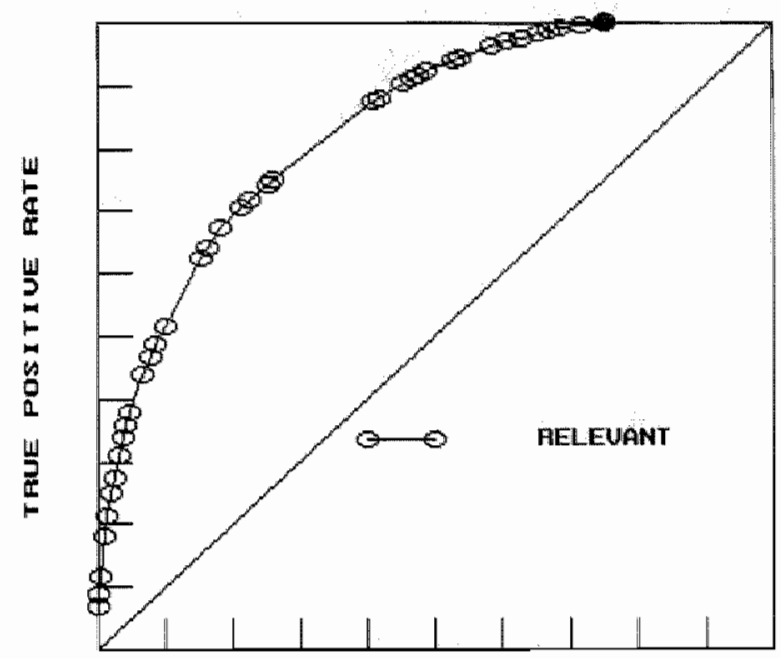

FALSE POSITIUE RATE

Figure VIIa ROC curve of the multi-class NPPA analysis - situation A.

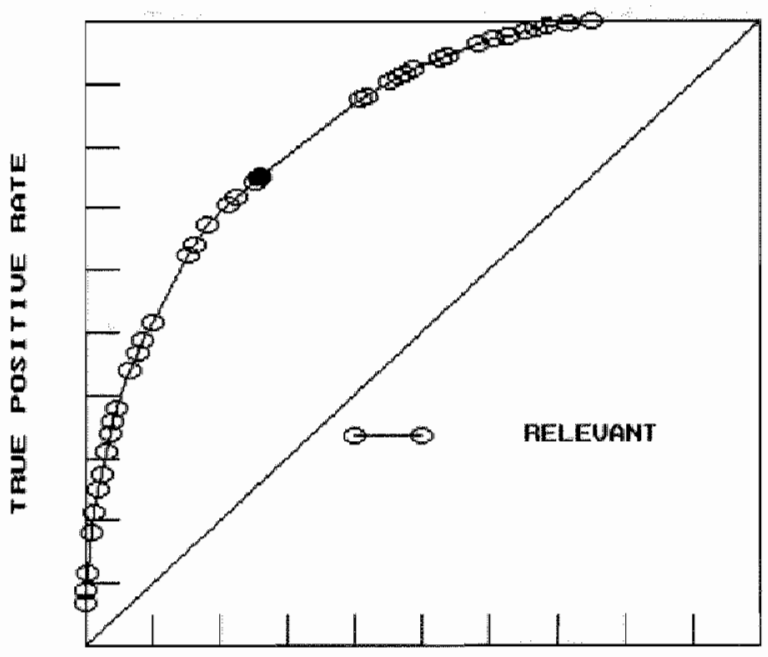

FALSE POSIITIUE RATE

Figure VIIb ROC curve of the multi-class NPPA analysis - situation B. 
missing any relevant endoscopic diagnosis. Nevertheless, in about $70 \%$ of the cases irrelevant or normal findings will be found. In situation $B$, the aim is to drastically reduce the number of negative endoscopies, for example with $75 \%$ : the specificity (1-FPR) then should be $75 \%$, and the sensitivity is $74 \%$ (black dot in Figure VIIb). As a consequence, 421 endoscopic examinations (37\% of 1147) would have been performed: $200(48 \%)$ revealing relevant and $221(52 \%)$ revealing irrelevant or normal endoscopic findings. Now less than $40 \%$ of the endoscopic investigations would have been done, but $26 \%$ of the relevant diagnoses would have been missed.

This study has further demonstrated that the presence of endoscopic co-pathology does not hinder the prediction of specific endoscopic diagnoses. Although the classification trees for the 'mixed diagnoses' were more complex than the corresponding trees for the 'pure diagnoses', both trees revealed similar discriminative variables.

Of the three relevant disorders, the presence of peptic ulcers could be predicted rather accurately. Age above 45 years, previous ulcer disease, empiric medical treatment, use of NSAIDs, signs of upper GI bleeding, smoking, and 'hunger pain' were clearly related to the presence of a gastric ulcer. In contrast with others ${ }^{18,21,38-}$ ${ }^{40}$, we did not observe an association between duodenal ulcer and patient characteristics such as male gender, a history of peptic ulcer disease, and smoking. In general, patients having a duodenal ulcer were recognised by the presence of epigastric pain and the absence of retrosternal pain. A number of symptoms have been referred to as 'classical ulcer symptoms' in textbooks ${ }^{41,42}$ and previous publications ${ }^{7.13 .43-45}$. Of these symptoms, especially 'hunger pain' and 'night pain' have been reported to be typical features of duodenal ulcer disease ${ }^{18,36-38,43,45}$. In the present study, however, none of these symptoms have been identified as predictors of duodenal ulcers. However, it has to be realised that our study dealt with patients referred for endoscopy. It is possible that the general practitioners might have used the presence or absence of these "textbook symptoms" as an argument for either starting empiric treatment or for requesting an endoscopy, respectively.

Patients with endoscopic gastritis could hardly be discriminated from patients with a normal endoscopy. With respect to the ongoing discussion on the clinical relevance of endoscopic gastric mucosal inflammation, this observation may support the assumption that the endoscopic picture of gastritis should not be accepted as the explanation for dyspeptic complaints per se ${ }^{46-51}$. It must be recognised, however, that 'endoscopic gastritis' as defined in this study includes a wide range of endoscopic appearances of mucosal inflammation, and that a more differentiated grading might have given a better discrimination.

Patients with duodenitis/bulbitis could be discriminated reasonably well from patients having a normal endoscopy, although this required application of a large number of rather complex classification rules. The variables predictive of duodenitis/bulbitis were those one might traditionally have expected in patients with a duodenal ulcer: age; male gender, and cigarette consumption ${ }^{52.53}$. 
Reflux-like symptoms such as heartburn - especially increasing with lying and/or bending - and retrosternal pain were discriminative variables in the classification trees for both hiatus hernia and oesophagitis. The corresponding ROC curves have demonstrated that it is hardly possible to make these diagnoses on the basis of symptomatology alone. In consequence, it can be speculated that many patients with a normal endoscopy will have symptomatic gastro-oesophageal reflux without evidence of inflammation at endoscopy.

In conclusion, this study has shown that it is possible to discriminate patients with a gastric or duodenal ulcer, but not those with oesophagitis, from patients having a normal endoscopy. The prediction of clinically relevant endoscopic findings in patients referred for diagnostic upper GI endoscopy by applying a symptombased algorithm is hardly feasible, due to the high complexity of the classification tree. The latter result makes it questionable whether such a prediction model would give any practical advantage in daily endoscopic practice. 


\section{Addendum}

\section{DESCRIPTION OF THE NON-PARAMETRIC PARTITIONING ALGORITHM}

In a set of cases the probability of occurrence of class $j p(j)$ is estimated, $j=1 . . c, c$ the number of different classes.

The uncertainty in class membership is measured by means of the entropy:

$$
E=-\sum_{j} p(j)^{2} \log p(j)
$$

When the set of cases is partitioned in two subsets using variable $v$ with threshold $\lambda$ the entropy for the two subsets is given by

$$
E(v \leq \lambda)=-\sum_{i} p(j \mid v \leq \lambda)^{2} \log p(j \mid v \leq \lambda)
$$

and

$$
E(\nu>\lambda)=-\sum_{i} p(j \mid v>\lambda)^{2} \log p(j \mid v>\lambda)
$$

respectively, in which $p(j \mid v>\lambda)$ is the probability of occurrence of class $\mathrm{j}$ given $v>\lambda$.

The entropy reduction $(E R)$ achieved by a split is given by

$$
E R=E-E(v \leq \lambda) \sum_{j} p(j, v \leq \lambda)-E(v>\lambda) \sum_{j} p(j, v>\lambda)
$$

in which $p(j, v<\lambda)$ is the probability of occurrence of class $\mathrm{j}$ and $\mathrm{v}<\lambda$.

For each variable a threshold is determined that will maximise $E R$. Next the variable with the maximum $E R$ is selected as variable for splitting. The splitting process is continued for each of the subsets until a subset only contains cases of a single class or until some other stop criterion is met. In the algorithm, three additional stop criteria are implemented.

According to the first criterion, a class is considered to be properly represented when the number of cases of that class exceeds a certain threshold. The user can specify this minimal number of cases. From previous experience with the algorithm (23), it appeared that at least three cases is a workable size for each class; this limit was used throughout all our experiments.

A second criterion tests the reliability of the split. It has been shown that $2 N^{*} E R, \mathrm{~N}$ being the number of cases, has a $\chi^{2}$ distribution with $(\mathrm{c}-1)^{*}(\mathrm{~s}-1)$ degrees of freedom (df); for binary splits in a two-class situation $\mathrm{df}=1$. Given a certain $E R$ the probability that the reduction occurred by chance alone can be calculated. When that probability exceeds 0.025 , the splitting process is stopped. We consider 1 minus that probability to be the reliability of the split.

As a third criterion, splitting is also stopped when the product of the reliabilities along the path from the node under analysis to the root of the tree is less then 0.95 . 


\section{References}

1. Jones $\mathbb{R}$, Lydeard $S$. Prevalence of symptoms of dy spepsia in the community. $B r M e d J 1989$; 298: $30-32$.

2. Nyrén $\mathrm{O}$, Adami H-O, Gustavsson $S$, Lööf L, Nyberg A. Social and economic effects of nonulcer dyspepsia. Scand $J$ Gastroenterol 1985; 20 Supp1 109:41-45.

3. Nyrên $\mathrm{O}$, Adami $\mathrm{H}-\mathrm{O}$, Gustavsson $\mathrm{S}$, Löof L. Excess sick-listing in nomulcer dyspepsia. $J$ Clin Gastroenterol 1986; 8 (3): 339-345.

4. Gear MWL, Barnes RJ. Endoscopic studies of dyspepsia in a general practice. $\mathrm{Br}$ Med J 1980; 280: 1136-1137.

5. Kahn KL, Greenfield $S$. The efficacy of endoscopy in the evaluation of dyspepsia. A review of the literature and development of a sound strategy. $J$ Clin Gastroenterol 1986; 8 (3): 346-358.

6. Colin-Jones DG. Endoscopy or radiology for upper gastrointestinal symptoms. Lancet 1986; 1 : 1022-1023.

7. Colin-Jones DG, Bloom B, Bodemar G, Crean G, Freston J, Gugler R, et al. Management of dyspepsia: report of a working party. Lancet 1988; 1: 576-579.

8. Williams B, Luckas M, Ellingham JHM, Dain A, Wicks ACB. Do young patients with dyspepsia need investigation? Lancet 1988; II: 1349-1351.

9. Scott B, Atkinson M. Gastroenterology services: a regional review of changes over a five year period (1981-86). Gut 1989; 30: 695-700.

10. Working Party of the Clinical Services Committee of the British Society of Gastroenterology. Provision of gastrointestinal endoscopy and related serwices for a district general hospital. Gut 1991; 32: 95-105.

11. Bramble MG. Open access endoscopy - a nationwide survey of current practice. Gut 1992; 33: 282-285.

12. Harvey RF, Salih SY, Read AE. Organic and functional disorders in 2000 outpatients attending a gastroenterology clinic. Lancet $1983 ;$ I: 632-634.

13. Talley NJ, Zinsmeister AR, Schleck CD, Melton LJ. Dyspepsia and dyspepsia subgroups: a population-based study. Gastroenterology 1992; 102: $1259-1268$.

14. Jones R, Lydeard S. Dyspepsia in the community: a follow-up study. Br J Clin Pract 1992; 46 (2): $95-97$.

15. Mann J, Holdstock G, Harman M, Machin D, Loehry CA. Scoring system to improve cost effectiveness of open access endoscopy. Br Med $J$ 1983; 287: 937-940.

16. Davenport PM, Morgan AG, Darnborough $\mathrm{A}$, de Dombal FT. Can preliminary screening of dyspeptic patients allow more effective use of investigational techniques? $\operatorname{Br}$ Med $J 1985 ; 290$ : 217-220.

17. Fjøsne U, Kleveland PM, Waldum $\mathrm{H}$, Halworsen $\mathrm{T}$, Petersen $\mathrm{H}$. The clinical benefit of routine upper gastrointestinal endoscopy. Scand J Gastroenterol 1986; 21 : 433 440.

18. Talley NJ, McNeil D, Piper DW. Discriminant value of dyspeptic symptoms: a study of the clinical presentation of 221 patients with dyspepsia of unknown cause, peptic ulceration, and cholelithiasis. Gut 1987; 28: 40-46.

19. Holdstock $G$, Harman M, Machin D, Patel C, Lloyd RS. Prospective testing of a scoring system designed to improve case selection for upper gastrointestinal investigation. Gastroenterology 1986; 90: 1164-1169.

20. Knill-Jones RP. Diagnostic systems as an aid to clinical decision making. Br Med J 1987; 295: 1392-1396.

21. Johannessen $T$, Petersen H, Kleveland PM, Dybdahl JH, Sandvik AK, Brenna E, et al. The predictive value of history in dyspepsia. Scand J Gastroenterol 1990; 25: 689-697. 
22. Adang RP, Vismans F-JFE, Ambergen AW, Talmon $J_{\mathrm{x}}$ Hasman A, Flendrig JA. Evaluation of computerised questionnaires designed for patients referred for gastrointestinal endoscopy. $/ \mathrm{w}$ J Biomed Comp 1991: 29: 31-44.

23. Talmon JL. Partern recognition of the ECG: a structured analysis. Thesis 1983.

24. Talmon IL. A multiclass nonparametric partitioning algorithm. Pantern Recognition Letters $1986 ; 4: 31-38$.

25. Schijven RAJ, Talmon JL. Machine learning as a tool for knowledge acquisition. In: Talmon JL, Fox I (eds) Lecture Notes in Medical Informatics. Knowledge Based Systems in Medicine. Methods, Applications and Evaluation. Ith ed. 1989. Springer-Verlag, Berlin, Heidelberg, New York: 27-35.

26. Talmon JL, Braspenning P, Brender J, McNair P. Machine learning in Data Rich Domains: Some Experiences from the KAVAS Project. In: Stefanelli M. Hasman A, Fieschi M. Talmon J (eds) Lecture Notes in Medical Informatics. AIME 91 Proceedings of the Third Conference on Artificial Intelligence in Medicine, Maastricht, June 1991. 1th ed. 1991; Springer-Verlag, Berlin, Heidelberg. New York: 283-293.

27. Weinstein MC, Fineberg HV. The use of diagnostic information to revise probabilities. In: Clinical decision analysis. Philadelphia: WB Saunders Company. 1980: 114-127.

28. Hanley JA, McNeil BJ. The meaning and use of the area under a receiver operating characteristic (ROC) curve. Radiology 1982; 143: 29-36.

29. Centor RM. A Visicalc program for estimating the area under a receiver operating characteristic (ROC) curve. Med Decis Making 1985; 5: $139-148$.

30. Centor RM, Keightley GE. Receiver operating characteristic (ROC) curve area analysis using the ROC ANALYZER. SCAMC Proceedings 1989; 13: 222-226.

31. Centor RM, Keightley J. The ROC ANALYZER reference guide (Version 6.0). Blue Ridge Express BBS, Richmond, Virginia. 1992.

32. Hanley JA, McNeil BJ. A method of comparing the areas under receiver operating characteristic curves derived from the same cases. Radiology 1983; 148: 839-843.

33. Spiegelhalter DJ. Statistical methodology for evaluating gastrointestinal symptoms. Clin Gastroenterol 1985; 14: 489-515.

34. Spiegellatter DJ, Crean GP, Holden R, Knill-Jones RP. Taking a calculated risk: Predictive scoring systems in dyspepsia. Scand J/ Gastroenterol 1987; 22 Suppl 128: 152-160.

35. Naji SA, Brunt PW. Hagen $S$, Mowat NAG, Russell IT, Sinclair TS, et al. Improving the selection of patients for upper gastrointestinal endoscopy. GMt 1993; 34: 187-191.

36. Mansi C, Savarino V, Mella GS, Picciotto A, Mele MR, Celle G. Are clinical patterns of dyspepsia a valid guideline for appropriate use of endoscopy? A report on 2253 dyspeptic patients. Am J Gastroenterol 1993; 88 (7): 1011-1015.

37. Crean GP, Holden RJ, Knill-Jones RP, Beattie AD, James WB, Marjoribanks FM, et al. A database on dyspepsia. Gut 1994; 35: $191-202$.

38. Edenholm M, Gustavsson R, Jansson $\mathrm{O}$, Lingfors $\mathrm{H}$, Nilsson $\mathrm{O}$, Söderlind $\mathrm{T}$, et al. Endoscopic findings in patients with ulcer-like dyspepsia. Scand $J$ Gastroenterol 1985; 20 Supp] 109 : 163-167.

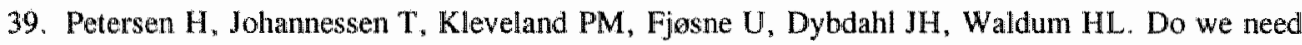
to listen to the patient? The predictive value of symptoms. Scand J Gastroenterol 1988; 23 Suppl 155: $30-34$.

40. Johnsen R, Straume B, Forde OH. Peptic ulcer and non-ulcer dyspepsia - a disease and a disorder. Scand I Prim Health Care 1988; 6: 239-243.

41. Isenberg JI, McQuæd KR, Laine L, Rubin W. Acid-peptic disorders. In: Yamada T, editor. Textbook of gastroenterology. Volume one. Philadelphia: J.B. Lippingcott company. 1991: 1263-1264. 
42. Thompson WG. Symptoms and signs of upper gastrointestinal disease. In: Gustavsson $\mathrm{S}$, Kumar D, Graham DY, editors. The stomach. New York: Churchill Livingstone. 1992: 143156.

43. Crean GP, Card WI, Beattie AD, Holden RJ, James WB, Knill-Jones RP, et al. "Ulcer-like dyspepsia". Scand J Gastroenterol 1982; 17 Suppl 79: 9-15.

44. Heading RC. Definitions of dyspepsia. Scand J Gastroenterol 1991; 26 Suppl 182: 1-6.

45. Talley NJ, Weaver AL, Tesmer DL, Zinsmeister AR. Lack of discriminant value of dyspepsia subgroups in patients referred for upper endoscopy. Gastroenterology 1993; 105: 1378-1386.

46. Cheli R, Perasso A, Giacosa A. Dyspepsia and chronic gastritis. Hepato-gastroenterol 1983: 30: 21-23.

47. Villako K, Ihamäki $T$, Tamm $A$, Tammur $R$. Upper abdoninal complaints and gastritis. Ann Clin Res 1984; 16: 192-194.

48. Toukan AU, Kamal MF, Amr SS, Arnaout MA, Abu-Romiyeh AS. Gastroduodenal inflammation in patients with nonulcer dyspepsia. A controlled endoscopic and morphometric study. Dig Dis Sci 1985; 30 (4): 313-320.

49. Akdamar K, Ertan A, Agrawal NM, McMahon FG, Ryan J. Upper gastrointestinal endoscopy in normal asymptomatic volunteers. Gastrointest Endosc 1986; 32 (2): 78-80.

50. Højgaard L, Matzen P, Christoffersen P. Gastritis * A clinical entity? Scand J Gastroenterol 1987; 22 Suppl 128: 90-92.

51. Varis K. Gastritis - A misused term in clinical gastroenterology. Scand J Gastroenterol 1988; 23 Suppl 155: 53-58.

52. Venables C. Duodenitis. Scand J Gastroenterol 1988; 23 Suppl 155: 61-65.

53. Jörsson $\mathbb{K}-A$, Gotthard $R$, Bodemar $G$, Brodin $U$. The clinical relevance of endoscopic and histologic inflammation of gastroduodenal mucosa in dyspepsia of unknown origin. Scand $J$ Gastroenterol 1989; 24: 385-395. 


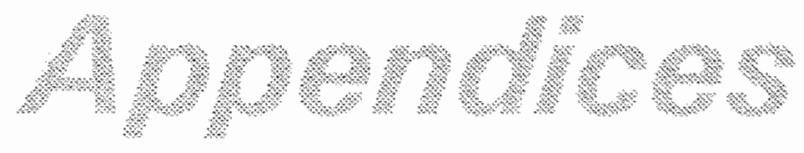


NAME :

DATE :

BIRTH DATE :

SEX
o Male
o Female

\section{REFERRING DOCTOR}

o General practitioner

o Internist / gastroenterologist

a Surgeon

o Other specialist

\section{REFERRAL INDICATIONS}

o Dyspepsia

o Previous peptic ulcer

o Proximal dysphagia (swallowing problems)

o Distal dysphagia

o Retrosternal pain

o Haematemesis

o Melaena

o Faecal occult blood

o Iron deficiency anaemia

o Anorexia and weight loss

o Abnormal upper GI X-ray

o Other referral indications 
PAIN LOCALISATIONS

- No pain

- Retrosternal

o Epigastric

- Right upper abdomen

- Left upper abdomen

- Umbilical

- Right mid abdomen

- Left mid abdomen

o Mid lower abdomen

o Right lower abdomen

o Left lower abdomen

\section{PAIN RADIATION SITES}

- No radiation

o Right side

o Left side

- Interscapular

o Back

- Upper abdomen

o Lower abdomen

\begin{tabular}{|l|l|l|l|}
\hline \multirow{2}{*}{ DRUG TREATMENT } & \multicolumn{3}{|c|}{ Duration of treatiment } \\
\cline { 2 - 4 } & $<6$ weeks & 6 weeks -1 year & $>1$ year \\
\hline $\mathrm{H}_{2}$ receptor antagonists & & & \\
Antacids & & & \\
Cytoprotective drugs & & & \\
Prokinetic agents & & & \\
NSAlDs & & & \\
Steroids & & & \\
Anticoagulant agents & & & \\
\hline
\end{tabular}




\section{OESOPHAGEAL DIAGNOSES}

o Normal oesophageal investigation

o Oesophagitis grade I

o Oesophagitis grade II

o Oesophagitis grade III

o Oesophagitis grade IV

o Candida oesophagitis

o Mallory-Weiss lesion

o sliding hernia

o Paraoesophageal hernia

o Combined hernia

o Cardia insufficiency

o Nissen fundoplication

o Barrett epithelium

o Polyp

o Diverticulum

o Xanthelasma

o Oesophageal cancer

o Stenosis

- Varices grade I

o Varices grade II

a Varices grade III

o Varices grade IV

o Bleeding varices

o Other oesophageal diagnoses

\section{GASTRIC DIAGNOSES}

o Normal gastric investigation

o Haemorrhagic gastritis

o Erosive gastritis

- Atrophic gastritis

o Varioliform gastritis

o Hypertrophic gastritis

- Active gastric ulcer

o Healing (scarring) ulcer

o Perforated ulcer

o Gastric cancer

o Polyp

o Diverticulum

o Pyloric stenosis

o Billroth I-resection

o Billroth II-resection

- Subtotal gastric resection

o Roux-Y anastomosis

o GI stoma

o Other resections

o Post-gastrectomy anastomositis

o Cancer in the resected stomach

o Bile reflux

o Gastric retention

o Other gastric diagnoses

\section{DUODENAL DIAGNOSES}

o Normal duodenal investigation

o Duodenitis

o Bulbitis

o Active duodenal ulcer

o Healing (scarring) ulcer

o Duodenal cancer

o Papillary cancer

o Bulbar deformation

o Stenosis

a Other duodenal diagnoses 
1. Do you have epigastric pain?
a. no (18)
b. yes ( 2 )

2. Would you describe this pain as
a. dull
b. buining
c. gnawing
d. sharp
e. boring
f. cramping
g. another description

3. How long have you had this pain?
a. years
b. months
c. weekks
d. days

4. Are you having this pain for the first time in your life?
a. yes
b. no, I have also had this pain in the past

5. Are there any periods that you do not have this pain?
a. no, I have this pain every day
b. yes, sometimes I have no pain for several days
c. yes, sometimes I have no pain for several weeks
d. yes, sometimes I have no pain for several months

6. How is the course of this pain during the day?
a. this pain is almost equally present during the whole day
b. this pain is unequally present during the whole day
c. this pain is present during periods of more than one hour
d. this pain is present during periods of less than one hour

7. Does this pain occur seasonally?
a. no
b. yes, mainly in the autumn and winter
c. yes, mainly in the spring and summer

8. Do you also have this pain during the night?
a. no
b. yes, but once I am sleeping I do not awake because of this pain
c. yes, I even awake because of this pain 
9. Does this pain arise and/or increase before meal?
a. no
b. yes

10. Does this pain decrease after meal?
a. yes
b. no

11. Does this pain arise and/or increase after meal?
a. no (13)
b. yes, however only with certain foods (12)
c. yes, after each meal (13)

12. The pain arises and/or increases with certain foods as
a. coffee
b. carbonated liquids
c. alcoholic liquids
d. strongly seasoned food
e. fat meals
f. cabbage
g. uncooked food
h. other foods

13. Does this pain arise and/or increase prior to discharge?
a. no
b. yes

14. Does this pain decrease following discharge?
a. no
b. yes

15. Does this pain arise and/or increase following discharge?
a. no
b. yes

16. Does this pain arise and/or increase with lying or bending?
a. no
b. yes

17. How much are you hampered by this pain in daily life?
a. I am severely hampered
b. I am moderately hampered
c. I am not hampered at all 
18. Do you have retrosternal pain?
a. no (32)
b. yes (1.9)

19. Would you describe this pain as
a. dull
b. burning
c. gnawing
d. sharp
e. boring
f. cramping
g. another description

20. How long have you had this pain?
a. years
b. months
c. weeks
d. days

21. Are you having this pain for the first time in your life?
a. yes
b. no, I have also had this pain in the past

22. Are there any periods that you do not have this pain?
a. no, I have this pain every day
b. yes, sometimes I have no pain for several days
c. yes, sometimes I have no pain for several weeks
d. yes, sometimes I have no pain for several months

23. How is the course of this pain during the day?
a. this pain is almost equally present during the whole day
b. this pain is unequally present during the whole day
c. this pain is present during periods of more than one hour
d. this pain is present during periods of less than one hour

24. Does this pain occur seasonally?
a. no
b. yes, mainly in the autumn and winter
c. yes, mainly in the spring and summer

25. Do you also have this pain during the night?
a. no
b. yes, but once I am sleeping I do not awake because of this pain
c. yes, I even awake because of this pain 
26. Does this pain arise and/or increase before meal?
a. no
b. yes

27. Does this pain decrease after meal?
a. yes
b. no

28. Does this pain arise and/or increase after meal?
a. no (30)
b. yes, however only with certain foods (29)
c. yes, after each meal (30)

29. The pain arises and/or increases with certain foods as
a. coffee
b. carbonated liquids
c. alcoholic liquids
d. strongly seasoned food
e. fat meals
f. cabbage
g. uncooked food
h. other foods

30. Does this pain arise and/or increase with lying or bending?
a. no
b. yes

31. How much are you hampered by this pain in daily life?
a. I am severely hampered
b. I am moderately hampered
c. I am not hampered at all

32. Are you troubled with heartburn?
a. no (35)
b. yes (33)

33. How long have you been troubled with heartburn?
a. years
b. months
c. weeks
d. days

34. Does the heartburn arise and/or increase with lying or bending?
a. no
b. yes 
35. Are you troubled with belching?
a. no (37)
b. yes (36)

36. How long have you been troubled with belching?
a. years
b. months
c. weeks
d. days

37. Do you suffer from nausea?
a. no (39)
b. yes, several times a week (38)
c. yes, daily (38)

38. How long have you suffered from nausea?
a. years
b. months
c. weeks
d. days

39. Do you suffer from romiting?
a. no (42)
b. no, I only suffer from nausea( 42 )
c. yes, I vomit several times a week (40)
d. yes, I vomit daily (40)

40. How long have you suffered from vomiting?
a. years
b. months
c. weeks
d. days

41. Do you vomit after the ingestion of food?
a. no, there is no relation between ingestion and vomiting
b. yes, I usually vomit within half an hour after ingestion
c. yes, I usually vomit more than half an hour after ingestion

42. Does food pass with difficulty or even get stuck?
a. never
b. only in case of solid food
c. also in case of soft food
d. even in case of liquids 
43. Has your appetite decreased in comparison with the past?
a. no
b. yes

44. Do you have an aversion for certain foods?
a. no
b. yes, for meat
c. yes, for vegetables
d. yes, for coffee
e. yes, for alcoholic liquids
f. yes, for other foods

45. Are you early satisfied after a small meal?
a. no
b. yes

46. Do you suffer from bloating?
a. no
b. yes

47. Do you suffer from rumblings in your abdomen?
a. no
b. yes

48. Do you suffer from flatulence?
a. no
b. yes

49. Did you observe black stool during the last weeks?
a. no
b. yes

50. Do you drink alcohol?
a. never
b. sometimes and then moderately
c. regularly and then moderately
d. regularly and then excessively
e. daily and then moderately
f. daily and then excessively

51. Do you smoke?
a. never
b. less than 15 cigarettes daily
c. between 15 and 30 cigarettes daily
d. more than 30 cigarettes daily
e. other tobacco 
52. Have you had previous stomach surgery?
a. no
b. yes, less than 5 years ago
c. yes, between 5 and 20 years ago
d. yes, more than 20 years ago

53. Have you had previous gall-bladder surgery?
a. no
b. yes, less than 5 years ago
c. yes, between 5 and 20 years ago
d. yes, more than 20 years ago

54. Are you known to have gallstones?
a. no
b. yes

55. Do you have a strenuous life in comparison with the past?
a. no
b. yes

56. Did you recently have a troublesome time?
a. no
b. yes

57. Do your 'complaints' increase with stress?
a. no
b. yes

1 Each question in the computerised questionnaire contains an additional 'escape answer' (I don"t know; I don't understand; The correct answer is not available), besides the answer options also present in the paper questionnaire; ${ }^{2}$ The answers to the 'branching questions' $(1,18,32,35,37$, and 39) are followed by a number between brackets, indicating the question where to continue. 
Appendix C (I) The originally recorded referral indications.

\section{REFERRAL INDICATIONS}

Dyspepsia

Previous peptic ulcer

Proximal dysphagia

Distal dysphagia

Retrosternal pain

Haematemesis

Melaena

Faecal occult blood

Iron deficiency anaemia

Anorexia and weight loss

Abnormal upper GI X-ray

Other referral indications
Number of patients $(\%)$

$\begin{array}{rr}1562 & (53.9) \\ 168 & (5.8) \\ 61 & (2.1) \\ 127 & (4.4) \\ 263 & (9.1) \\ 226 & (7.8) \\ 164 & (5.7) \\ 23 & (0.8) \\ 155 & (5.3) \\ 143 & (4.9) \\ 30 & (1.0) \\ 368 & (12.7)\end{array}$

1 Total number exceeds $2900(100 \%)$, as multiple referral indications in individual patients occurred. 
Appendix C (II) The originally recorded pain localisations and pain radiation sites.

\begin{tabular}{lrc}
\hline PAIN LOCALISATIONS & \multicolumn{2}{c}{ Number of patients (\%) } \\
\hline No pain & 1006 & $(35.4)$ \\
Retrosternal & 426 & $(15.0)$ \\
Epigastric & 1340 & $(47.1)$ \\
Right upper abdomen & 131 & $(4.6)$ \\
Left upper abdomen & 97 & $(3.4)$ \\
Umbilical & 31 & $(1.1)$ \\
Right mid abdomen & 14 & $(0.5)$ \\
Left mid abdomen & 8 & $(0.3)$ \\
Mid lower abdomen & 30 & $(1.1)$ \\
Right lower abdomen & 21 & $(0.7)$ \\
Left lower abdomen & 14 & $(0.5)$ \\
\hline
\end{tabular}

PAIN RADIATION SITES

Number of patients (\%)

No radiation

$1533(83.5)$

Right sidle

$61 \quad(3,3)$

Left side

Interscapular

$6 \quad(0.3)$

Back

$136 \quad(7.4)$

Upper abdomen

$55 \quad(3.0)$

Lower abdomen

$32 \quad(1.7)$

Total numbers exceed $2843(100 \%)$ and 1837 (100\%) respectively, as multiple pain localisations and/or pain radiation sites occurred in individual patients. 
Appendix $\mathbf{C}$ (III) The originally recorded drug regimens and the duration of treatment.

\begin{tabular}{lccccc}
\hline \multirow{2}{*}{ DRUG TREATMENT } & \multicolumn{3}{c}{ Duration of treatment } & \multicolumn{2}{c}{ Number of patients (\%) } \\
\cline { 2 - 5 } & $<6$ weeks & 6 weeks - 1 year & $>1$ year & & \\
\hline H $_{2}$ receptor antagonists & 546 & 185 & 116 & 847 & $(29.7)$ \\
Antacids & 119 & 25 & 15 & 159 & $(5.6)$ \\
Cytoprotective drugs & 91 & 12 & 3 & 106 & $(3.7)$ \\
Prokinetic agents & 62 & 13 & 3 & 78 & $(2.7)$ \\
NSAIDs & 91 & 92 & 48 & 231 & $(8.1)$ \\
Steroids & 16 & 24 & 23 & 63 & $(2.2)$ \\
Anticoagulant agents & 16 & 15 & 31 & 62 & $(2.2)$ \\
\hline
\end{tabular}

${ }^{1}$ Including proton pump inhibitors. 
Appendix C (IV) The originally recorded oesophageal endoscopic diagnoses.

\begin{tabular}{|c|c|c|}
\hline \multirow{2}{*}{$\frac{\text { OESOPHAGEAL DIAGNOSES }}{\text { Normal oesophageal investigation }}$} & \multicolumn{2}{|c|}{ Number of patients $(\%)$} \\
\hline & 1852 & $(64.6)$ \\
\hline Oesophagitis grade I & 211 & $(7.4)$ \\
\hline Oesophagitis grade II & 103 & $(3.6)$ \\
\hline Desophagitis grade III & 46 & $(1.6)$ \\
\hline Oesophagitis grade IV & 37 & $(1.3)$ \\
\hline Candida oesophagitis & 43 & $(1.5)$ \\
\hline Mallory-Weiss lesion & 15 & $(0.5)$ \\
\hline Sliding hernia & 488 & $(17.0)$ \\
\hline Paraoesophageal herniat & 3 & $(0.1)$ \\
\hline Combined hernia & 6 & $(0.2)$ \\
\hline Cardia insufficiency & 120 & $(4.2)$ \\
\hline Nissen fundoplication & 5 & $(0.2)$ \\
\hline Barrett epithelium & 53 & $(1.8)$ \\
\hline Polyp & 11 & $(0.4)$ \\
\hline Diverticulum & 24 & $(0.8)$ \\
\hline Xanthelasma & 1 & $(0.0)$ \\
\hline Oesoplaageal cancer & 15 & $(0.5)$ \\
\hline Stenosis & 20 & $(0.7)$ \\
\hline Varices grade I & 21 & $(0.7)$ \\
\hline Varices grade II & 9 & $(0.3)$ \\
\hline Varices grade III & 7 & $(0.2)$ \\
\hline Varices grade IV & 2 & $(0.1)$ \\
\hline Bleeding varices & 2 & $(0.1)$ \\
\hline Other oesophageal dingnoses & 71 & $(2.5)$ \\
\hline
\end{tabular}

1 Total number exceeds $2865(100 \%)$, as multiple oesophageal diagnoses in individual patients occurred. 
Appendix C (V) The originally recorded gastric endoscopic diagnoses.

\section{GASTRIC DIAGNOSES}

Normal gastric investigation

Haemorrhagic gastritis

Erosive gastritis

Alrophic gastritis

Varioliform gastritis

Hypertrophic gastritis

Active gastric ulcer

Healling (scarring) ulcer

Perforated ulcer

Gastric cancer

Polyp

Diverticulum

Pyloric stenosis

Billroth I-resection

Billroth II-resection

Subtotall gasitric resection

Roux- $Y$-anastomosis

GI stoma

Other resections

Post-gastrectorny anastomositis

Cancer in the resected stomach

Bile reflux

Gastric retention

Other gastric diagnoses
Number of patients (\%) ${ }^{1}$

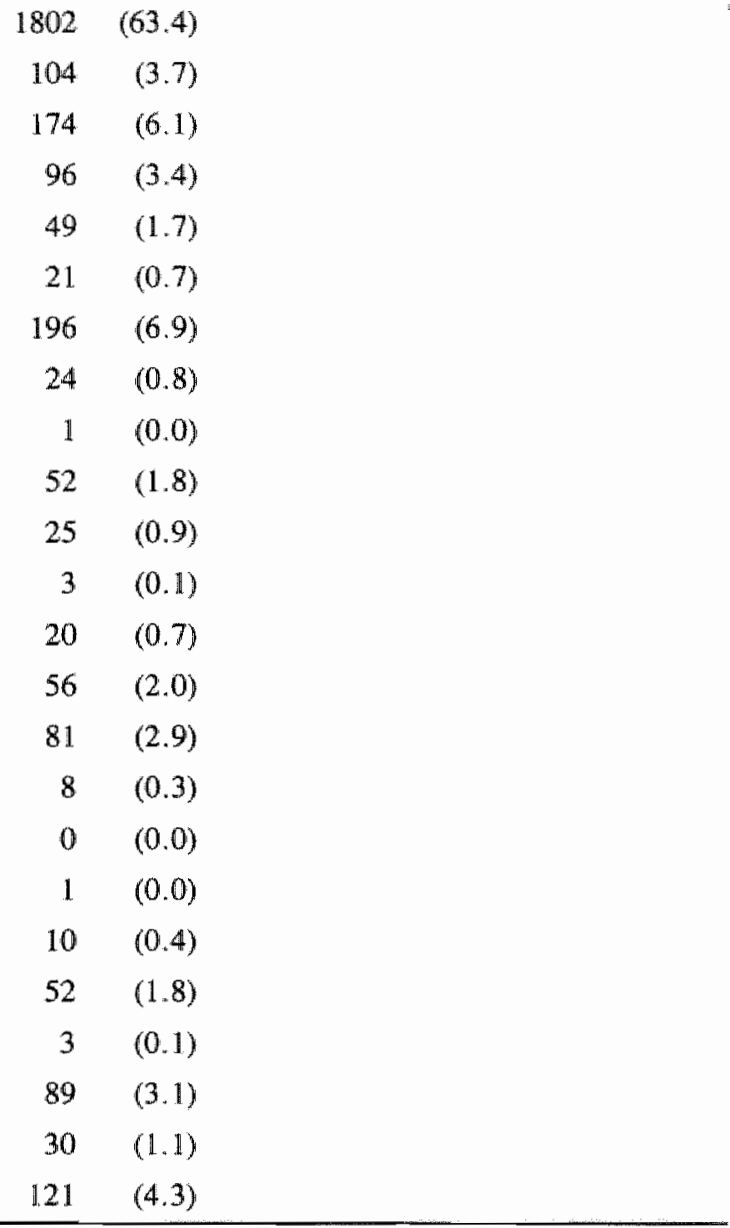

Total number exceeds 2841 (100\%), as multiple gastric diagnoses in individual patients occurred. 
Appendix $\mathbf{C}$ (VI) The originally recorded duodenal endoscopic diagnoses.

\section{DUODENAL DIAGNOSES}

Normal duodenal investigation

Duodenitis

Bulbitis

Active duodenal uleer

Healing (scarring) ulcer

Duodenal cancer

Papillary cancer

Bulbar deformation

Stenosis

Other duodenal diagnoses Number of patients $(\%)^{\text {i }}$

$\begin{array}{rr}2157 & (76.6) \\ 148 & (5.3) \\ 246 & (8.7) \\ 216 & (7.7) \\ 18 & (0.6) \\ 0 & (0.0) \\ 1 & (0.0) \\ 31 & (1.1) \\ 6 & (0.2) \\ 79 & (2.8)\end{array}$

1 Total number exceeds $2817(100 \%)$, as multiple duodenal diagnoses in individual patients accurred. 


\begin{tabular}{|c|c|c|c|c|c|}
\hline$Q 1$ & & Q7 & Q13 & Q20 & Q27 \\
\hline a. & 38.6 & a. $\quad 77.0$ & a. 75.3 & a. 29.3 & a. 66.2 \\
\hline$b$ & 57.2 & 5.3 & b. 14.5 & b. 36.5 & b. $\quad 20.4$ \\
\hline \multirow[t]{2}{*}{$?$} & 4.2 & 1.4 & 10.2 & c. 23.4 & 13.4 \\
\hline & & $? \quad 16.3$ & & 5.5 & \\
\hline $\mathrm{Q}^{2}$ & & & Q14 & 5.3 & Q28 \\
\hline a. & 21.0 & Q8 & a. 71.8 & & a. 45.8 \\
\hline b. & 14.0 & a. 25.8 & b. 14.6 & Q21 & b. $\quad 22.2$ \\
\hline c. & 14.5 & b. 22.3 & 13.6 & a. $\quad 40.1$ & c. $\quad 19.3$ \\
\hline d. & 13.1 & c. 45.3 & & b. $\quad 54.2$ & 12.7 \\
\hline e. & 1.8 & 6.6 & Q15 & 5.7 & \\
\hline f. & 17.8 & & a. $\quad 81.7$ & & Q29 \\
\hline $\mathrm{g}$. & 1.2 & Q9 & 5.0 & Q22 & a. 11.0 \\
\hline \multirow[t]{2}{*}{$?$} & 16.6 & a. 68.3 & 13.3 & a. 30.5 & 8.3 \\
\hline & & b. $\quad 18.1$ & & b. 35.8 & 3.7 \\
\hline Q3 & & 13.6 & Q16 & c. $\quad 14.5$ & 5.5 \\
\hline a. & 25.9 & & a. $\quad 50.2$ & d. $\quad 14.5$ & 8.3 \\
\hline b. & 39.5 & Q10 & b. $\quad 39.0$ & 4.7 & 5.5 \\
\hline c. & 26.4 & a. 58.5 & 10.8 & & 1.8 \\
\hline d. & 6.3 & b. $\quad 29.7$ & & $\mathrm{Q} 23$ & h. $\quad 10.1$ \\
\hline \multirow[t]{2}{*}{$?$} & 1.9 & 11.8 & Q17 & a. $\quad \mathbb{1 4 . 7}$ & 45.8 \\
\hline & & & a. $\quad 32.2$ & b. 37.3 & \\
\hline Q4 & & Q11 & b. 50.3 & c. 18.7 & Q30 \\
\hline a. & 37.5 & a. 41.0 & c. 11.1 & d. 22.8 & a. 50.1 \\
\hline b. & 57.6 & b. $\quad 28.0$ & 6.4 & 6.5 & b. 39.5 \\
\hline \multirow[t]{2}{*}{$?$} & 4.9 & c. 19.4 & & & 10.4 \\
\hline & & 11.6 & Q18 & Q24 & \\
\hline Q5 & & & a. $\quad 49.0$ & a. $\quad 77.4$ & Q31 \\
\hline a. & 31.4 & Q12 & b. 42.8 & 5.7 & a. 29.1 \\
\hline b. & 39.2 & a. $\quad 12.5$ & 8.2 & 2.0 & b. 48.3 \\
\hline c. & 11.7 & 3.3 & & 14,9 & c. 14.1 \\
\hline d. & 13.6 & 1.1 & Q19 & & 8.5 \\
\hline \multirow[t]{2}{*}{$?$} & 4.1 & 7.1 & a. $\quad 19.6$ & Q25 & \\
\hline & & 8.7 & b. $\quad 17.7$ & a. 28.7 & Q32 \\
\hline Q6 & & 6.0 & c. 12.4 & b. 21.6 & a. 47.8 \\
\hline a. & 14.0 & 1.6 & d. 13.6 & c. 43.0 & b. 46.6 \\
\hline b. & 39.8 & 9.2 & 3.5 & 6.7 & 5.6 \\
\hline c. & 23.0 & $? \quad 50.5$ & f. $\quad 19.3$ & & \\
\hline d. & 17.8 & & 1.4 & Q26 & \\
\hline \multirow[t]{3}{*}{$?$} & 5.4 & & $? \quad 12.5$ & a. 75.8 & \\
\hline & & & & b. 12.6 & \\
\hline & & & & $? \quad 11.6$ & \\
\hline
\end{tabular}




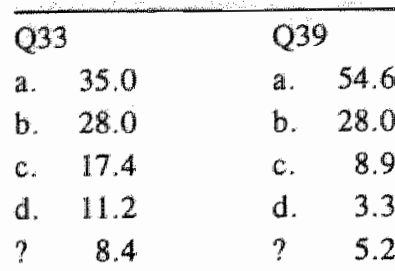

\section{Q34}

a. 41.5

b. 45.6

? $\quad 12.9$

\section{Q35}

a. $\quad 32.9$

b. 62.6

? 4.5

\section{Q36}

a. 26.3

b. 34.0

c. 23.8

d. 9.1

? 6.8

\section{Q37}

a. $\quad 57.4$

b. 23.9

c. 13.8

? 4,9

\section{Q38}

$\begin{array}{lr}\text { a. } & 20.4 \\ \text { b. } & 35.9 \\ \text { c. } & 28.9 \\ \text { d. } & 6.9\end{array}$

\section{Q40}

a. 25.0

b. 32.1

c. 28,6

d. 9.3

? 5.0

\section{Q41}

a. 41.4

b. 28.6

c. 24.3

$\begin{array}{ll}\text { ? } & 5.7\end{array}$

Q42

a. $\quad 54.9$

b. $\quad 18.9$

c. 3.5

d. 8.1

? 14.6

Q43

a. 55.1

b. 40.6

? 4.3

\section{Q44}

a. 56.2

b. 8.1

c. 2.0

d. 7.3

e. 4.4

f. $\quad 9.2$

? $\quad 12.8$

Q45

a. 46.6

b. 46.3

? 7.1

\section{Q46}

a. 39.3

b. 52.5

? 8.2

Q47

a. 37.4

b. 55.5

? 7.1

Q48

a. 33.8

b. 61.0

? 5.2

Q49

a. $\quad 78.9$

b. 120

? 9.1

\section{Q50}

a. 27.4

b. 42.4

c. 15.0

d. 2.3

e. 8.9

f. $\quad 0.3$

? $\quad 3.7$

Q51

a. 51.0

b. 22.5

c. 18.4

d. $\quad 1.7$

e. 2.4

? 4.0

Q52

a. 88.5

b. 2.4

c. 1.9

d. 3.8

? 3.4

Q53

a. 91.1

b. 1.4

c. 2.5

d. 1.3

$\begin{array}{ll}\text { ? } & 3.7\end{array}$

Q54

a. 88.3

b. $\quad 5.9$

? $\quad 5.8$

? 7.9

Q Question; " No answer or multiple answers in the paper questionnaire or "escape answer" (I don "t know; I don"t understand; The correct answer is not available) in the computerised questionnaire; Percentages are given of the number of patients who have actually answered a question: the 'refinement questions' (Q2-27, Q19-31, Q33-34, Q36, Q38, Q40-41) were answered only by those patients who had answered the preceding 'branching question' (Q1, Q18, Q32, Q35, Q37, Q39) affirmatively. 
CODE FOR CLUSTERING OF THE ORIGINALLY RECORDED ANISWER OPTIONS

Since there are some basic differences between the paper questionnaire and the computerised history taking system, we have adapted some rules for jointly analysing the history data as obtained by either paper or computerised questionnaire:

(1) Those questions that were skipped in the paper questionnaire were handled the same way as questions that were answered with an 'escape answer' in the computerised questionnaire.

(2) Those questions that were answered with more than one option in the paper questionnaire were handled the same way as questions that were answered with an 'escape answer' in the computerised questionnaire. An exception to the latter rule are some questions for which multiple answers were treated as a regular answer option: Q2 as option g; Q12 as option h; Q19 as option g; Q29 as option h; Q44 as option f; Q52 as option c; Q53 as option c.

For the studies presented in Chapters VII and VIII the originally recorded answers were clustered and recoded for further statistical analyses. The code for the clustering procedure is listed below:
Q2: $a+b+c+f ; d+e$
Q22: $c+d$
Q39: $a+b ; c+d$
Q3: $c+d$
Q23: $a+b ; c+d$
Q40: $c+d$
Q5: $c+d$
Q24: $b+c$
Q41: $\mathrm{b}+\mathrm{c}$
Q6: $a+b ; c+d$
Q25: $b+c$
Q42: $c+d$
Q7: $b+c$
Q28: $b+c$
Q44: $\mathrm{b}+\mathrm{c}+\mathrm{d}+\mathrm{e}+\mathrm{f}$
Q8: $b+c$
Q31: $b+c$
Q50: $\mathrm{d}+\mathrm{e}+\mathrm{f}$
Q11: $b+c$
Q33: $c+d$
Q51: $b+e ; c+d$
Q17: $b+c$
Q36: $c+d$
Q52: $b+c+d$
Q19: $a+b+c+f ; d+e$
Q37: $b+c$
Q20: $\mathrm{c}+\mathrm{d}$
Q38: $c+d$
Q53: $b+c+c$

Q12 and Q29 have been left out from the analyses. 


\section{Summary and conclusions}

The aims of the studies described in this thesis were: 1 ) to assess whether it is possible to predict the presence of clinically relevant endoscopic findings in patients referred for diagnostic upper gastrointestinal endoscopy and 2) to assess whether it is possible to distinguish patients with specific endoscopic diagnoses from patients having a normal endoscopy by analysing pre-endoscopically collected patient characteristics and symptoms; 3) to assess the applicability of computerised questionnaires in routine clinical practice of an endoscopy unit; 4) to determine the impact of patient age on the diagnostic yield of upper gastrointestinal endoscopy; 5) to evaluate the open access facility at our endoscopy unit by comparing the endoscopic outcome in patients referred directly from general practice to the outcome in hospital in- and outpatients; and 6) to evaluate the appropriateness of several indications for diagnostic upper gastrointestinal endoscopy by assessing their association with relevant endoscopic disease.

In Chapter I introductory remarks about dyspepsia and on the diagnostic role of upper gastrointestinal endoscopy in dyspepsia are made, and the literature concerning the predictive value of dyspeptic symptoms for upper gastrointestinal disorders is reviewed. Dyspeptic symptoms are common in the general population and constitute a frequent reason for consultation with general practitioners and subsequent referral to gastroenterology outpatient departments. Endoscopy is generally considered the investigation of first choice and is mandatory for a precise diagnosis of dyspepsia. Since the institution of open access services for general practitioners, the demand for endoscopy has outstripped the available resources, resulting in long waiting lists in many centres. Moreover, in a large proportion of patients endoscopy reveals no serious organic disease, and this seems to be an expensive luxury in these days of scarce resources. Consequently, the open access to endoscopy has been questioned and guidelines for selection of patients have been proposed, such as the refusal of endoscopy in patients under 45 years of age with uncomplicated dyspepsia and 
without previous empiric treatment. It still has to be established whether it is possible to select patients for endoscopy on the basis of clinical symptomatology.

In Chapter II the methods of data acquisition and the study material are described in detail. Data were collected during everyday practice at a single endoscopy unit of a teaching/general hospital providing an unrestricted open access service for specialists and general practitioners. A study form containing predefined referral indications, pain localisations and pain radiation sites, previous drug regimens, and endoscopic diagnoses was used for consistent and uniform data acquisition. The data on 2900 consecutive patients referred for their first diagnostic upper gastrointestinal endoscopy formed the basis for the studies presented in this thesis.

History data were obtained by two different means. In the first phase of the study, the patients were offered a paper questionnaire and in the second phase the patients were interviewed by a computerised history taking system. In Chapter III the evaluation of the applicability of such a history taking system in everyday practice of an endoscopy unit is presented. This evaluation was performed at the time that the computerised questionnaires had been in use for period of five months. The paper questionnaires were answered by $70 \%$ of the patients and $64 \%$ of the patients had been able to answer the history taking system. The ability to answer either type of questionnaire was negatively correlated with patient age. The computerised questionnaires were completed on average in eleven minutes, which makes interrogation possible within the normal waiting time before endoscopy is performed. The history data obtained with both types of questionnaires were highly reproducible. The patient attitude towards the history taking system was generally favourable: answering the questionnaire was considered to be easy, interesting, and was experienced as not time consuming. A considerable proportion of the patients expressed that the insight in their complaints had increased and that they could put their complaints into words more easily after answering the questionnaire. However, onequarter felt that they had not the opportunity to express all their complaints.

The open access service for general practitioners was evaluated by comparing the endoscopic outcome in patients referred by their general practitioner to the outcome in hospital in- and outpatients (Chapter IV). The patients referred by general practitioners differed in many aspects from those referred by specialist. They were younger and more often referred because of dyspepsia and less often because of so-called 'alarm symptoms'. A larger proportion of the general practice referrals had epigastric and/or retrosternal pain and had been empirically treated. However, the diagnostic yield of endoscopy was similar in both patient groups. We conclude that this may be an argument for continuing the open access policy and that abandoning the open access facility would probably not result in a more effective use of the endoscopy service. The proportion of clinically relevant endoscopic findings disease increased with increasing age from $23 \%$ in patients under 45 years to $32 \%$ in those above 45 years of age. No malignancies were diagnosed in patients younger than 45 years. 
The appropriateness of several referral indications has been evaluated by assessing their association with relevant endoscopic disease (Chapter V). The generally approved alarm symptoms such as history or signs of upper gastrointestinal bleeding, dysphagia, and anorexia and weight loss were clearly associated with clinically significant endoscopic findings. Dyspepsia as an isolated symptom was evaluated regarding the following aspects: 1) the age of the patients; 2) whether patients had been empirically treated prior to referral; and 3) whether they had epigastric and/or retrosternal pain. From the results we conclude that dyspeptic complaints in patients above 45 years of age and dyspeptic complaints persisting or recurring despite an adequate course of medical treatment - irrespective of age - are appropriate reasons for requesting an endoscopy. On the other hand, endoscopy for dyspeptic symptoms in patients under 45 years who have not been empirically treated has a rather low diagnostic yield, especially when these patients do not have epigastric and/or retrosternal pain.

The studies presented in Chapters IV and V include the study population of 2900 patients, whereas the studies presented in Chapters VII and VIII are based on the 1147 patients who answered the questionnaires.

Chapter VI deals with three issues. First, the reasons why 1753 patients did not answer the questionnaires are discussed. Secondly, the patients who answered the questionnaires (responders) are compared with those who did not (non-responders) to assess whether selection bias might have influenced the studies that were based on only those patients who answered the questionnaires. Thirdly, the pain localisations as reported in the questionnaires are compared with the pain presentation in the interview conducted by the endoscopist.

The questionnaires were not answered by approximately $60 \%$ of the patients, because of mental or physical disorders $(30 \%)$, technical problems $(12 \%)$, or secretarial understaffing (32\%). In $26 \%$ of the non-responders the reasons for not answering had not been recorded.

The group of responders differed in several aspects from the non-responders: they were younger, had a male preponderance and were more often referred directly from general practice. In responders dyspeptic complaints were by far the most frequent reason for doing an endoscopy; alarm symptoms occurred in not more than $10 \%$ of these patients. The fact that more than $40 \%$ of this group of patients had been treated with anti-peptic agents prior to referral may have influenced symptoms and endoscopic findings. Relevant endoscopic findings were diagnosed in less than one-quarter of the responders, but in about one-third of the non-responders. Oesophagitis was equally prevalent in both groups, though peptic ulcers were diagnosed more often in non-responders.

The pain localisations presented in the questionnaires differed from those reported to the endoscopist: the patients expressed more often epigastric pain and less often a combination of epigastric and retrosternal pain in the pre-endoscopic interview. The variations in pain localisation can be partly explained by the differences between the methods of assessment. 
In "two-class models" patients with a specific endoscopic diagnosis were compared with patients having a normal endoscopy, By this, we wanted to assess whether these diagnoses have a more or less typical symptom profile. In a so-called 'multi-class model' we assessed whether it is possible to predict the presence of relevant endoscopic findings in patients referred for diagnostic upper gastrointestinal endoscopy by anallysing pre-endoscopically collected characteristics and history data. Forward stepwise logistic regression was used for the analyses in Chapter VII and a non-parametric method (NPPA) was used in Chapter VIII. The logistic regression analysis identifies the most discriminative variables, whereas NPPA results in a binary classification tree which renders insight in what (combinations of) variables are important for the discrimination between the diagnostic categories. For each prediction model a Receiver Operating Characteristic (ROC) curve can be constructed, and the Area Under the ROC Curve (AUC) gives an impression of the overall discriminative power of the model. The results of the logistic regression analyses and the non-parametric analyses were comparable, although NPPA in general reached a higher discriminative accuracy (Table $\mathrm{D}$ ).

Patients with peptic ulcers could rather accurately be discriminated from patients with a normal endoscopy. Age above 45 years, a history of peptic ulcer disease, previous empiric treatment, smoking, and signs of upper gastrointestinal bleeding were clearly associated with gastric ulcer in both types of analyses. Age, smoking, signs of upper gastrointestinal bleeding, epigastric pain and 'stress' were related to the detection of a duodenal ulcer in the logistic regression analysis; the presence of

Table I Areas under the Receiver Operating Characteristic (ROC) curves of the logistic regression analysis (LRA) and non-parametric partitioning algorithm (NPPA) models, comparing patients with specific endoscopic diagnoses to patients having a normal endoscopy $(n=390)$ and comparing patients with clinically relevant endoscopic disease $(n=269)$ to those without $(n=878)$.

\begin{tabular}{lll}
\hline ENDOSCOPIC DIAGNOSES $(\mathrm{n})$ & LRA & NPPA \\
& AUC & AUC \\
\hline Hiatus hernia $(\mathrm{n}=186)$ & 0.78 & 0.80 \\
Oesophagitis $(\mathrm{n}=141)$ & 0.77 & 0.82 \\
Endoscopic gastritis $(\mathrm{n}=167)$ & 0.73 & 0.81 \\
Gastric ulcer $(\mathrm{n}=56)$ & 0.86 & 0.94 \\
Duodenitis/bulbitis $(\mathrm{n}=152)$ & 0.75 & 0.88 \\
Duodenal ulcer $(\mathrm{n}=78)$ & 0.85 & 0.94 \\
Relevant endoscopic disease $(\mathrm{n}=269)$ & 0.63 & 0.84 \\
\hline
\end{tabular}

n Number of patients; LRA Forwatd stepwise logistic regression analysis; NPPA Non-parametric partitioning algorithm; AUC Area Under the ROC Curve. 
epigastric pain and the absence of retrosternal pain were selected as discriminative variables in the classification tree comparing duodenal ulcer to normal endoscopy. Of the so-called "classical ulcer symptoms', as referred to in textbooks and previous publications, only 'hunger pain' was found to be associated with the presence of a gastric ulcer.

Both techniques had about the same discriminative power for hiatus hernia and oesophagitis. Male gender and reflux-like symptoms such as heartburn - especially if increasing with lying and/or bending or when existing during several months or years - and retrosternal pain were associated with both diagnoses. Since it was hardly possible to establish these diagnoses on the basis of symptomatology alone, it can be hypothesized that many patients with a normal endoscopy will have symptomatic gastro-oesophageal reflux without evidence of oesophagitis.

Patients with endoscopic gastritis could hardly be discriminated from patients having a normal endoscopy by applying either of both prediction models. This may support the assumption that the endoscopic picture of gastritis should not be accepted as the explanation for dyspeptic complaints per se. However, it has to be realised that 'endoscopic gastritis' as defined in our studies includes a wide range of endoscopic appearances of mucosal inflammation, and that a more differentiated grading might have given a better discrimination.

Whereas the AUC of the ROC curve of the logistic regression based prediction model for clinically relevant endoscopic disease was 0.63 , the AUC of the ROC curve of the non-parametric based prediction model was 0.84 . This difference may be (partly) explained by the fact that the non-parametric algorithm was handled in a real multi-class approach, because only at the level of the terminal nodes the (eight) disease classes were merged into a relevant and non-relevant category. On the other hand, the logistic regression model was in fact a two-class model. For the non-parametric method we have demonstrated (not in this thesis) that merging of disease classes before statistical analysis reduces the discriminative performance of the model. Whereas age was not selected by the logistic regression analysis, age was the most important predictor of relevant endoscopic disease in the NPPA model.

\section{CONCLUSIONS}

From the studies described in this thesis, it can be concluded: 1) that there is no reason to reconsider the open access endoscopy service for general practitioners; 2) that so-called alarm symptoms are appropriate indications for endoscopy as are dyspeptic symptoms in patients above 45 years of age and persisting or recurring dyspeptic complaints despite previous empiric treatment (irrespective of patient age); 3 ) that the diagnostic yield of endoscopy in patients under 45 years of age with uncomplicated dyspepsia without previous empiric treatment is rather low; 4) that it is possible to discriminate patients with a gastric or duodenal ulcer from patients having a normal endoscopy on the basis of their clinical presentation; 5) that it is not possible to discriminate patients with oesophagitis or hiatus hernia from patients with a normal investigation; 6) that it is possible to reduce the number of endoscopic 
examinations with approximately $20 \%$ without missing any relevant endoscopic diagnosis when applying the NPPA model on the study population.

At this point some remarks should be made regarding the design and the practical consequences of the studies presented in this thesis. First, in clinical reality selection of patients for endoscopy takes place in the referral setting and not - as has been studied in this thesis - in the endoscopy unit setting. This has to be realised when extrapolating our study results to general practice or to the outpatient department. Secondly, a symptom-based prediction model as described in this thesis can only be implemented in clinical practice when enough personnel are available to introduce the patients to the history taking system. Under this aspect, we have been able to analyse history data only of those (selected) patients who had answered the paper or computerised questionnaire. Thirdly, the consequences of the fact that we have studied endoscopic (and not histopathological) diagnoses are discussed in detail in chapter VII. Fourthly, the results of the present models and evaluations are based on a unique patient population referred to a single hospital. It may be that similar models must be created for each centre and must be readapted periodically. Finally, we have not addressed the importance of a negative endoscopy for patient management and reassurance. The value of documenting normal endoscopic findings can, therefore, be assessed only by the referring doctor. 


\section{Samenvatting en conclusies}

De vraagstellingen die ten grondslag lagen aan dit proefschrift waren: 1) Is het mogelijk om het vóórkomen van klinisch relevante endoscopische bevindingen bij patiënten verwezen voor een gastroscopie te voorspellen aan de hand van patiëntenkenmerken en dyspeptische klachten? 2) Is het mogelijk om patiënten met specifieke endoscopische diagnoses te onderscheiden van patiënten bij wie geen afwijkingen zijn gevonden bij endoscopisch onderzoek? 3) Kan een 'computer-ondersteund anamnese systeem' routinematig worden gebruikt op een endoscopie-afdeling? 4) Wat is de invloed van de leeftijd van patiënten op de diagnostische opbrengst van een gastroscopie? 5) Hebben patiënten die verwezen zijn door de huisarts dezelfde endoscopische bevindingen als ziekenhuispatiënten? 6) Welke indicaties tot het verrichten van endoscopisch onderzoek leveren de meeste relevante endoscopische diagnoses op?

In Hoofdstuk I worden inleidende opmerkingen gemaakt betreffende dyspepsie en de rol van endoscopie in de diagnostiek van dyspepsie. De literatuur betreffende de voorspellende waarde van dyspeptische symptomen ten aanzien van afwijkingen in het proximale gedeelte van de tractus digestivus wordt samengevat. Dyspeptische klachten komen vaak voor in de samenleving en vormen een frequente reden om de huisarts te raadplegen met vervolgens verwijzing naar een gastroenterologische polikliniek. Endoscopie wordt in het algemeen beschouwd als onderzoek van eerste keuze voor dyspepsie en is onontbeerlijk voor een precieze diagnose. Sedert de 'open toegang' ('open acces') voor huisartsen tot endoscopie-afdelingen heeft de vraag naar gastroscopieën de beschikbare capaciteit overschreden, hetgeen resulteerde in lange wachtlijsten in vele endoscopie-afdelingen. Daarbij wordt in een groot deel van de patiënten bij endoscopisch onderzoek geen ernstige organische aandoening aangetroffen. De vraag rijst of "open toegang" tot de endoscopie-afdeling in deze vorm gehandhaafd kan worden. Er zijn regels voor selectie van patiënten voorgesteld, zoals het niet verrichten van endoscopie bij patiënten jonger dan 45 jaar 
met ongecompliceerde dyspepsie die niet tevoren zijn behandeld. Tot heden kon niet overtuigend worden aangetoond dat het mogelijk is patiẻnten voor endoscopie te selecteren op grond van hun klachten.

In Hoofdstuk II worden de methodes besproken waarmee de gegevens werden werzameld en woorts wordt de studiepopulatie uitgebreid besproken. Gegevens werden verzameld in de dagelijkse praktijk van de endoscopie-afdeling van het Academisch Ziekenhuis Maastricht met een 'open toegang' tot gastroscopie voor specialisten en huisartsen. Een studie-formulier werd gebruikt om tevoren gedefinieerde gegevens zo consistent mogelijk te verzamelen. De gegevens van 2900 opeenvolgende patiënten die verwezen waren voor hun eerste gastroscopie, vormden de basis voor de studies beschreven in dit proefschrift.

Anamnestische gegevens werden verkregen middels twee verschillende methodes: In de eerste fase van het onderzoek kregen patiënten een met de pen in te vullen vragenlijst en later gebeurde dit met een computer-ondersteund anamnese systeem. In Hoofdstuk III wordt beschreven of een dergelijk anamnese systeem in de dagelijkse praktijk van een endoscopie-afdeling toepasbaar is. Deze evaluatie werd verricht nadat het anamnese systeem gedurende een periode van vijf maanden in gebruik was. De vragenlijsten werden beantwoord door $70 \%$ van de patiënten, terwijl $64 \%$ van de patiënten met het computer systeem overweg bleek te kunnen. Het vermogen om elk van beide te beantwoorden nam af met toenemende leeftijd. Het anamnese systeem werd gemiddeld in 11 minuten beantwoord, hetgeen deze manier van ondervragen tijdens de wachttijd voor het endoscopisch onderzoek mogelijk maakt. De anamnestische gegevens die middels beide methodes verkregen werden, waren goed reproduceerbaar. De mening van de patiënten betreffende het anamnese systeem was in het algemeen zeer positief. Het beantwoorden werd als makkelijk en interessant beschouwd en duurde naar de mening van de patiënten niet te lang. Een aanzienlijk deel van de patiënten vond dat het inzicht in hun klachten was toegenomen en dat zij hun klachten beter konden verwoorden nadat zij het anamnese systeem hadden beantwoord. Een kwart van de patiënten opperde echter dat zij niet al hun klachten had kunnen uiten.

De 'open toegang' tot endoscopie voor huisartsen werd geëvalueerd door de endoscopische opbrengst bij hun patiënten te vergelijken met die bij ziekenhuispatiënten (Hoofdstuk IV). De patiënten verwezen door een huisarts verschilden in menig opzicht van de patiënten verwezen door een specialist: $\mathrm{Zij}$ waren jonger en waren vaker verwezen vanwege dyspepsie en minder vaak vanwege zogenaamde 'alarmsymptomen'. Een groot deel van de huisartspatiënten had epigastrische en/of retrosternale pijn en had tevoren een proefbehandeling gehad. Ondanks deze verschillen was de diagnostische opbrengst van gastroscopie in beide groepen patiënten vrijwel identiek. Op grond hiervan concluderen wij dat er geen reden is de 'open toegang' voor huisartsen te herzien en dat het afschaffen ervan waarschijnlijk niet zal resulteren in een efficiënter gebruik van de endoscopische voorzieningen. Het percentage klinisch relevante endoscopische bevindingen nam toe met het stijgen van de leeftijd: Van $23 \%$ bij patiënten jonger dan 45 jaar, tot $32 \%$ bij patiënten boven 
45 jaar. Maligniteiten werden niet gediagnostiseerd onder de leeftjdsgrens van 45 jaar.

De waarde van verschillende verwijsindicaties werd geëvalueerd door hun associatie met relevante endoscopisch gestelde diagnoses te bepalen (Hoofdstuk V). De algemeen geaccepteerde alarmsymptomen zoals tekenen van gastrointestinaal bloedverlies, dysfagie, anorexie en gewichtsverlies waren duidelijk geassocieerd met klinisch relevante endoscopische bevindingen. Dyspepsie als een op zichzelf staand symptoom werd geanalyseerd rekening houdend met de volgende aspecten: 1) De leeftijd van de patiënten; 2) Of patiënten voorafgaande aan de verwijzing een proefbehandeling hadden gehad; en 3) Of zij epigastrische en/of retrosternale pijn hadden. Op grond van de resultaten van deze analyses concluderen wij dat zowel dyspeptische klachten bij patiënten ouder dan 45 jaar, als dyspeptische klachten die persisteren of terugkeren ondanks adequate medicamenteuze behandeling, maar dan onafhankelijk van de leeftijd, geschikte redenen zijn om een gastroscopie aan te vragen. Daartegenover heeft endoscopie vanwege dyspeptische klachten bij patiënten jonger dan 45 jaar, die tevoren niet zijn behandeld, een relatief lage diagnostische opbrengst, met name als deze patiënten geen epigastrische of retrosternale pijn hebben.

De studies beschreven in de hoofdstukken IV en V omvatten de gehele groep van 2900 patiënten, terwijl die in de hoofdstukken VII en VIII gebaseerd zijn op de 1147 patiënten die een vragenlijst of het anamnese systeem hebben beantwoord.

Hoofdstuk VI behandelt een drietal onderwerpen. Als eerste worden de redenen waarom bij 1753 patiënten geen anamnese werd afgenomen besproken. Vervolgens worden de patiënten die ondervraagd werden (de responders) vergeleken met diegenen waarvan geen anamnestische gegevens beschikbaar zijn (de niet-responders), om op deze wijze een mogelijke beïnvloeding van de studies betreffende de responders door selectie aan te tonen. Ten derde worden de pijnlocalisaties zoals aangegeven in de vragenlijsten vergeleken met de pijnlocalisaties zoals deze aan de endoscopist worden vermeld.

De vragenlijsten werden niet beantwoord door $60 \%$ van de patiënten, vanwege geestelijke of lichamelijke belemmering (30\%), technische problemen met het computer-ondersteund systeem (12\%), of door secretariële onderbezetting op de endoscopie-afdeling (32\%). Van $26 \%$ van de niet-responders werd de reden voor het niet beantwoorden van de vragenlijsten niet geregistreerd.

De groep responders verschilde in meerdere aspecten van de niet-responders: $\mathrm{Zij}$ waren jonger, vaker van het mannelijke geslacht en waren vaker door de huisarts verwezen. Bovendien vormden dyspeptische klachten bij de responders veruit de belangrijkste reden om een gastroscopie aan te vragen. Alarmsymptomen daarentegen kwamen bij niet meer dan $10 \%$ van deze patiënten voor. Het feit dat meer dan $40 \%$ van deze groep patiënten medicamenteus behandeld was kan hun klachtenpatroon en de bevindingen bij endoscopisch onderzoek beïnvloed hebben. Relevante endoscopische aandoeningen werden bij minder dan een kwart wan de responders gediagnostiseerd, echter bij ongeveer een derde deel van de niet-responders. Oeso- 
phagitis kwam in dezelfde frequentie voor in beide groepen, maar peptische ulcera werden vaker gediagnostiseerd bij de niet-responders.

De pijnlocalisaties zoals weergegewen in de vragenlijsten verschilden van de localisaties zoals deze aan de endoscopist werden vermeld: Patiënten gaven vaker epigastrische pijn en minder vaak een combinatie van epigastrische en retrosternale pijn aan in het door de endoscopist gehouden vraaggesprek. Dit kan gedeeltelijk worden verklaard door de verschillende manieren waarop patiënten werden ondervraagd.

In 'twee klassen' modellen werden patiënten met een specifieke endoscopische diagnose vergeleken met patiënten die normale bevindingen bij endoscopie hadden. Op deze wijze trachtten wij te onderzoeken of deze diagnoses zich presenteren met een meer of minder typisch klachtenpatroon. In een zogenaamd 'meer klassen' model bestudeerden wij of het mogelijk is de aanwezigheid van relevante endoscopische bevindingen bij patiënten verwezen voor een gastroscopie te voorspellen aan de hand van patiẻntenkenmerken en anamnestische gegevens. Voor de analyses in Hoofdstuk VII werd logistische regressie gebruikt en in Hoofdstuk VIII werd een niet-parametrische methode (NPPA) toegepast. De logistische regressie analyse identificeert de variabelen die het belangrijkst zijn voor het maken van een onderscheid tussen diagnostische categorieën, terwijl NPPA in een classificatie-boom resulteert waardoor de (combinaties van) meest onderscheidende variabelen kunnen worden herkend. Voor elk voorspellend model kan een zogenaamde 'Receiver Operating Characteristic' (ROC) curve worden gemaakt en de oppervlakte onder een ROC curve (AUC, 'Area Under the Curve') geeft een indruk van het onderscheidend vermogen van het bijbehorend model. De resultaten van de logistische regressie analyses en van de niet-parametrische analyses waren vergelijkbaar, ofschoon NPPA in het algemeen een hoger onderscheidend vermogen bereikte (Tabel I).

Patiënten met peptische ulcera konden redelijk goed worden onderscheiden van patiënten met een normaal onderzoek. Leeftijd boven 45 jaar, een ulcus in de voorgeschiedenis, eerdere proefbehandeling, roken en tekenen van gastrointestinaal bloedverlies waren duidelijk geassocieerd met een ulcus ventriculi in beide analyses. Leeftijd, roken, tekenen van gastrointestinaal bloedverlies, epigastrische pijn en 'stress' waren gerelateerd aan het aantonen van een ulcus duodeni in de logistische regressie analyse. De aanwezigheid van epigastrische pijn en de afwezigheid van retrosternale pijn werden als onderscheidende variabelen geselecteerd in de classificatie-boom waarbij patiënten met een ulcus duodeni werden vergeleken met patienten met een normale endoscopie. Van de zogenaamde 'klassieke ulcus symptomen', zoals beschreven in vele boeken en wetenschappelijke publikaties, bleek alleen 'hongerpijn' geassocieerd met het aantonen van een ulcus ventriculi.

Beide technieken hadden nagenoeg hetzelfde onderscheidend vermogen voor hiatus hernia en oesophagitis. Mannelijk geslacht en reflux-symptomen zoals zuurbranden - met name bij liggen en/of bukken of indien gedurende enkele maanden tot jaren bestaand - en retrosternale pijn waren geassocieerd met beide diagnoses. 
Tabel I Oppervlakten onder de ROC curves (AUC) behorende bij de logistische regressie modellen (LRA) en de niet-parametrische (NPPA) modellen, die patienten met spectfieke endoscopische diagnoses vergeleken met patiènten die een normale endoscopie hadden $(n=390)$ en die patiënten met klinisch relevante endoscopische diagnoses $(n=269)$ vergeleken met patienten zonder relevante bevindingen $(n=878)$.

\begin{tabular}{lll}
\hline ENDOSCOPISCHE DIAGNOSES $(\mathrm{n})$ & LRA & NPPA \\
& AUC & AUC \\
\hline Hiatus hernia $(\mathrm{n}=186)$ & 0.78 & 0.80 \\
Oesophagitis $(\mathrm{n}=141)$ & 0.77 & 0.82 \\
Endoscopische gastritis $(\mathrm{n}=167)$ & 0.73 & 0.81 \\
Ulcus ventriculi $(\mathrm{n}=56)$ & 0.86 & 0.94 \\
Duodenitis/bulbitis $(\mathrm{n}=152)$ & 0.75 & 0.88 \\
Ulcus duodeni $(\mathrm{n}=78)$ & 0.85 & 0.94 \\
Relevante endoscopische bevindingen $(\mathrm{n}=269)$ & 0.63 & 0.84 \\
\hline
\end{tabular}

n Aantal patiënten; LRA Logistische regressie analyse; NPPA Niet-parametrische methode; AUC Oppervlakte onder de ROC curve.

Omdat het nauwelijks mogelijk was deze diagnoses te stellen op grond van symptomatologie alleen veronderstellen wij dat veel patiënten met een normale endoscopie symptomatische gastro-oesophageale reflux zonder tekenen van oesophagitis zullen hebben.

Patiënten met endoscopische gastritis konden nauwelijks worden onderscheiden van patiënten met een normaal onderzoek middels deze voorspellende modellen. Dit kan gezien worden als een argument voor de aanname dat het endoscopische beeld van gastritis niet vanzelfsprekend moet worden aanvaard als de verklaring voor dyspeptische klachten. Men moet zich echter realiseren dat 'endoscopische gastritis', zoals gedefinieerd in onze studies, een breed scala aan endoscopische verschijningsvormen van mucosale ontsteking omvat en dat een meer gedifferentieerde benadering mogelijk in een betere onderscheiding van patiënten met gastritis had geresulteerd.

Terwijl de oppervlakte onder de ROC curve in het logistische regressie model voor klinisch relevante endoscopische aandoeningen 0.63 bedroeg, was de oppervlakte onder de ROC curve behorende bij het niet-parametrische model 0.84 . Dit verschil kan (gedeeltelijk) worden verklaard door het feit dat het niet-parametrische algoritme werd gehanteerd in een echte 'meer klassen" benadering, waarbij pas op het einde van de classificatie-bomen de (acht) verschillende klassen werden samengevoegd in een relevante en een niet-relevante categorie. Daarentegen, was het logistische regressie model in feite een 'twee klassen' model. Voor de niet-parametrische methode hebben wij aangetoond (niet in dit proefschrift) dat het samenvoegen van klassen alvorens deze te analyseren het onderscheidend vermogen van het model 
reduceert. Terwijl leeftijd niet werd geselecteerd door de logistische regressie analy-

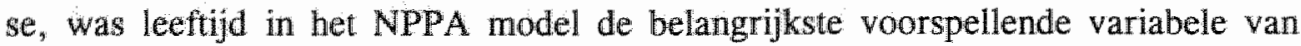
relevante endoscopische aandoeningen.

\section{CONCLUSIES}

Op grond van de studies beschreven in dit proefschrift kan het volgende worden geconcludeerd: 1) Er bestaat geen reden om de 'open toegang' tot endoscopie voor huisartsen te heroverwegen; 2) Zogenaamde alarmsymptomen zijn geschikte indicaties voor gastroscopie evenals dyspeptische klachten bij patiënten ouder dan 45 jaar en persisterende of terugkerende dyspeptische klachten ondanks adequate medicamenteuze behandeling (onafhankelijk van leeftijd); 3) De diagnostische opbrengst van endoscopie bij patiënten jonger dan 45 jaar met ongecompliceerde dyspepsie en zonder eerdere behandeling is relatief laag; 4) Het is redelijk goed mogelijk om patiënten met een ulcus ventriculi of een ulcus duodeni te onderscheiden van patiënten met een normaal onderzoek op grond van hun klinische presentatie; 5) Het is niet mogelijk patiënten met oesophagitis of hiatus hernia te onderscheiden van patiënten met een normale endoscopie; 6) Het is mogelijk het aantal endoscopische verrichtingen met $20 \%$ te reduceren zonder dat relevante endoscopische diagnoses worden gemist door toepassing van het NPPA model op de studiepopulatie.

Op deze plaats moeten enkele kanttekeningen worden geplaatst betreffende de opzet en de praktische consequenties van de studies zoals in dit proefschrift beschreven: Ten eerste, in de klinische praktijk vindt de selectie van patiënten voor endoscopie plaats op het niveau van de verwijzer en niet - zoals bestudeerd in dit proefschrift - op de endoscopie-afdeling. Dit moet men zich realiseren wanneer men onze resultaten extrapoleert naar de huisartsenpraktijk of naar de polikliniek. Ten tweede, een voorspellend model zoals beschreven in dit proefschrift kan slechts in de klinische praktijk worden toegepast wanneer er voldoende personeel is om patiënten te helpen bij het beantwoorden van het 'computer-ondersteund anamnese systeem'. Mede door personeelsgebrek waren wij slechts in staat om de anamnnestische gegevens van die groep patiënten te analyseren die de vragenlijsten of het computer systeem beantwoord hadden. Ten derde, de consequenties van het feit dat wij endoscopische (en niet histopathologische) diagnoses hebben bestudeerd. Deze worden uitgebreid besproken in hoofdstuk VII. Ten vierde, de resultaten van de voorspellende modellen zijn gebaseerd op een unieke populatie van patiënten verwezen naar één enkele endoscopie-afdeling. Het is niet ondenkbeeldig dat vergelijkbare modellen voor elke endoscopie-afdeling afzonderlijk moeten worden ontwikkeld en zo nodig periodiek moeten worden bijgesteld. Tenslotte, we zijn niet ingegaan op de waarde van een normale endoscopie voor de geruststelling van de patiënt en het verdere beleid. De waarde van het vastleggen van normale endoscopische bevindingen kan derhalve uitsluitend door de verwijzer worden ingeschat. 


\section{Dankwoord}

Graag wil ik iedereen bedanken die heeft bijgedragen aan de totstandkoming van dit proefschrift. Zonder iemand te kort te willen doen, wil ik een aantal personen met name noemen.

Jon Vismans, jij stond aan de wieg van het onderzoek zoals beschreven in dit proefschrift en ik waardeer het ten zeerste dat jij na jouw vertrek naar 'de periferie' tot het einde toe actief bij het onderzoek betrokken bent gebleven. Ik hoop dat ik jouw geesteskind een aardig eind op weg heb geholpen en dat ik het nu naar jouw tevredenheid aan de wereld kan toevertrouwen.

Een speciaal woord van dank richt ik aan jou, Hooggeleerde Stockbrügger, beste Reinhold. Zonder jou was dit proefschrift er niet gekomen. Vanaf het begin van jouw aanstelling als hoogleraar Gastroenterologie heb jij mij gesteund om het reeds lopende onderzoek zo goed mogelijk af te maken. Jouw helder inzicht en intensieve begeleiding zijn voor mij van onschatbare waarde geweest.

Dit proefschrift is het resultaat van een goede samenwerking tussen de afdeling Interne Geneeskunde van het Academisch Ziekenhuis Maastricht en de vakgroep Medische Informatica van de Rijksuniversiteit Limburg. Hooggeleerde Hasman, beste Arie, vanaf het begin van het onderzoek hield jij de grote lijn in de gaten en plaatste waar nodig kritisch commentaar.

Jan Talmon, jij analyseerde met veel enthousiasme de patiëntengegevens met een door jou aangedragen non-parametrische techniek, hetgeen resulteerde in een onnoemelijk aantal classificatie-bomen. Gelukkig bleef jij wel door de bomen het bos zien op de momenten dat ik reddeloos was verdwaald.

Ton Ambergen en Mickey Chenault, verbonden aan de vakgroep Methodologie en Statistiek van de Rijksuniversiteit Limburg, dank ik voor het uitvoeren van de Iogistische regressie analyses zoals beschreven in hoofdstuk VII.

De leden van de beoordelingscommissie, Prof.dr. P.B. Soeters, Prof.dr.ir. J.H. van Bemmel, Prof.dr. P.G. Knipschild, Prof.dr. P. Pop en Prof.dr. G.N.J. Tytgat, 
bedank ik voor hun bereidwilligheid het manuscript te lezen en voor het geven van waardevolle adviezen.

In dierbare herinnering en met veel respect denk ik terug aan Prof.dr. J.A. Flendrig. Hij gaf mij de gelegenheid de opleiding tot internist te volgen en als opleider was hij voor mij een groot voorbeeld. Nadat Jon Vismans was vertrokken heeft hij mij waar mogelijk gesteund zodat het onderzoek voortgang kon vinden. Voor zijn warme menselijke belangstelling ben ik hem oprecht dank verschuldigd.

Het onderzoek zou niet mogelijk zijn geweest zonder de medewerking van de vele patiënten die de tijd en moeite namen voorafgaande aan hun endoscopie een vragenlijst in te vullen of - vaak voor het eerst in hun leven - met behulp van een computer vragen te beantwoorden.

Het onderzoek werd verricht op de endoscopie-afdeling van het Academisch Ziekenhuis Maastricht. De endoscopisten, Cor Baeten, Robert-Jan Brummer, Cees van Deursen, Norman Egger, Leopold Engels, Paul Kingma, Ruud Loffeld, Alex Saleh, Tijmen Stelling, Wiedjin Tan, Jon Vismans, Pierre Willemse en Raoul Zeyen, dank ik voor het nauwgezet invullen van de studie-formulieren.

Het hoofd van de endoscopie-afdeling, de balie-medewerksters en endoscopieassistenten welke werkzaam waren gedurende de studieperiode, Marja Greeve, Andy Hameleers, Lucie Jongen, Monique Kempeners, Liesbeth Theunissen, Daisy Brants, Thomas Kaldijk, en Tineke Zandstra, dank ik allen voor hun inspanningen en de prettige samenwerking.

Felix van de Wissel heeft zich als student-assistent verdienstelijk gemaakt en behield zijn opgewekt karakter tijdens het vervelende werk van het invoeren van patiëntengegevens in een data base.

Het werk dat tot dit proefschrift heeft geleid, werd verricht tijdens mijn opleiding tot internist. Mijn collegae arts-assistenten ben ik dankbaar voor hun belangstelling voor de voortgang van het onderzoek en voor hun bereidheid zonodig klinische taken over te nemen.

Nadat ik geveld werd door een appendicitis acuta heeft Tiny Wouters mij in de nachtelijke uren geholpen bij het uitprinten van het manuscript zodat het nog net op tijd (of eigenlijk net te laat) bij de drukker kon worden afgeleverd.

Mijn ouders bedank ik voor het feit dat ze mij hebben laten studeren.

Tot slot dank ik jou, Astrid. Alleen jij weet hoeveel avonden en weekeinden ik de laatste jaren aan de totstandkoming van dit proefschrift heb gewerkt. Jij hebt mij gedurende deze gehele periode steeds met liefde en vertrouwen ter zijde gestaan.

Stephan en Roderick, nu zal er meer tijd woor jullie zijn. 


\section{Curriculum vitae}

De auteur van dit proefschrift werd geboren op 22 augustus 1962 te Vaals. Na het behalen van het eindexamen Atheneum $B$ aan scholengemeenschap Sophianum te Vaals in 1980, studeerde hij aan de Rijksuniversiteit Utrecht achtereenvolgens Scheikunde (van 1980 tot 1981) en Geneeskunde (vanaf 1981). Het artsexamen werd cum laude behaald in april 1988. Na 11 maanden werkzaam te zijn geweest als assistentgeneeskundige niet-in-opleiding, startte hij april 1989 met de opleiding Interne Geneeskunde in het Academisch Ziekenhuis Maastricht (opleiders wijlen Prof.dr. J.A. Flendrig, Prof.dr. A.C. Nieuwenhuijzen Kruseman en Prof.dr. H.F.P. Hillen). $\mathrm{Na}$ de registratie als internist op 1 april 1995 ving hij an met de opleiding Gastroenterologie in het Academisch Ziekenhuis Maastricht (opleider Prof.dr. R.W. Stockbrügger). 